\title{
International Students' Adjustment Challenges in the United States: A Case Study of West Virginia University
}

\author{
Lawrencia Baaba Okai \\ West Virginia University, lbokai@mix.wvu.edu
}

Follow this and additional works at: https://researchrepository.wvu.edu/etd

Part of the International and Area Studies Commons

\section{Recommended Citation}

Okai, Lawrencia Baaba, "International Students' Adjustment Challenges in the United States: A Case Study of West Virginia University" (2020). Graduate Theses, Dissertations, and Problem Reports. 7974.

https://researchrepository.wvu.edu/etd/7974

This Dissertation is protected by copyright and/or related rights. It has been brought to you by the The Research Repository @ WVU with permission from the rights-holder(s). You are free to use this Dissertation in any way that is permitted by the copyright and related rights legislation that applies to your use. For other uses you must obtain permission from the rights-holder(s) directly, unless additional rights are indicated by a Creative Commons license in the record and/ or on the work itself. This Dissertation has been accepted for inclusion in WVU Graduate Theses, Dissertations, and Problem Reports collection by an authorized administrator of The Research Repository @ WVU.

For more information, please contact researchrepository@mail.wvu.edu. 
International Students' Adjustment Challenges in the United States: A Case Study of West Virginia University

\author{
Lawrencia Baaba Okai
}

Dissertation submitted to the Davis College of Agriculture, Natural Resources and Design West Virginia University

In partial fulfillment of the requirements for the degree of

Doctor of Philosophy in Human and Community Development

\author{
Peter Schaeffer, Ph.D., Chair \\ Alan Collins, Ph.D. \\ Cheryl Brown, Ph.D. \\ Michael Dougherty, Ph.D.
}

Division of Design and Community Development

\author{
Morgantown, West Virginia \\ 2020
}

Keywords: international students, adjustment challenges, host institutions

Copyright: 2020 Lawrencia Baaba Okai 


\section{Abstract \\ International Students Adjustment Challenges in The United States: A Case Study of West Virginia University \\ Lawrencia Baaba Okai}

International students face challenges as they endeavor to study abroad ranging from host government policies to the host country's attitudes vis-à-vis foreign students and immigration. In some instances, they also face obstacles leaving their country of origin. The United States is the largest destination country with $24 \%$ of all international students worldwide, followed by the United Kingdom, Australia, France, and Germany. In the United States, international students make up about $6 \%$ of all college students. They make significant contributions to the United States economy and bring several benefits, particularly to federal and state governments. They contribute to the federal government's net income through the payment of SEVIS fees, visa processing fees, tuition, and income taxes, among others. They also contribute cultural benefits and intellectual gains. While settling and adjusting into their host society, international students may experience culture shock, language barriers, neo-racism, financial stress, visa problems, and other social challenges.

Despite these challenges, the number of international students coming to the United States continues to increase. The purpose of this study was to investigate the challenges that international students encounter as they adjust to their new environment. This study focused on international students at West Virginia University and their perceptions of how West Virginia University assists them in meeting their challenges. In addition, this study also evaluated coping mechanisms that these students utilized to adjust to their new environment. This was done through a survey of international students where they were asked to identify resources and 
coping mechanisms they used to adjust. The three research questions that guided the study are; 1 . What are the adjustment challenges facing international students at West Virginia University? 2. What are the students' perceptions of West Virginia University's role in addressing the adjustment challenges? 3. What coping mechanisms or adaption strategies do international students use to survive the adjustment challenges in West Virginia University?

The instrument used for this study was a modified version of the Michigan International Students Problem Inventory (MISPI) developed by Porter and Haller in 1962. An online questionnaire was administered using Qualtrics to survey all international students at West Virginia University (WVU). Descriptive (mean and standard deviation) and inferential ( $t$-test, One Factor ANOVA, and Chi square) statistical methods were used to analyze the data. The results revealed that social /personal problems (treatment received at social functions, being accepted in social groups, insufficient personal- social counseling), English language problems (understanding, writing, and speaking English), transportation problems, health insurance problems, and orientation service problems (attitude of some students towards international students, attitude of some U.S. citizens to skin color, relationship between faculty and students) were the key challenges of international students at West Virginia University. The findings also revealed that international students often face racism, discrimination and relationship difficulties between faculty and other students.

It is recommended from this study that faculty members should be friendly and make students feel welcome. They should also continue to inspire, encourage, and offer guidance to students and let the students know that they are willing to assist them in articulating their ideas. International students should feel able to make new friends and interact with other students without feeling intimidated or embarrassed by their foreign accents. Host institutions should not 
only provide services to students but ensure that international students are aware of them so they can access those services as they adjust to their new environment. English language workshops and writing seminars should be organized to help address language difficulties. The Office of Diversity \& Inclusion should conduct research to identify the particular needs of international students and offer solutions or services that address these needs. It is finally recommended that West Virginia University should offer training and continuous orientation to faculty and staff on peculiar learning and thinking styles of international students, and efforts should be made to address racism and discrimination. 


\section{DEDICATION}

This work is humbly dedicated to my loving and sweet

heavenly Father and my Lord Yeshua

Hamashiach

"In You alone I move and have my being, I have come this

far ONLY by Your grace” 


\section{Acknowledgements}

"Through all the changing scenes of life, in trouble and in joy, the praises of my God shall still, my heart and tongue employ" (Methodist Hymn Book, MHB 427). I'm eternally grateful to my most gracious and loving God on whose arms I lean, and for seeing me through my doctoral studies. I never would have made it without You, my God. Thank You for everything. "Jesus my Shepherd, Brother, Friend, my Prophet, Priest and King. My Lord, my Life, my Way, my End, accept the praise I bring” (MHB 99). Ebenezer, I'm thankful for thus far You have brought me and being with me every step of the way. It has been a difficult and challenging journey, but Your steadfast love, grace, and strength has seen me through. I thank You and love You so much. Sweet Holy Spirit, my Confidant, Helper, and Guide, You never gave up on me even when I wanted to give up, You are the best Partner.

I am highly indebted to my dissertation committee members for all the support and guidance. My advisor and committee chair, Dr. Peter Schaeffer, I cannot find enough words to thank you for your immense support, mentorship, confidence in me, and checking on me and my family frequently. You are simply the best! I'm immeasurably thankful to you, Dr. Allan Collins for the step by step guidance, especially with my data analysis. Your invaluable feedback, contribution, and assistance have been enormously helpful. I appreciate you Dr. Michael Dougherty for your positive and prompt feedback as always, and your support. Dr. Cheryl Brown, I'm grateful for your significant contributions to my work and support.

My heartfelt gratitude goes to Dr. Harlan Amandus and Mrs. Sandra Amandus, your unwavering support, unconditional love and encouragement has been invaluable through the years. I'm humbled and privileged to call you papa and momma, the love I receive from the entire family is enormous and matchless, and I love you all so much. Special appreciation to 
you Dr. Felix Kumah-Abiwu for your inspiration, encouragement, tremendous support, and availability always for consultation. I truly appreciate your wisdom and significant contribution to my personal and professional development. Many thanks to my friend Fadi Mugheirbi for assisting me with my data and statistical analysis, you are a true and dependable friend, thank you so much for everything. Special thanks to the Office of Global Affairs for all the assistance with sending out my survey to international students and amazing support with my work. I'm most grateful to the Director of University Relations-Digital Services, Cathy Orndorff, for the tremendous assistance with the distribution of my survey. You went above and beyond to support my work and I'm grateful. I'm thankful to the Electronic Theses and Dissertations Coordinator, Debby Borrelli, for your patience and countless times of help. Last but not the least, I want to thank my two adorable and wonderful sons Jeffrey Okai and Kenneth Okai, you are a huge blessing to me and I thank God for you. Your unconditional love, faith in me, and patience have contributed significantly every step of the way. Your constant prayers and encouragement with the scriptures will forever be cherished. Thank you all and God bless. 


\section{Table of Contents}

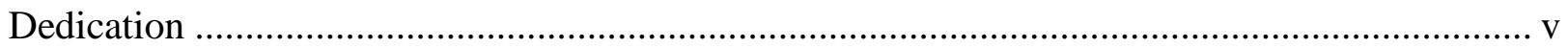

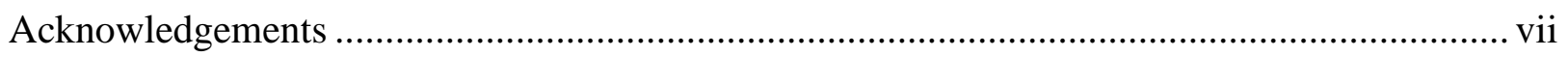

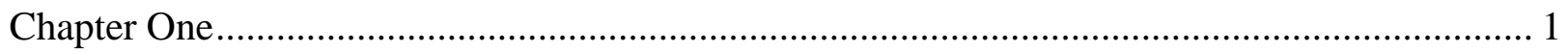

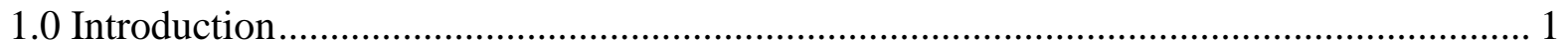

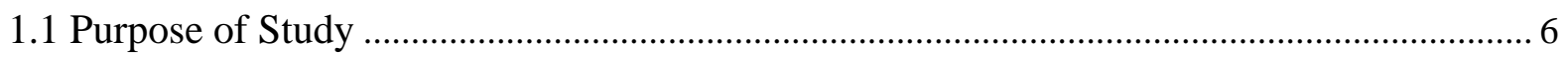

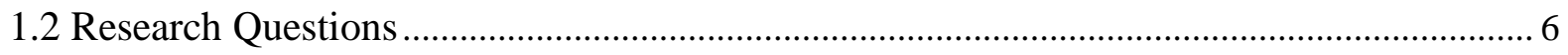

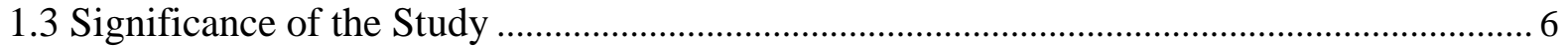

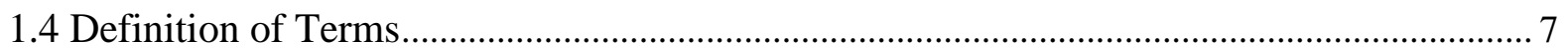

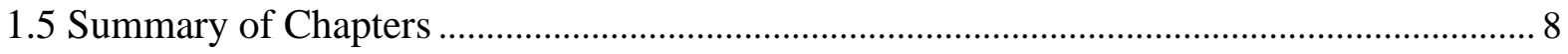

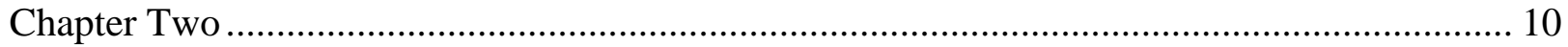

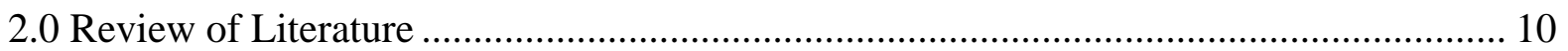

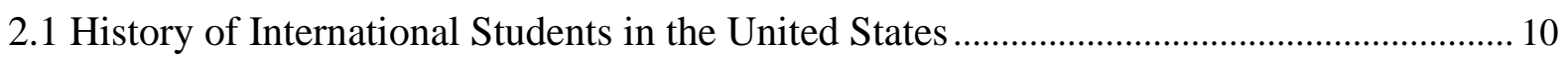

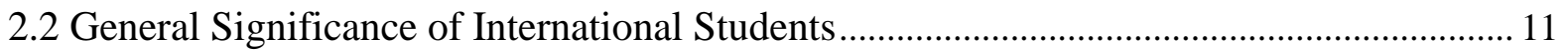

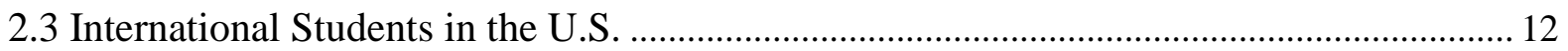

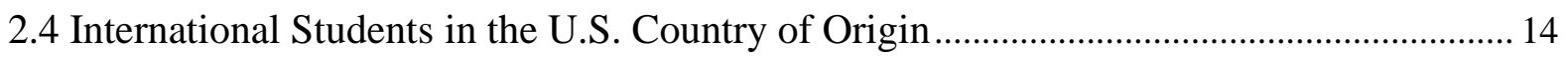

2.5 Importance of International Students in the U.S............................................................ 15

2.6 Factors Influencing International Student's Choice of Destination. ................................... 17

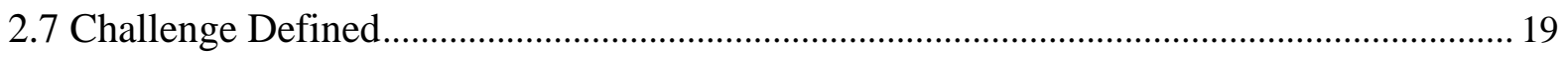

2.8 General Challenges Faced by All Students...................................................................... 19

2.9 Expectations and Challenges Faced by International Students ........................................ 21

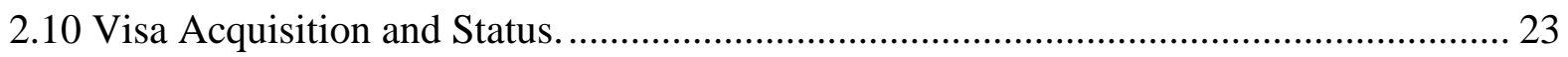

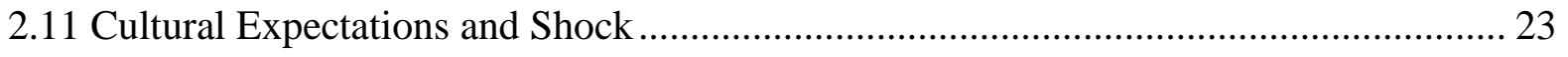

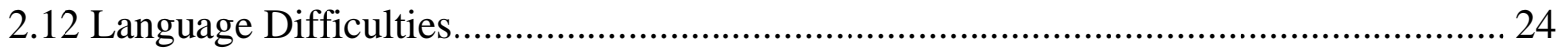

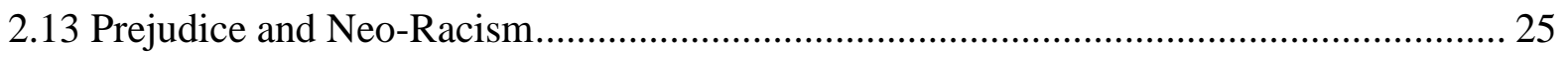

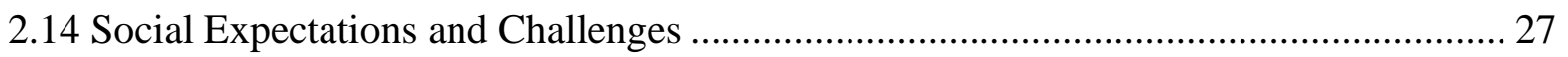

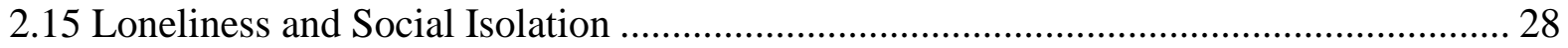

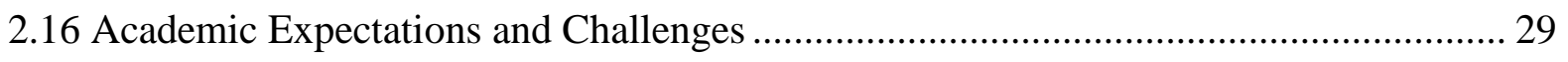

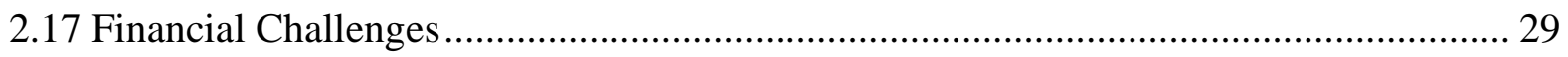

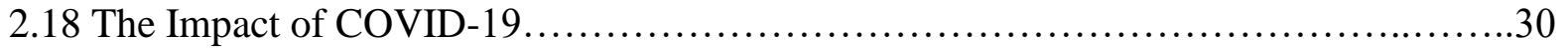

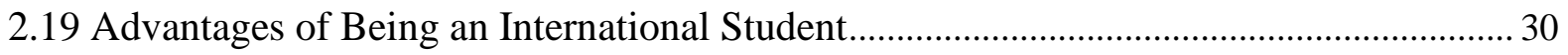




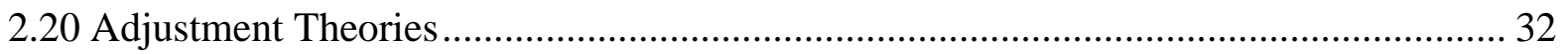

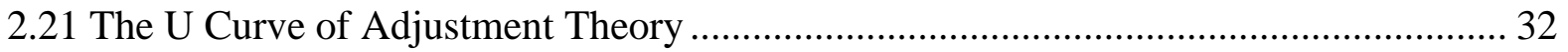

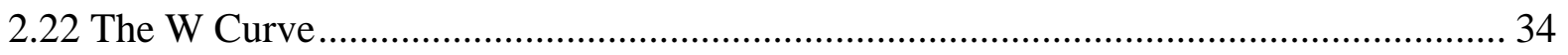

2.23 Possible Factors Affecting Adjustment ……………................................................. 35

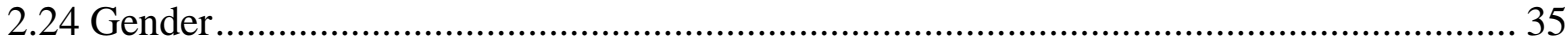

2.25 Age

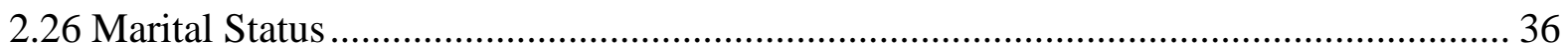

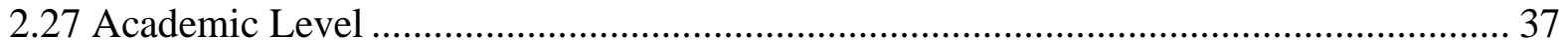

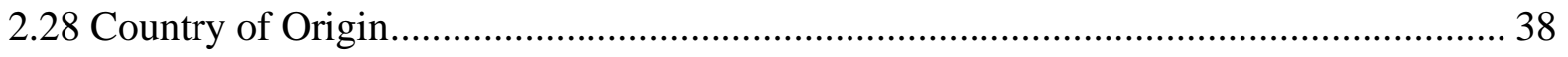

2.29 Studies on Adjustment Challenges Using Surveys and MISPI ..................................... 38

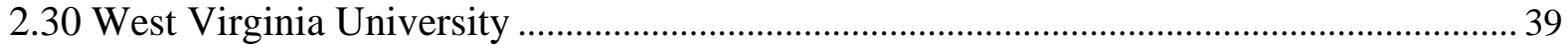

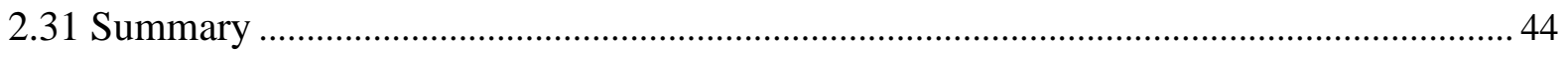

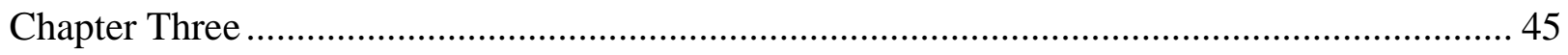

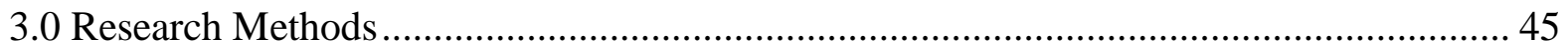

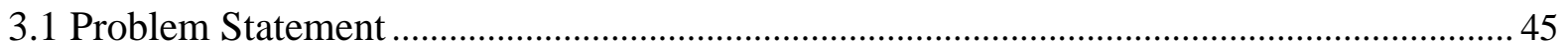

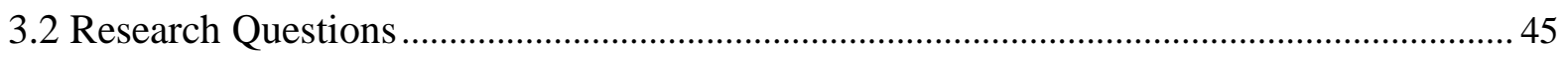

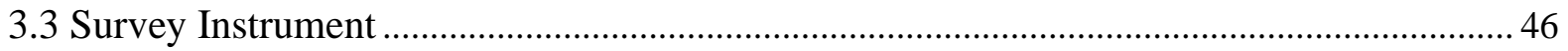

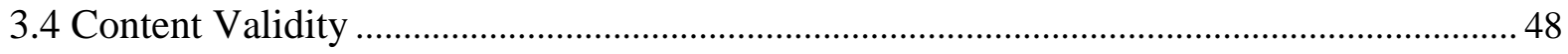

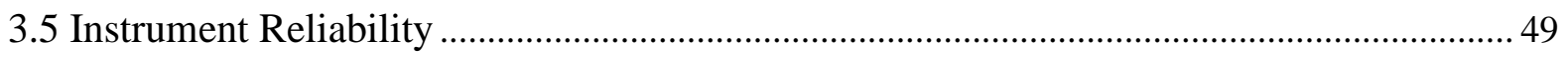

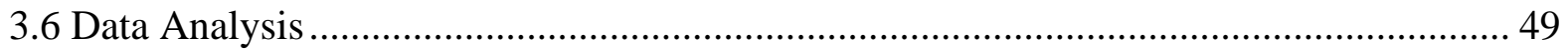

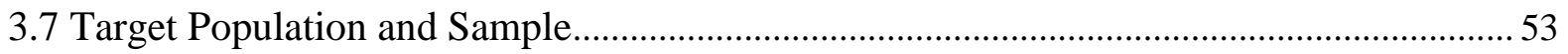

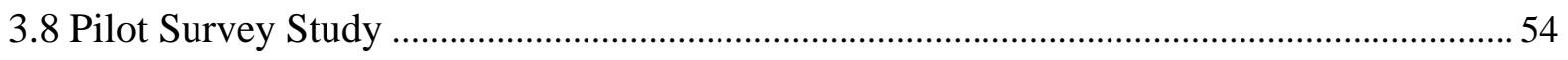

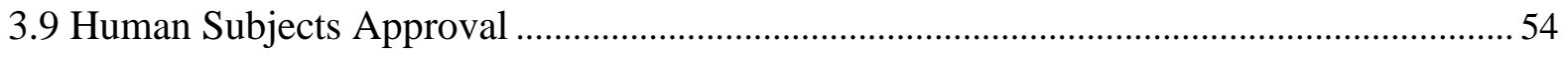

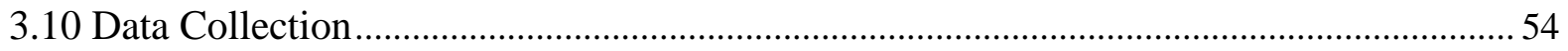

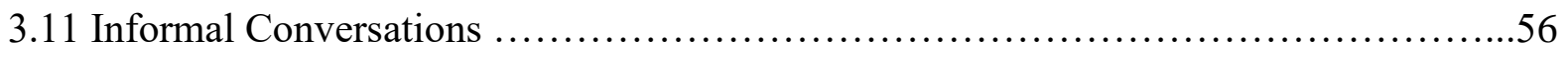

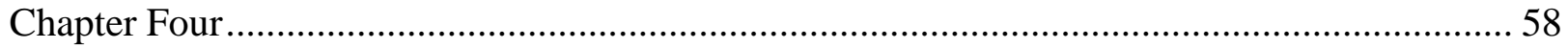

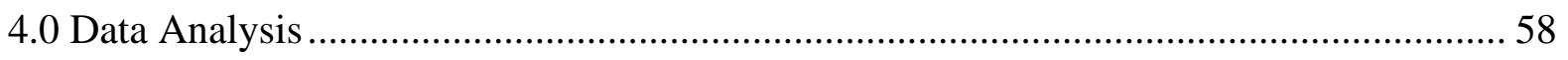

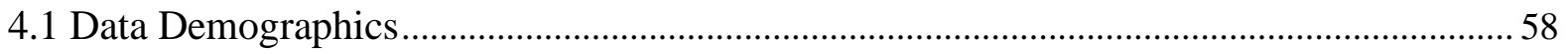

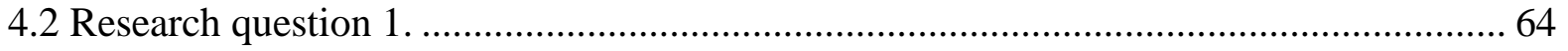

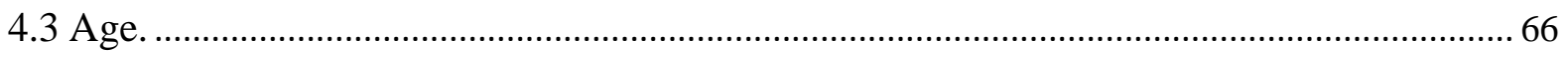

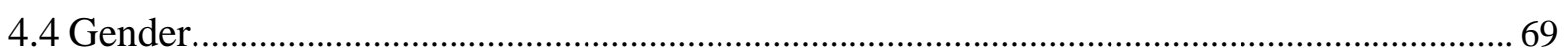




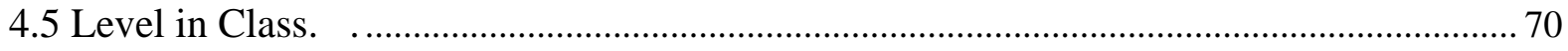

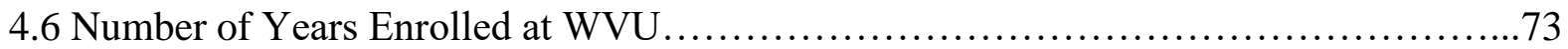

4.7 Number of Years Being Enrolled in Other U.S. Colleges Prior to Being Enrolled in WVU 76

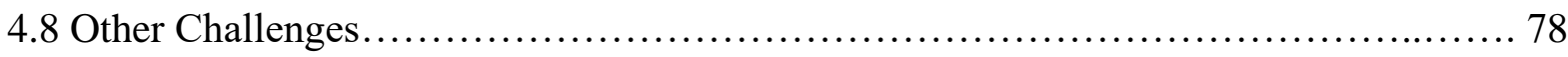

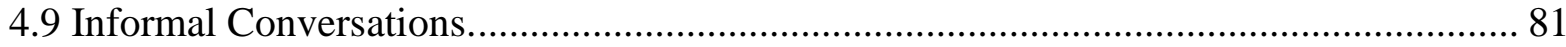

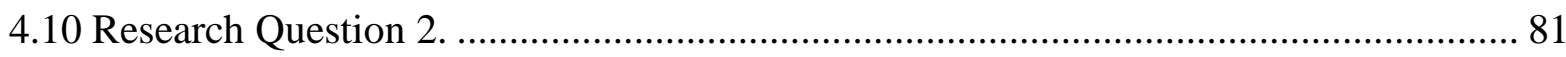

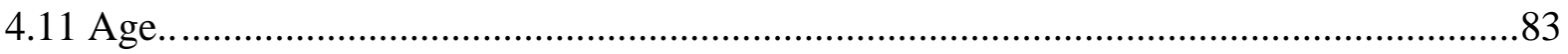

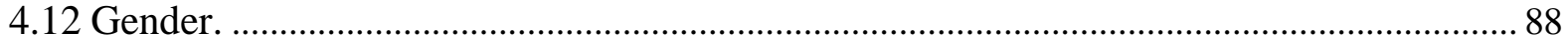

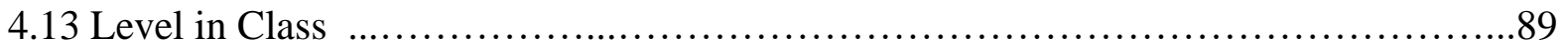

4.14 Number of Years Being Enrolled at WVU..................................................................... 91

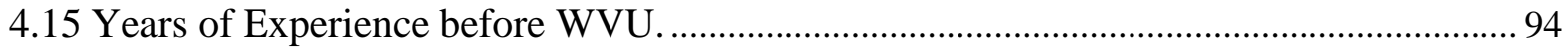

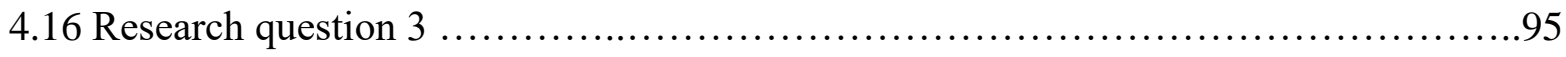

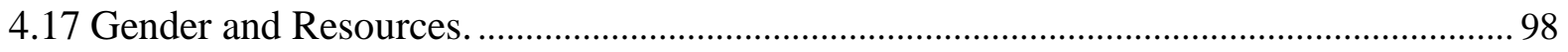

4.18 Years of Experience prior to WVU.............................................................................. 99

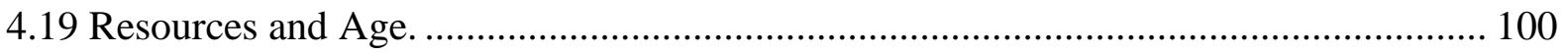

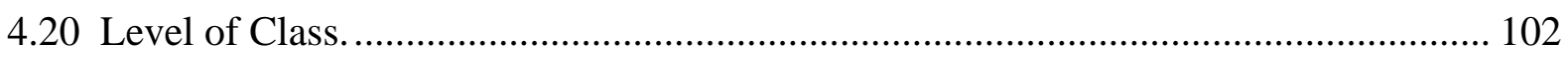

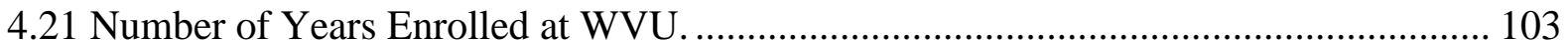

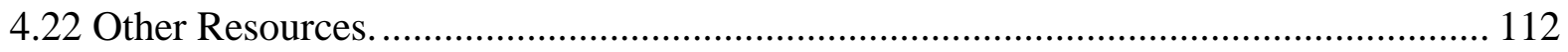

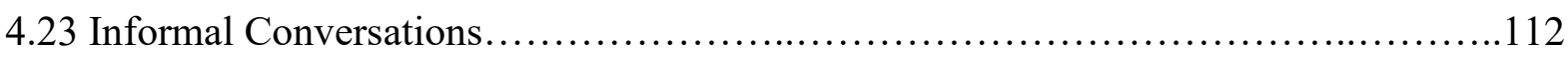

4.24 Comparison of Challenges and Resources................................................................ 113

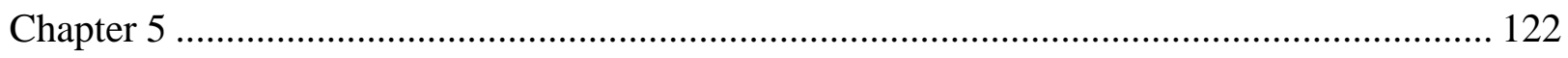

5.0 Conclusions, Summary, and Recommendations.......................................................... 122

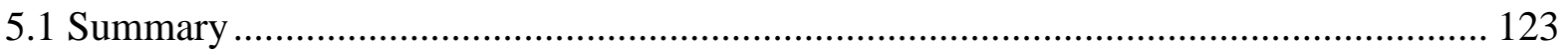

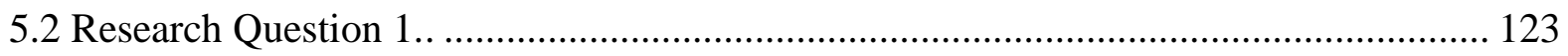

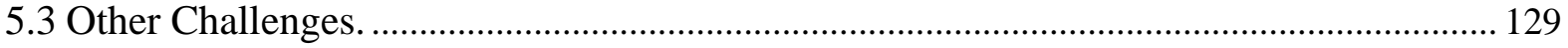

5.4 Informal Conversations.......................................................................................... 129

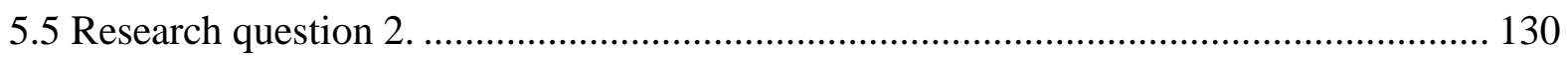

5.6 Research Question 3. ........................................................................................ 134

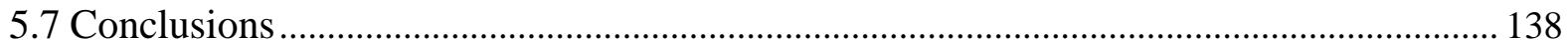

5.8 Recommendations for Host Institutions .................................................................... 141 


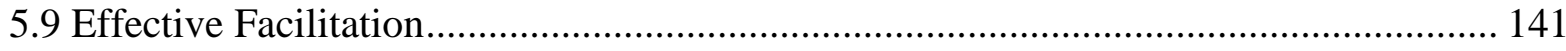

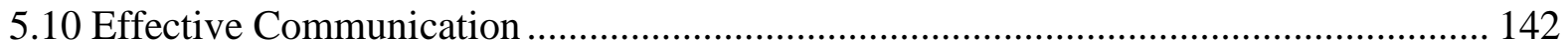

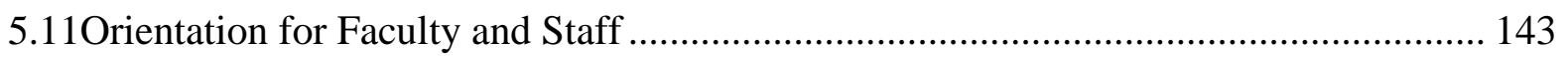

5.12 Community Relationship ..................................................................................... 143

5.13 Language and Writing Centers ............................................................................... 144

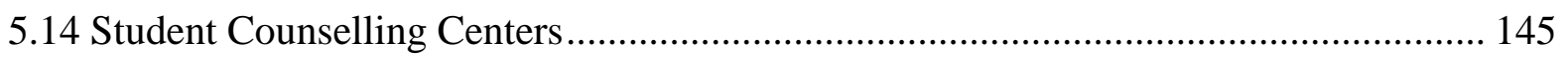

5.15 Student Inclusion and Diversity Programs .............................................................. 146

5.16 Additional Institutional Resources............................................................................ 147

5.17 For Faculty ……………………………………………………………………. 147

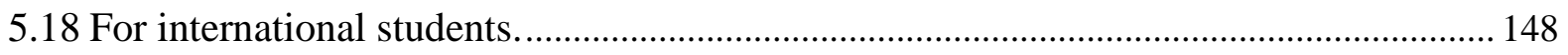

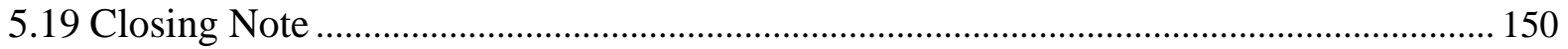

5.20 Limitations and Recommendation for Further Study ………......................................... 151

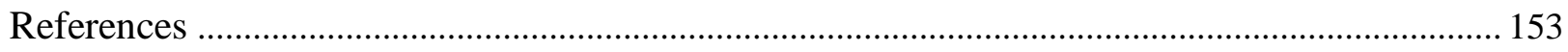

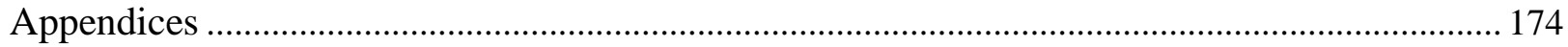

Appendix A: Institutional Review Board Approval Letter ..................................................... 175

Appendix B: Cover Letter for International Student Survey ................................................... 178

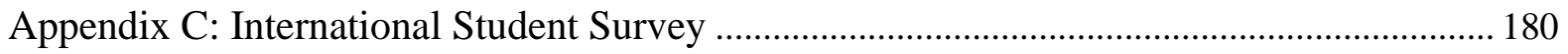

Appendix D: Descriptive Analysis for Challenges ............................................................. 187

Appendix E: One Factor ANOVA Analysis for Challenges with Age ……........................... 192

Appendix F: One Factor ANOVA Analysis for Challenges and Years Enrolled at WVU.... 198

Appendix G: Responses to Survey Question 2- Other Challenges ........................................... 204

Appendix H: Descriptive Analysis and Distribution of Responses for Addressed Challenges

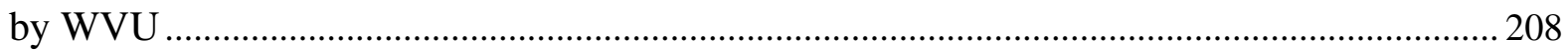

Appendix I: One Factor ANOVA Analysis of Challenges Addressed and Age .................... 222

Appendix J: One Factor ANOVA Analysis for Addressed Challenges with Number of

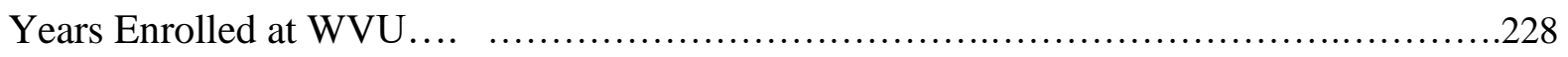

Appendix K: Descriptive Analysis for Resources Used by students to Adjust....................... 234

Appendix L: One Factor ANOVA Analysis of Resources Utilized by Students and Age .... 237

Appendix M: One Factor ANOVA Analysis of Resources Utilized by Students with Years

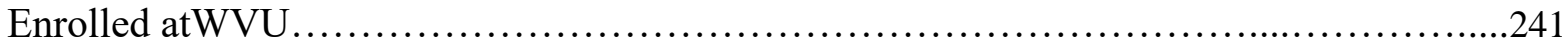

Appendix N: Responses to Survey Question 4................................................................2. 245 
Appendix O: Responses to Survey Question 5.

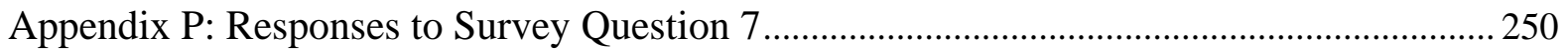

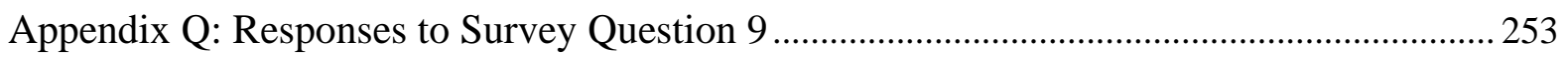




\section{List of Tables}

Table 1 Top 25 Institutions Hosting International Students, 2016/2017 \&2017/2018 13

Table 2 Top 25 Countries of Origin of International Students, 2016/17 \& 2017/2018 15

Table 3 International Students Enrollment Trends at West Virginia University 41

Table 4 Top 20 Countries of Origin for International Students in West Virginia University.... 43

Table 5 List of Actions Taken to Encourage Student Participation in Survey 55

Table 6 Demographics of Participants of Informal Conversations .57

Table 7 Countries of Origin of Respondents. 62

Table 8. Comparison of Countries of Origin Between Survey Respondents and WVU International Students

Table 9 Survey Response Mean and Standard Deviation for International Students Challenges. .

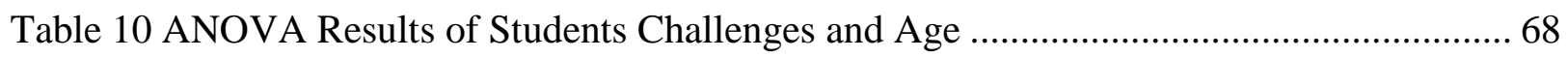

Table 11 Results for $t$-test of Students Challenges and Gender ................................................ 69

Table $12 t$-test Results of Students Challenges and Class Standing........................................... 71

Table 13 Results of ANOVA Tests of Students Challenges with Years Being Enrolled at WVU .75

Table $14 t$-test Results of Students Challenges and Prior Experiences 76

Table 15 Other Challenges Reported by WVU International Students 79 
Table 16 Descriptive Statistics for Response to WVU Assistance with Challenges of International Students 83

Table 17 Summary of ANOVA Analysis of Age and WVU's Assistance in Addressing Challenges

Table 18 Analysis Gender Differences for WVU Assistance in Addressing Challenges 89

Table 19 WVU's Assistance in Addressing Challenges with Class Standing 90

Table 20 ANOVA Analysis of Number of Years Being Enrolled and WVU Assistance with Addressing Challenges 93

Table 21 Analysis of Years of Prior Experience in the U.S. and WVU Assistance with Addressing Challenges 95

Table 22 Item Numbers and Corresponding Resources .97

Table 23 Descriptive Statistics for Responses to WVU Resources 98

Table 24 Responses to WVU Resources by Gender 99

Table 25 Responses to WVU Resources by Years of Prior Experiences in the U.S. 100

Table 26 ANOVA Analysis of Responses to WVU Resources and Respondent Age 102

Table 27 Responses to WVU Resources based upon the Number of Years Enrolled at WV.105

Table 28 Summary Responses of How Families/Friends Helped International Students to Adjust .105

Table 29 Other Resources Apart From family and Friends Used to Adjust 108

Table 30 Category of Challenges and Corresponding Resources 
Table $31 \mathrm{Chi}^{2}$ Table of Challenges and Resources for Category 1- Admission Selection ......115

Table $32 \mathrm{Chi}^{2}$ Table of Challenges and Resources for Category 2- Orientation Service.........116

Table $33 \mathrm{Chi}^{2}$ Table of Challenges and Resources for Category 3- Social/Personal ...........117

Table $34 \mathrm{Chi}^{2}$ Table of Challenges and Resources for Category 4- Financial Aid .............118

Table $35 \mathrm{Chi}^{2}$ Table of Challenges and Resources for Category 5- English Language..........119

Table $36 \mathrm{Chi}^{2}$ Table of Challenges and Resources for Category 6- Immigration Regulations.119

Table $37 \mathrm{Chi}^{2}$ Table of Challenges and Resources for Category 7 Religious Services .........120

Table $38 \mathrm{Chi}^{2}$ Table of Challenges and Resources for Category 8 Health Service .............121

Table 39 List of Item Numbers and Names..................................... 124

Table 40 List of Item Numbers and Corresponding Names ..............................130 


\section{List of Figures}

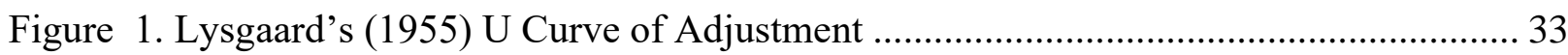

Figure 2 The Gullahorn W Curve Transition Model.................................................................. 34

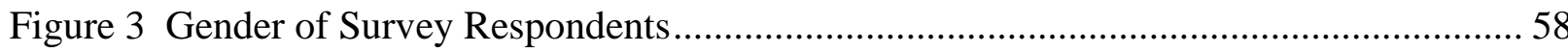

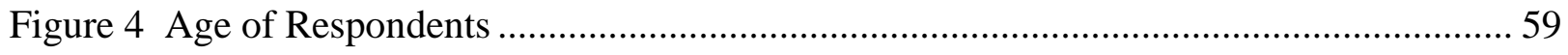

Figure 5 Dependency Status of Respondents ...................................................................... 59

Figure 6 Level in College. Comparison of Survey Participants and WVU International Students 60

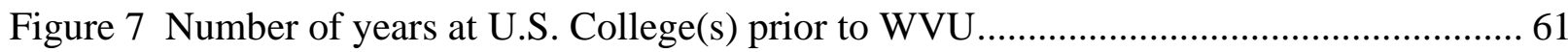

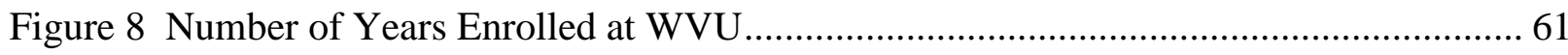

Figure 9 Mean Analysis of Students Challenges and Gender ............................................... 70

Figure 10 Mean of Students Challenges and Class Standing ................................................... 72

Figure 11 Mean Analysis of Challenges and Previous Experience............................................ 77

Figure 12 Other Challenges Reported by Respondents............................................................ 79

Figure 13 WVU's Assistance with Addressing Challenges and Age ...................................... 85

Figure 14 Mean Analysis of Resources Utilized by Students to Survive ................................. 96

Figure 15 Response Means for WVU Resources and Level of Class ...................................... 103

Figure 16 Other Resources that Students Use to Adjust ........................................................... 106

Figure 17 Resources Outside of WVU that Students Utilize to Adjust at WVU ..................... 107

Figure 18 International Students Engagement with Family and Fiends .................................. 109

Figure 19 Engagement with Families/Friends by Gender....................................................... 110 
Figure 20 Other Resources Used to Adjust.

Figure 21 Mean of International Students Challenges...................................................... 125

Figure 22 International Students Challenges with Age ........................................................ 126

Figure 23 International Students Challenges and Number of Years Enrolled at WVU ........... 128

Figure 24 International Students Perception of WVU Addressed Challenges.......................... 131

Figure 25 Addressed Challenges and Gender ……………………............................... 132

Figure 26 Addressed Challenges and Years Enrolled at WVU.............................................. 133

Figure 27 Resources and Years of Prior Experience............................................................ 135

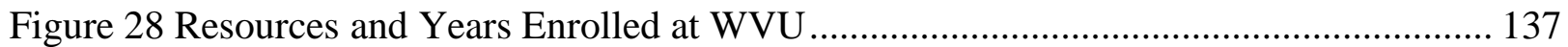




\section{Chapter One}

1.0

\section{Introduction}

The United States (U.S.) began to open its borders and encourage international students after World War II when it realized the importance of knowledge about other countries for security reasons (Leikvold, 1997). The economic, social and cultural environment during this period was very different from the twenty-first century due to technological and social changes from globalization. Colleges and universities are incorporating internationalization rapidly and are intensifying efforts to enroll more international students, faculty, and encourage international research collaborations (Scott, 2006). International students travel outside their own country to study in a higher education institute for a minimum of one year to a maximum of seven years (International Organization for Migration [IOM], 2018). It is important for students to be equipped with communication and cognitive skills to enable them to adjust to the changing environment.

The number of international students worldwide has increased steadily, and the U.S. has been the most frequent destination for international students, with 1.1 million (24\%) students enrolled in 2017, out of 4.6 million students worldwide (IIE, Open Doors, 2019). This share of $24 \%$ is down from $28 \%$ in 2016 . The United Kingdom is the second largest study abroad destination followed by Australia, France, Germany, and Russia (Institute of International Education [IIE], 2019).

The reputation of top-ranked institutions such as Harvard, Yale, University of Pennsylvania, Cornell, Princeton, Stanford, and MIT contribute to make the U.S. the most desirable study abroad destination (Migration Policy Institute [MPI], 2017). However, Hazen \& Alberts (2006), and Obst \& Forster (2007) argue that top ranking institutions is not the only factor influencing study abroad destination but also the possibility of securing jobs after graduation. The addition of 291,000 (3\%) new international students in the 2016/2017 academic year is a decrease of 10,000 international students 
over the previous period and the smallest recorded growth since the 2009/2010 academic year (Association of International Educators [NAFSA], 2019). This decrease translates into a loss of some $\$ 150$ million to the U.S. economy (IIE, 2019). The decrease is due to more visa denials, unfavorable political environment in the U.S., improving opportunities in the countries of origin of students, and rising competition from other countries, including Britain and Australia (Lee \& Rice, 2007). The largest number of international students in the United States come from China (32.0\%) followed by India (17.9\%), South Korea (5.0\%), Saudi Arabia (4.1\%), and Canada (2.4\%).

The U.S. Department of Commerce posits that in the year 2018, international students contributed a total of $\$ 45$ billion to the U.S. economy (IIE, 2020), and generated about 458,290 jobs in the 2018/2019 academic year (NAFSA, 2020). Apart from the financial gains, international students also contribute significantly to science, innovation, and patents awarded to both university and nonuniversity institutions, as well as increases in total patent applications (Chellaraj, Maskus, \& Mattoo, 2008).

All students (international or domestic) encounter challenges as they endeavor to study and Lee (2007) postulates that very little effort is made by the host institutions to understand the challenges that students encounter as they enroll in their institutions. The extent to which these challenges are experienced differs by culture and place of origin, financial resources, language and communication skills, discrimination, and unfamiliar social norms and educational system causing major challenges for students. For example, a survey conducted by North Carolina State University among 6,000 domestic students from 10 community colleges in North Carolina, California, Texas, Michigan, Virginia, Nebraska, Wisconsin, South Dakota, and Wyoming revealed that too many hours of work left students with very little time to study and the difficulties of high living expenses (Ashley, 2019). 
The Collins dictionary defines a challenge as something difficult which requires great effort and determination (Collins dictionary, n.d.). Students perceive a challenge when their actual experiences do not match their expectations. International students expect a study abroad education to offer them a higher quality education than what they would receive in their country of origin. They have high expectations of improving their communication skills and interacting with people from diverse cultures to build long lasting relationships (Lee, 2007). They expect through their education abroad and exposure to utilize advanced learning techniques and to establish businesses in their countries of origin with investors from their host countries (Rhea, 1997), or earn higher incomes in their home countries by taking up leadership positions upon their return home (Schmidt \& Pardo, 2017). International students, however, frequently encounter a reality different from what they were expecting. For example, they may perform below their expectations due to unfamiliarity with the U.S. academic system and struggle to interact and communicate easily in the absence of known and familiar cultural signs and symbols (Chapdelaine \& Alexitch, 2004). This results in culture shock as they realize that unrealistic expectations left them less prepared to function in their new environment. The differences or gaps between the actual experiences and expectations result in challenges which differ by each student depending on their background and initial expectations.

As an example, key challenges international students studying in Ghana encounter are financial difficulties and lack of internship and employment opportunities (Osei-Owusu \& AwunyoVitor, 2012). Pressure from parents to succeed combined with rote learning and memorization are the key challenges students face in Singapore as this causes undue stress, anxiety and other health problems (Ang, \& Huan, 2006). Chinese students face challenges because of lack of professional opportunities, poor living standards, and low income (Pang, 2001). 
Students who choose to study abroad also face challenges with adaptation and adjustment (Leong \& Chou, 1996). This is mainly due to the adjustment process that students go through in their new environment as they experience cultural differences (Chapdelaine \& Alexitch, 2004). Students who have families and acquaintances already living in their study abroad destination may experience fewer adjustment challenges or adjust better thanks to support from their families.

International students expect better higher education than in their country of origin and a U.S. education ranks at the top of countries that will increase opportunities for securing jobs globally. Some international students expect to enhance their communication skills and exposure to diverse cultures and people that they would not experience in their country of origin (Lee, 2007). The first and foremost challenge every international student experience is the cumbersome visa application process and rigorous background security checks by the U.S. Department of Homeland Security. After clearing the first hurdle, international students face a series of challenges in settling and adjusting to their new environment. Some international students experience culture shock, their usual way of doing things in their original country has to be altered in their new environment, which includes, socialization among foreign nationals, style of dressing, and cultural values. Even though some students may have prior knowledge of cold weather conditions in the U.S. and may expect to adjust easily, the severity of the weather is often underestimated until it is experienced, which usually causes students to feel homesick and depressed (Galloway, \& Jenkins, 2009).

Language is a key challenge for most international students as English is the only language of instruction and communication in many institutions and countries with international students. Students with little or no background in English are obliged to write, speak, and communicate fluently in English, which sometimes can be frustrating to the international students and their instructors too (Chen, 2014). International students who originally come from English speaking countries expect little or no 
challenges only to experience differences in articulation expressed as accents (Galloway, \& Jenkins, 2009). Language differences result in difficulty understanding and communicating. Academic challenges experienced by international students are frequently caused by lack of English proficiency and the unaccustomed academic educational system (Wang, 2004).

Neo-racism, according to Lee (2007), is another difficulty that international students may encounter. International students encounter discrimination from students, and professors, and from the federal government in terms of political and immigration policies and regulations. This is even worse against students from Africa, East Asia, Latin America, Middle East, and India (Lee, \& Rice, 2007).

An educational system without transitional and adjustment challenges is impossible as a mismatch between students' experiences and expectations will always result in adjustment challenges. As part of intellectual growth and personal development, students, regardless of being international or domestic, are expected to be challenged in their pursuit of higher education. These challenges, however, should not be beyond the student's ability to overcome but provide potential for personal development and mastery (Ramsey, Jones, and Barker, 2007), which Ramsey et al. (2007) posit, can be comparatively realized if international students are provided with support as they transition to their new environment. The four types of support international students can be offered to assist in their transitional process is practical support to ensure adequate material support, emotional support to affirm the students' feelings of value, social support to offer companionship, and informational support to provide students counsel and cognitive guidance (Ramsey et al., 2007).

West Virginia University is a public land grant university in the U.S. with its main campus located in Morgantown, West Virginia. Its other campuses are West Virginia University Institute of Technology in Beckley, WV, Potomac State College of West Virginia University in Keyser, WV, and the Charleston Area Medical Center in Charleston, WV. The school had a total student population of 
26,839 (undergraduate 21,086, and graduate students-4,263) in the Fall 2019 semester (WVU Institutional Research, 2019). However, international student enrollment decreased from 2,316 in 2017 to 2,028 in 2018 and increased again slightly to 2,040 (WVU Institutional Research, 2019) in the Fall 2019 semester. This study is important in identifying key challenges international students face as they study at West Virginia University. This will help in the successful retention of the students and create a positive and all-inclusive environment at West Virginia University.

\subsection{Purpose of Study}

The purpose of this study is to examine the adjustment challenges that international students encounter as they study at West Virginia University (WVU), their perception of West Virginia University's role in helping them overcome these challenges, and their coping mechanisms.

\subsection{Research Questions}

The following research questions are addressed;

1. What are the important adjustment challenges facing international students at West Virginia University?

2. What are the students' perceptions of West Virginia University's role in addressing the adjustment challenges?

3. What coping mechanisms or adaptation strategies do international students use to survive the adjustment challenges at West Virginia University?

\subsection{Significance of the Study}

Recruiting, retaining, and building relationships among a diverse student population, and especially international students, is a challenge for colleges and universities (McMahon, 2006), including West Virginia University. Graduate international student enrollments at WVU have fluctuated between 2006 and 2013 and decreased steadily since 2014. The number of international 
graduate students fell from 914 in 2006 to 710 in 2018. The undergraduate international student population has steadily increased from 323 in 2006 to 1,528 in 2017, but decreased in 2018 to 1,299. This resulted in a decrease in overall international student enrollment from 2,316 in 2017 to 2,028 in 2018.

For institutions to successfully recruit, build relationships, and sustain international student enrollments, important challenges facing international students should be identified and addressed. International students' smooth transitioning to their college program is necessary in ensuring successful retention of the students, which in turn has a positive effect on recruitment. Different students have unique challenges and characteristics. They are often inadequately equipped to deal with the rigors and obligations of college life, especially in an educational setting far away from home (Misra \& McMahon, 2006). This study will help in identifying major challenges faced by international students at WVU for the benefit of university offices who administer to or are charged with recruiting them. The study will also provide information for incoming and currently enrolled international students at WVU on survival strategies for overcoming challenges. In summary, this study will inform the creation of a positive and inclusive environment on campuses to foster mutually beneficial relationships between international and local students.

\subsection{Definition of Terms}

1. International Students: "Students who undertake all or part of their higher education experience in a country other than their home country or who travel across a national boundary to a country other than their home country to undertake all or part of their higher education experience." (Institute of International Education, 2019).

2. Host Institutions: Colleges and universities that admit international students.

3. Destination Country: Countries where international students travel for educational purposes. 
4. SEVIS: The Student and Exchange Visitor Information System is "a web-based system for maintaining information on international nonimmigrant students and exchange visitors to the United States.” (Retrieved January 11, 2019 from https://www.ice.gov/sevis).

5. IIE: Institute of International Education.

6. NAFSA: Originally stood for National Association of Foreign Student Advisers. In May 1990, it was renamed Association of International Educators, but the acronym was retained.

7. Adjustment: "Adjustment can be conceptualized as a psychosocial concept which has to do with the process of achieving harmony among the individual and the environment.

Usually this harmony is achieved through changes in the individual's knowledge, attitudes, and emotions about his or her environment. This culminates with satisfaction, feeling more at home in one's new environment, improved performance, and increased interaction with host country persons" (Hannigan, 1990, p.91).

8. WVU: West Virginia University (Morgantown Campus).

9. UCT: The U Curve of Adjustment theory developed by Lysgaard (1955)

\subsection{Summary of Chapters}

Chapter One introduces international student enrollment in the U.S. It highlights the challenges that international students face in adjusting and settling in their new environment, and the support that can be provided to help them adjust is also discussed. The benefits that countries, specifically the U.S., derive from international students is also mentioned. The importance of identifying key challenges international students encounter at West Virginia University to sustain international student enrollment and create a positive all-inclusive environment is discussed. This leads us to the purpose and significance of this study. 
Chapter Two reviews the literature on challenges of international students, the roles of the host institutions in helping international students overcome these challenges, and the factors affecting international students' adjustment. Chapter Three describes research methodology of this study. Chapter Four presents survey results and analysis. Chapter Five presents a summary of the study, research findings, and conclusions. It discusses the limitations, implications and offers recommendations for further practice. 


\section{Chapter Two}

\section{Review of Literature}

\subsection{History of International Students in the United States}

Leikvold (1997) reports that before World War II, wealthy Americans sent their children to colleges and universities in Europe to study at British or German universities. This was deemed necessary for a well-rounded education. After the war, the federal government supported colleges and universities to encourage students from other countries to study in the U.S. These efforts had only limited effects because of dissent about civil rights and the Vietnam War, which disrupted campuses and distracted government's attention to international matters (Kerr, 1980). Today, students from the U.S. continue to study abroad in various countries and students from other countries also continue to study in the U.S. In the year 2015, 313,415 students from the U.S. studied abroad (IIE, 2019) with the United Kingdom being the leading destination with 38,189 students followed by Italy (33,768 students), Spain (28, 325 students), France (18,198 students) and China (12,790 students).

With globalization and the growing interdependence of nations, colleges and universities are rapidly incorporating internationalization as part of their mission (Scott, 2006). Institutions worldwide are increasing efforts to admit more international students and faculty, encourage international student and faculty exchanges, and foster international research collaborations (Scott, 2006). An international student, also referred to as an internationally mobile student, is defined by UNESCO as "An individual who has physically crossed an international border between two countries with the objective to participate in educational activities in a country, where the destination country is different from his or her country of origin" (IOM, 2019). The distinguishing characteristic of international students is the fact that their presence in the foreign country is solely for educational purposes and they are enrolled in a higher education institution which permits them to stay for a minimum of a year and a maximum 
of seven years (IOM, 2019). Green card holders are permanent residents and granted the right to stay indefinitely and engage in any legal activity not requiring citizenship (uscis.gov), unlike international students who have work restrictions and are required by law to return to their home countries after completing their studies. By contrast, green card holders are statutorily entitled to apply for citizenship after living continuously for five years in the U.S. (uscis.gov).

\subsection{General Significance of International Students}

According to the Institute of International Education (IIE, 2019), the number of international students worldwide has been on the increase. Altbach (1998) states that unstable political environments, and harsh economic conditions compel students to study abroad. Of the 4.6 million international students that enrolled in colleges and universities worldwide in the year 2017, 1.1 million were enrolled in the U.S. which represents $24 \%$ of the total; this is a decrease of from $28 \%$ in the previous year. The United Kingdom is the second largest destination country followed by, Australia, France, Germany, and Russia (IIE, 2019).

Douglass and Edelstein (2009) reveal from their analysis of international students' that more than $15 \%$ of Australia's higher education tuition revenue is derived from international students. Japan increased international student enrollment as a source of generating income, and New Zealand's support for higher education is highly dependent on international students' fees (Douglass \& Edelstein, 2009). In 2014, income earned from the exportation of education related services in the United Kingdom such as insurance, drink, and food, rose to about $\$ 24,267$ billion (U.K. Department of Education Research Report, 2017) and in 2015, international students contributed $\$ 33,367$ billion to the United Kingdom economy (IIE, Open Doors, 2019). Apart from the financial gains derived from international students, they also contribute significantly to science, innovation, and the patents awarded 
to both university and non-university institutions, as well as an increase in total patent applications (Chellaraj, Maskus, \& Mattoo, 2008).

\subsection{International Students in the U.S.}

In the U.S., international students hold a temporary non-immigrant visa which permits them to study at undergraduate, graduate, and post graduate levels; they make up about $6 \%$ of all university students (ICE, 2017). The IIE (2019) reports that in the 2017/2018 academic year, 1,094,792 international students were enrolled in the U.S., of which 203,462 were in Optional Practical Training (OPT). Even though this is an increase of $1.5 \%$ from 1,078,822 in the previous year, this is the smallest increase since 2005. The decrease in international student enrollment in the U.S. could have negative impacts on the economy in terms of financial and job losses (Douglass \& Edelstein, 2009).

The United States and United Kingdom are the most frequently chosen destinations of international students (Migration Policy Institute (MPI), 2017) due to the comprehensive academic system, excellence in higher education, and comparatively open labor markets. Top ranked universities

such as Harvard, Yale, Cornell, Princeton, Stanford, and MIT also account for reasons why the U.S. is a popular destination. New York University enrolled the largest number of international students $(17,552)$ in the $2017 / 2018$ academic year, which is an increase from $17,326(1.3 \%)$ students in the previous year (Table 1). 
Table 1.Top 25 U.S. Institutions Hosting International Students, 2016/2017 \&2017/2018

\begin{tabular}{|c|c|c|c|c|}
\hline Institution & City & $\underline{\underline{\text { State }}}$ & $\underline{\underline{2016 / 17}}$ & $\underline{\underline{2017 / 18}}$ \\
\hline New York University & New York & NY & 17,326 & 17,552 \\
\hline University of Southern California & Los Angeles & CA & 14,327 & 16,075 \\
\hline Northeastern University & Boston & MA & 13,201 & 14,905 \\
\hline Columbia University & New York & NY & 14,096 & 14,615 \\
\hline Arizona State University & Tempe & $\mathrm{AZ}$ & 13,164 & 13,459 \\
\hline University of Illinois & Urbana-Champaign & IL & 12,454 & 13,445 \\
\hline University of California & Los Angeles & $\mathrm{CA}$ & 12,199 & 12,017 \\
\hline Purdue University & West Lafayette & IN & 11,288 & 11,044 \\
\hline University of California - San Diego & La Jolla & $\mathrm{CA}$ & 9,065 & 9,883 \\
\hline Boston University & Boston & MA & 8,992 & 9,742 \\
\hline University of Texas - Dallas & Richardson & TX & 9,305 & 9,713 \\
\hline University of California & Berkeley & $\mathrm{CA}$ & 8,000 & 9,331 \\
\hline University of Washington & Seattle & WA & 8,019 & 8,902 \\
\hline Pennsylvania State University & University Park & PA & 9,134 & 8,636 \\
\hline Carnegie Mellon University & Pittsburgh & PA & 7,653 & 8,604 \\
\hline University of Michigan & Ann Arbor & MI & 8,163 & 8,442 \\
\hline University of California & Irvine & $\mathrm{CA}$ & 6,792 & 7,902 \\
\hline Michigan State University & East Lansing & MI & 7,779 & 7,624 \\
\hline Indiana University & Bloomington & IN & 7,502 & 7,343 \\
\hline University of California & Davis & $\mathrm{CA}$ & 6,266 & 7,316 \\
\hline University of Minnesota - Twin Cities & Minneapolis & MN & 7,197 & 7,212 \\
\hline SUNY University at Buffalo & Buffalo & NY & 7,252 & 7,126 \\
\hline Ohio State University & Columbus & $\mathrm{OH}$ & 7,684 & 7,110 \\
\hline University of Wisconsin & Madison & WI & 6,769 & 7,080 \\
\hline Texas A\&M University & College Station & $\mathrm{TX}$ & 6,960 & 6,894 \\
\hline $\begin{array}{l}\text { Top } 25 \text { Total }(23.0 \% \text { of all international } \\
\text { students) }\end{array}$ & & & $\underline{\underline{240,587}}$ & $\underline{\underline{251,972}}$ \\
\hline
\end{tabular}

Source: IIE (2018) 
The University of Southern California has the second highest enrollment with 16,075, which is also an increase from $14,327(12.2 \%)$ in the previous year. These two institutions are followed by Northeastern University in Boston with 14,905 students (Table 1), an increase from 13,201 (12.9\%) (IIE, 2018). Universities such as Pennsylvania State University, University of California in Los Angeles, and Purdue University in Indiana recorded decreases of $-5.5 \%,-1.5 \%$, and $-2.2 \%$ respectively.

\subsection{International Students in the U.S. Country of Origin}

The highest number of international students come from China (Table 2), accounting for 363,341 or $33.2 \%$ of all international students, followed by India with 196,271 (17.9\%), South Korea with 54,555 (5\%), Saudi Arabia with 44,432 (4.1\%), and Canada with 25,909 (2.4\%).

The number of international students from China increased by 12,586 (3.6\%) from the previous year and those from India by 10,004 (5.4\%). However, the number of international students from South Korea, Saudi Arabia, and Canada decreased by 7.0\%, 15.5\%, and 4.3\%, respectively (Table 2). This is partially due to government suspension and decrease of scholarships and programs in these countries (ICE, 2018). 
Table 2. Top 25 Countries of Origin of International Students in the U.S., 2016/17 \& 2017/2018

\begin{tabular}{|c|c|c|c|}
\hline Place of Origin & Rank & $\mathbf{2 0 1 6} / \mathbf{1 7}$ & $\mathbf{2 0 1 7 / 1 8}$ \\
\hline China & 1 & 350,755 & 363,341 \\
\hline India & 2 & 186,267 & 196,271 \\
\hline South Korea & 3 & 58,663 & 54,555 \\
\hline Saudi Arabia & 4 & 52,611 & 44,432 \\
\hline Canada & 5 & 27,065 & 25,909 \\
\hline Vietnam & 6 & 22,438 & 24,325 \\
\hline Taiwan & 7 & 21,516 & 22,454 \\
\hline Japan & 8 & 18,780 & 18,753 \\
\hline Mexico & 9 & 16,835 & 15,468 \\
\hline Brazil & 10 & 13,089 & 14,620 \\
\hline Nepal & 11 & 11,607 & 13,270 \\
\hline Iran & 12 & 12,643 & 12,783 \\
\hline Nigeria & 13 & 11,710 & 12,693 \\
\hline United Kingdom & 14 & 11,489 & 11,460 \\
\hline Turkey & 15 & 10,586 & 10,520 \\
\hline Kuwait & 16 & 9,825 & 10,190 \\
\hline Germany & 17 & 10,169 & 10,042 \\
\hline France & 18 & 8,814 & 8,802 \\
\hline Indonesia & 19 & 8,776 & 8,650 \\
\hline Venezuela & 20 & 8,540 & 8,371 \\
\hline Malaysia & 21 & 8,247 & 8,271 \\
\hline Colombia & 22 & 7,982 & 7,976 \\
\hline Pakistan & 23 & 7,015 & 7,537 \\
\hline Bangladesh & 24 & 7,143 & 7,496 \\
\hline Spain & 25 & 7,164 & $\mathbf{1 , 0 9 4 , 7 9 2}$ \\
\hline Grand Total & & $\mathbf{1 , 0 7 8 , 8 2 2}$ & \\
\hline : $:$ IIE (2018) & & & \\
\hline
\end{tabular}

Source: IIE (2018)

\subsection{Importance of International Students in the U.S.}

International students contributed $\$ 39$ billion (revenue from SEVIS and visa processing) to the U.S. economy, $\$ 42.4$ billion in export revenue (Bureau of Economic Analysis,2018) and generated 455,622 jobs in the U.S. in the 2017/2018 academic year (NAFSA, 2018). Export revenue 
is the revenue generated by international students through spending on food, clothing, cars, etc. This figure ( $\$ 39$ billion) increases proportionally with the increase of international students. The Department of Commerce affirms that international students are an economic resource for the U.S., and they make significant contributions to the local economies, states, and the nation as a whole. The value of the education of international students according to Larmer (2019) is greater than the revenue the U.S. received from its top agricultural exports in 2017 which was $\$ 21.6$ billion.

International students also contribute to science and innovation in the U.S. Herman \& Smith (2010) assert that international students' contributions to American science and high-tech innovation have been recognized by policy makers, through academic studies and government reports. According to the National Foundation for American Policy (NFAP, 2017), international students provide an adequate number of students crucial for conducting research and retaining high profile faculty in the U.S. They also make it possible for universities in the U.S. to offer high quality science and engineering programs. In 2015, international students accounted for $81 \%$ of graduate students in electrical engineering, $79 \%$ of students enrolled in computer science, and $69 \%$ enrolled in statistics (NFAP, 2017). The U.S. Government Accountability Office (GAO, 2005) further notes that international students are important sources of productivity and innovation to the U.S. economy. "International students have been considered a significant source of skilled labor for host societies and international education is recognized as an important channel of labor migration" (Liu-Farrer, 2014: 185). One out of every three engineers in Silicon Valley came to the U.S. as an international student according to Kotkin (1993), along with one out of every four researchers at IBM's Yorktown Heights Laboratory, and two out of five researchers at the AT\&T laboratories (Kotkin, 1993).

Bier and Rota (1997) posit that a decrease in international student enrollment would lead to a significant loss of money to their institutions and communities, educational benefits, and loss of 
businesses. International students are not only needed for the survival and growth of smaller institutions but also to aid those institutions in maintaining the quality of the education they provide (Zimmermann, 1995).

\subsection{Factors Influencing International Student's Choice of Destination.}

Several factors account for international students' choice of study abroad destination. Marginson and Van der Wende (2007) state that the global rankings of the institutions in a country and the influence of friends and families are possible factors that determine a country of destination for an international student. Mazzarol and Soutar (2002) identify six reasons that influence the decision of international students to choose a country: 1. The knowledge of and awareness about the foreign country. 2. Recommendations from friends and family. 3. Tuition and living expenses in the foreign country. 4. The learning environment and culture of the people of the foreign country. 5. The geographic location of the foreign country and its proximity to the country of origin. 6. Social links.

Mazzarol and Soutar (2002) further explain that the decision to study in a foreign country is motivated by push and pull factors. They state the push factors as: 1 . Lack or difficulty of the student to access higher education in country of origin. 2 . The perception of the student with regards to the quality of higher education or tertiary education in country of origin. 3. Unavailability of technologybased programs in country of origin. These push factors compel students to find study destinations abroad.

The pull factors are: 1 . The commonality of or familiarity with the language spoken in the foreign country. 2 . The geographic location or proximity of the foreign country to the country of origin. 3. The reputation of the institution (ranking, prestige, alumni network). 4. The marketing and promotional activities of the institution in the foreign country. 5. Knowledge of opportunities abroad 
by academic staff and faculty in the origin country. These factors motivate and attract students to leave their countries to study in a foreign country.

Yang (2007) sought to determine the push and pull factors that influence Chinese students and found that students go to Australia for higher education because of the following push factors: 1 . Inadequate educational capacity in China and a growing demand for higher education; 2. Desire for enhanced skills for the future; and 3. A quest for more prestigious higher education. The pull factors were: 1. Recommendations from family members and friends who had studied abroad; 2. The reputation of the institution and foreign country; 3 . The geographic location and proximity of the study abroad destination; and 4. Climate and other environmental issues.

These push and pull factors were questioned by Jiani (2007, p. 566) “ $\ldots$ because it overlooked the micro-level elements and student characteristics in the decision-making process. Jiani (2017) consequently modified the factors to include the student's quest for academic and professional growth, and improved social status (Li and Bray, 2007), increased opportunity to experience Western culture, improved job opportunities (Chen, 2007), competitive global career opportunities (Bamber, 2014), and increased opportunity to migrate (Mazzarol and Soutar 2002; Schaeffer, 2005). Mazzarol and Soutar (2002) examined the reasons influencing international students and found that it is a three-stage process: 1. deciding to study abroad instead of in the home country 2 . selection of study abroad destination and 3. selection of higher education institution. Chen (2007) disagrees with this and posits that students in some instances choose the institution directly thereby deciding which country to study. Both (Mazzarol and Soutar (2002) and Chen, (2007) developed a synthesis model to explain the decision-making process of graduate international students which is "the so-called predisposition stage", "search/selection/application stage", and "the choice stage" (Jiani, 2017). The models according to 
Jiani (2017) have some limitations, even though they assist in understanding international students' decision-making process.

Financial conditions (Anderson, 1976; Cain and McClintock, 1984; Church and Gillingham, 1985; Reed, Lahey, and Downey, 1984) were an important element influencing international students' choice of study abroad destination. Vaugh, Pitlik and Hansotia (1978) add that the cost of attending a college or university abroad is a key factor for international students. Bourke (2000), Conard and Conard (2000), and Moogan, Baron, and Harris (1999) support the argument that cost influences students' choices

\subsection{Challenge Defined}

A challenge according to the Collins dictionary is something difficult which requires great effort and determination (Collins dictionary, n.d.). Studying to obtain a degree requires great effort and determination which can be challenging to students.

\subsection{General Challenges Faced by All Students}

All students (domestic and international) encounter challenges as they endeavor to study. These challenges are, however, experienced at different stages by each student during their course of study and the extent to which these challenges are experienced differs from culture to culture with home sickness, financial challenges, language and communication challenges, discrimination, and adjusting to new social norms and educational systems being the main challenges (Thurber \& Walton, 2012). The general challenges faced by students are:

1. Tuition- Tuition for college is much higher today than two decades ago and paying for college can be challenging. The choice of college for most students is determined by the cost of tuition as an average $40 \%$ of students decline their admission by their first-choice schools because of 
tuition cost, and some students, especially low-income students, fail to complete their degree due to affordability (Perna, 2002).

2. Housing and Cost of Living- The Times Higher Education reports soaring cost of living for students and that this is even worse for international students. Cost of living typically includes rent, books and supplies, groceries, health insurance, and transportation (Minsky, 2016).

3. Homesickness- Homesickness is common among college students especially in their freshman year. For most students, attending college is their first time of being separated from family and living alone, which causes nostalgic feelings, depression, stress, and difficulty focusing on studying (Thurber \& Walton, 2012). Students are often excited about going to college and spend considerable time preparing without anticipating how they will miss their familiar environment. Homesickness basically occurs due to unfamiliarity and difficulty adjusting to a new environment.

4. Institution Mismatch for Students- The size of a college can pose a challenge and be unpleasant match for students. A student who grew up in a small town or suburban area and attended small size schools will have difficulty adjusting in a large college or a college situated in a large city, as there are relatively more adjustment challenges with large colleges than small ones (Yeo, 2006). There is more cohesion among students in smaller colleges which makes the student navigate through their new environment more easily and adjust with fewer challenges.

5. Healthcare- Living for the first time in dormitories and housing arrangements with other students exposes students to many health risks coupled with the pressure of academic life. The stress that students go through in addition to lifestyle changes that comes with college life not only impacts their physical health but their mental health as well. Students begin to develop common psychiatric conditions such as anxiety, depression, and suicidal thoughts (Liu et al., 2019). Most colleges offer health services and promote student awareness of health challenges. Affordable health insurance plans 
offered by colleges for students are a major concern as they lack year-round coverage (Retrieved November 1, 2019 from https://www. healthcare.gov).

\subsection{Expectations and Challenges Faced by International Students}

An international student's decision to study abroad is often motivated by a desire for higher quality education compared to the educational standards in their country of origin and a belief that an international education will enhance their career prospects. Some international students also see study abroad as an opportunity to improve their foreign language skills with the expectation of interacting and building relationships that will boost their confidence and communication skills. This, however, comes with challenges, the extent of which depend on a student's cultural background. International students encounter challenges with acculturation (Jung, Hecht, \& Wadsworth, 2007; Rahman \& Rollock, 2004; Wadsworth, Hecht, \& Jung, 2008) negative stereotypes (Bonazzo \& Wong, 2007; Lee Rice, 2007), discrimination (Frey \& Roysircar, 2006; Hanassab, 2006; Poyrazli \& Lopez, 2007; Wei et al., 2008) and reduced access to support systems (Frey and Roysircar, 2008). Language or communication challenges, homesickness, financial difficulties, adjusting to new social norms and educational system, and discrimination are among the challenges faced by international students (Hull, 1978). This is confirmed in later studies (Olivas \& Li, 2006; Sumer, Poyrazli, \& Grahame, 2008) that add additional factors that challenge international students. Some challenges depend on the size and location of the host institution and available resources (Chen and Yang, 2014). The level of discrimination and prejudice faced by international students may also not be the same for all students. Those from the Middle East and Africa face more discrimination and prejudice than students from European countries (Hanassab, 2006). Boafo-Arthur (2013) confirms this and explains that this causes acculturative stress for students from Africa. Students from China face challenges with English, racial discrimination, homesickness, and unfriendliness from some American students, which makes their 
adjustment more difficult (Perkins, 1977). Chinese students additionally experience financial difficulties, challenges adjusting to a different lifestyle, school, value system, difficulty in securing employment after school because of a language barrier, high parental expectations, and, upon completions of their studies, the difficulty of adjusting back to their original culture (Yao, 1983). Another study (Sue \& Zane, 1985) reports that Chinese international students experienced the most social and emotional challenges and encountered significant academic and social difficulties despite the fact they performed well academically.

Wang (2004) underscores the peculiar difficulties international students encounter and classifies challenges and differences in cultural encounters as one main problem. He argues that this could be a mismatch resulting from differences in value systems and cultures of international students and local students. Furnham and Bochner (1986) support this argument and explain that while people from Australia esteem individuality and privacy similar to Americans, Indonesians value group conformity. Consequently, international students who are accustomed to group conformity will be challenged in a culture that values individualism. Communication barriers may also arise from differences in language and context (low or high). An example of low context can be seen in the American culture which has a high level of openness and directness in verbal communication; many Asian cultures are examples of high context where their culture is less direct and open in how they communicate verbally. This again may result in a poor fit causing international students from such cultures to feel unaccepted and misunderstood. 


\subsection{Visa Acquisition and Status}

Visa acquisition and processing challenges increased for international students after the 9/11 attack. Galloway and Jenkins (2009) posit that intensified security measures, more stringent rules and cumbersome application procedures coupled with rigorous background checks instigated by SEVIS (Student and Exchange Visitor Information System) are a major challenge for international students. The visa status of international students comes with restrictions which can be challenging. For example, international students are allowed very limited hours to work and none outside of their colleges. International students from countries such as Iran are issued single entry visas which do not allow travel outside the U.S. until completion of their studies. Thus, in any emergency they must apply for an exit visa before departing the U.S. (Fischer, 2019).

\subsection{Cultural Expectations and Shock}

Culture can be defined as a learned "... set of values, attitudes, beliefs, behaviors and customs that distinguish a society ..." (Mahoney, Trigg, Griffin, \& Pustay, 2001, p. 373). Culture shock refers to the difficulties individuals endure in a different cultural environment (Townsend \& Poh, 2008). International students expect to be exposed to diverse cultures, people, and ideas that they would not experience in their home countries and make long lasting friendships (Lee, 2007). They expect to gain a broader perspective of the world, become open minded, and appreciate the different lifestyle choices of others. Peng (2006) describes that Chinese students who had experienced other cultures and languages were more culturally sensitive to others than other Chinese who had no such experiences. Individuals experience culture shock in the absence of known and familiar cultural signs and symbols which causes anxiety and frustration (Chapdelaine \& Alexitch, 2004). Culture shock sets in when individuals realize that they had unrealistic expectations of their new environment and are unprepared to deal with the realities of their new environment (Usunier, 1998). 
Shenoy (2001) adds that crossing cultural, communication, interpersonal, language, and social boundaries are all part of the migration process and having to deal with all these differences is what leads to culture shock. He notes that knowledge and understanding of the stress and adjustment challenges faced by international students is limited as compared to local students. She adds that international students are faced with the same common stressors that the average college student faces in the host country in addition to socio-cultural differences which compound their adjustment challenges. International students encounter several challenges away from home which take time to adjust to. The usual way of doing things in their original country will be altered in their new environment which includes their lifestyle, socialization among foreign nationals, style of dressing, religious practices, food, cultural values, and several others (Zimmermann, 1995). These struggles may lead to distortion in the stability and peace of the international student and their family if they relocated with their family. International students feel separated from their families which results in daily emotional crises. Culture shock may also include weather in the destination country, especially for international students who have never experienced extreme cold and snow or prolonged heat and humidity.

\subsection{Language Difficulties}

Language is a critical challenge for most international students in the U.S., especially those whose first language is not English (Chen 2014). English is the language spoken and medium of instruction at most universities and in the countries which attract the largest numbers of international students. Even when international students speak and understand English, they may struggle getting accustomed to unfamiliar accents and idioms. Although international students from non-English speaking countries are required to take an English proficiency test before they can be admitted to a college or university, passing the test does not guarantee success as it is usually just a general 
knowledge test (Kuo, 2011). It is essential for international students to write according to the western academic writing style, and speak and communicate fluently in English (Chen, 1999; Mori, 2000). Chen (1999) and Mori (2000) posit that language challenges make it difficult for international students to understand lectures which tend to impact their written assignments and examinations. A language barrier can also make it difficult for these students to actively participate in class. This is confirmed in research conducted among international students which shows the relationship between English proficiency and academic performance (Poyrazli et al., 2001; Stoynoff, 1997; Zhang \& Brunton, 2007). The study which was conducted among 27 faculty and staff members about their perceptions of the English proficiency of international students revealed that proficiency in the English language among international students was a major challenge that affected their academic performance. Understanding English is also a challenge because of the differences in articulation which are usually denoted as “accents" (Galloway \& Jenkins 2009). In overcoming these challenges, international students need to get accustomed to a new way of life. Appreciating their challenges will go a long way to help them adjust (Zimmermann, 1995).

\subsection{Prejudice and Neo-Racism}

In terms of ethnicity, language proficiency, cultural norms, religion, race, and behavioral patterns, international students form one of the most diverse groups in colleges and universities in the U.S. (Hanassab, 2006; Spencer-Rodgers, 2001). Sadly, however, they are seen as a large homogenous group (Schmitt, Spears, \& Branscombe, 2003). They are discriminated against and stereotyped as "generalized other" (Urban \& Orbe, 2007, p.128) and considered cultural outsiders. International students searching for a higher education institution seek institutions that not only offer value for their

money but also an atmosphere of belonging and acceptance. However, Hanassab (2006) reports from a survey conducted among 640 international students that shows that international students face 
discrimination from both domestic students and professors. Discrimination tends to be more severe against students from Africa, Latin America, Middle East, East Asia and India as compared to those from Canada, Europe, Australia, and New Zealand. Spencer-Rodgers (2001) expands on this with information from a survey conducted among 100 American college students. Although international students are perceived as hardworking, disciplined, and eager to learn, they are also perceived as a homogenous group that is socially and culturally awkward, confused, distressed, and naïve (SpencerRodgers, 2001). Hanassab (2006) concludes that international students of color and those with stronger foreign accents experienced more adjustment difficulties. She argues that discrimination extended to job applications, using public transport, and finding accommodations.

Lee and Rice (2007) term this "neo racism" which is a result of the skin color, culture and country of origin of the student. They add that not only do international students experience neo-racism from other domestic students but also from within the government in terms of political and immigration policies and regulations. This is confirmed in the research they conducted among 501 international students through an online survey and in-depth interviews among 24 international students.

The Patriot Act is an example of neo-racism which denies immigrants due process, permits the detention of immigrants without limits, violates the freedom of immigrants, and institutes cumbersome tracking systems and national security procedures (Lee \& Rice, 2007). They continue that international students also experience neo-racism within the educational setting. Instructors, academic advisors, and fellow students are reluctant to form interpersonal relationships with international students, which sometimes makes it difficult for the students to discuss their academic challenges with their advisors or colleagues who also depict their culture negatively and make negative comments about them.

The media also discriminates against international students by portraying them negatively through publications for higher education (Rhee \& Sagaria, 2004), which has contributed to the 
negative sentiments towards international students. Most discussions in the media highlight the costs of hosting international students over the benefits international students bring to the U.S. (Brader, Valentino, \& Suhay, 2008). It is important to note that the benefits and costs area unevenly distributed among different government entities. Local governments provide services such as schooling for dependents or health care, while the federal government is more likely to receive income tax revenues (Schaeffer, 1983).

In a critical discourse analysis by Rhee and Sagaria (2004) of 78 articles in the Chronicle of Higher Education between 1996 and 1999, international students were portrayed as "a bad U.S. public investment, as diligent migrant workers, and as persons with diminished individual identity" (p. 91). They continue to argue that international students are sadly seen as an economic resource who only work hard because they fear losing their visa. Lee and Rice (2007) strengthen this argument and assert that the challenges are not solely because of adjustments to a new environment, but also because of factors, such as racial or cultural discrimination.

\subsection{Social Expectations and Challenges}

International students look forward to experiencing advanced learning techniques and opportunities of studying and conducting research in world-class facilities and laboratories. They expect to become entrepreneurs after graduating to establish businesses in their home countries with investors from the foreign countries where they studied (Rhea, 1997). They expect this to be possible and that they will manage such businesses successfully because of their international education and exposure. It is however impossible for international students not to encounter challenges as they strive to achieve these goals or adjust in their new environment. According to Ramsey et al. (2007), the challenges that both international and domestic students encounter in colleges or academic institutions 
are necessary for the intellectual and personal growth of the student. The challenges however should not be beyond a student's capacity but stepping-stones for the student's growth and mastery.

\subsection{Loneliness and Social Isolation}

Isolation and loneliness are common among students and more severe among international students (Thurber \& Walton, 2012) which impacts their physical and mental health. This is caused by separation from family and/or friends, lack of a support system during important events in the life of family in the home country, expense of visiting "Back Home" and difficulty of re-entry into the U.S. Another cause for loneliness and social isolation among international students according to Townsend and Poh (2008) is the cultural norms, and nature of friendships in the international student's country of origin which makes it difficult for them to make friends in their new location. Triandis (1999) agrees and asserts that international students from Asia had more difficulty establishing friendships as compared to international students from Europe, due to Asian culture being collectivistic while western culture was more individualistic, assertive, and self-sufficient (Mori, 2000; Yeh and Inose, 2003). "Different cultures use different interaction methods and communication strategies, which leads to discrepancies in language, body language, conflict resolution, directness, and closure (Townsend and Poh 2008; p. 246). Quality relationships among international students from the same countries and domestic students greatly impact international students' adjustment and identification with their institution (Kashima and Loh, 2006). Kashima and Loh (2006) who surveyed 100 Asian students at an Australian university found that international students with proficient English language skills, and stronger relationships adjusted easily and connected well to their institutions, whereas language challenges make it difficult for international students to interact and socialize with local students (Chen, 1999; Mori, 2000). 


\subsection{Academic Expectations and Challenges}

International students expect to gain valuable experience, a quality education, and form human capital which will enable them to take leadership positions upon returning to their home countries. They expect to earn higher incomes than if they study in their home countries (Schmidt and Pardo, 2017). They look forward to enhancing their analytical and creative problem-solving skills through the foreign experience (Cho and Morris, 2015). Unfortunately, international students perform below their expectations, which is usually below their performance in their country of origin. This is due to challenges arising from unfamiliarity with the academic system in the U.S., the difficulty of learning in a non-native language, and adjusting to the new educational environment (Wang, 2004). This is worsened by pressure from sponsoring institutions in their home country to perform and maintain high academic standards or lose their funding (Chen, 1999; Mori, 2000; Pedersen, 1991). International students have to go through a series of orientations and acquaint themselves with new teaching styles, modes of study, activities and facilities available at the universities to enable them to cope and adjust to their new academic environment and also help them understand the techniques and modes of study (Chen and Yang, 2014). International students, for example, who are used to rote learning in their countries have difficulty with the critical thinking learning style in western universities (Aubrey, 1991). A study to examine the educational experiences of 682 international students from Asia (Liberman, 1994) reveals that international students had difficulty with the critical thinking, and interactive teaching style which caused higher stress levels among them.

\subsection{Financial Challenges}

Almost all international students face financial challenges (Li \& Kaye,1998; Poyrazli \& Grahame, 2007; Roberts et al., 1990) which are mostly caused by work restrictions and a significantly higher cost of tuition for international students (Chen, 1999; Mori, 2000). The visa status of 
international students restricts how much and where they can work and make them ineligible for federal financial aid (Pell Grants, Stafford Loans, etc.). This multiplies their financial challenges making it difficult for them to cover their educational costs and gain work experience (Schulte \& Choudaha, 2014). Johnston et al. (1997) posit that the inputs and technology utilized by both international and local students are the same, yet domestic students benefit from government support and subsidy while there is a set or structured fee that international students are obliged to pay. Geo (2008) posits that the exchange rates of the currency of students' countries of origin to the U.S. dollar are frequently unfavorable to international students.

Church (1982) claims that the challenges international students face is not much different from that of domestic students, the unique cultural background of the international students however accounts for the challenges and difficulties they encounter. Thus, international students have to undergo several adjustments: (1) to student life, (2) to a new culture and learning environment, (3) as a growing and maturing individual striving to achieve personal goals, and (4) as a national representative, mindful of their national identity and ethnic background (Bochner, 1972). Despite the difficulty in reckoning the level of adjustment difficulties that international students encounter (Church, 1982), adjusting academically and professionally seems to be easier than adjusting socially (Hull, 1978).

\subsection{The Impact of COVID-19}

The outbreak of COVID-19 disease had an impact on all college students and even more catastrophic consequences for international students. Colleges had to shut down their campuses and switch to online classes during the Spring 2020 semester. Domestic students returned to their homes whiles international students were left to find new housing as dormitories were closed in a period where the nation was under lockdown. Most international students lost their jobs during this period as campuses were shut down and could not work off campus due to visa restrictions which resulted in 
extreme financial difficulties during this period. International students were excluded from federal aid by the U.S. government to help students pay for housing and other expenses during this period, international students who were able to fly out to their home countries face uncertainty of returning as international borders are closed (Dickerson, 2020). The recent federal guidance passed by ICE (U.S. Immigration and Customs Enforcement) in June 2020 which mandated international students to depart the U.S. if they were taking all of their classes online brought enormous fear and panic which caused undue stress to international students (Anderson and Svriuga, 2020). Even though the guideline was rescinded in July 2020 and international students can remain in the U.S. while taking all classes online in the Fall 2020 semester, international students continue to live in fear and uncertainty of what the future holds for them in the U.S.

\subsection{Advantages of Being an International Student}

International students are more respected and valued in their home countries than students who undertake their studies locally, and this consequently enhances the relationship between their home country and their study abroad destination country. A survey by Norris and Gillespie (2009) of 17,000 international students in the U.S. between 1950 and 1999 revealed that their study abroad experiences significantly impacted their career, especially of those who studied abroad for a full year as compared to those who studied abroad for just a semester. Another study (Murphy et al., 2014) on the role of study abroad in developing global awareness and global engagement shows that students who have studied abroad are globally engaged and participate actively in the development and civic affairs of their communities upon returning to their home countries.

Being an international student comes with several opportunities such as jobs, internships, international conferences and other resources. They are also able to gain the trust and confidence of foreign investors since they possess international degrees and experience (Rhea, 1997). The challenges 
that international students overcome while adjusting to their new environment prepares them and makes them successful in adjusting easily and overcoming difficult challenges wherever they get a job in whatever country as they develop personal skills and learn to be financially independent.

\subsection{Adjustment Theories}

How individuals adjust to new cultures differs greatly from person to person and due to factors like flexibility, interpersonal skills, and communication skills. It can also be because of age and proficiency in the host country language. There are four stages of adjustment to a new environment (Oberg, 1960): 1. The honeymoon stage; where the student is optimistic, fascinated, and eagerly looks forward to the new environment without paying attention to perceived challenges. 2 . The crisis stage which is usually the stage marked by confusion when the reality of challenges begins to set in, the individual experiences hostility and stereotyped attitudes causing doubt in their ability to cope and questions whether to stay or leave. 3 . The recovery stage is the self-discovery stage where interaction with domestic students is frequent and easy, the student increases their knowledge level of the host country's language, and friends are made. 4. The adjustment stage: there is loss of anxiety at this stage, the student has adjusted to the new environment, the student feels accepted and is now prepared for the adventures in their new environment.

\subsection{The U Curve of Adjustment Theory}

The U curve of adjustment theory (UCT) was developed by Lysgaard (1955) and is one of the most cited adjustment models. It is similar to Oberg's (1960) stages of adjustment. He theorizes that before productivity can occur in a new cultural environment, there must be a period of learning the new cultural values and social norms. A study (Lysgaard, 1955) among 200 Fulbright students from Norway who studied in the U.S. for 0-6months, 6-18months, and over 18 months showed that the adjustment process was a function of time. Lysgaard's (1955) UCT depicts that in the new culture, the preliminary 
stage is the honeymoon or elation period as the individual is fascinated by the new sights and sounds. The individual is intrigued by the differences and similarities between the new and home culture. This is followed by the culture shock stage which occurs during the period of disillusionment of having to cope with hostility and stereotyping. The individual becomes homesick as the excitement of the new culture has worn off. The adjustment stage is where the individual is becoming familiar with the new culture, and finally, the mastery or adaptation stage as the individual has learned to adapt. The UCT (Figure 1) has been widely used to confirm adjustment challenges that individuals experience. It also gives a realistic expectation of the process of adjustment and establishes the need for developing coping mechanisms. The stages of the UCT however may not be applicable to everyone and the length of time for each stage may also vary from person to person (Black, \& Mendenhall, 1991).

\section{Figure 1. Lysgaard's (1955) U Curve of Adjustment}

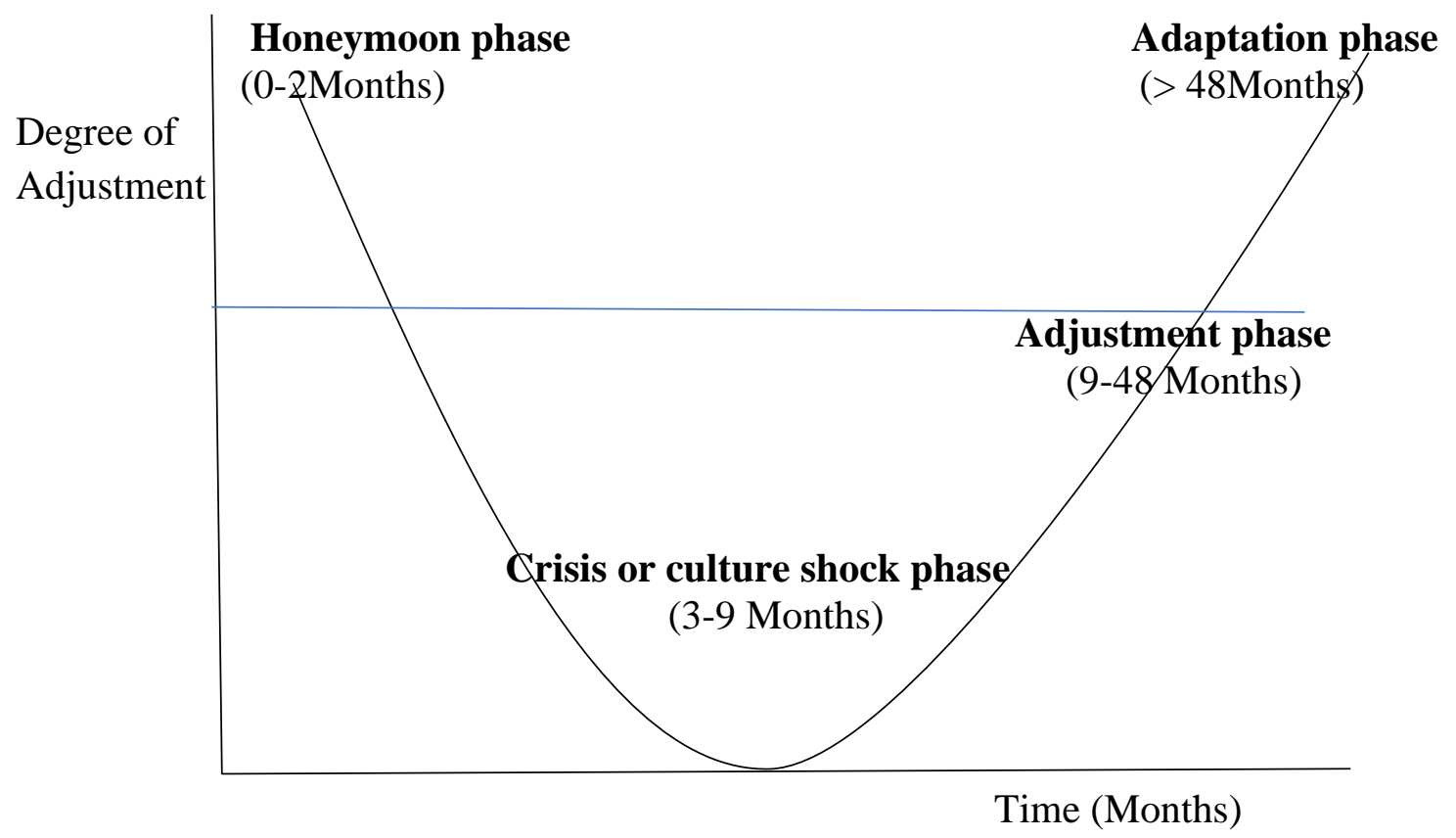


The UCT theory has been criticized by scholars as lacking consistency, being inconclusive, vague, weak and applicable only in a few cases (Becker, 1968; Breitenbach, 1970; Selby \& Woods, 1966; Spaulding \& Flack, 1976). A study by Selby and Woods (1966) of 68 non-European students at Stanford University revealed that the social and academic morale of the student rises and falls at different times of the academic year and not necessarily in a U curve.

\subsection{The W Curve}

The W curve (Figure 2) was later developed by Gullahorn and Gullahorn (1963). They assert that after developing transitional skills and confidently adjusting to a new culture, international students may return home to their countries of origin, old friends, and values which makes them experience a second re-acculturation phase marked by mental isolation which is the final stage of acceptance and integration.

\section{Figure 2. The Gullahorn W Curve Transition Model}

\section{Honeymoon $\quad$ Initial Adjustment Acceptance and Re-Integration}

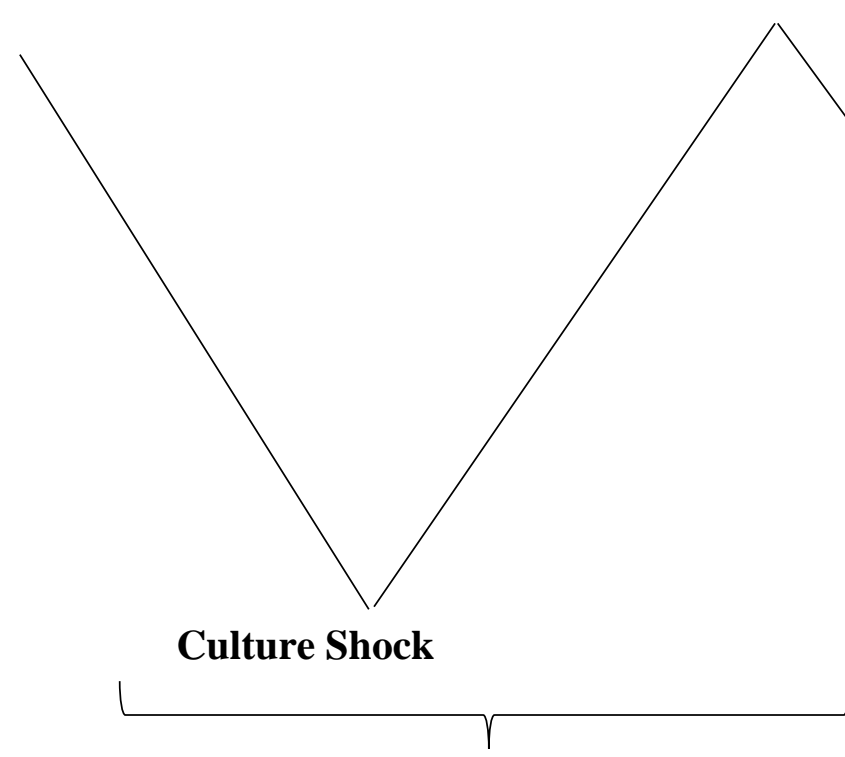

Study Abroad

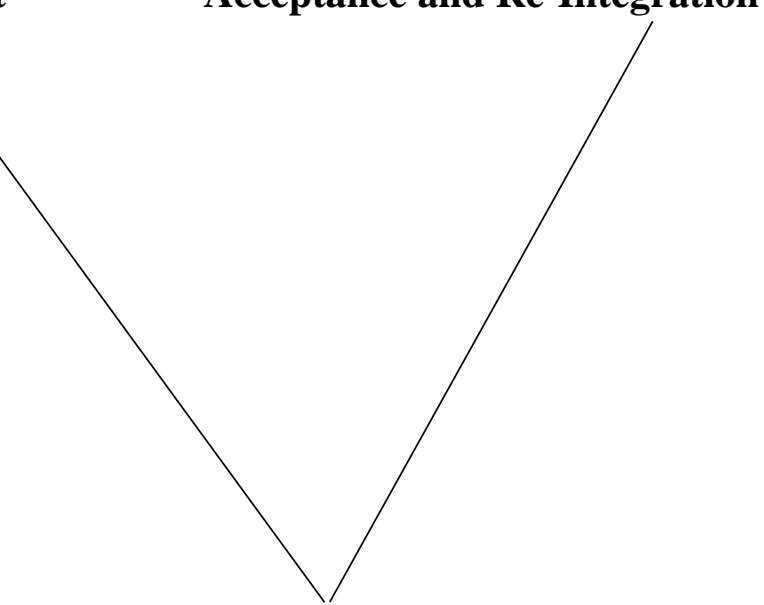

Mental Isolation

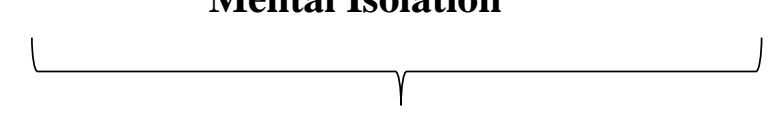

Back in Home Country 


\subsection{Possible Factors Affecting Adjustment}

International students face various adjustment challenges, the most common being language difficulties, homesickness, isolation, and cultural misunderstandings (Jacob, 2001). Sheehan \& Pearson (1995) claim that the differences or similarities between the cultures of the international students' home country and the host country are connected to the adjustment challenges. Tseng and Newton (2002) propose that despite the numerous challenges, international students have approximately eight strategies that they can utilize for smooth adjustments. These include establishing and continuing relationships with advisors and instructors, relationship building, making cultural and social contacts, making an effort to know others and themselves, having an open mind, and asking for help when needed.

Possible independent variables influencing international students' adjustment are gender, age, marital status, academic level, country of origin, and college size, which contribute to the unique and common challenges they experience while adjusting to their new environment due to the diversity among them (Jacob, 2001).

\subsection{Gender}

Studies of gender's influence on international student adjustment challenges are limited (Church, 1982). Among the studies, Haynes, Bulosan, Citty, Grant-Harris, Hudson, and KoroLjungber, (2012) note that women experience more role conflicts than men, with their greatest role conflict being between their personal and academic life. Church (1982) agrees that female international students encounter more adjustment challenges than male students in the U.S. and suggests that this is due to the traditional cultures of some Asian countries which results in inner conflicts for females from those cultures. A study by Misra and Chris (2003) of 143 international students to analyze how academic stressors, life stress, perceived stressors and reaction to stressors related to each other 
revealed that male international students reacted less to the stressors. This could be due to socialization or cultural upbringing that instills within them that expressing themselves emotionally is a sign of weakness and non-masculinity. Female international students however reacted more emotionally, psychologically, and behaviorally to the stressors. Therefore, Question 2 of the international student survey asks respondents to identify their gender which will be used to analyze how gender affects adjustment.

\subsection{Age}

Age is used as another factor. Older international students are known to adjust more easily than younger students. Older students tend to have better coping abilities as they have the advantage of having more life experiences and maturity and therefore adjust better Older international students may also have some disadvantages such as difficulty in making changes as they are more grounded in their culture and values (Poyrazli, Arbona, \& Bullington, 2001). Younger international students seem to adjust easily culturally and socially as they have an advantage in learning the English language (Wang, 2004).

\subsection{Marital Status}

The marital status of international students may influence their decision to stay after graduation. Many factors, such as social support and social relationships, spousal support, family ties, and others influence international students' decisions to stay after their education (Arthur \& Flynn, 2011). The most important factor, however, according to Musumba, Jin, and Mjelde (2009) is the marital status of the international student explaining that international students who were married were more likely to stay in the U.S. after completion of their studies as compared to international students who were single. This, according to Copelanda and Norell (2002), is because of the fact that spousal dependency is higher in a foreign country. This decision to stay after graduation may enable them to easily build coping 
mechanisms during the crisis stage and thus transition quickly to the adjustment stage of the UCT. Although students living with their spouse also encounter challenges, they may also emotionally support each other. Therefore, marital status will be used to determine how it contributes to the student's ability to adjust and transition to the adaptation or mastery stage of the UCT.

Walsh (2007) expounds that the process of deciding to stay in a foreign country after completion of studies for single international students is simpler as their main focus is on themselves, their appointments, parents at home, and leisure time enjoyment. This however is the opposite for married international students as they play multiple roles and will have to take into consideration their spouses and children making the decision process more complex. Carr, Inkson, and Thorn (2005) affirm this argument and add that factors that influence the decision to stay depend largely on support and satisfactory living conditions such as affordable and quality education for their children and adequate income to sustain the family.

\subsection{Academic Level}

This is the class standing (undergraduate/graduate level) of the international student. According to the U curve adjustment theory, the longer an international student stays, the easier the student's adjustment to the new environment and culture. Item 7 on the international student survey asked students about time spent in the U.S. prior to enrolling at WVU.

These students, however, are not devoid of challenges when applying for practical training, and internships. A comparison of adjustment challenges between international undergraduate students and international graduate students shows that undergraduate students adjust socially more successfully while graduate students adjust academically more successfully (Gullahorn \& Gullahorn, 1966). This may be due to differences in goals as younger undergraduate students are driven by personal 
development goals while the older graduate international students are driven by professional development goals (Church, 1982).

\subsection{Country of Origin}

Due to the diversity of international students, the adjustment challenges they encounter vary. Students from Asia, South America, and Africa are more comfortable with the customs and cultural practices of their countries while international students from European countries easily accept bicultural attitudes because the European culture and customs are similar to those in the U.S. (Sodowsky \& Plake, 1992). Country of origin will be used to determine the specific adjustment challenges peculiar to students from specific countries.

\subsection{Studies on Adjustment Challenges Using Surveys and MISPI}

Surveys are widely used in research due to their ease of access and low cost. They can be completed by hundreds of respondents at the same time via the internet while guaranteeing that the respondents' identity is protected. Using an online survey, Wang (2003) conducted a study of the adjustment of international graduate students at American universities, including both resilience characteristics and traditional background factors. Two hundred and eighty-nine (289) international students at Florida State University responded to the survey and 82 international students responded at Georgia State University. Responses from the study conducted among students of Florida State University indicated that resilience characteristics such as gender and country of origin highly influenced adjustment challenges. Some adjustment challenges revealed in the research include student health insurance, loneliness, course selection, academic advisors, language difficulties, unconcerned attitudes of Americans, stress, legal, and tax issues. A key challenge revealed in this research was lack of legal services for international students. In the study of international students at Georgia State 
University, cultural differences or challenges were the key reported challenge. Other challenges were loneliness, attitudes of staff and faculty, and speaking up in class.

Another study (Sonari, 1993) of 108 international students at Oregon State University, also using an online survey to identify problems in an English language program, showed that English language barriers, specifically understanding and writing term papers, were the key challenges faced by the students. Other challenges of concern were admission selection, social and personal challenges, students' activities and orientation, health, and financial aid. The least challenge was about religion and religious practices in the U.S. The age and country of origin significantly corelated with the challenges. Younger students reported more challenges than older students and students from African countries reported the most challenges followed by students from the Middle East, Asia, Europe and Latin America.

Atebe (2011) conducted a study of 39 international students at a public university in the Southern U.S. and 144 international students at a private university in the Northeast using the MISPI in an online survey. The study investigates the challenges that international students encounter while attending American universities and the extent to which these challenges were met by their host institutions. The key challenges revealed in this study were religious services, social and personal problems, academic records, and student activity. Financial aid challenges, admission selection challenges, orientation, student activity, and academic challenges were the least met by their host institutions.

\subsection{West Virginia University}

West Virginia University (WVU) is a public land grant university in the U.S. with its main campus located in Morgantown, West Virginia. Its other campuses are WVU Institute of Technology in Beckley, West Virginia, WVU Potomac State College in Keyser, West Virginia, and Charleston 
Area Medical Center in Charleston, West Virginia. Originally established in 1867 as the Agricultural College of West Virginia, it was renamed College of West Virginia in the same year (Doherty, \& Summers, 1982) and is now a major research university. Harriet Lyon was part of the first class of students and the first female to receive a degree from WVU in June 1891 which gave way for women being accepted as students and educators (WVU Student Government, 2007). The university experienced rapid growth in the late 1950s with enrollment reaching 14,000 in the 1960 s and 22,000 in the late 1970s (WVU Student Government, 2007). In the Fall 2019 semester, WVU had a total student population of 26,839 .

Walehiro Koraku from Japan was the first international student to be enrolled at WVU in 1890 to pursue a law degree (page 61, WVU Cat 1890-91). The first international student to graduate from WVU was Tokichi Masao also from Japan. He graduated from the College of Law in the 1894/95 academic year. International student enrollment at WVU kept increasing and reached 1,202 students in 2006. The growth continued and enrollment reached 2,028 in 2018 (WVU Institutional Research, 2020). This is, however, a decrease from its peak of 2,314 in 2017 (Table 3). The international student population grew only slightly to 2,040 in Fall 2019 (WVU Institutional Research, 2020).

The international undergraduate student population increased steadily from 323 in 2006 to 1,528 in 2017 and then decreased to 1,299 in 2018. The international graduate student population was 868 in 2006 and has remained relatively level with fluctuations (Table 3). It reached a peak of 914 in 2014 but fell steadily for the following four years to 710 in 2018 . The trend in total international enrollments at WVU reflects international student enrollment in the U.S. which increased steadily from 526,670 in the $2005 / 2006$ academic year to 903,127 in the $2016 / 2017$ academic year but decreased to 891,330 in the $2017 / 2018$ academic year (IIE, 2018). 
Table 3. International Students Enrollment Trends at West Virginia University

\begin{tabular}{|c|c|c|c|c|}
\hline Year & Undergraduate & Graduate & Professional* & Total \\
\hline Fall 2006 & 323 & 868 & 11 & 1,202 \\
\hline Fall 2007 & 353 & 860 & 15 & 1,228 \\
\hline Fall 2008 & 397 & 879 & 16 & 1,292 \\
\hline Fall 2009 & 426 & 863 & 48 & 1,337 \\
\hline Fall 2010 & 488 & 877 & 38 & 1,403 \\
\hline Fall 2011 & 584 & 853 & 43 & 1,480 \\
\hline Fall 2012 & 719 & 882 & 46 & 1,647 \\
\hline Fall 2013 & 906 & 882 & 32 & 1,820 \\
\hline Fall 2014 & 1,108 & 914 & 26 & 2,048 \\
\hline Fall 2015 & 1,242 & 907 & 20 & 2,169 \\
\hline Fall 2016 & 1,386 & 855 & 22 & 2,263 \\
\hline Fall 2017 & 1,528 & 775 & 13 & 2,316 \\
\hline Fall 2018 & 1,299 & 710 & 19 & 2,028 \\
\hline Fall 2019 & 1,310 & 711 & 19 & 2040 \\
\hline
\end{tabular}

* Law, health sciences, etc.

Source: West Virginia University Institutional Research,2020.

Students at WVU face many of the same challenges and stresses that students encounter elsewhere at other U.S. institutions. Higgenbotham (2016) examines the perceived stress and coping mechanisms of students at WVU using attachment theory. The study revealed that "a better understanding of individuals' attachment dynamics and chosen coping strategies may be useful in furthering the understanding of individual experiences of distress in the university environment" (Higgenbotham, 2016, p.97). 
The highest number of international students at WVU come from Kuwait (Table 4) with 462 students in 2018, a decrease from 555 in 2017. Kuwait is followed by Saudi Arabia, China, and India. International students from China increased from 203 in 2006 to 259 in 2014, and then decreased to 151 in 2018. With just 39 students in 2006, Saudi Arabia is now the second largest origin country with 348 students in 2018, even though this is a decrease from 430 students in 2017. 
Table 4. Top 20 Countries of Origin for International Students in West Virginia University

\begin{tabular}{|c|c|c|c|c|c|c|c|c|c|c|c|c|c|}
\hline Country & $\begin{array}{l}\text { Fall } \\
2019\end{array}$ & $\begin{array}{l}\text { Fall } \\
2018\end{array}$ & $\begin{array}{l}\text { Fall } \\
2017\end{array}$ & $\begin{array}{l}\text { Fall } \\
2016\end{array}$ & $\begin{array}{l}\text { Fall } \\
2015\end{array}$ & $\begin{array}{l}\text { Fall } \\
2014\end{array}$ & $\begin{array}{l}\text { Fall } \\
2013\end{array}$ & $\begin{array}{l}\text { Fall } \\
2012\end{array}$ & $\begin{array}{l}\text { Fall } \\
2011\end{array}$ & $\begin{array}{l}\text { Fall } \\
2010\end{array}$ & $\begin{array}{l}\text { Fall } \\
2009\end{array}$ & $\begin{array}{l}\text { Fall } \\
2008\end{array}$ & $\begin{array}{l}\text { Fall } \\
2007\end{array}$ \\
\hline Kuwait & 367 & 462 & 555 & 162 & 88 & 129 & 89 & 63 & 57 & 55 & 43 & 30 & 20 \\
\hline Saudi Arabia & 261 & 348 & 430 & 273 & 255 & 450 & 400 & 329 & 231 & 158 & 126 & 94 & 61 \\
\hline China & 174 & 151 & 172 & 144 & & 259 & 262 & 251 & 224 & 219 & 227 & 209 & 219 \\
\hline India & 118 & 117 & 126 & 147 & 181 & 201 & 204 & 201 & 198 & 239 & 254 & 284 & 270 \\
\hline Oman & 78 & 68 & 80 & 64 & 60 & 61 & 40 & 35 & 36 & 21 & 12 & 8 & 10 \\
\hline Nigeria & 73 & 75 & 84 & 48 & 48 & 80 & 73 & 70 & 52 & 33 & 29 & 25 & 23 \\
\hline Bangladesh & 50 & 40 & 35 & 28 & 21 & & & & & & & & \\
\hline Iran & 47 & 47 & 56 & 43 & 56 & 70 & 60 & 54 & 42 & 28 & 26 & 15 & 19 \\
\hline $\begin{array}{l}\text { United Arab } \\
\text { Emirates }\end{array}$ & 38 & 70 & 86 & 81 & 76 & 40 & 20 & 19 & 23 & 20 & 15 & 12 & 14 \\
\hline Canada & 36 & 38 & 41 & 34 & 36 & 34 & 35 & 29 & 13 & 19 & 20 & 23 & 22 \\
\hline Spain & 34 & 34 & 35 & 35 & 37 & 36 & 33 & 29 & 19 & 10 & 12 & 14 & 19 \\
\hline Brazil & 27 & 28 & 29 & 22 & 77 & 90 & 36 & 32 & 29 & 21 & 17 & 13 & 10 \\
\hline Nepal & 26 & 28 & 25 & 19 & 10 & 25 & 26 & 25 & 22 & 23 & 20 & 26 & 26 \\
\hline Malaysia & 25 & 28 & 24 & 25 & 23 & 34 & 33 & 29 & 32 & 36 & 39 & 35 & 35 \\
\hline Egypt & 24 & & & & & & & & & & & & \\
\hline Korea South & 23 & 22 & 21 & 11 & 9 & 22 & 21 & 22 & 24 & 26 & 26 & 26 & 21 \\
\hline France & 22 & 20 & 19 & & & & & & & & & & \\
\hline United Kingdom & 21 & 16 & 30 & & & & & & & & & & \\
\hline Japan & 20 & 25 & 20 & 23 & 23 & 35 & & & & & & & \\
\hline Mexico & 18 & & & & & & & & & & & & \\
\hline
\end{tabular}

Source: West Virginia University Institutional Research, 2020. 


\subsection{Summary}

The number of international students studying abroad has been increasing with the U.S., the United Kingdom, Australia, France, Germany, and Russia being the most frequently chosen destinations (IIE, 2018). Economic factors are among the influencers on the choice of study abroad destination (Miller, 1990). International students contribute economically and to science and innovation in countries where they study. Studying abroad is also an opportunity for students from developing countries to meet educational goals and demands which cannot be met in their home country due to political instability and lack of adequate or internationally competitive educational facilities. As students make a transition to study abroad, they are faced with adjustment challenges such as homesickness, culture shock, prejudice and neo-racism, and healthcare challenges among others. The host institutions in its quest to accommodate them also experiences challenges, such as ethical enrollment procedures for international students, internationalization of policies, curriculum adjustments, organizational adjustments, and financial constraints to sustain programs that international students enroll in. West Virginia University, a public research university located in Morgantown, West Virginia in the U.S. has a total international student population of 1,864 (Fall 2019) from 26 different countries. Host institutions recognize the importance of offering a support system to assist international students while they transition to their new college home. International student services (Misra et al., 2003) are recognized officially as the main provider of support. The level and amount of support has a significant impact on the students' psychological well-being in their new environment (Mallinckrodt \& Leong, 1992). It is therefore important for host institutions, apart from efforts to increase international student enrollments, to offer support systems with a strategic and long-term perspective to support and manage the diversity that international students bring to their campus. 


\section{Chapter Three}

This chapter outlines the research design, population, sample, procedures, instrument and statistical methods used for data analysis to explore the research objectives and address the statement of the problem. The limitations and delimitations are also expounded.

\subsection{Problem Statement}

The primary purpose of this study was to investigate international students' adjustment challenges at West Virginia University and their perceptions of how the University assists them in

meeting these challenges. The secondary purpose of this study was to identify and analyze coping mechanisms and strategies that international students at West Virginia University adopt to overcome their adjustment challenges.

\subsection{Research Questions}

The research questions are:

1. What are the major adjustment challenges facing international students at West Virginia University?

2. What are the students' perceptions of West Virginia University's role in addressing the adjustment challenges?

3. What coping mechanisms or adaptation strategies do international students use to survive the adjustment challenges in West Virginia University? 


\subsection{Survey Instrument}

A mixed method of study was utilized for this research. Informal conversations and an online survey were used. John W. Porter's Michigan International Students Problem Inventory (MISPI) has been widely used to identify challenges that international students encounter on various campuses (Wang, 2003; Sonari, 1993; \& Atebe, 2011). Spaulding and Flack (1976, p.33) add that the "The Michigan International Student Problem Inventory is a quick and reliable way of identifying problems perceived by students on an individual campus". The MISPI is used for this research because of its suitability to the purpose of this study. It has been widely used in previous studies to identify international students challenges which will make it feasible to compare the results of previous studies to those of this research. In addressing the research questions for this study, a modified version of MISPI survey instrument was used. This instrument, which was originally created in 1962 and modified in 1977 according to Wang (2004), is divided into 132 items. Pedersen (1991) affirms that the MISPI has been widely used by counselling centers to identify international students' challenges. For this study, the researcher reduced the number of items to 24; questions that were not relevant to this study were eliminated. Other questions were added by the researcher to help address questions specific to this study. The 24 items from the MISPI are divided into eight main problem areas. They guided this research in identifying the adjustment challenges that international students face in West Virginia University. The eight problem areas and how the items specifically direct this research are as follows.

Items 1,2, and 3 (Appendix B) address admission selection challenges of international students. Specifically, these questions seek to identify challenges encountered during the admissions process. One of the questions asks about student orientation to West Virginia University and another asks if differences between the education system in the United States versus the country of origin 
pose as a barrier to being admitted. Items 4,5 , and 6 seek to identify and address the orientation service challenges that students encounter. Items 7, 8 and 9 aim to identify social and personal challenges, such as acceptance in social groups. Do they experience some difficulties and are they treated differently? How does this affect them? Items 10, 11, and 12 seek to ascertain financial challenges. Does the status of international students make it difficult for them to get jobs between semesters? Does this cause financial hardships? Is it easy for international students to find part-time jobs? Do they experience challenges in meeting unexpected needs? Items 13,14, and 15 deal with language challenges. Can they understand their professors in class? Are papers and assignments a challenge? Items 16,17, and 18 seek to address immigration challenges. Items 19, 20, and 21 are about challenges related to religion, such as difficulties to find a place or group to worship with. Finally, items 22, 23, and 24 are directed towards health services and possible challenges international students face with accessing healthcare.

In the survey, respondents were asked to rate their perception of how each item poses a challenge, and how WVU assists in meeting this challenge. This was done on a scale from 1 to 7 below:

\begin{tabular}{|l|l|}
\hline $\begin{array}{l}\text { Ratings of Your Perception of the } \\
\text { Challenge: }\end{array}$ & $\begin{array}{l}\text { Ratings of WVU's Assistance Dealing with } \\
\text { the Challenge: } \\
7=\text { Much greater challenge than expected } \\
7=\text { Much better than expected }\end{array}$ \\
6= Greater challenge than expected & $6=$ Better than expected \\
5 = Somewhat expected & $5=$ Somewhat better than expected \\
$4=$ Neutral-Exactly what I expected & $4=$ Neutral-Exactly as I expected \\
$3=$ Easier than expected & $3=$ Less than expected \\
$2=$ Much easier than expected & $2=$ Much less than expected \\
$1=$ No challenge at all & $1=$ No assistance at all \\
\end{tabular}


The survey questionnaire was comprised of both open-ended and closed-ended questions and was disseminated for on-line responses in the Fall 2019, and Spring 2020 semesters to all international students - undergraduate, graduate, and professional - at West Virginia University through the listserv for international students by the WVU Office of International Students and Scholars. A reminder email was sent out after two weeks to all the international students previously contacted to complete the survey if they had not already done so. The survey was sent out again on November 25, 2019 through UNEWS (main campus announcement platform) to all international students. The announcement was repeated after two weeks and posted on the main website for WVU students (http://students.wvu.edu). Students were given a final opportunity to participate in the survey in the Spring 2020 semester.

\subsection{Content Validity}

"Content validity is the degree to which a test measures an intended area" (Gay \& Airasian, 2000, p. 163), and it is important that the individual items of the instrument test the related content area and all the items of the instrument in their totality cover the entire content area. Porter measured content validity by hypothesizing that the individual items in the MISPI have a higher possibility of being selected at least once by international students than by American students. Chi-square tests revealed a significant difference at the 0.05 level in the proportion of items that were checked at least once by the two groups. This result suggests content validity and is evidence in support of Porter's hypothesis that even though the items on the MISPI and the Mooney Problem Checklist College Form share many similarities, several individual items on the MISPI measured problems and concerns specific to international students (Porter, 1966). Hence the MISPI is a valid instrument. 


\subsection{Instrument Reliability}

"Instrument reliability is defined as the degree to which an instrument measures what it is supposed to measure and permits appropriate interpretation of results" (Gay \& Airasian, 2000, p.169) and confirms the consistency of the produced results. In testing the internal consistency reliability of the MISPI, Porter (1966) used the Kuder Richardson formula and the Spearman-Brown split half reliability test. For the Spearman Brown split half method, he obtained a reasonably strong total scale reliability estimate of 0.67 and obtained a total scale reliability estimate of 0.58 for the Kuder Richardson formula, and subscale reliability estimates ranging from 0.47 to 0.76 . MISPI was hence established as a reasonably reliable instrument (Porter, 1966).

\subsection{Data Analysis}

Data analysis according to Roberts (2010) is "the descriptive or inferential statistical test and procedures you used, how they were treated, and the level of statistical significance that guided your analysis" (p.158). Below is a description of how data were analyzed in this study to answer the research questions;

\section{What are the key adjustment challenges international students encounter as they study} at West Virginia University? According to Lysgaard's UCT, international students go through four stages of adjustment: the honeymoon, culture shock, adjustment, and adaptation stage. From the UCT, international students begin to experience challenges within the first 3- 9 months of arriving at their destination country. Question 1 on the survey instrument is comprised of 24 Likert scale items which asked international students in WVU to rate the extent to which the various challenges presented posed as a challenge to them. Their perception of their challenge is based on the difference between their expectation and actual experience of the stated challenge. The challenges are divided into 8 problem areas; admission selection, orientation service, personal/social, financial, 
language, immigration, religious, and health challenges. In identifying the key adjustment challenges, the results of the challenges were compared to each other, the mean of the data for each challenge was analyzed and compared. This helped identify the most important challenges. A One Factor ANOVA analysis was performed to test for any statistical differences with the challenges and the age of students. The student age was categorized into 3 groups (students 20 years and less, $21-$ 25years, and 26years and above). A $t$-test was performed to test for differences in students' challenges based on gender (male/female) and their level in class (undergraduate/graduate). Students challenges based on the number of years a student had been enrolled at WVU were analyzed using a One Factor ANOVA. The number of years a student had been enrolled at WVU was organized into 3 categories (less than 1 year, 1 to 3 years, 3 years and above). Finally, students' challenges based on the number of years they had been enrolled in other U.S. colleges prior to being enrolled in WVU (students with prior experiences in other U.S. colleges before enrolling at WVU, and students with no prior experience in other U.S. colleges) was analyzed using a $t$-test.

\section{The second question this study seeks to examine is the student's perception of WVU's} role in addressing the adjustment challenges they encounter. From the UCT, international students reach an adjustment stage after the culture shock or crisis stage. This study ascertains students' perceptions of WVU's role in assisting to address the adjustment challenges. Again, the actual experiences of the students compared to their expectations is important in determining their perception of WVU's role in addressing adjustment challenges. The international student survey used in this research asked students to rank on a scale from 1 to 7 how well WVU assists them in meeting their perceived challenges. This assists in determining whether WVU is providing sufficient resources or an enabling environment for students to adjust. The responses of the ratings were compared with each other, and the mean also compared with each other. The students' perceptions of WVU's role in 
addressing the adjustment challenges they encounter were analyzed with age using a One Factor ANOVA. A $t$-test was done to analyze students' perceptions of WVU's role in addressing the adjustment challenges they encounter with gender (male/female), level of class (graduate/undergraduate), and the number of years they had been enrolled in other U.S. colleges prior to being enrolled in WVU. A final One Factor ANOVA Analysis was made with the number of years students had been enrolled at WVU.

\section{The final research question seeks to address the adaptation strategies or coping} mechanisms international students use to meet the challenges at WVU. According to the UCT, students are able to go beyond the adjustment stage and adapt to the culture of the destination country (the mastery stage). The UCT guided this study to explore whether the coping mechanisms or strategies students utilize to adjust are external (campus resources, family, church, etc.), or internal (personal coping skills) as suggested by UCT. Questions 3 to 6 on the survey used for this study helped in identifying these coping skills and resources. These resources were analyzed with gender (male/female), level of class (undergraduate/graduate), and the number of years of experience a student had prior to being enrolled with WVU using a $t$-test to check for any statistical differences. A One Factor ANOVA was also performed with resources and age, and the number of years a student had been enrolled at WVU. Students through the survey described how their engagement with available resources (family, church, friends, etc.) helped them to cope or adjust.

In addition to using the UCT, this study utilized the survey designed to ascertain whether international students' challenges persisted throughout their stay at WVU or they go through the various adjustment stages as theorized by Lysgaard's UCT. This study helped in identifying whether all students especially WVU students reach the adaptation stage at all and if they do, at what stage in the students' life does the student adapt to the host country culture. The UCT is useful in determining the 
challenges that international students encounter while establishing the need for planning for adjustment challenges. It is easy to understand and gives a realistic expectation of the process of transition and adjustment.

Despite Lysgaard's UCT' usefulness in this study, it was difficult to use this theory to ascertain what causes international students to transition from one stage to the other and what coping skills or strategies individuals gain to help them adapt. For example, what causes international students to transition from the crisis stage to the adjustment stage, and what factors cause international students to adjust well or stay longer at the adjustment stage? The UCT suggests that there is one pattern of adjustment (positive beginnings- negative -positive ending) that every person experiences; however, this may be unrealistic and not applicable to every student.

Mean, mode, standard deviation, $t$-test, and One Factor ANOVA analysis were used to analyze data from this study. ANOVA analyses are appropriate for this study as it is a helpful statistical tool in comparing means and identifying significant differences between study results. It has been widely used and provides a strong statistical analysis among several study samples (Montgomery, 2001). ANOVA "is the most used statistical technique" (Howell, 2002, p.318). Demographic questions such as age, gender, class level, years of experience in other U.S. colleges, and number of years at WVU, were analyzed together with the research questions. For research question 1, each of the 24 Likert Scale questions had a rating from 7- "Greater than expected" to 1- "no challenges experienced at all. The rating from 1 to 7 by the students for each item determined their perception of the challenge for all the 24 items (challenges). The mean of the responses for each item was analyzed. For research question 2, the perception of the institution meeting the challenge was also rated on a scale of 1 "No assistance at all" to 7 "Much better than I expected". The mean for each response was analyzed. Research question 
$3 \mathrm{had}$ a set of 11 Likert Scale questions. Students rated the resources that they utilize to adjust on a scale of 1 "Not at all" to 5 "Very Helpful". The mean for each response was analyzed.

At the end of the data collection and analysis, the data was presented as it was. A summary of the mean and distribution of all the survey data is presented (Figure 7). To limit bias and ensure that the sample population was representative of the entire international student population, the sample population was compared with the international student population (Table 14). An email inviting students to participate in the study was sent through the Office of International Students and Scholars. This was to ensure that all students had equal chances of participating in the survey.

\subsection{Target Population and Sample}

According to reports from the IIE (2018), a total of 1,094,792 international students were enrolled in the U.S. during the 2017/2018 academic year. This is an increase of $1.5 \%$ from $1,078,822$ in the previous year. The "target population is the set of all elements. It is the larger group to which a researcher wants to generalize his or her sample results" (Johnson \& Christensen, 2014, p. 291). The target population in this study is all international students (2040) enrolled at West Virginia University in the Fall 2019/Spring 2020 academic year. This includes undergraduates, graduates, and professional students. The target sample size for this study was 350 to 400, based on Krejci and Morgan (1970). They established that population size becomes irrelevant beyond a point $(\mathrm{N}=5,000)$ where $\mathrm{N}$ is the number of elements or subjects in a sample, and Gay, Mills and Airasian (2006) confirm that 400 subjects are sufficient to obtain a representative sample. The reminder email that was sent to international students after the first email inviting them, the repetition of the survey through UNEWS, and the posting of the survey to participate in the study at the WVU student website were efforts to increase participants' response rate. 


\subsection{Pilot Survey Study}

A small group of international students were selected for a pilot study and the survey instrument was administered to them using Qualtrics. This was done before administering the survey instrument to the intended population to allow the researcher to uncover any issues or unanticipated problems and to ensure the survey questions were clear and well understood by the students. Overall the students were satisfied with the design and content with the survey instrument, however a few offered comments. One student suggested that the demographic questions be asked at the end of the survey instead of the beginning of the survey. Another student suggested that some of the Likert scale questions needed to be more specific than they were. These suggestions were applied accordingly.

\subsection{Human Subjects Approval}

For the protection of human subjects, approval was obtained from the West Virginia University Institutional Review Board (IRB) prior to conducting any study activities (Appendix A)

\subsection{Data Collection}

The Assistant Director for International Students and Scholars Services at West Virginia University was contacted by email to request an email to be sent out to all the undergraduate, graduate and professional international students (combined total of 1962 students) enrolled in the 2019/2020 academic year. The international student listserv was used to encourage and direct all the students to the survey. The link to the survey website was provided in the email. The Director of University Relations- Digital Service was contacted through email for the survey to be sent out through the campus announcement platform (UNEWS), and also for the survey to be posted on the official students website (http://students.wvu.edu) of WVU. 
Table 5. List of Actions Taken to Encourage Student Participation in Survey

\begin{tabular}{|c|c|c|}
\hline Date & Action & Result \\
\hline $10 / 24 / 2019$ & $\begin{array}{l}\text { First email sent to Assistant Director of } \\
\text { WVU-OISS to invite students to } \\
\text { participate in the survey. }\end{array}$ & $\begin{array}{l}\text { Survey sent out on } 10 / 31 / 2019 \text { to all } \\
\text { international students through } \\
\text { international students' listserv. Thirty- } \\
\text { five students participated in the survey. }\end{array}$ \\
\hline 11/13/2019 & $\begin{array}{l}\text { Second email sent to Assistant } \\
\text { Director of WVU-OISS to remind } \\
\text { students to participate in the survey }\end{array}$ & $\begin{array}{l}\text { Reminder email sent out to all } \\
\text { international students on } 11 / 19 / 2019 \\
\text { through the international students' } \\
\text { listserv. Thirty students responded in } \\
\text { addition to the previous } 35 \text {. }\end{array}$ \\
\hline $11 / 22 / 2019$ & $\begin{array}{l}\text { First email sent to Director of } \\
\text { University Relations- Digital Services } \\
\text { to invite students through UNEWS to } \\
\text { participate in survey }\end{array}$ & $\begin{array}{l}\text { Announcement sent out on } 11 / 25 / 2019 \\
\text { through UNEWS to students. Fifty } \\
\text { students responded in addition to the } \\
\text { previous responses }\end{array}$ \\
\hline $12 / 05 / 2019$ & $\begin{array}{l}\text { Second email sent to Director of } \\
\text { University Relations- Digital Services } \\
\text { to post survey on students' website } \\
\text { students.wvu.edu }\end{array}$ & $\begin{array}{l}\text { Announcement posted on students' } \\
\text { website at students.wvu.edu. No } \\
\text { response from students }\end{array}$ \\
\hline 12/07/2019 & $\begin{array}{l}\text { Third email sent to Director of } \\
\text { University Relations- Digital Services } \\
\text { to remind students to participate in } \\
\text { survey }\end{array}$ & $\begin{array}{l}\text { Second announcement sent out on } \\
12 / 10 / 2019 \text { through UNEWS. Forty- } \\
\text { six students responded in addition to } \\
\text { the previous responses }\end{array}$ \\
\hline $01 / 27 / 2020$ & $\begin{array}{l}\text { Sent emails to leaders of the top } \\
\text { international student groups from the } \\
\text { five top countries where students come } \\
\text { from at WVU }\end{array}$ & No response from student groups \\
\hline $01 / 27 / 2020$ & $\begin{array}{l}\text { Reached out through telephone calls to } \\
\text { the top five groups of international } \\
\text { students }\end{array}$ & $\begin{array}{l}\text { Agreed to send announcement to } \\
\text { students. } 2 \text { responses }\end{array}$ \\
\hline $01 / 28 / 2020$ & $\begin{array}{l}\text { Third email sent to Assistant Director } \\
\text { of WVU-OISS to invite students to } \\
\text { participate in survey }\end{array}$ & $\begin{array}{l}\text { Unable to send out survey due to busy } \\
\text { schedule of WVU-OISS }\end{array}$ \\
\hline $01 / 28 / 2020$ & $\begin{array}{l}\text { Fourth email sent to Director of } \\
\text { University relations- Digital Services } \\
\text { to remind students to participate in } \\
\text { survey }\end{array}$ & $\begin{array}{l}\text { Final announcement sent to students } \\
\text { on } 01 / 28 / 2020 \text { through UNEWS. } 47 \\
\text { students responded }\end{array}$ \\
\hline $02 / 04 / 2020$ & $\begin{array}{l}\text { Final reminder email sent to top five } \\
\text { groups of international students }\end{array}$ & 2 students responded \\
\hline
\end{tabular}


The students were requested to submit the questionnaire online through Qualtrics. After two weeks, the Assistant Director for International Students and Scholars Services at West Virginia University was contacted again to send an email through the listserv to remind the international students to complete the survey if they had not done so already. The researcher did not get the anticipated number of students (350-400) to complete the survey, the Director of University Relations

- Digital Service was contacted again to have the announcement repeated.

The survey was sent out again through UNEWS (main campus announcement platform) in the Spring 2020 semester. Emails were also sent out to international student associations from the five top origin countries, namely Kuwait, Saudi Arabia, China, India, and Oman. The emails were followed-up with several telephone calls by the researcher. These steps were taken to ensure maximum participation of students in the survey. A complete list of actions taken by the researcher is presented in Table 5 .

\subsection{Informal Conversations}

In addition to the international student survey, the researcher also had informal conversations with 12 international students; 5 of these were graduate students and 7 were undergraduates. Four of the students were interviewed on January 21, 2020, 5 were interviewed on January 30, 2020, and the last three on February 18, 2020. All of the conversations were conducted and transcribed by the researcher at the student union building (Mountain lair) which was convenient and chosen by the students. The conversation was informal, and all the students were asked the same questions. The students were contacted through telephone calls and personal contacts to select a convenient location and time. The participants for the conversations were chosen based on their country of origin. Kuwait, Saudi Arabia, China, India, and Oman are the top 5 countries where students come from in WVU. Consequently, 3 of the participants were from Kuwait, 3 from Saudi Arabia, 2 from China, 2 from India, and 2 from Oman (Table 6). Each student was asked to describe expectations before arriving at 
the WVU campus and current experiences. They were also asked to explain key challenges as international students, the resources and strategies used to adjust, and recommendations on how existing resources could be improved. A table showing the demographics of participants in the informal conversations is presented below in table 6 .

Table 6. Demographics of Participants of Informal Conversations

\begin{tabular}{|c|c|c|c|c|}
\hline Gender & Age & $\begin{array}{c}\text { Country of } \\
\text { Origin }\end{array}$ & Level of Class & $\begin{array}{c}\text { Prior } \\
\text { Experience in } \\
\text { Other U.S. } \\
\text { Colleges } \\
\end{array}$ \\
\hline \multirow[t]{2}{*}{ Male - 6} & 20 years or less- 3 & Kuwait - 3 & Graduate -5 & $\begin{array}{l}\text { Some Experience } \\
\text { in other U.S. } \\
\text { Colleges - } 7\end{array}$ \\
\hline & & Saudi -Arabia -3 & & \\
\hline \multirow[t]{3}{*}{ Female - 6} & $21-25$ years -3 & China - 2 & Undergraduate -7 & $\begin{array}{l}\text { No prior } \\
\text { experiences in } \\
\text { other U.S. } \\
\text { Colleges }-5\end{array}$ \\
\hline & & India - 2 & & \\
\hline & $\begin{array}{c}26 \text { years and } \\
\text { above }-6\end{array}$ & Oman - 2 & & \\
\hline
\end{tabular}




\section{Chapter Four}

\section{Data Analysis}

This chapter shows the detailed analysis of the data gathered by using descriptive and other statistical methods. Data cleaning was done first before analyzing the data, and the demographic information of the respondents was also presented. For the analysis, a One Factor ANOVA and $t$-test were used. This research used a research questions format instead of a hypothesis to be tested since the outcome of the research results was not predictable.

\subsection{Data Demographics}

A total of 220 responses were recorded from the international student survey. This represents $11 \%$ of the international student population (2040) at WVU. Not all the 220 responses were usable, as some of the responses were incomplete. Responses that were at least $75 \%$ complete were used for the data analysis. A complete analysis of the data demographics is presented below.

\section{Figure 3. Gender of Survey Respondents}

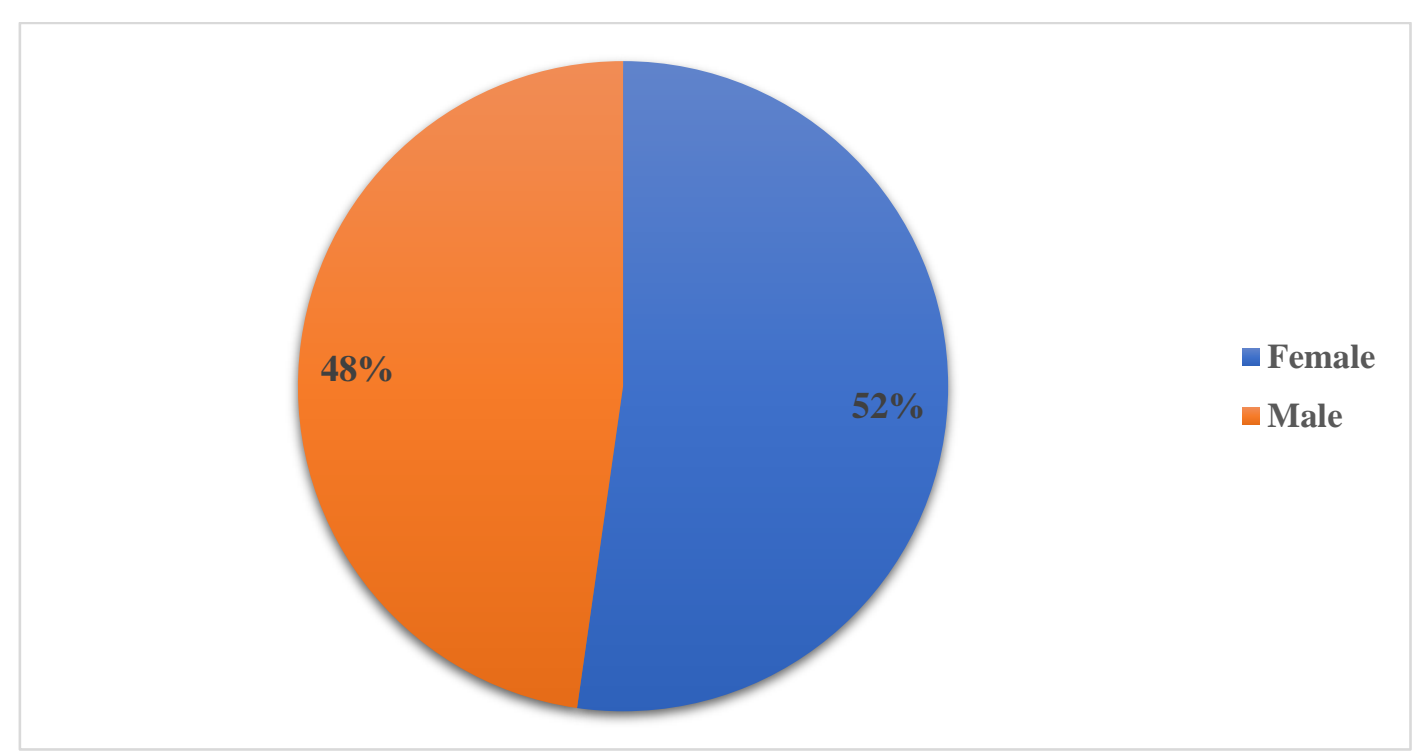

Out of the complete responses, 95 (48\%) were males and 104 (52\%) were females (Figure 3). 


\section{Figure 4. Age of Respondents}

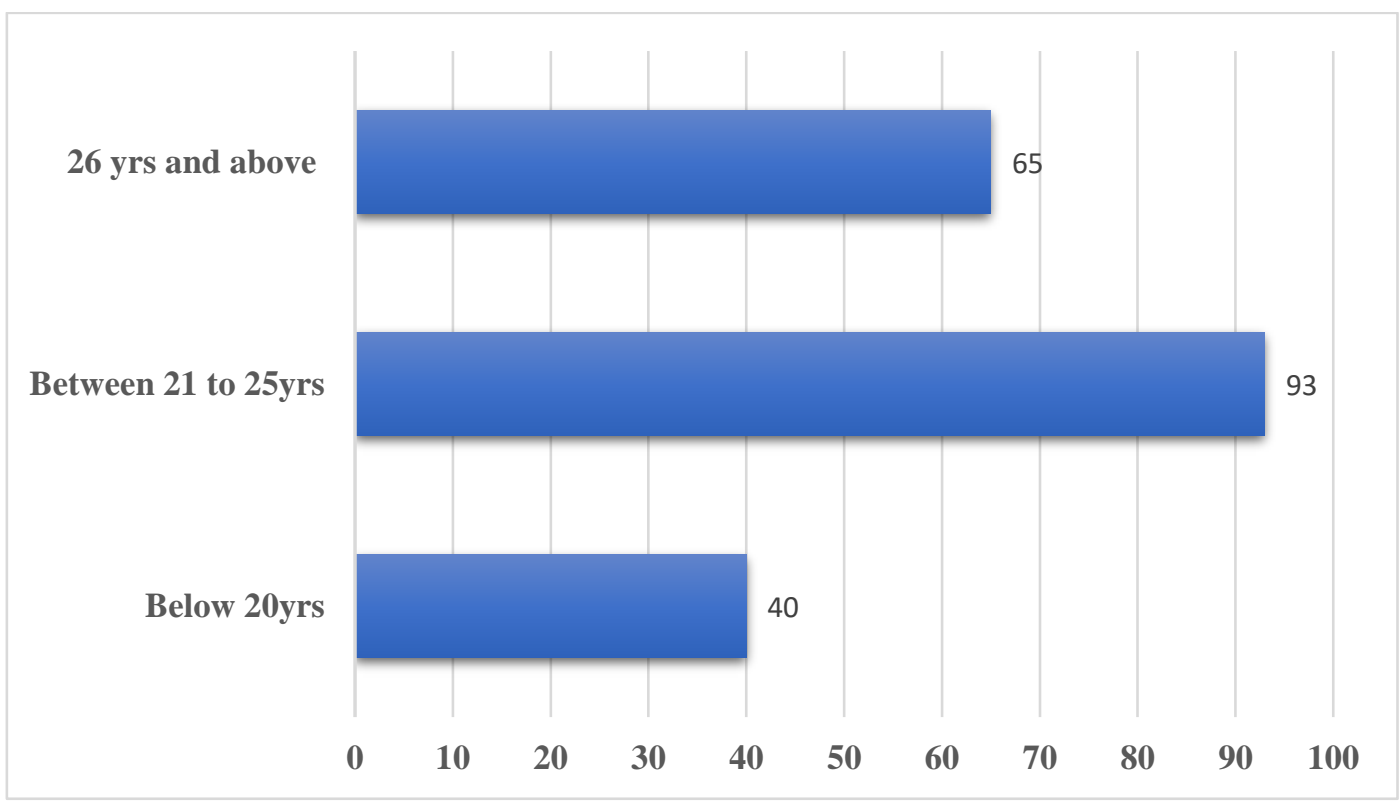

Ninety-three of the participants (47\%) of the survey were between the ages of 21 and 25 years (Figure 4), followed by those followed by those who were 26 years and above (65 or 33\%). There were 40 students who were 20 years or less $(20 \%)$.

\section{Figure 5. Dependency Status of Respondents}

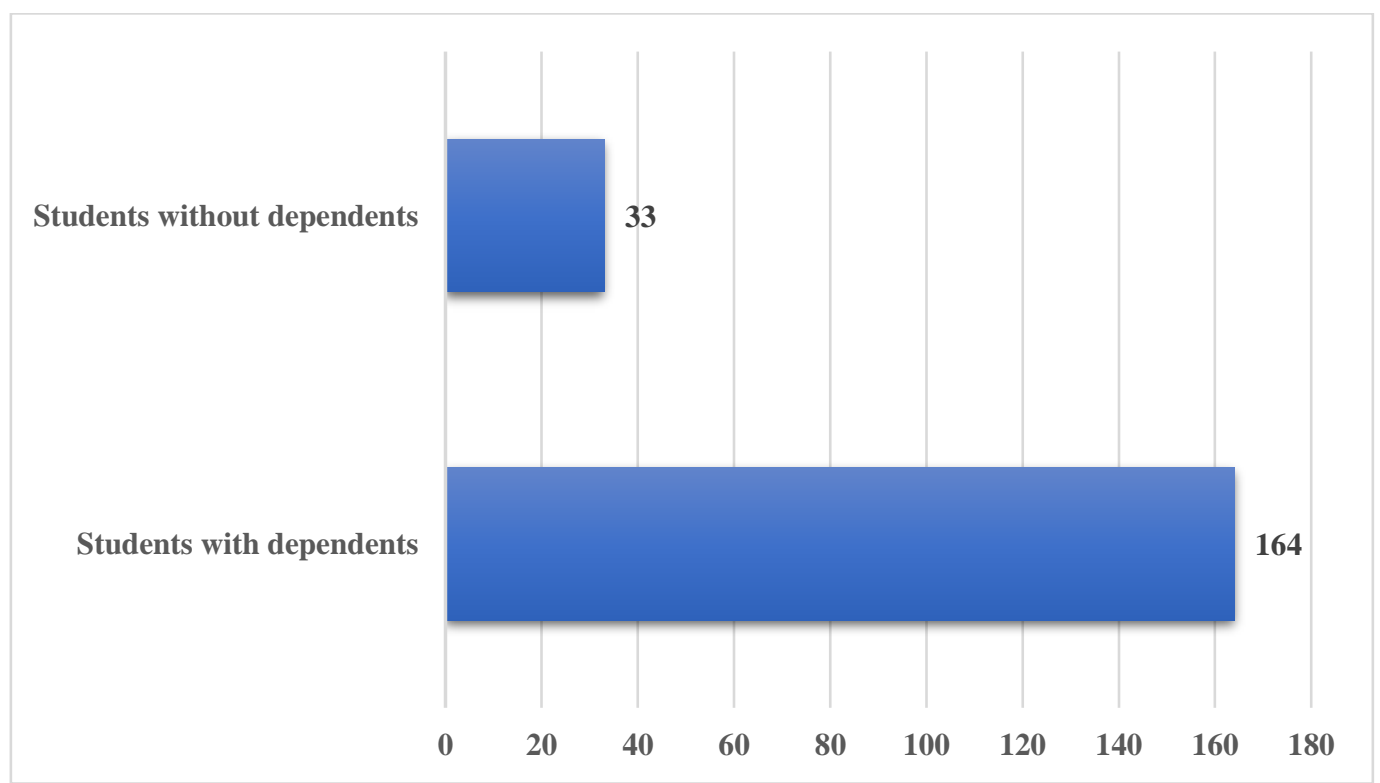


Among the participants of the survey, 164 (83\%) had dependents (children/ or spouse) living with them here in the U.S., and 33 (17\%) had no dependents (Figure 5).

\section{Figure 6. Level in College. Comparison of Survey Participants and WVU International Students}

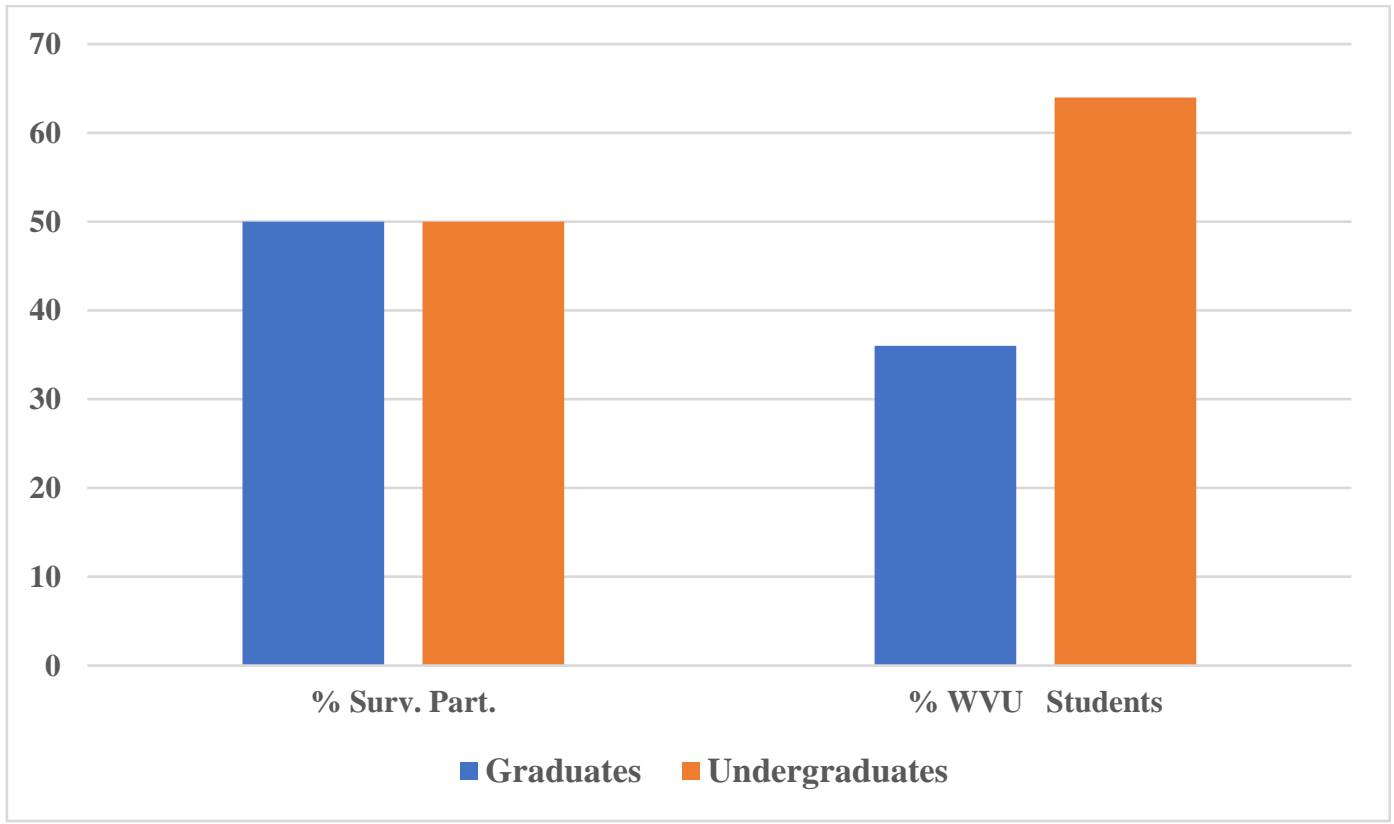

International graduate students represent $36 \%$ of the international student population at WVU, and undergraduates represent $64 \%$. In the survey, equal numbers of the respondents were graduates (99) and undergraduates (99) as shown in figure 6 above which implies that graduate students were overrepresented and undergraduate students underrepresented. 
Figure 7. Number of Years at U.S. College(s) Prior to WVU

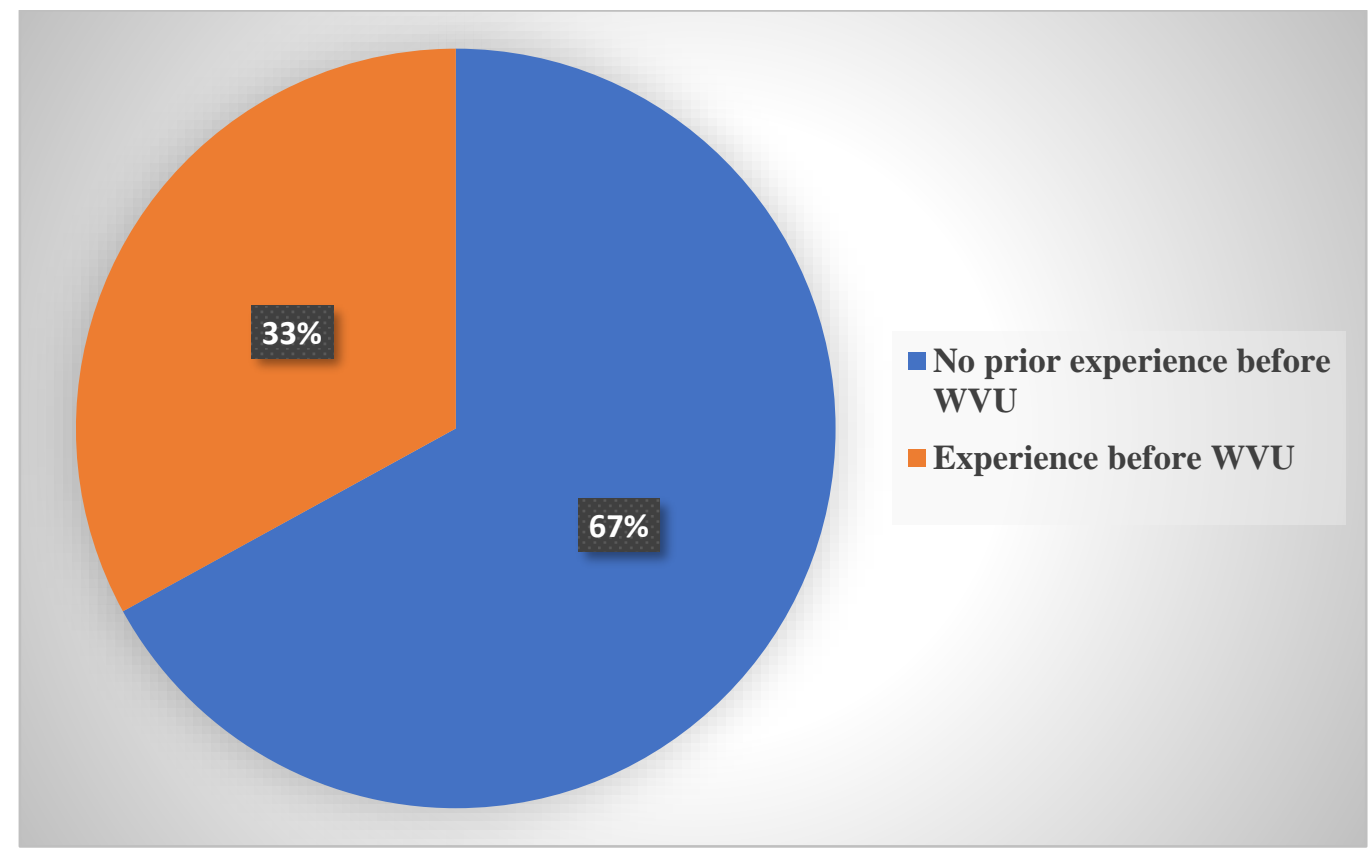

$33 \%$ (65) of the respondents had some experience at other U.S. colleges before enrolling at WVU, and 67\% (132) had no prior experience (Figure 7).

The survey asked students how many years they had been enrolled at WVU. $100(51 \%)$ of the respondents had been enrolled at WVU for at most 1year (0-12 months), 56 (29\%) students had been at WVU between 1 and 3 years (Figure 8), and 39 (20\%) students had been enrolled at WVU for more than 3 years. 


\section{Figure 8. Number of Years Enrolled at WVU}

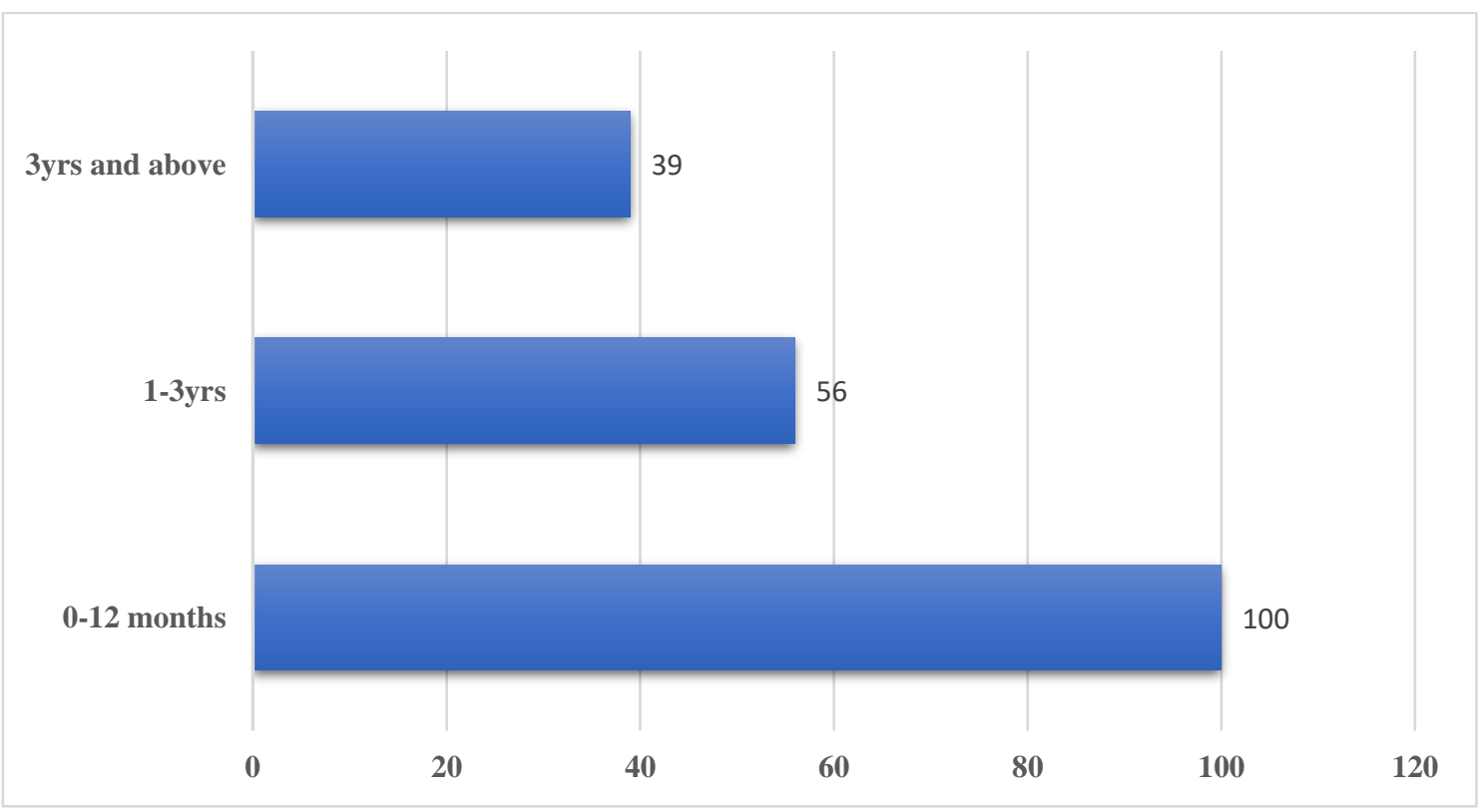

Table 7. Countries of Origin of Respondents

\begin{tabular}{|c|c|c|c|c|c|}
\hline Country & Students & Country & Students & Country & Students \\
\hline India & 15 & Kenya & 4 & Syria & 1 \\
\hline France & 10 & Nepal & 3 & Zimbabwe & 1 \\
\hline Bangladesh & 9 & Ukraine & 3 & United Arab Emirates & 1 \\
\hline Kuwait & 9 & Pakistan & 3 & Columbia & 1 \\
\hline Nigeria & 9 & Japan & 3 & Belgium & 1 \\
\hline Saudi Arabia & 8 & Ecuador & 3 & Bolivia & 1 \\
\hline China & 7 & Ghana & 3 & United Kingdom & 1 \\
\hline Spain & 7 & Vietnam & 3 & Greece & 1 \\
\hline Brazil & 7 & Sri Lanka & 3 & Estonia & 1 \\
\hline Russia & 6 & Canada & 2 & Switzerland & 1 \\
\hline Mexico & 6 & Italy & 2 & Serbia & 1 \\
\hline Oman & 5 & Cameroon & 2 & Iraq & 1 \\
\hline South Korea & 5 & Argentina & 2 & Libya & 1 \\
\hline Malaysia & 5 & South Africa & 2 & Europe & 1 \\
\hline Egypt & 5 & Thailand & 1 & Uruguay & 1 \\
\hline Paraguay & 4 & England & 1 & Jamaica & 1 \\
\hline Iran & 4 & Turkmenistan & 1 & Turkey & 1 \\
\hline Australia & 4 & Jordan & 1 & & \\
\hline
\end{tabular}


The countries of origin of respondents are presented in Table 7. The responses of the survey were representative of the international students' population at WVU (Table 8). Participants came from all 54 countries represented at WVU including Japan (2\%), Nigeria (5\%), Brazil (4\%), South Korea (3\%), and France (5\%).

Table 8. Comparison of Countries of Origin Between Survey Respondents and WVU International Students

\begin{tabular}{|c|c|c|c|c|c|}
\hline $\begin{array}{l}\text { Countries of } \\
\text { Origin }\end{array}$ & $\begin{array}{l}\text { WVU } \\
\text { Int. } \\
\text { Students }\end{array}$ & $\begin{array}{l}\text { Survey } \\
\text { Participants }\end{array}$ & $\begin{array}{l}\text { Countries } \\
\text { of Origin }\end{array}$ & $\begin{array}{l}\text { WVU } \\
\text { Int. } \\
\text { Students }\end{array}$ & $\begin{array}{l}\text { Survey } \\
\text { Participants }\end{array}$ \\
\hline Kuwait & $16 \%$ & $4.9 \%$ & Japan & $1 \%$ & $1.6 \%$ \\
\hline Saudi Arabia & $11 \%$ & $4.3 \%$ & Mexico & $1 \%$ & $3.3 \%$ \\
\hline China & $8 \%$ & $3.8 \%$ & Sri Lanka & $1 \%$ & $3.3 \%$ \\
\hline India & $5 \%$ & $8.2 \%$ & Pakistan & $1 \%$ & $1.6 \%$ \\
\hline Oman & $3 \%$ & $2.7 \%$ & Russia & $1 \%$ & $3.3 \%$ \\
\hline Nigeria & $3 \%$ & $4.9 \%$ & Libya & $1 \%$ & $0.5 \%$ \\
\hline Bangladesh & $2 \%$ & $4.9 \%$ & Bahrain & $1 \%$ & $0.0 \%$ \\
\hline Iran & $2 \%$ & $2.2 \%$ & Turkey & $1 \%$ & $0.5 \%$ \\
\hline United Arab Emirates & $2 \%$ & $0.5 \%$ & Vietnam & $1 \%$ & $1.6 \%$ \\
\hline Canada & $2 \%$ & $1.1 \%$ & Ecuador & $1 \%$ & $1.6 \%$ \\
\hline Spain & $1 \%$ & $3.8 \%$ & Germany & $1 \%$ & $0.0 \%$ \\
\hline Brazil & $1 \%$ & $3.8 \%$ & Italy & $1 \%$ & $1.1 \%$ \\
\hline Nepal & $1 \%$ & $1.6 \%$ & Taiwan & $<1 \%$ & $0.0 \%$ \\
\hline Malaysia & $1 \%$ & $2.7 \%$ & Ghana & $<1 \%$ & $2 \%$ \\
\hline Egypt & $*$ & $2.7 \%$ & Columbia & $<1 \%$ & $0.5 \%$ \\
\hline Korea South & $1 \%$ & $2.7 \%$ & Australia & $*$ & $2.2 \%$ \\
\hline France & $1 \%$ & $5.4 \%$ & Paraguay & $*$ & $2.2 \%$ \\
\hline \multirow[t]{2}{*}{ United Kingdom } & $1 \%$ & $0.5 \%$ & Kenya & $*$ & $2.2 \%$ \\
\hline & & & Others & $9 \%$ & $12.3 \%$ \\
\hline
\end{tabular}

Note: * indicates missing data.

The highest number of participants in this survey were from India (8\%) which is an overrepresentation of international students from India in WVU (5\%). India is the fourth-largest country sending international students to WVU (Table 8). Participants from Kuwait were under- 
represented (5\%) because Kuwait is the largest country of origin of international students in WVU (16\%). Nigeria and Bangladesh were also over-presented in this survey with a 5\% representation from both countries. Saudi Arabia and China were both under-represented with $4 \%$ of survey participants as compared to international students in WVU from Saudi Arabia (11\%) and China (8\%). Data for WVU international students from Australia, Paraguay, Kenya, and Egypt were not available. The comparison of the countries of origin of international students at WVU and countries of origin of survey participants are presented in Table 8 .

The results of the international student survey are analyzed together with the research questions as follows:

\subsection{Research question 1. What are the key adjustment challenges international students encounter as they study at West Virginia University?}

Question 1 on the survey instrument comprises of 24 Likert scale questions which asked international students at WVU to rate the extent to which the various challenges presented posed as a challenge to them. The ratings of the Likert scale questions were;

$7=$ Much greater challenge than expected

$6=$ Greater challenge than expected

$5=$ Somewhat expected

$4=$ Neutral-Exactly what I expected

$3=$ Easier than expected

$2=$ Much easier than expected

$1=$ No challenge at all

The perception of their challenges is based on the difference between their expectations and actual experiences of the stated challenge. The challenges are divided into 8 problem areas; admission selection, orientation service, personal/social, financial, language, immigration, religious, and health 
challenges. In identifying the key adjustment challenges, the results of each challenge (item) were compared, the mean, standard deviation and descriptive analysis of each challenge was analyzed and compared for all respondents of the survey $(\mathrm{N}=220)$. A $t$-test was computed with the level of respondents (undergraduates/graduates), the years of experience they had in other colleges before enrolling at WVU, and their gender to test for any significant differences. A One Factor ANOVA was also carried out for the age of the respondents, and the number of years they had been enrolled at WVU.

Table 9. Survey Response Mean and Standard Deviation for International Students Challenges.

\begin{tabular}{|c|c|c|c|c|}
\hline Item & Challenge & $\mathrm{M}$ & $\mathrm{SD}$ & $\begin{array}{l}\text { Confidence } \\
\text { Interval ( } \pm \text { ) }\end{array}$ \\
\hline \multirow[t]{2}{*}{1} & Differences between U.S. and Home Country & & & \\
\hline & Education System & 4.61 & 1.58 & 0.22 \\
\hline 2 & Orientation to WVU & 4.59 & 1.52 & 0.21 \\
\hline 3 & Relationship with international student advisor & 4.31 & 1.82 & 0.25 \\
\hline \multirow[t]{2}{*}{4} & Attitude of some students towards international & & & \\
\hline & students & 4.77 & 1.64 & 0.23 \\
\hline 5 & Attitude of some U.S. citizens to skin color & 4.45 & 1.89 & 0.26 \\
\hline 6 & Relationship between faculty and students & 4.88 & 1.64 & 0.23 \\
\hline 7 & Treatment received at social functions & 4.60 & 1.50 & 0.21 \\
\hline 8 & Being accepted in social groups & 4.75 & 1.62 & 0.23 \\
\hline 9 & Insufficient personal- social counseling & 4.20 & 1.49 & 0.21 \\
\hline 10 & Unexpected financial needs & 3.98 & 1.77 & 0.25 \\
\hline 11 & Finding employment between semesters & 3.86 & 1.77 & 0.25 \\
\hline 12 & Lack of money to meet expenses & 3.88 & 1.68 & 0.24 \\
\hline 13 & Speaking English & 4.66 & 1.90 & 0.27 \\
\hline 14 & Ability to write English & 4.83 & 1.89 & 0.27 \\
\hline 15 & Understanding lectures in English & 4.87 & 1.93 & 0.27 \\
\hline 16 & Immigration regulations & 4.33 & 1.69 & 0.24 \\
\hline 17 & Immigration work restrictions & 3.99 & 1.93 & 0.27 \\
\hline 18 & Finding part time work & 3.72 & 1.75 & 0.25 \\
\hline 19 & Finding a worship group of own faith & 3.89 & 1.73 & 0.24 \\
\hline 20 & Religion and morals in the U.S & 4.07 & 1.78 & 0.25 \\
\hline 21 & Religious practices in U. S & 4.10 & 1.72 & 0.24 \\
\hline 22 & Finding adequate health services & 4.19 & 1.81 & 0.26 \\
\hline 23 & Dietary problems & 4.25 & 1.73 & 0.24 \\
\hline 24 & Feeling stressed & 4.32 & 1.86 & 0.26 \\
\hline
\end{tabular}


The means, standard deviations, and summary descriptive statistics for survey responses are presented in Table 9 above. A complete descriptive analysis for each challenge is attached as Appendix D. The challenge with the highest mean was item 6 (relationship between faculty and students) with a mean of 4.88. Item 15 (understanding lectures in English) had the second highest mean with 4.87 followed by item 14 (ability to write in English) with a mean of 4.83 . Item 4 (attitude of some students toward international students) had a mean of 4.77, and item 8 (being accepted in social groups) had a mean of 4.75. Items 1 (differences between U.S. and home education system), and 7(treatment received at social functions) had almost the same mean of 4.61 and 4.60. Item 17 (immigration work restrictions), item 10 (unexpected financial needs), and item 19 (finding a worship group of own faith) had a similar mean of 3.99, 3.98, and 3.89. Item 18 (finding part time work) had the lowest mean. As indicated from table 8, relationship between faculty and students is the greatest challenge experienced by all international students. Even though this is the greatest challenge, it was ranked below somewhat expected. Understanding lectures in English, and ability to write in English were the second greatest challenges. The least challenge experienced is finding part time work.

\subsection{Age}

To test for any differences in perceptions of students based on age, a One Factor ANOVA was performed for each individual challenge. The age of the students was categorized into 3 groups (students 20 years or less, students between 21-25 years, and students 26 years and above. The Means, Standard Deviations and results of the ANOVA are presented in Table 10. The complete ANOVA analysis is attached as Appendix E. From Table 9, students of the age 20 or less had the highest mean for most of the challenges compared to students within the other age groups, item 4 , attitude of some students toward international students (5.19) was their greatest challenge followed by item 8, being accepted into social groups (4.81) and item 15 understanding lectures in English 
(4.78) . Ability to write English (4.87) item 14 was the greatest challenge for students between 21 and 25 years followed by understanding lectures in English (4.81) item 15 and relationship between faculty and students (4.79) item 6. Relationship between faculty and students (5.08), item 6 was the greatest challenge for students above the age of 26 followed by item 15, understanding lectures in English (4.91) and treatment received at social functions (4.88), item 7. The lowest mean (least challenge) for all age categories was (3.86) finding adequate health services (item 22), for those of age of 20 or less, finding a worship group of own faith (3.76) item 19 for those between 21 and 25 years old and item 18, finding part time work (3.30) for those 26 years and above. The challenge with a statistical difference was item 18, finding part time work $(d f=2, F=3.33, p<.05)$. The mean for students 20 years or less for this item was significantly higher (4.16) than those between the age of 21 and 25 years (3.81), 26years and above (3.30). This indicates that finding part time work is perceived as a much greater challenge to students 20 years or less than students 26 years and above, and students between the age of 21 and 25 years. Table 10 shows the significant differences in the mean of item 18, finding part time work. 
Table 10. ANOVA Results of Student Challenges and Age

\begin{tabular}{|c|c|c|c|c|c|c|c|c|c|c|}
\hline \multirow[b]{2}{*}{ Item } & \multirow[b]{2}{*}{ Challenge } & \multicolumn{2}{|c|}{20 yrs or less } & \multicolumn{2}{|c|}{ Between 21-25 yrs } & \multicolumn{2}{|c|}{26 yrs and above } & \multirow[b]{2}{*}{$d f$} & \multirow[b]{2}{*}{$\mathbf{F}$} & \multirow[b]{2}{*}{$\boldsymbol{P}$} \\
\hline & & Mean & Variance & Mean & Variance & Mean & Variance & & & \\
\hline 1 & Differences between U.S. and Home Country & & & & & & & & & \\
\hline & Education System & 4.48 & 1.92 & 4.48 & 2.82 & 4.71 & 2.36 & 2 & 0.83 & 0.44 \\
\hline 2 & Orientation to WVU & 4.57 & 3.03 & 4.66 & 1.96 & 4.45 & 2.50 & 2 & 0.38 & 0.68 \\
\hline 3 & Relationship with international student advisor & 4.46 & 2.87 & 4.27 & 3.31 & 4.37 & 3.33 & 2 & 0.15 & 0.86 \\
\hline 4 & $\begin{array}{l}\text { Attitude of some students towards international } \\
\text { students }\end{array}$ & 5.19 & 2.10 & 4.56 & 2.86 & 4.82 & 2.58 & 2 & 2.06 & 0.13 \\
\hline 5 & Attitude of some U.S. citizens to skin color & 4.62 & 3.35 & 4.35 & 3.46 & 4.39 & 3.67 & 2 & 0.29 & 0.75 \\
\hline 6 & Relationship between faculty and students & 4.68 & 2.95 & 4.79 & 2.94 & 5.08 & 2.07 & 2 & 0.91 & 0.41 \\
\hline 7 & Treatment received at social functions & 4.62 & 2.52 & 4.34 & 2.43 & 4.88 & 1.70 & 2 & 2.42 & 0.09 \\
\hline 8 & Being accepted in social groups & 4.81 & 2.99 & 4.62 & 2.49 & 4.86 & 2.34 & 2 & 0.47 & 0.63 \\
\hline 9 & Insufficient personal- social counseling & 4.16 & 2.64 & 4.15 & 2.06 & 4.19 & 2.15 & 2 & 0.01 & 0.99 \\
\hline 10 & Unexpected financial needs & 4.42 & 2.82 & 3.88 & 3.47 & 3.81 & 2.58 & 2 & 1.57 & 0.21 \\
\hline 11 & Finding employment between semesters & 4.03 & 2.60 & 3.82 & 3.20 & 3.79 & 3.01 & 2 & 0.24 & 0.79 \\
\hline 12 & Lack of money to meet expenses & 4.43 & 2.84 & 3.82 & 2.92 & 3.63 & 2.27 & 2 & 2.80 & 0.06 \\
\hline 13 & Speaking English & 4.67 & 3.94 & 4.67 & 3.83 & 4.53 & 3.27 & 2 & 0.11 & 0.90 \\
\hline 14 & Ability to write English & 4.77 & 4.01 & 4.87 & 3.85 & 4.66 & 3.05 & 2 & 0.23 & 0.80 \\
\hline 15 & Understanding lectures in English & 4.78 & 4.75 & 4.81 & 3.77 & 4.91 & 3.13 & 2 & 0.07 & 0.94 \\
\hline 16 & Immigration regulations & 4.36 & 3.27 & 4.39 & 3.03 & 4.25 & 2.19 & 2 & 0.15 & 0.86 \\
\hline 17 & Immigration work restrictions & 4.17 & 4.03 & 3.91 & 3.88 & 3.97 & 3.33 & 2 & 0.23 & 0.79 \\
\hline 18 & Finding part time work & 4.16 & 2.92 & 3.81 & 2.99 & 3.30 & 2.78 & 2 & 3.33 & $0.04 *$ \\
\hline 19 & Finding a worship group of own faith & 3.92 & 3.97 & 3.76 & 2.56 & 3.97 & 2.90 & 2 & 0.30 & 0.74 \\
\hline 20 & Religion and morals in the U.S. & 4.27 & 3.42 & 3.93 & 3.17 & 4.14 & 2.74 & 2 & 0.57 & 0.57 \\
\hline 21 & Religious practices in U.S. & 4.21 & 3.26 & 3.90 & 2.59 & 4.23 & 3.01 & 2 & 0.87 & 0.42 \\
\hline 22 & Finding adequate health services & 3.86 & 3.62 & 4.09 & 3.10 & 4.42 & 3.03 & 2 & 1.24 & 0.29 \\
\hline 23 & Dietary problems & 4.76 & 3.58 & 4.14 & 2.85 & 4.06 & 2.41 & 2 & 2.26 & 0.11 \\
\hline 24 & Feeling stressed & 4.62 & 2.80 & 4.41 & 3.65 & 4.06 & 3.43 & 2 & 1.23 & 0.29 \\
\hline
\end{tabular}

Note. ${ }^{*}$ significant at $p<.05$ 
4.4 Gender. A $t$-test was performed to test for differences in students' challenges based on gender (Table 11). The $t$ - test showed no statistical differences between male and female students and their perceived challenges.

Table 11. Results for $t$-test of Students Challenges and Gender

\begin{tabular}{|c|c|c|c|c|}
\hline Item & Challenge & $\begin{array}{l}\text { Male } \\
\text { Mean }\end{array}$ & $\begin{array}{c}\text { Female } \\
\text { Mean }\end{array}$ & $\boldsymbol{P}$ \\
\hline & Differences between U.S. and Home Country & & & \\
\hline 1 & Education System & 4.67 & 4.57 & 0.65 \\
\hline 2 & Orientation to WVU & 4.78 & 4.37 & 0.06 \\
\hline 3 & Relationship with international student advisor & 4.30 & 4.35 & 0.85 \\
\hline & Attitude of some students towards international & & & \\
\hline 4 & students & 4.78 & 4.73 & 0.81 \\
\hline 5 & Attitude of some U.S. citizens to skin color & 4.45 & 4.36 & 0.74 \\
\hline 6 & Relationship between faculty and students & 4.89 & 4.81 & 0.72 \\
\hline 7 & Treatment received at social functions & 4.60 & 4.56 & 0.83 \\
\hline 8 & Being accepted in social groups & 4.70 & 4.72 & 0.92 \\
\hline 9 & Insufficient personal- social counseling & 4.03 & 4.32 & 0.19 \\
\hline 10 & Unexpected financial needs & 4.09 & 3.86 & 0.37 \\
\hline 11 & Finding employment between semesters & 3.95 & 3.75 & 0.43 \\
\hline 12 & Lack of money to meet expenses & 3.90 & 3.88 & 0.91 \\
\hline 13 & Speaking English & 4.57 & 4.71 & 0.61 \\
\hline 14 & Ability to write English & 4.90 & 4.69 & 0.45 \\
\hline 15 & Understanding lectures in English & 4.82 & 4.90 & 0.77 \\
\hline 16 & Immigration regulations & 4.47 & 4.18 & 0.23 \\
\hline 17 & Immigration work restrictions & 4.15 & 3.81 & 0.22 \\
\hline 18 & Finding part time work & 3.77 & 3.64 & 0.62 \\
\hline 19 & Finding a worship group of own faith & 3.95 & 3.81 & 0.59 \\
\hline 20 & Religion and morals in the U.S & 4.27 & 3.87 & 0.11 \\
\hline 21 & Religious practices in U.S & 4.30 & 3.84 & 0.06 \\
\hline 22 & Finding adequate health services & 4.24 & 4.07 & 0.51 \\
\hline 23 & Dietary problems & 4.43 & 4.03 & 0.11 \\
\hline 24 & Feeling stressed & 4.50 & 4.16 & 0.20 \\
\hline
\end{tabular}


Ability to write English (item 14) was the greatest challenge for males with a mean of 4.90, for the same challenge females had a mean of 4.69 which indicates that ability to write in English is a greater challenge for males than females (Figure 9). Understanding lectures in English (item 15) was a greater challenge for females (4.90) than males (4.82). The least challenge for both males and females was item 18 (finding part-time work) with a mean of 3.64 for females and 3.77 for males.

\section{Figure 9. Mean Analysis of Students Challenges and Gender}

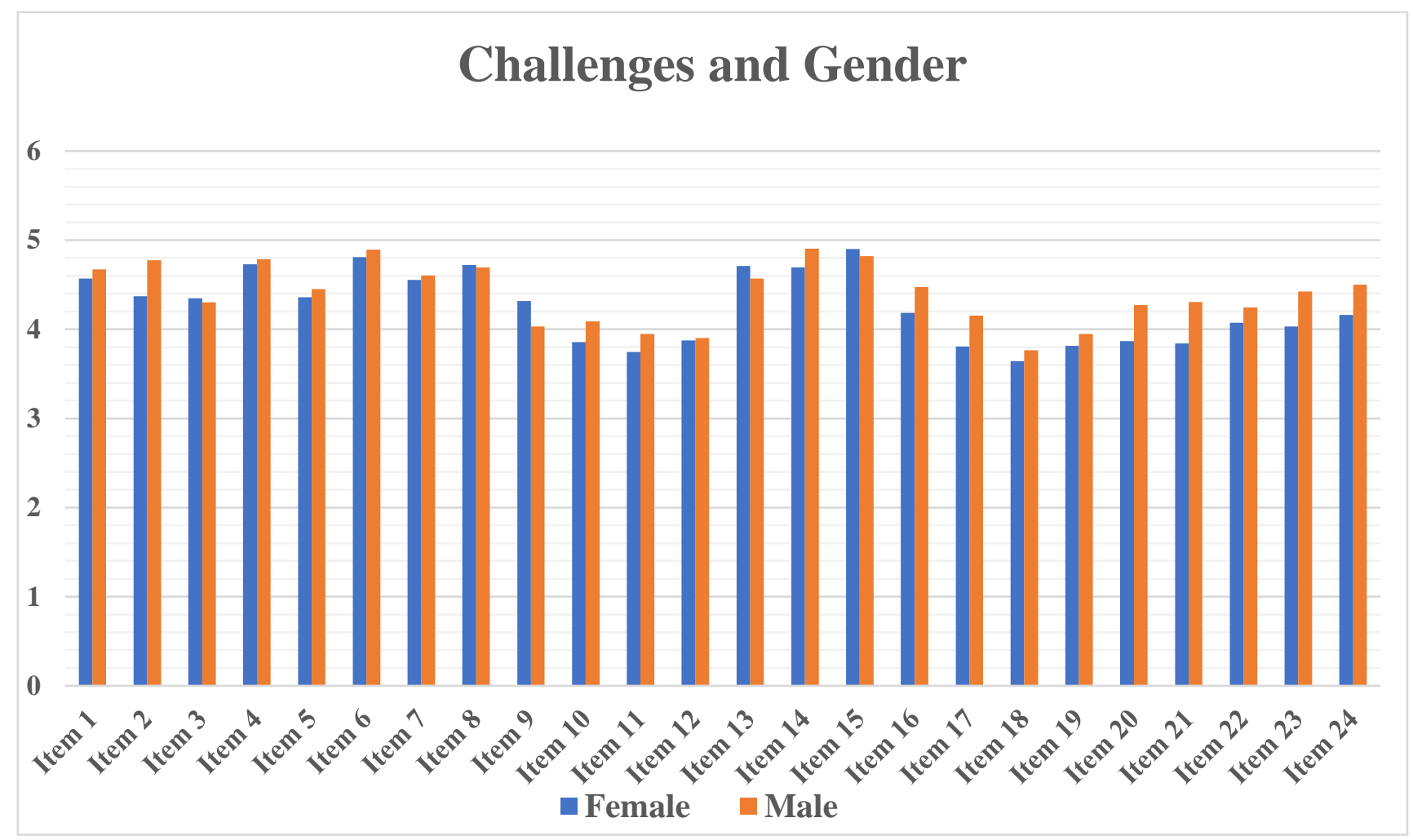

4.5 Level in Class. The $t$-test performed confirmed no statistical differences between the class level of students and their perceived challenges as shown in table 12 below. 
Table 12. $t$-test Results of Students Challenges and Class Standing

\begin{tabular}{|c|c|c|c|c|}
\hline Item & Challenge & $\begin{array}{c}\text { Graduate } \\
\text { Mean }\end{array}$ & $\begin{array}{c}\text { Undergrad } \\
\text { Mean }\end{array}$ & $\boldsymbol{P}$ \\
\hline 1 & Differences between U.S. and Home Country & & & \\
\hline & Education System & 4.67 & 4.56 & 0.63 \\
\hline 2 & Orientation to WVU & 4.63 & 4.50 & 0.56 \\
\hline 3 & Relationship with international student advisor & 4.21 & 4.44 & 0.39 \\
\hline 4 & $\begin{array}{l}\text { Attitude of some students towards international } \\
\text { students }\end{array}$ & 4.83 & 4.68 & 0.54 \\
\hline 5 & Attitude of some U.S. citizens to skin color & 4.40 & 4.41 & 0.95 \\
\hline 6 & Relationship between faculty and students & 4.95 & 4.75 & 0.41 \\
\hline 7 & Treatment received at social functions & 4.73 & 4.43 & 0.17 \\
\hline 8 & Being accepted in social groups & 4.83 & 4.59 & 0.29 \\
\hline 9 & Insufficient personal- social counseling & 4.23 & 4.13 & 0.63 \\
\hline 10 & Unexpected financial needs & 4.08 & 3.85 & 0.37 \\
\hline 11 & Finding employment between semesters & 3.73 & 3.96 & 0.38 \\
\hline 12 & Lack of money to meet expenses & 3.85 & 3.93 & 0.76 \\
\hline 13 & Speaking English & 4.56 & 4.73 & 0.54 \\
\hline 14 & Ability to write English & 4.68 & 4.92 & 0.38 \\
\hline 15 & Understanding lectures in English & 4.82 & 4.90 & 0.79 \\
\hline 16 & Immigration regulations & 4.28 & 4.38 & 0.68 \\
\hline 17 & Immigration work restrictions & 4.04 & 3.90 & 0.62 \\
\hline 18 & Finding part time work & 3.58 & 3.83 & 0.32 \\
\hline 19 & Finding a worship group of own faith & 3.89 & 3.86 & 0.90 \\
\hline 20 & Religion and morals in the U.S & 4.02 & 4.11 & 0.74 \\
\hline 21 & Religious practices in U.S & 3.96 & 4.19 & 0.36 \\
\hline 22 & Finding adequate health services & 4.40 & 3.92 & 0.06 \\
\hline 23 & Dietary problems & 4.22 & 4.23 & 0.98 \\
\hline 24 & Feeling stressed & 4.28 & 4.37 & 0.74 \\
\hline
\end{tabular}


The mean of the students' class standing (graduate/undergraduate) was analyzed (Figure 10). The highest mean for graduate students was 4.95 for item 6, relationship between faculty and students implying that as their greatest challenge. They had a mean of 4.83 for both item 4 (attitude of some students towards international students) and item 8 (being accepted into social groups) as their second greatest challenges. The highest mean for undergraduate students was 4.92 for item 14 (ability to write English) followed by 4.90 for item 15 (understanding lectures in English) and 4.75 for item 6 (relationship between faculty and students. The least mean for graduate students was 3.58 , finding part time work and 3.83 for undergraduates for the same challenge revealing that, finding part time work is the least challenge for both undergraduate and graduate students.

\section{Figure 10. Mean of Student Challenges and Class Standing}

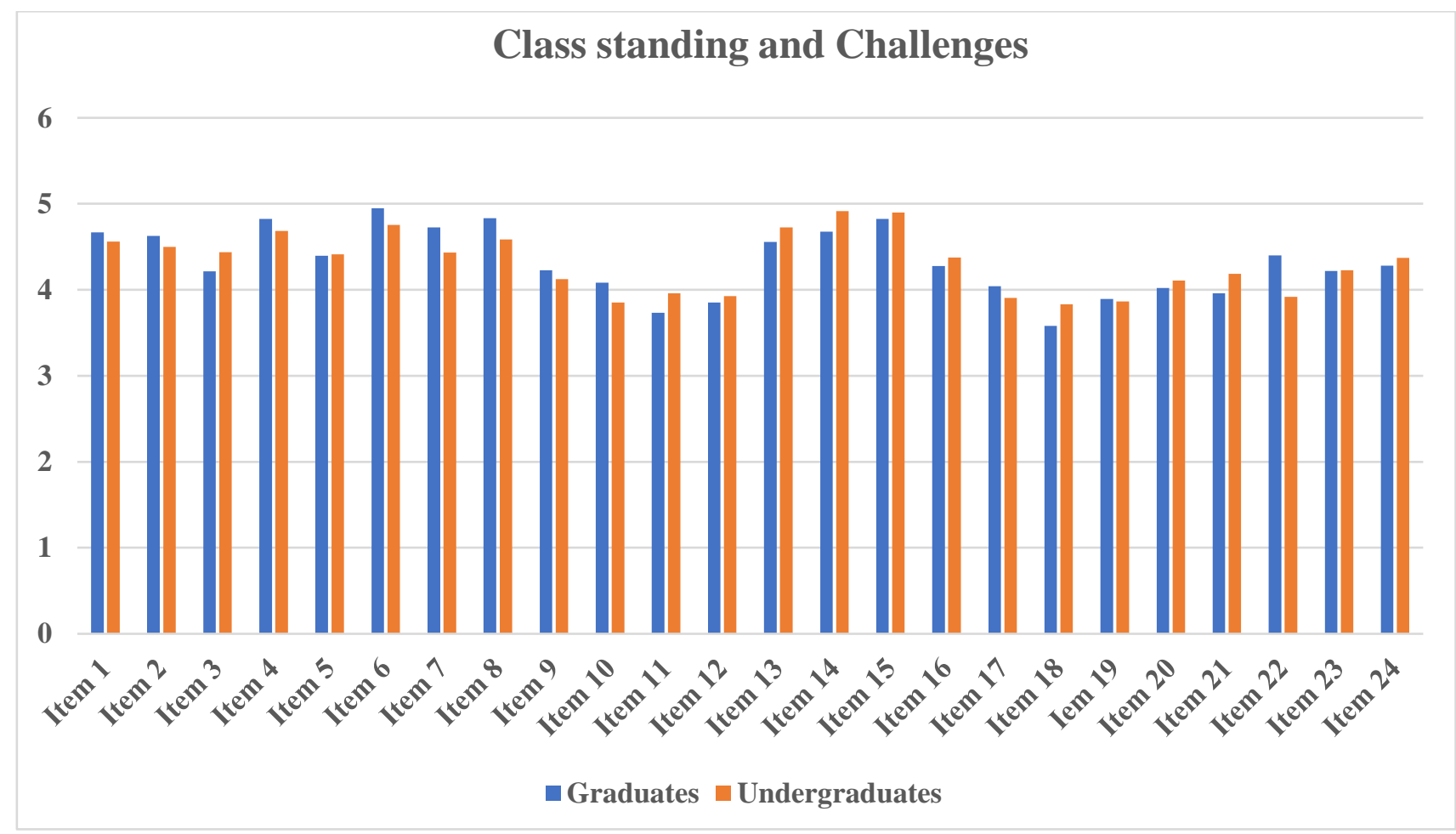


4.6 Number of Years Enrolled at WVU. Students perception of challenges based on the number of years a student had been enrolled at WVU was analyzed using a One Factor ANOVA. The number of years a student had been enrolled at WVU was put into 3 categories (less than 1 year, 1 to 3years, 3 years and above). The mean, standard deviations, and detailed ANOVA analysis carried out is attached as (Appendix F) and a summary is presented in table 13. The highest mean for students who had been enrolled less than 1 year was 4.97 for item 4 (attitude of some students towards international students). Their second highest mean was 4.78 for item 6 (relationship between faculty and students). They had the same mean of 4.77 for both the ability to write English (item 14) and to understand lectures in English (item 15). Their lowest mean was 3.96 for item 11 (finding employment between semesters). Students who had been enrolled at WVU for 1-3years had the highest mean for all three challenges within the English Language Problem category (item 13,14,15speaking English 5.35, ability to write English 5.18, and understanding lectures in English 5.13) indicating that English language problems were their greatest challenges. Their least mean was 3.49 for item 18 (finding part time work). The greatest challenge for students who had been enrolled for 3 years and above was 5.0 for item 6 (relationship between faculty and students) followed by 4.63 for item 15 (understanding lectures in English) and 4.51 for item 8 (being accepted into social groups). The least mean for this group was 3.25 for item17 (immigration work restrictions).

This analysis signifies that the greatest challenges for all students are; students who have been enrolled less than 1 year - attitude of some students towards international students, students enrolled between 1 and 3 years- English language problems, students enrolled 3 years and above- relationship between faculty and students. The least challenges for all students are; students who have been enrolled less than 1 year -finding employment between semesters, students who had been enrolled at 
WVU within 1-3years- finding part time work, and students who had been enrolled for 3 years and above -immigration work restrictions.

The One Factor ANOVA test showed some statistical differences (Table 13). The challenges that showed statistical differences were item 13, speaking English $(d f=2, F=5.24, p<.05)$, and item 17, immigration work restrictions $(d f=2, F=4.33, p<.05)$. For item 13 , students enrolled for less than 1 year had a mean of 4.43 , students enrolled for 1 to 3 years had a mean of 5.35 , and students enrolled for 3 years and above had a mean of 4.29, implying that speaking English was a greater challenge for students enrolled within 1 and 3 years than all the other age categories. This pattern of challenge is unusual because students in the other categories (students enrolled 1 year or less, and students enrolled 3 years and above) experienced greatest challenges with relationship with faculty and students, and attitude of some students toward international students but students enrolled within 1 and 3 years experienced greatest challenges with English language. For item 17, students enrolled less than 1 year had a mean of 4.32, students enrolled within 1 and 3 years had 3.95, and students enrolled 3 years and above had a mean of 3.25 showing that immigration work restrictions was a much greater challenge to students who had been enrolled less than 1 year than students in the other age categories 
Table 13. Results of ANOVA Tests of Students Challenges with Years Being Enrolled at WVU

\begin{tabular}{|c|c|c|c|c|c|c|c|c|c|c|}
\hline \multirow[b]{2}{*}{ Item } & \multirow[b]{2}{*}{ Challenge } & \multicolumn{2}{|c|}{ Less than 1 yr } & \multicolumn{2}{|l|}{ 1-3 yrs } & \multicolumn{2}{|c|}{3 yrs and Above } & \multirow[b]{2}{*}{$d f$} & \multirow[b]{2}{*}{$\mathbf{f}$} & \multirow[b]{2}{*}{$p$} \\
\hline & & Mean & Variance & Mean & Variance & Mean & Variance & & & \\
\hline 1 & Differences between U.S. and Home Country & & & & & & & & & \\
\hline & Education System & 4.75 & 2.33 & 4.63 & 2.82 & 4.38 & 2.40 & 2 & 0.76 & 0.47 \\
\hline 2 & Orientation to WVU & 4.70 & 2.41 & 4.43 & 1.85 & 4.50 & 2.69 & 2 & 0.64 & 0.53 \\
\hline 3 & Relationship with international student advisor & 4.63 & 3.02 & 4.11 & 3.44 & 3.95 & 3.37 & 2 & 2.71 & 0.07 \\
\hline 4 & $\begin{array}{l}\text { Attitude of some students towards international } \\
\text { students }\end{array}$ & 4.97 & 2.83 & 4.66 & 2.59 & 4.49 & 2.20 & 2 & 1.45 & 0.24 \\
\hline 5 & Attitude of some U.S. citizens to skin color & 4.59 & 3.61 & 4.49 & 3.25 & 3.95 & 3.52 & 2 & 1.69 & 0.19 \\
\hline 6 & Relationship between faculty and students & 4.78 & 2.75 & 4.84 & 2.68 & 5.00 & 2.70 & 2 & 0.24 & 0.79 \\
\hline 7 & Treatment received at social functions & 4.68 & 2.20 & 4.55 & 2.18 & 4.30 & 2.44 & 2 & 0.86 & 0.42 \\
\hline 8 & Being accepted in social groups & 4.67 & 2.66 & 4.96 & 2.33 & 4.51 & 2.81 & 2 & 0.98 & 0.38 \\
\hline 9 & Insufficient personal- social counseling & 4.21 & 2.00 & 4.32 & 2.55 & 3.92 & 1.85 & 2 & 0.87 & 0.42 \\
\hline 10 & Unexpected financial needs & 4.06 & 3.08 & 3.89 & 2.90 & 4.00 & 3.30 & 2 & 0.17 & 0.85 \\
\hline 11 & Finding employment between semesters & 3.96 & 2.82 & 3.78 & 3.32 & 3.86 & 3.06 & 2 & 0.18 & 0.83 \\
\hline 12 & Lack of money to meet expenses & 4.09 & 2.41 & 3.82 & 2.86 & 3.66 & 3.31 & 2 & 1.06 & 0.35 \\
\hline 13 & Speaking English & 4.43 & 3.67 & 5.35 & 3.23 & 4.29 & 3.24 & 2 & 5.24 & $0.01 *$ \\
\hline 14 & Ability to write English & 4.77 & 3.86 & 5.18 & 2.82 & 4.47 & 3.61 & 2 & 1.71 & 0.18 \\
\hline 15 & Understanding lectures in English & 4.77 & 4.09 & 5.13 & 3.02 & 4.63 & 3.81 & 2 & 0.89 & 0.41 \\
\hline 16 & Immigration regulations & 4.60 & 2.88 & 4.27 & 2.35 & 3.84 & 2.70 & 2 & 2.98 & 0.05 \\
\hline 17 & Immigration work restrictions & 4.32 & 3.78 & 3.95 & 3.05 & 3.25 & 3.51 & 2 & 4.33 & $0.01 *$ \\
\hline 18 & Finding part time work & 4.00 & 2.96 & 3.49 & 2.40 & 3.47 & 3.45 & 2 & 2.14 & 0.12 \\
\hline 19 & Finding a worship group of own faith & 4.11 & 3.54 & 3.55 & 2.18 & 3.95 & 2.16 & 2 & 1.88 & 0.15 \\
\hline 20 & Religion and morals in the U.S. & 4.23 & 3.54 & 3.93 & 2.65 & 3.92 & 2.76 & 2 & 0.72 & 0.49 \\
\hline 21 & Religious practices in U.S. & 4.15 & 3.19 & 4.05 & 2.35 & 3.97 & 3.14 & 2 & 0.16 & 0.85 \\
\hline 22 & Finding adequate health services & 4.23 & 3.29 & 3.95 & 3.13 & 4.37 & 2.78 & 2 & 0.74 & 0.48 \\
\hline 23 & Dietary problems & 4.34 & 3.06 & 4.13 & 2.95 & 4.26 & 2.25 & 2 & 0.28 & 0.76 \\
\hline 24 & Feeling stressed & 4.51 & 3.37 & 4.30 & 3.60 & 3.97 & 3.22 & 2 & 1.17 & 0.31 \\
\hline
\end{tabular}

Note. * Significant at $p<.05$ 


\subsection{Number of Years Being Enrolled in Other U.S. Colleges Prior to Being Enrolled}

in WVU. Students challenges based on the number of years they had been enrolled in other U.S.

colleges prior to being enrolled in WVU was analyzed. A $t$-test was performed to test for any

statistically significant differences. The $t$-test (Table 14) showed no statistically significant

differences between the years of prior experiences students had and the challenges they encountered.

Table 14. $t$-test Results of Students Challenges and Prior Experiences

\begin{tabular}{|c|c|c|c|c|}
\hline Item & Challenge & $\begin{array}{c}\text { No } \\
\text { experience } \\
\text { Mean } \\
\end{array}$ & $\begin{array}{c}\text { Some exp } \\
\text { Mean }\end{array}$ & $\boldsymbol{P}$ \\
\hline 1 & Differences between U.S. and Home Country & & & \\
\hline & Education System & 4.74 & 4.40 & 0.17 \\
\hline 2 & Orientation to WVU & 4.63 & 4.42 & 0.35 \\
\hline 3 & Relationship with international student advisor & 4.29 & 4.39 & 0.72 \\
\hline 4 & $\begin{array}{l}\text { Attitude of some students towards international } \\
\text { students }\end{array}$ & 4.89 & 4.54 & 0.16 \\
\hline 5 & Attitude of some U.S. citizens to skin color & 4.40 & 4.46 & 0.84 \\
\hline 6 & Relationship between faculty and students & 4.83 & 4.90 & 0.78 \\
\hline 7 & Treatment received at social functions & 4.53 & 4.69 & 0.50 \\
\hline 8 & Being accepted in social groups & 4.63 & 4.90 & 0.26 \\
\hline 9 & Insufficient personal- social counseling & 4.20 & 4.15 & 0.81 \\
\hline 10 & Unexpected financial needs & 4.02 & 3.92 & 0.73 \\
\hline 11 & Finding employment between semesters & 3.95 & 3.67 & 0.31 \\
\hline 12 & Lack of money to meet expenses & 3.92 & 3.87 & 0.85 \\
\hline 13 & Speaking English & 4.76 & 4.45 & 0.31 \\
\hline 14 & Ability to write English & 4.90 & 4.65 & 0.40 \\
\hline 15 & Understanding lectures in English & 4.88 & 4.81 & 0.84 \\
\hline 16 & Immigration regulations & 4.44 & 4.10 & 0.20 \\
\hline 17 & Immigration work restrictions & 4.05 & 3.87 & 0.56 \\
\hline 18 & Finding part time work & 3.71 & 3.74 & 0.91 \\
\hline 19 & Finding a worship group of own faith & 3.98 & 3.73 & 0.35 \\
\hline 20 & Religion and morals in the U.S. & 4.19 & 3.85 & 0.23 \\
\hline 21 & Religious practices in U.S. & 4.06 & 4.15 & 0.72 \\
\hline 22 & Finding adequate health services & 4.20 & 4.13 & 0.80 \\
\hline 23 & Dietary problems & 4.33 & 4.06 & 0.30 \\
\hline 24 & Feeling stressed & 4.42 & 4.19 & 0.40 \\
\hline
\end{tabular}


The greatest challenges facing students who had some years of prior experience in other universities before enrolling in WVU were item 6, relationship between faculty and students, and item 8, being accepted into social groups. Both challenges had the highest mean of 4.90 (figure 11). Their second greatest challenge was item 15, understanding lectures in English (4.81) followed by item 7, treatment received at social functions (4.69). The highest mean for students with no prior experience was 4.90 for item 14, ability to write in English, followed by item 4, attitude of some students towards international students (4.89), and item 15, understanding lectures in English (4.88) The least mean for students with no prior experience was 3.71 for item 18, finding part time work. The least mean for students with some years of prior experience was item 11, finding employment between semesters (3.67). This reveals that the greatest challenge for students with no prior experience is ability to write in English, and the greatest challenges for students with some prior years of experience are relationship between faculty and students along with being accepted into social groups. The least challenge for students with no prior experience is finding part time work and the least challenge for students with some years of experience is finding employment between semesters. 


\section{Figure 11. Mean Analysis of Challenges and Previous Experience}

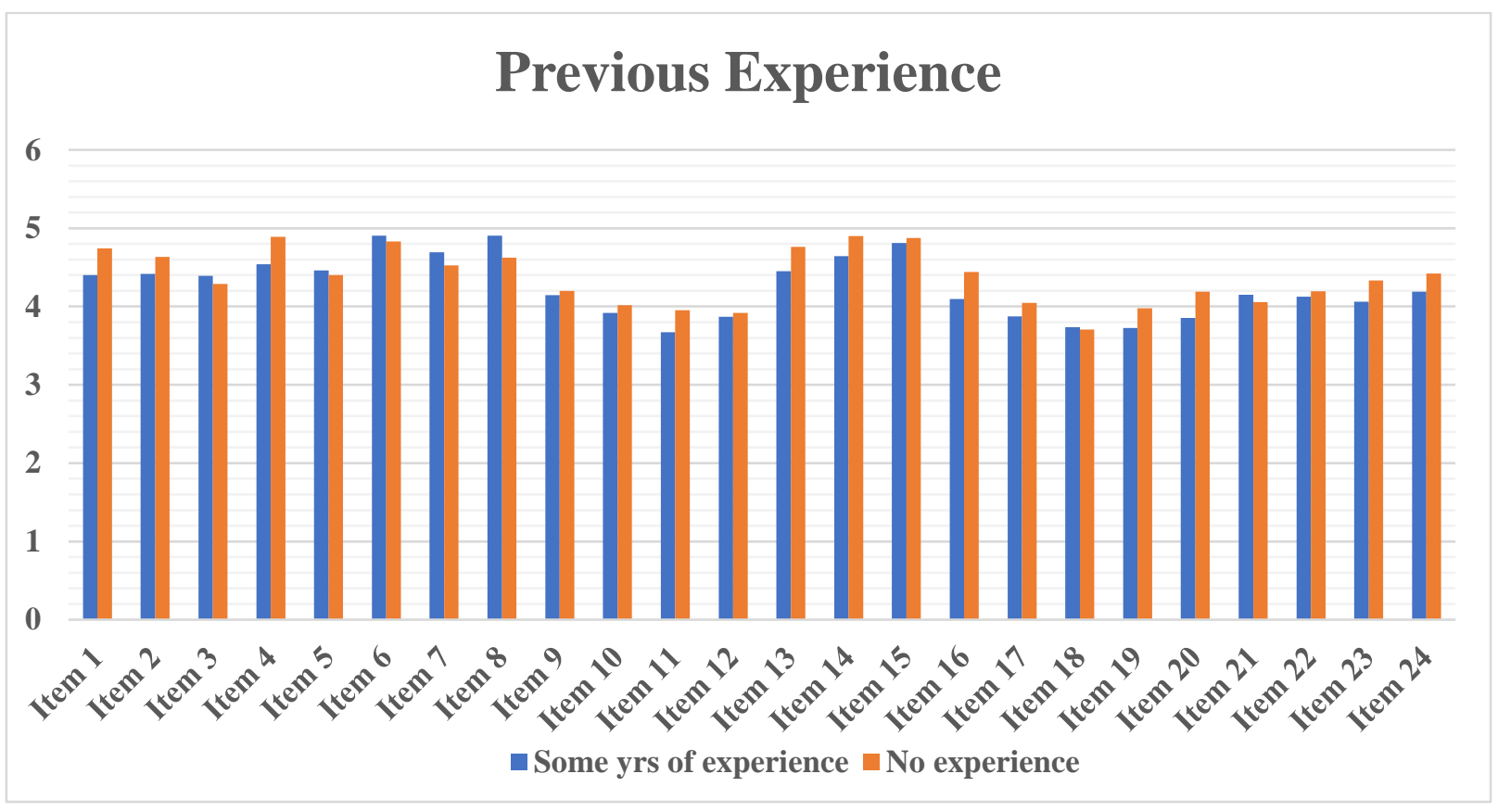

\subsection{Other Challenges}

In addition to the Likert-Scale questions in the international student survey that asked to rate their challenges, question 2 of the survey asked students to describe any additional situations that posed a challenge that were not listed in the previous section. The challenges the students reported were quite different from the results of the Likert-Scale questions, with the greatest challenge (53\%) being racism and discrimination from professors and faculty. Transportation was the second greatest challenge (14\%), health insurance was 12\%, immigration issues were 11\%, and others 10\% (Figure 12). A summary of the challenges is presented in Table 15, and a complete list of the challenges reported by students are attached as Appendix G. 
Figure 12. Other Challenges Reported by Respondents.

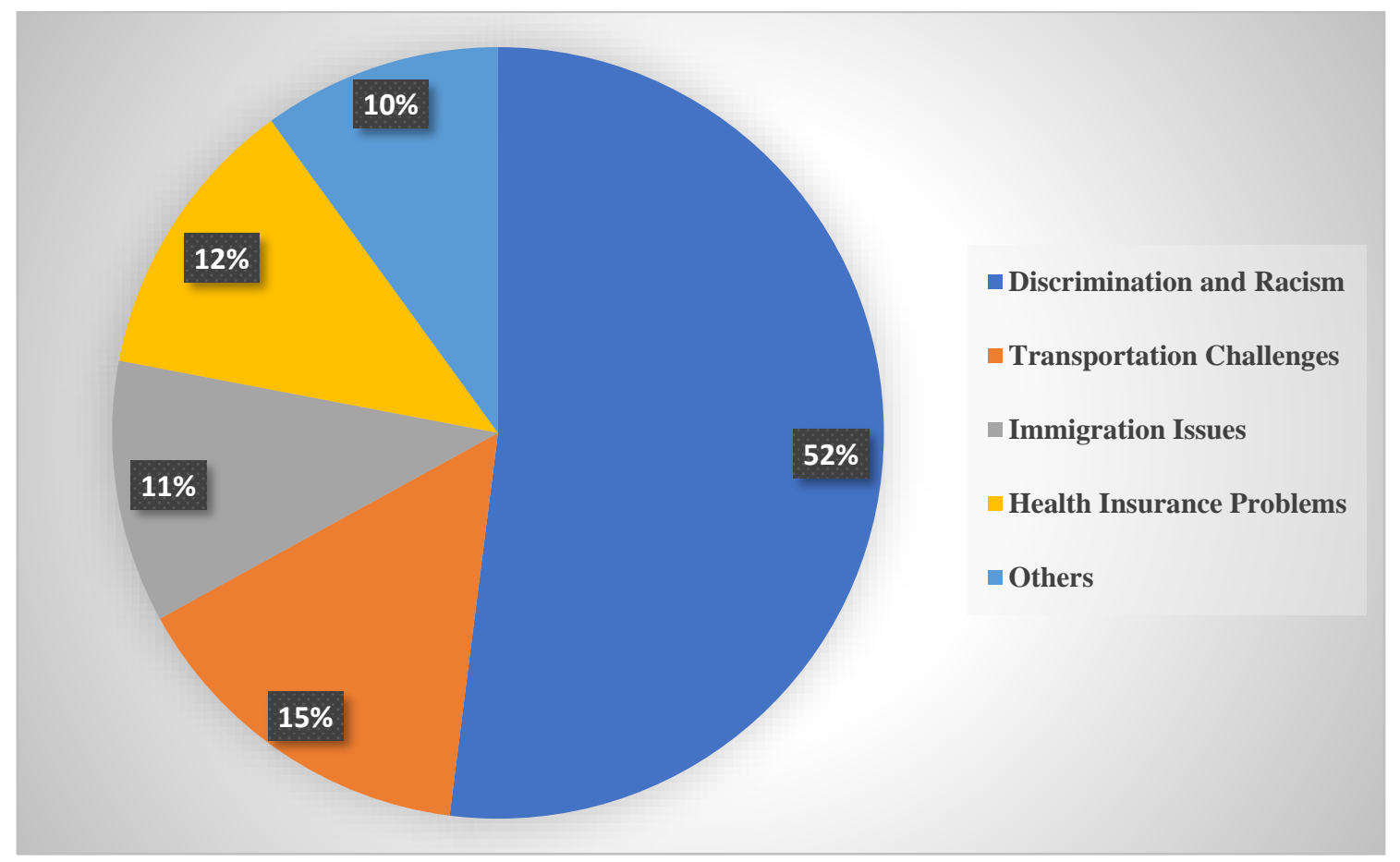

Table 15. Other Challenges Reported by WVU International Students

\begin{tabular}{|l|l|}
\hline $\begin{array}{l}\text { Category of } \\
\text { Challenges }\end{array}$ & Challenges Directly Quoted by Students \\
\hline $\begin{array}{l}\text { Discrimination } \\
\text { and Racism }\end{array}$ & $\begin{array}{l}\text { 1.This university are bunch of racists } \\
\text { 2.Student and advisor relationship. I had a bitter experience with my advisor } \\
\text { which has taken a toll on me. } \\
\text { 3.Professors are racist } \\
\text { 4.Discrimination by faculty } \\
\text { 5.Students and professors being racist toward me } \\
\text { 6.I faced so many racisms with the prof toward Middle Eastern students }\end{array}$ \\
\hline Transportation & $\begin{array}{l}\text { 1.Transportation to major cities/airports, roads in Morgantown. } \\
\text { 2.Public transportation. As international students we don't have cars so } \\
\text { moving around is difficult, we always need to rely on others to do grocery } \\
\text { shopping for example. } \\
\text { 3.Transportation upon arrival. } \\
\text { 4.The public transportation was a challenge, it's so important to know how it } \\
\text { works and the bus stops. Maybe if they implement a guided tour but in public } \\
\text { transportation instead the WVU buses }\end{array}$ \\
\hline
\end{tabular}




\begin{tabular}{|c|c|}
\hline & $\begin{array}{l}\text { 5.Finding ways to travel out of Morgantown without having a car (assistance } \\
\text { could be better). }\end{array}$ \\
\hline $\begin{array}{l}\text { Health } \\
\text { Insurance }\end{array}$ & $\begin{array}{l}\text { 1. The health insurance and health services are too expensive, there are better } \\
\text { and cheaper options of health insurance. } \\
\text { 2.Mental health as an international student } \\
\text { 3.Better Health insurance needed urgently } \\
\text { 4.Healthcare is a joke and poses so much trouble, let alone stress! } \\
\text { 5.Health insurance. I had to pay a lot of money and being in debt for a year } \\
\text { and a half just because I went to the ER }\end{array}$ \\
\hline $\begin{array}{l}\text { Immigration } \\
\text { Issues }\end{array}$ & $\begin{array}{l}\text { 1. Setting up bank account was difficult without a social security number and } \\
\text { generally accessing money from home was quite hard. } \\
\text { 2. Getting a driver's license. No help from university } \\
\text { 3.Acquiring a driver license. It is of high importance and WVU offers no } \\
\text { help. A system to help international students find a car to take the practical } \\
\text { driving test should be established. } \\
\text { 4. The problem which I am facing currently is change of I- } 20 \text { from one major } \\
\text { to another. It is taking a very long time. Actually, to say they are not } \\
\text { responding }\end{array}$ \\
\hline $\begin{array}{l}\text { Social/Personal } \\
\text { Challenges }\end{array}$ & $\begin{array}{l}\text { 1. The lack of activity to Morgantown } \\
\text { 2. Finding social groups from similar situation } \\
\text { 3.Off-campus student housing roommates, roommates crossing boundaries in } \\
\text { work/school. }\end{array}$ \\
\hline $\begin{array}{l}\text { Housing } \\
\text { Challenges }\end{array}$ & $\begin{array}{l}\text { 1.Rent laws is a major challenge and we find little help from WVU to the } \\
\text { problem } \\
\text { 2.Off-campus student housing roommates, roommates crossing boundaries in } \\
\text { work/school } \\
\text { 3.Renting a house here being from another country is hard and necessary }\end{array}$ \\
\hline $\begin{array}{l}\text { Orientation } \\
\text { Challenges }\end{array}$ & $\begin{array}{l}\text { 1. Graduate international students' orientation. WVU put us together with } \\
\text { young one semester exchange students. It would have been good to have been } \\
\text { put together for socialization appropriateness } \\
\text { 2.Course registration until the end of the first week is very dangerous for } \\
\text { students that could not arrive before the first day of classes and because of } \\
\text { professors do not reply to student's mail, that is why is very difficult to have } \\
\text { an idea of which course fits with our home country study plan } \\
\text { 3.Include time management in orientation class. } \\
\text { 4.Rent laws is a major challenge and we find little help from WVU to the } \\
\text { problem }\end{array}$ \\
\hline $\begin{array}{l}\text { English } \\
\text { Language }\end{array}$ & $\begin{array}{l}\text { 1.Less learning support for non-English native students. } \\
\text { 2.Conversation etiquette, accent }\end{array}$ \\
\hline
\end{tabular}


4.9 Informal Conversations. The results from the face to face interview were not different from the results of the survey. All 12 students interviewed complained about discrimination and racism particularly from professors. Some students reported that finding grocery stores in Morgantown with ethnic food items from their home country in Morgantown was a challenge compelling them to travel to Pittsburgh and other states just to purchase food items. Students with dependents and families described the difficulty of finding affordable daycare while they attended classes. Some students complained that most of the scholarships, grants, and Graduate Assistantships available through their departments or the Office of Graduate Education and Life were only for citizens or green card holders.

Other challenges asserted by the students were: adjustment to American food, transportation, not being able to access scholarships and funding due to 'international student status', difficulty finding religious groups of own faith, and language problems. Out of the 12 people interviewed, 8 claimed that their greatest challenge was discrimination and mistreatment from their professor/advisor. These students had some prior experience of being enrolled in other U.S. colleges prior to being enrolled at WVU. Transportation, and expensive health insurance making healthcare inaccessible was the greatest challenge for 6 students, 4 asserted that the cumbersome and lengthy processes at the Office of International Students were their greatest challenge, speaking and understanding English was the greatest challenge for 4 people, and 2 persons stated loneliness was their greatest challenge.

\subsection{Research question 2. What are the students' perceptions of West Virginia University's role in addressing the adjustment challenges they encounter? In addressing this issue, the international student survey asked students to rank, on a scale of 1-7, how WVU assists them in meeting their perceived challenges. The ratings were;}




\section{Ratings of WVU's Assistance Dealing with the Challenge:}

$7=$ Much better than expected

$6=$ Better than expected

$5=$ Somewhat better than expected

$4=$ Neutral-Exactly as I expected

$3=$ Less than expected

$2=$ Much less than expected

$1=$ No assistance at all

The responses of the ratings were compared, and the mean also compared. The standard deviation and descriptive analysis of each response was analyzed and compared for all respondents of the survey $(\mathrm{N}=220)$. A $t$-test was computed with the level of respondents in college (undergraduates/ graduates), the years of experience they had in other colleges before enrolling at WVU, and their gender to test for any significant differences. A One Factor ANOVA was also carried out for the age of the respondents, and the number of years they had been enrolled at WVU. A higher mean in this analysis means WVU was more helpful with this item and a lower mean means WVU was less helpful.

Table 15 shows that item 15 (understanding lectures in English) had the highest mean of 5.00, followed by item 14 (ability to write in English- mean of 4.98), and item 6 (relationship between faculty and students- mean of 4.86). Item 10 (unexpected financial needs-mean of 3.64), item 11 (finding employment between semesters-mean of 3.63), and item 12 (lack of money to meet expenses- mean of 3.62) were among the lowest mean with the least being item 18 (finding part time work- mean of 3.55). These results reveal that students perceive WVU greatest assistance with understanding lectures in English (item 14) and the least assistance from WVU with finding part 
time work (item 18). Summary statistics for responses are presented in Table 16. A complete descriptive analysis is attached as Appendix $\mathrm{H}$.

Table 16. Descriptive Statistics for Responses to WVU Assistance with Challenges of International Students (Higher means indicates WVU was more helpful)

\begin{tabular}{rrrrr}
\hline Item & Addressing Challenges & Mean & SD & $\begin{array}{c}\text { Confidence } \\
\text { Interval( }(\mathbf{)}\end{array}$ \\
\hline 1 & Differences between U.S. and Home Country & 4.58 & 1.69 & 0.25 \\
& Education System & 4.81 & 1.63 & 0.24 \\
2 & Orientation to WVU & 4.30 & 1.99 & 0.29 \\
3 & Relationship with international student advisor & & & \\
4 & Attitude of some students towards international & 4.62 & 1.81 & 0.27 \\
& students & 4.44 & 1.90 & 0.28 \\
5 & Attitude of some U.S. citizens to skin color & 4.86 & 1.76 & 0.26 \\
6 & Relationship between faculty and students & 4.53 & 1.67 & 0.25 \\
7 & Treatment received at social functions & 4.51 & 1.74 & 0.26 \\
8 & Being accepted in social groups & 4.16 & 1.66 & 0.25 \\
9 & Insufficient personal- social counseling & 3.64 & 1.85 & 0.28 \\
10 & Unexpected financial needs & 3.63 & 1.74 & 0.26 \\
11 & Finding employment between semesters & 3.62 & 1.82 & 0.27 \\
12 & Lack of money to meet expenses & 4.77 & 1.73 & 0.26 \\
13 & Speaking English & 4.98 & 1.65 & 0.24 \\
14 & Ability to write English & 5.00 & 1.64 & 0.24 \\
15 & Understanding lectures in English & 4.45 & 1.71 & 0.25 \\
16 & Immigration regulations & 3.88 & 1.89 & 0.28 \\
17 & Immigration work restrictions & 3.55 & 1.78 & 0.26 \\
18 & Finding part time work & 3.96 & 1.87 & 0.28 \\
19 & Finding a worship group of own faith & 3.97 & 1.82 & 0.27 \\
20 & Religion and morals in the U. S & 4.11 & 1.80 & 0.27 \\
21 & Religious practices in U. S & 3.98 & 1.89 & 0.28 \\
22 & Finding adequate health services & 3.76 & 1.83 & 0.27 \\
23 & Dietary problems & 3.90 & 1.92 & 0.28 \\
24 & Feeling stressed & & & \\
\hline
\end{tabular}

4.11 Age. The students' perceptions of WVU's role in addressing the adjustment challenges they encounter was analyzed by age (Table 17). Students below the age of 20 had the highest means for almost all the questions with their highest being 5.28 for both item 4 (attitude of some students 
towards international students) and item 8 (being accepted into social groups). The second highest mean for students below age 20 was 5.25 for item 14 (ability to write in English) followed by 5.20 for item 6 (Relationship between faculty and students). Their lowest mean was 3.64 for item 11 (finding employment between semesters). Students between the ages of 21 and 25 years had the highest mean of 4.93 for item 6 (relationship between faculty and students) followed by 4.85 for item 2 (orientation to WVU) and 4.82 for item 14 (ability to write in English). Their lowest mean was 3.56 for item 12 (lack of money to meet expenses). Students aged 26 years and above had the highest mean of 5.17 for item 15 (understanding lectures in English) followed by 4.95 for item 14 (ability to write in English) and 4.79 for item 13 (speaking in English). Their lowest mean was 2.91 for item 18 (finding part time work).

This analysis implies that while students from age 26 on perceive WVU's greatest assistance to them in understanding lectures in English, students below 20 years of age perceive their greatest assistance from WVU with being accepted into social groups and attitude of some students towards international students. Students between the ages of 21 and 25 years perceive their greatest assistance from WVU with relationship between them and faculty. Students between the ages of 21 and 25 years perceive WVU's least assistance with lack of money to meet expenses while students of 26 years and above perceive their least assistance from WVU with finding part time work. Students below the age of 20 years perceive their least assistance from WVU as finding employment between semesters (Figure 13). 


\section{Figure 13. WVU's Assistance with Addressing Challenges and Age}

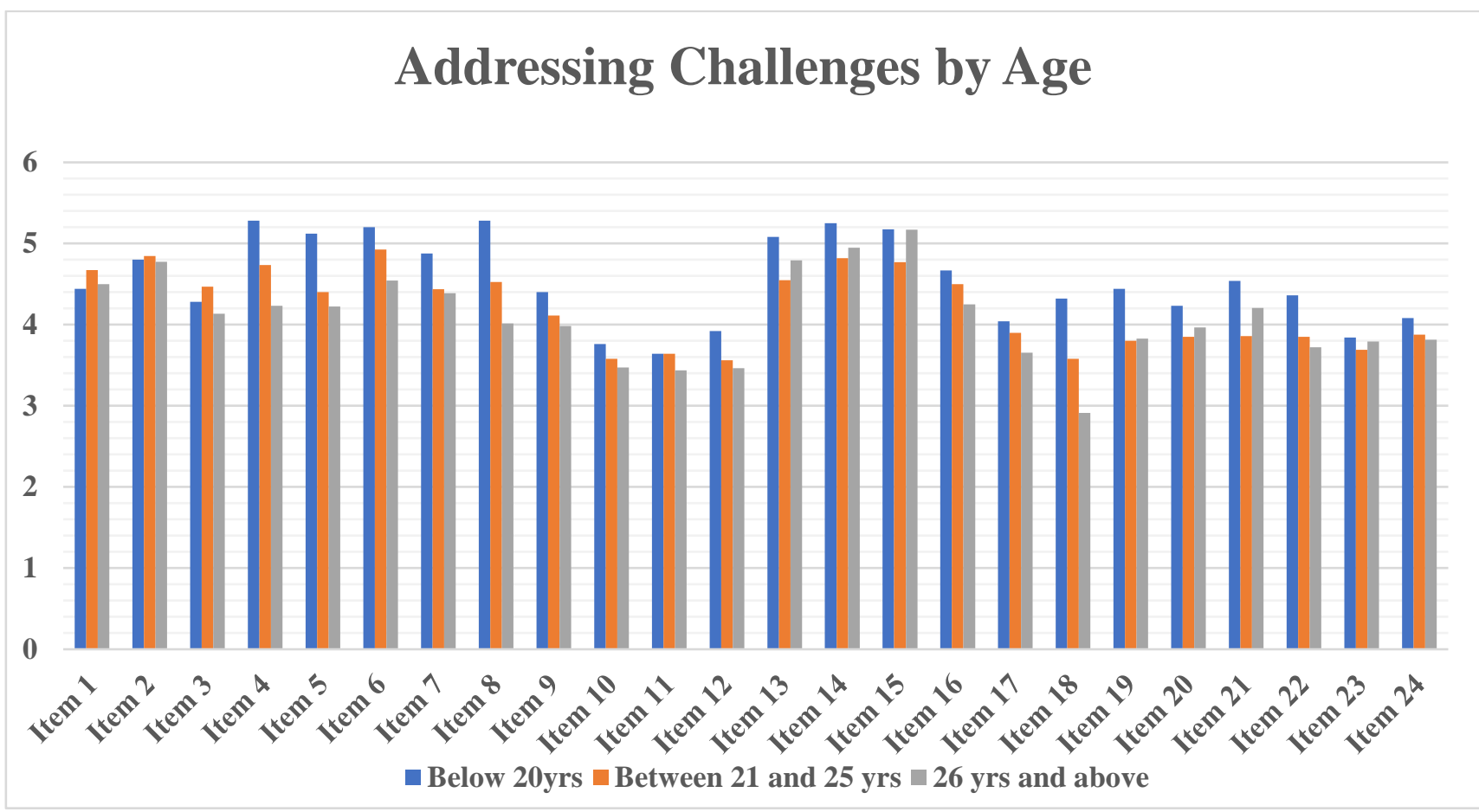

A one factor ANOVA analysis showed some statistically significant differences (Table 17).

Students the age of 20 years or less had the highest mean for all the items with statistical differences and students above the age of 26 years had the least mean with all the items with statistical differences signifying that students above the age of 26 years did not perceive WVU's assistance with those items as greatest compared to students 20 years. The items with statistically significant differences were item 4 , attitude of some students toward international students $(d f=2, F=3.30$, $P<5)$, item 8 , being accepted into social groups $(d f=2, F=5.06, P<.05)$, and item 18, finding part time work ( $d f=2, F=6.80, \mathrm{P}<.05)$. The mean for students above age 26 for item 4 was $4.23,4.73$ for students between ages 21 and 25, and 5.28 for students 20 years or less. This means that students 20 years or less perceive WVU's greatest assistance with attitude of some students towards international students more than the other age groups. Students 20 years or less had a mean of 5.28 
for item 8, 4.52 for students between the ages of 21 and 25 years and 4.02 for students 26 years and above, implying that students 20 years or less again perceive WVU's assistance with being accepted into social groups as greatest as compared to the other age groups. Students above the age of 26 had 2.91 for item 18, students between the ages of 21 and 25 years had a mean of 3.58, and students 20 years or less had 4.32 signifying that students 20 years or less perceived WVU as assisting them much more with finding part time work than students in the other categories. A summary of the ANOVA analysis is presented below in table 16 and a complete analysis attached as Appendix I. 
Table 17. Summary of ANOVA Analysis of Age and WVU Assistance in Addressing Challenges

\begin{tabular}{|c|c|c|c|c|c|c|c|c|c|c|}
\hline \multirow[b]{2}{*}{ Item } & \multirow[b]{2}{*}{ Challenge } & \multicolumn{2}{|c|}{20 yrs or less } & \multicolumn{2}{|c|}{ Between 21-25yrs } & \multicolumn{2}{|c|}{ 26yrs and above } & \multirow[b]{2}{*}{$d f$} & \multirow[b]{2}{*}{$\mathbf{F}$} & \multirow[b]{2}{*}{$\boldsymbol{P}$} \\
\hline & & Mean & Variance & Mean & Variance & Mean & Variance & & & \\
\hline 1 & $\begin{array}{l}\text { Differences between U.S. and Home Country Education } \\
\text { System }\end{array}$ & 4.44 & 2.26 & 4.67 & 3.06 & 4.50 & 3.00 & 2 & 0.27 & 0.76 \\
\hline 2 & Orientation to WVU & 4.80 & 2.83 & 4.85 & 2.58 & 4.78 & 2.67 & 2 & 0.03 & 0.97 \\
\hline 3 & Relationship with international student advisor & 4.28 & 3.54 & 4.47 & 4.06 & 4.14 & 4.19 & 2 & 0.49 & 0.62 \\
\hline 4 & Attitude of some students towards international students & 5.28 & 2.92 & 4.73 & 2.86 & 4.23 & 3.88 & 2 & 3.30 & $0.04 *$ \\
\hline 5 & Attitude of some U.S. citizens to skin color & 5.12 & 2.94 & 4.40 & 2.86 & 4.22 & 4.32 & 2 & 2.12 & 0.12 \\
\hline 6 & Relationship between faculty and students & 5.20 & 3.33 & 4.93 & 2.41 & 4.54 & 3.80 & 2 & 1.50 & 0.23 \\
\hline 7 & Treatment received at social functions & 4.88 & 2.81 & 4.44 & 2.57 & 4.39 & 3.24 & 2 & 0.77 & 0.46 \\
\hline 8 & Being accepted in social groups & 5.28 & 1.71 & 4.52 & 2.82 & 4.02 & 3.33 & 2 & 5.06 & $0.01^{*}$ \\
\hline 9 & Insufficient personal- social counseling & 4.40 & 2.25 & 4.11 & 2.83 & 3.98 & 2.84 & 2 & 0.56 & 0.57 \\
\hline 10 & Unexpected financial needs & 3.76 & 3.86 & 3.58 & 3.40 & 3.47 & 3.15 & 2 & 0.21 & 0.81 \\
\hline 11 & Finding employment between semesters & 3.64 & 2.07 & 3.64 & 3.13 & 3.44 & 2.89 & 2 & 0.26 & 0.77 \\
\hline 12 & Lack of money to meet expenses & 3.92 & 4.41 & 3.56 & 3.36 & 3.47 & 2.60 & 2 & 0.57 & 0.57 \\
\hline 13 & Speaking English & 5.08 & 3.38 & 4.55 & 2.62 & 4.79 & 3.22 & 2 & 1.00 & 0.37 \\
\hline 14 & Ability to write English & 5.25 & 3.33 & 4.82 & 2.57 & 4.95 & 2.47 & 2 & 0.67 & 0.52 \\
\hline 15 & Understanding lectures in English & 5.17 & 3.33 & 4.77 & 2.74 & 5.17 & 2.22 & 2 & 1.26 & 0.29 \\
\hline 16 & Immigration regulations & 4.67 & 3.19 & 4.50 & 3.12 & 4.25 & 2.39 & 2 & 0.64 & 0.53 \\
\hline 17 & Immigration work restrictions & 4.04 & 3.61 & 3.90 & 3.57 & 3.66 & 3.23 & 2 & 0.48 & 0.62 \\
\hline 18 & Finding part time work & 4.32 & 2.39 & 3.58 & 3.07 & 2.91 & 2.36 & 2 & 6.80 & $0.00^{*}$ \\
\hline 19 & Finding a worship group of own faith & 4.44 & 3.51 & 3.80 & 3.46 & 3.83 & 3.27 & 2 & 1.23 & 0.30 \\
\hline 20 & Religion and morals in the U.S. & 4.23 & 3.54 & 3.85 & 3.39 & 3.97 & 2.93 & 2 & 0.44 & 0.64 \\
\hline 21 & Religious practices in U.S. & 4.54 & 3.46 & 3.86 & 3.02 & 4.21 & 2.94 & 2 & 1.66 & 0.19 \\
\hline 22 & Finding adequate health services & 4.36 & 3.41 & 3.85 & 3.55 & 3.72 & 3.60 & 2 & 1.03 & 0.36 \\
\hline 23 & Dietary problems & 3.84 & 3.64 & 3.69 & 3.46 & 3.79 & 3.01 & 2 & 0.09 & 0.92 \\
\hline 24 & Feeling stressed & 4.08 & 3.64 & 3.88 & 4.16 & 3.81 & 3.26 & 2 & 0.17 & 0.85 \\
\hline
\end{tabular}

Note. * Significant at $p<.05$ 
4.12 Gender. Students' perceptions of WVU's role in addressing adjustment challenges was analyzed by gender. Males had a higher mean in all the challenges addressed except for item 9 (insufficient personal-social counselling). A $t$-test confirmed these and showed even more significant differences (Table 18). On six of the challenges, males had a significantly higher mean than females. Males had a mean of 3.86 while females had a mean of 3.31 for item 10 (unexpected financial needs), showing that males perceived WVU as assisting much more with unexpected financial needs than females. For item 11 (finding employment between semesters) males had 3.87 while females had 3.34, item 14 (ability to write English) males had 5.24 and females had 4.67, item 16 (immigration regulations) males had 4.71 and females had 4.18, item 19 ( finding a worship group of own faith) males had 4.24 and females had 3.64, item 20 (religion and morals in the U.S.) males had 4.33 and females had 3.60, item 21 (religious practices in the U.S.) males had 4.35 and females had 3.80, and item 23 (dietary problems) males had 4.01 and females had 3.78. This reveals that in all these items, males perceive WVU as assisting more than females. The least perceived assistance from WVU for females was item 10 (unexpected financial needs) with a mean of 3.31. The least perceived assistance from WVU by males was for item 18 (finding part time work) with a mean of 3.67 
Table 18. Analysis Gender Differences for WVU Assistance in Addressing Challenges

\begin{tabular}{|c|c|c|c|c|}
\hline \multirow[b]{2}{*}{ Item } & \multirow[b]{2}{*}{ Challenges Addressed } & \multirow{2}{*}{$\begin{array}{l}\text { Male } \\
\text { Mean }\end{array}$} & \multicolumn{2}{|l|}{ Female } \\
\hline & & & Mean & $\boldsymbol{P}$ \\
\hline 1 & Differences between U.S. and Home Country & & & \\
\hline & Education System & 4.69 & 4.48 & 0.42 \\
\hline 2 & Orientation to WVU & 5.05 & 4.59 & 0.06 \\
\hline 3 & Relationship with international student advisor & 4.57 & 4.11 & 0.13 \\
\hline 4 & Attitude of some students towards international & & & \\
\hline & students & 4.78 & 4.45 & 0.22 \\
\hline 5 & Attitude of some U.S. citizens to skin color & 4.66 & 4.16 & 0.08 \\
\hline 6 & Relationship between faculty and students & 4.86 & 4.79 & 0.82 \\
\hline 7 & Treatment received at social functions & 4.56 & 4.42 & 0.60 \\
\hline 8 & Being accepted in social groups & 4.56 & 4.38 & 0.49 \\
\hline 9 & Insufficient personal- social counseling & 4.02 & 4.20 & 0.49 \\
\hline 10 & Unexpected financial needs & 3.86 & 3.31 & $0.05^{*}$ \\
\hline 11 & Finding employment between semesters & 3.87 & 3.34 & $0.04 *$ \\
\hline 12 & Lack of money to meet expenses & 3.76 & 3.48 & 0.31 \\
\hline 13 & Speaking English & 4.90 & 4.60 & 0.26 \\
\hline 14 & Ability to write English & 5.24 & 4.67 & $0.02 *$ \\
\hline 15 & Understanding lectures in English & 5.20 & 4.78 & 0.09 \\
\hline 16 & Immigration regulations & 4.71 & 4.18 & $0.04 *$ \\
\hline 17 & Immigration work restrictions & 4.04 & 3.67 & 0.20 \\
\hline 18 & Finding part time work & 3.67 & 3.36 & 0.24 \\
\hline 19 & Finding a worship group of own faith & 4.24 & 3.64 & $0.03 *$ \\
\hline 20 & Religion and morals in the U.S. & 4.33 & 3.60 & $0.01 *$ \\
\hline 21 & Religious practices in U.S. & 4.35 & 3.80 & $0.04 *$ \\
\hline 22 & Finding adequate health services & 4.06 & 3.80 & 0.36 \\
\hline 23 & Dietary problems & 4.01 & 3.41 & $0.03 *$ \\
\hline 24 & Feeling stressed & 4.01 & 3.78 & 0.42 \\
\hline
\end{tabular}

Note. * Significant at $p<.0$

4.13 Level of Class. Students level of class (graduates/undergraduates) was analyzed with their perception of WVU addressing their challenges (Table 19). The highest mean (5.06) for undergraduate students was item 14 (ability to write English) followed by item 15 (understanding lectures in English) with a mean of 4.93 and item 2 (orientation to WVU) with a mean of 4.88. Their lowest mean was 3.68 for item 12 (lack of money to meet expenses). The highest mean for graduate 
students was 5.02 for item 15 (understanding lectures in English) followed by 4.83 for item 14 (ability to write English) and 4.81 for item 6 (relationship between faculty and students). The least mean for graduate students was item 18 (finding a worship group of own faith).

Table 19. WVU's Assistance in Addressing Challenges with Class Standing

\begin{tabular}{rrrrr}
\hline Item & & & \multicolumn{3}{c}{ Graduates } & Undergrads \\
& Challenges Addressed & Mean & Mean & $P$ \\
\hline 1 & Differences between U.S. and Home Country Education & & & \\
& System & 4.48 & 4.68 & 0.43 \\
2 & Orientation to WVU & 4.74 & 4.88 & 0.55 \\
3 & Relationship with international student advisor & 3.99 & 4.67 & $0.02^{*}$ \\
4 & Attitude of some students towards international students & 4.55 & 4.65 & 0.71 \\
5 & Attitude of some U.S. citizens to skin color & 4.42 & 4.38 & 0.90 \\
6 & Relationship between faculty and students & 4.81 & 4.83 & 0.94 \\
7 & Treatment received at social functions & 4.51 & 4.46 & 0.83 \\
8 & Being accepted in social groups & 4.22 & 4.72 & 0.06 \\
9 & Insufficient personal- social counseling & 4.03 & 4.20 & 0.50 \\
10 & Unexpected financial needs & 3.46 & 3.70 & 0.41 \\
11 & Finding employment between semesters & 3.43 & 3.77 & 0.20 \\
12 & Lack of money to meet expenses & 3.55 & 3.68 & 0.62 \\
13 & Speaking English & 4.65 & 4.84 & 0.47 \\
14 & Ability to write English & 4.83 & 5.06 & 0.37 \\
15 & Understanding lectures in English & 5.02 & 4.93 & 0.71 \\
16 & Immigration regulations & 4.35 & 4.54 & 0.46 \\
17 & Immigration work restrictions & 3.72 & 3.99 & 0.35 \\
18 & Finding part time work & 3.17 & 3.88 & $0.01 *$ \\
19 & Finding a worship group of own faith & 3.71 & 4.17 & 0.10 \\
20 & Religion and morals in the U. S & 3.83 & 4.07 & 0.39 \\
21 & Religious practices in U. S & 3.88 & 4.26 & 0.16 \\
22 & Finding adequate health services & 3.63 & 4.24 & $0.03 *$ \\
23 & Dietary problems & 3.71 & 3.69 & 0.94 \\
24 & Feeling stressed & 3.87 & 3.92 & 0.87 \\
\hline \hline
\end{tabular}

Note. * Significant at $p<.0$

A $t$-test showed significant differences for three items (Table 19). Undergraduate students had significantly higher means for 3 items: 4.67-relationship with international student advisor, 3.88- 
finding part time work, and 4.24-finding adequate health services. Graduate students on the other hand had a mean of 3.99- relationship with international student advisor, 3.17 -finding part time work, and 3.63- finding adequate health services. This shows that undergraduate students perceive WVU as assisting them more in these areas of challenges than graduate students.

4.14 Number of Years Being Enrolled at WVU. The number of years international students had been enrolled at WVU was analyzed with their perception of how WVU assists in addressing their challenges. The highest mean for students who had been enrolled for less than 1 year was 5.09 for item 6 (relationship between faculty and students), followed by item 2 (4.95-orientation to WVU). Item 4 (attitude of some students towards international students) and item 15 (understanding lectures in English) had the same mean of 4.93. Their least mean was 3.62 for item 12 (lack of money to meet expenses). The highest mean for students who had been enrolled between 1 and 3 years was 5.10 for item 14 (ability to write in English), followed by 5.06 (understanding lectures in English) for item 15, and 5.02 for item 13 (speaking English). Their least mean was 3.32 for item 18 (finding part time work). For students who had been enrolled for 3 years and above, their highest mean was 4.97 for item 14 (ability to write English) followed by 4.92 for item 15 (understanding lectures in English), and 4.56 for item 13 (speaking in English). Their least mean was 3.06 for item 17 (immigration work restrictions). This analysis shows that students who had been enrolled between 1 and 3 years, and students who had been enrolled for 3 years or more perceive WVU's greatest assistance with ability to write English, followed by understanding English, and speaking English which all make up the English language challenges. Students who had been enrolled for less than 1 year perceive their greatest assistance from WVU with relationship between faculty and students.

However, whiles students enrolled between 1 and 3 years perceive their least assistance from WVU with finding part time work, students enrolled 3 years and more perceive their least assistance 
from WVU coming from immigration work restrictions. Students who had been enrolled less than 1 year perceived the least assistance from WVU with lack of money to meet expenses.

A One Factor ANOVA computed showed some statistical differences (Table 20). The items that had statistical differences were item 4, attitude of some students towards international students $(d f=2, F=4.59, p<.05)$. The mean for students enrolled less than 1 year for this item was 4.93 , the mean for students enrolled between 1 and 3 years was 4.65, and the mean for students enrolled for 3 years and above was 3.86. This means that whiles students who had been enrolled less than 1 year perceived their greatest assistance from WVU with attitude of some students towards international students, students enrolled 3 years and above, and students enrolled between 1- 3years perceive otherwise. The next item with statistical difference was item 6 , relationship between faculty and students $(d f=2, F=3.69, p<.05)$. Students enrolled for less than 1 year had a mean of 5.09, students enrolled between 1 and 3 years had a mean of 4.82, and students enrolled 3 years and above had a mean of 4. 17. This shows that students enrolled 3 years and more, and students enrolled between 1 and 3 years did not perceive assistance from WVU with relationship between students and faculty differently than students enrolled less than 1 year. Item 17 , immigration work restrictions had a statistically significant difference $(d f=2, F=4.73, p<.05)$. Students enrolled less than 1 year had a mean of 4.14, students enrolled between 1 and 3 years had 4.02, and students enrolled 3 years and above had a mean of 3.06. This shows that while students enrolled for less than 1 year perceived their greatest assistance from WVU with immigration work restrictions, students enrolled 3 years and above disagreed. A complete ANOVA analysis is attached as Appendix J. 
Table 20. ANOVA Analysis of Number of Years Being Enrolled and WVU Assistance with Addressing Challenges

\begin{tabular}{|c|c|c|c|c|c|c|c|c|c|c|}
\hline \multirow[b]{2}{*}{ Item } & \multirow[b]{2}{*}{ Challenges Addressed } & \multicolumn{4}{|c|}{ Less than $1 \mathrm{yr}$} & \multicolumn{5}{|c|}{3 yrs and above } \\
\hline & & Mean & Variance & Mean & Variance & Mean & Variance & df & $\mathbf{f}$ & $\mathbf{P}$ \\
\hline 1 & Differences between U.S. and Home Country Education & & & & & & & & & \\
\hline & System & 4.74 & 2.49 & 4.59 & 2.61 & 4.31 & 3.65 & 2 & 0.87 & 0.42 \\
\hline 2 & Orientation to WVU & 4.95 & 2.60 & 4.58 & 2.13 & 4.83 & 3.15 & 2 & 0.87 & 0.42 \\
\hline 3 & Relationship with international student advisor & 4.61 & 3.48 & 3.96 & 5.00 & 4.28 & 3.52 & 2 & 1.74 & 0.18 \\
\hline 4 & Attitude of some students towards international students & 4.93 & 2.75 & 4.65 & 3.35 & 3.86 & 3.89 & 2 & 4.59 & $0.01 *$ \\
\hline 5 & Attitude of some U.S. citizens to skin color & 4.69 & 2.94 & 4.42 & 3.72 & 3.83 & 4.20 & 2 & 2.70 & 0.07 \\
\hline 6 & Relationship between faculty and students & 5.09 & 2.56 & 4.82 & 2.67 & 4.17 & 4.26 & 2 & 3.69 & $0.03 *$ \\
\hline 7 & Treatment received at social functions & 4.60 & 2.41 & 4.55 & 2.65 & 4.06 & 3.69 & 2 & 1.37 & 0.26 \\
\hline 8 & Being accepted in social groups & 4.67 & 2.65 & 4.54 & 2.50 & 3.94 & 4.34 & 2 & 2.30 & 0.10 \\
\hline 9 & Insufficient personal- social counseling & 4.19 & 2.55 & 4.06 & 2.94 & 4.06 & 2.68 & 2 & 0.14 & 0.87 \\
\hline 10 & Unexpected financial needs & 3.67 & 3.48 & 3.36 & 3.09 & 3.78 & 3.38 & 2 & 0.66 & 0.52 \\
\hline 11 & Finding employment between semesters & 3.70 & 2.73 & 3.56 & 3.11 & 3.60 & 3.13 & 2 & 0.11 & 0.89 \\
\hline 12 & Lack of money to meet expenses & 3.62 & 3.34 & 3.82 & 3.25 & 3.44 & 3.17 & 2 & 0.46 & 0.63 \\
\hline 13 & Speaking English & 4.72 & 3.07 & 5.02 & 2.70 & 4.56 & 3.23 & 2 & 0.84 & 0.43 \\
\hline 14 & Ability to write English & 4.90 & 3.09 & 5.10 & 2.29 & 4.97 & 2.14 & 2 & 0.23 & 0.80 \\
\hline 15 & Understanding lectures in English & 4.93 & 2.97 & 5.06 & 2.23 & 4.92 & 2.94 & 2 & 0.12 & 0.89 \\
\hline 16 & Immigration regulations & 4.58 & 2.95 & 4.53 & 2.81 & 4.08 & 2.48 & 2 & 1.22 & 0.30 \\
\hline 17 & Immigration work restrictions & 4.14 & 3.58 & 4.02 & 3.27 & 3.06 & 2.68 & 2 & 4.73 & $0.01 *$ \\
\hline 18 & Finding part time work & 3.87 & 3.02 & 3.32 & 2.88 & 3.14 & 2.92 & 2 & 2.89 & 0.06 \\
\hline 19 & Finding a worship group of own faith & 4.16 & 3.36 & 3.61 & 3.16 & 4.03 & 3.68 & 2 & 1.45 & 0.24 \\
\hline 20 & Religion and morals in the U.S & 4.05 & 3.45 & 3.88 & 3.39 & 3.89 & 2.84 & 2 & 0.17 & 0.84 \\
\hline 21 & Religious practices in U.S & 4.20 & 3.46 & 3.94 & 3.28 & 4.00 & 2.41 & 2 & 0.36 & 0.70 \\
\hline 22 & Finding adequate health services & 3.94 & 2.96 & 4.14 & 3.51 & 3.60 & 4.42 & 2 & 0.89 & 0.41 \\
\hline 23 & Dietary problems & 3.84 & 3.16 & 3.59 & 3.29 & 3.60 & 3.07 & 2 & 0.39 & 0.68 \\
\hline 24 & Feeling stressed & 3.90 & 3.65 & 4.12 & 3.51 & 3.58 & 3.85 & 2 & 0.83 & 0.44 \\
\hline
\end{tabular}

Note. * Significant at $p<.05$ 
4.15 Years of Experience before WVU. The number of years a student had been at other schools before being enrolled at WVU was analyzed with their perception of how WVU assists in addressing their challenges. The highest mean for students who had no prior experience was 5.11 for item 14 (ability to write English) followed by 5.07 for item 15 (understanding lectures in English), and 5.03 for item 2 (orientation to WVU). Their lowest mean was item 3.56 for item 10 (unexpected financial needs), which means that their perception of WVU assisting them was greatest with ability to write English and least with unexpected financial needs. Students who had some years of experience in other schools before being enrolled in WVU had a highest mean of 4.77 for item 15 (understanding lectures in English), followed by item 14 (ability to write English) and 4.47 for item 6 (relationship between faculty and students). Their least mean was 3.25 for both item 11 (finding employment between semesters) and item 12 (lack of money to meet expenses), showing that they perceive WVU as least assisting them with lack of money to meet expenses and finding employment between semesters. Their perception of greatest assistance from WVU was with understanding lectures in English.

The $t$-test showed some statistically significant differences (Table 21). For item 1 ( differences between U.S. and Home Country Education System), students with no prior experience had a mean of 4.82 and students with some years of prior experience had 4.14, indicating that students with no prior experience perceived WVU as assisting them more with addressing the differences between U.S. and Home Country Education System while students with some years of prior experience did not perceive that. For item 2 (orientation to WVU), students with no prior experience had a mean of 5.03 while students with some years of prior experience had 4.40, indicating that students with some years of experience did not perceive WVU as assisting them in orientation to WVU as much as students with no experience. 
Table 21. Analysis of Years of Prior Experience in the U.S. and WVU Assistance with Addressing Challenges

\begin{tabular}{|c|c|c|c|c|}
\hline \multirow[b]{2}{*}{ Item } & \multirow[b]{2}{*}{ Challenges Addressed } & \multirow{2}{*}{$\begin{array}{l}\text { No } \\
\text { experience } \\
\text { Mean }\end{array}$} & \multicolumn{2}{|c|}{ Some Exp } \\
\hline & & & Mean & $\boldsymbol{P}$ \\
\hline 1 & Differences between U.S. and Home Country Education & & & \\
\hline & System & 4.82 & 4.14 & $0.02 *$ \\
\hline 2 & Orientation to WVU & 5.03 & 4.40 & $0.03 *$ \\
\hline 3 & Relationship with international student advisor & 4.38 & 4.23 & 0.66 \\
\hline 4 & Attitude of some students towards international students & 4.75 & 4.35 & 0.19 \\
\hline 5 & Attitude of some U.S. citizens to skin color & 4.47 & 4.31 & 0.60 \\
\hline 6 & Relationship between faculty and students & 5.01 & 4.47 & 0.07 \\
\hline 7 & Treatment received at social functions & 4.53 & 4.43 & 0.73 \\
\hline 8 & Being accepted in social groups & 4.56 & 4.31 & 0.37 \\
\hline 9 & Insufficient personal- social counseling & 4.18 & 4.00 & 0.52 \\
\hline 10 & Unexpected financial needs & 3.56 & 3.65 & 0.75 \\
\hline 11 & Finding employment between semesters & 3.78 & 3.25 & 0.07 \\
\hline 12 & Lack of money to meet expenses & 3.81 & 3.25 & 0.07 \\
\hline 13 & Speaking English & 4.92 & 4.46 & 0.12 \\
\hline 14 & Ability to write English & 5.11 & 4.66 & 0.12 \\
\hline 15 & Understanding lectures in English & 5.07 & 4.77 & 0.30 \\
\hline 16 & Immigration regulations & 4.60 & 4.14 & 0.10 \\
\hline 17 & Immigration work restrictions & 3.97 & 3.63 & 0.26 \\
\hline 18 & Finding part time work & 3.61 & 3.35 & 0.38 \\
\hline 19 & Finding a worship group of own faith & 3.99 & 3.86 & 0.66 \\
\hline 20 & Religion and morals in the U. S & 4.05 & 3.79 & 0.39 \\
\hline 21 & Religious practices in U.S & 4.12 & 4.00 & 0.70 \\
\hline 22 & Finding adequate health services & 4.08 & 3.66 & 0.19 \\
\hline 23 & Dietary problems & 3.82 & 3.52 & 0.31 \\
\hline 24 & Feeling stressed & 3.89 & 3.93 & 0.91 \\
\hline
\end{tabular}

Note. * Significant at $p<.05$

\subsection{Research question 3. What coping mechanisms or adaptation strategies do international} students use to survive the adjustment challenges in West Virginia University?

In answering this research question, questions 3 to 6 on the survey used for this study helped in identifying these coping skills and resources. Question 3 was comprised of 11 Likert-Scale questions that asked students to rank on a scale of 1-5 how helpful the listed resources were to them. 
The ratings of the Likert scale questions were $1=$ not at all, $2=$ very little, $3=$ neutral. $4=$ somewhat helpful, and 5= very helpful. The results were compared (Figure 14); the mean, standard deviation and descriptive analysis (Appendix K) of each of the 11 resources was analyzed and compared for all respondents of the survey $(\mathrm{N}=220)$. A $t$-test was computed with the gender, years of experience they had in other colleges before enrolling at WVU, and class level in college (undergraduates/graduates) to test for any significant differences. A One Factor ANOVA was also carried out for the age of the respondents, and the number of years they had been enrolled in WVU.

\section{Figure 14. Mean Analysis of Resources Utilized by Students to Survive}

\section{Mean of resources}

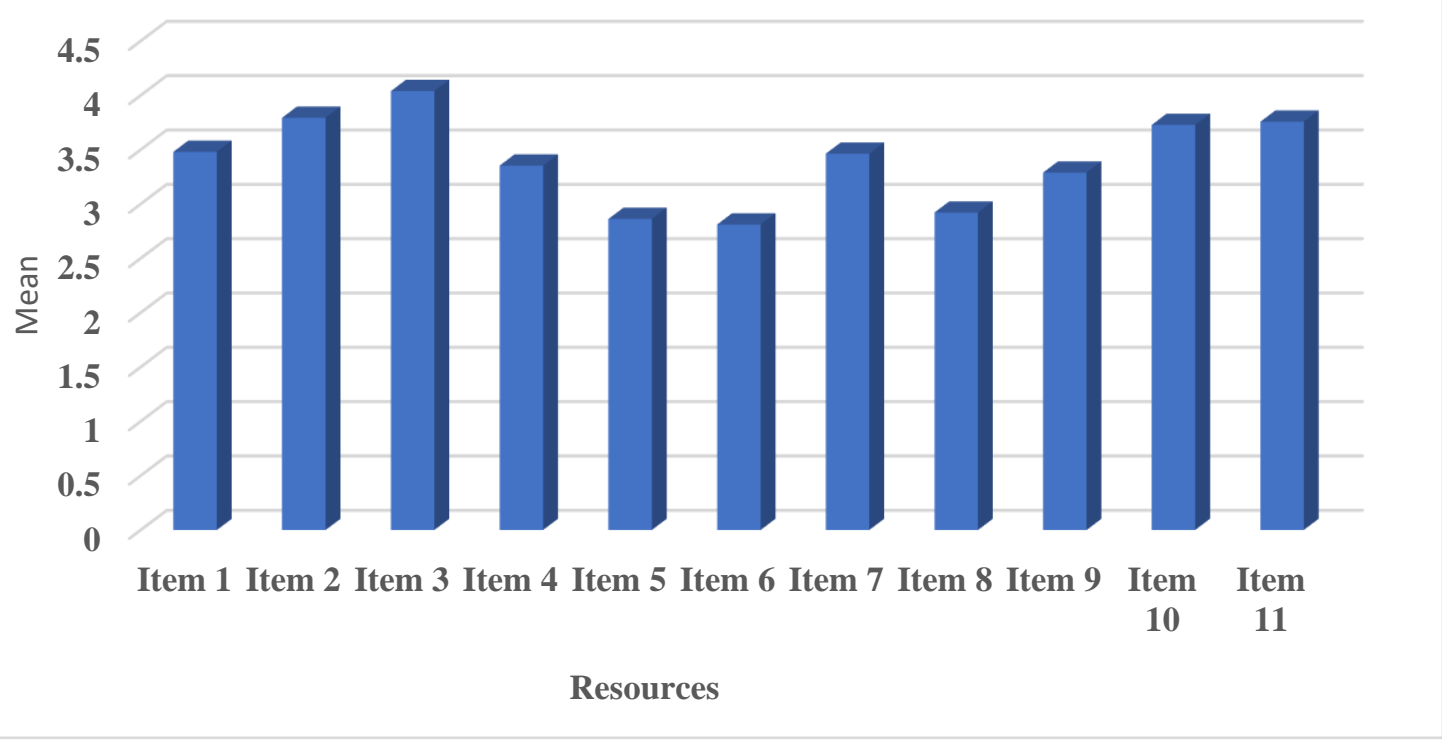


Table 22. Item Numbers and Corresponding Resources

\begin{tabular}{|c|c|c|c|}
\hline Item Number & Resource & Item Number & Resource \\
\hline $\mathbf{1}$ & $\begin{array}{c}\text { International Student } \\
\text { Organizations }\end{array}$ & $\mathbf{7}$ & $\begin{array}{c}\text { International Students } \\
\text { \& Scholars Services }\end{array}$ \\
\hline $\mathbf{2}$ & $\begin{array}{c}\text { Academic Advisor or } \\
\text { Major Professor }\end{array}$ & $\mathbf{8}$ & Writing Studio \\
\hline $\mathbf{3}$ & $\begin{array}{c}\text { Other International } \\
\text { Students }\end{array}$ & $\mathbf{9}$ & Student Orientation \\
\hline $\mathbf{4}$ & American Students & $\mathbf{1 0}$ & Staff \\
\hline $\mathbf{5}$ & Local Campus Groups & $\mathbf{1 1}$ & Instructors \\
\hline $\mathbf{6}$ & Office of Diversity \& & & \\
\hline
\end{tabular}

From Figure 14, the resource with the highest mean was item 3 (Other International Students). The second highest mean was item 2 (Academic Advisor or Major Professor) followed by item 11(Instructors). The least mean was for item 6 (Office of Diversity \& Inclusion). This shows that among the listed resources that WVU provides services to international students, the most helpful for international students is their fellow international students. Academic advisors and major professors, and instructors are the second and third most helpful resource, and the Office of Diversity \& Inclusion is the least helpful resource. A list of item numbers and their corresponding resources is presented in table 22 above. Descriptive statistics for responses to WVU resources are presented in Table 23. 
Table 23. Descriptive Statistics for Responses to WVU Resources

\begin{tabular}{rlrrr}
\hline No. & Resources & Mean & SD & $\begin{array}{c}\text { Confidence } \\
( \pm)\end{array}$ \\
\hline 1 & International Student Organizations & 3.48 & 1.28 & 0.18 \\
2 & Academic Advisor or Major Professor & 3.79 & 1.27 & 0.18 \\
3 & Other International Students & 4.04 & 1.12 & 0.15 \\
4 & American Students & 3.35 & 1.31 & 0.18 \\
5 & Local Campus Groups & 2.86 & 1.22 & 0.17 \\
6 & Office of Diversity \& Inclusion & 2.81 & 1.29 & 0.18 \\
& International Students \& Scholars & & & \\
7 & Services & 3.46 & 1.28 & 0.18 \\
8 & Writing Studio & 2.92 & 1.30 & 0.18 \\
9 & Student Orientation & 3.29 & 1.26 & 0.17 \\
10 & Staff & 3.73 & 1.14 & 0.16 \\
11 & Instructors & 3.76 & 1.15 & 0.16 \\
\hline \hline
\end{tabular}

4.17 Gender and Resources. The resources international students utilized were analyzed by gender and a $t$-test computed to check for any statistically significant differences (Table 24). The highest mean for females was 4.04 for item 3 (other international students) followed by 3.69 for item 11 (instructors) and 3.67 for item 2 (Academic advisor or major professor). The least mean for females was 2.63 for item 5 (local campus groups). Males had a highest mean of 4.03 for item 3 (other international students), followed by 3.92 for item 2 (academic advisor or major) and 3.88 for item 10 (staff). The lowest mean for males was 2.89 for item 6 (Office of Diversity, and Inclusion). This analysis indicates that other international students is the most helpful resource for both males and females, and the least helpful resource for females is the local campus groups while the Office of Diversity, and Inclusion is the least helpful resource for males. 
Table 24. Responses to WVU Resources by Gender

\begin{tabular}{rlrrr}
\hline No. & Resources & $\begin{array}{r}\text { Male } \\
\text { Mean }\end{array}$ & $\begin{array}{r}\text { Female } \\
\text { Mean }\end{array}$ & P \\
\hline 1 & International Student Organizations & 3.61 & 3.33 & 0.12 \\
2 & Academic Advisor or Major Professor & 3.92 & 3.67 & 0.17 \\
3 & Other International Students & 4.03 & 4.04 & 0.97 \\
4 & American Students & 3.45 & 3.22 & 0.21 \\
5 & Local Campus Groups & 3.07 & 2.63 & 0.01 \\
6 & Office of Diversity \& Inclusion & 2.89 & 2.67 & 0.21 \\
& International Students \& Scholars & & & \\
7 & Services & 3.56 & 3.34 & 0.21 \\
8 & Writing Studio & 2.93 & 2.87 & 0.77 \\
9 & Student Orientation & 3.44 & 3.12 & 0.07 \\
10 & Staff & 3.88 & 3.55 & 0.04 \\
11 & Instructors & 3.79 & 3.69 & 0.55 \\
\hline
\end{tabular}

Note. ${ }^{*}$ Significant at $p<.05$

The $t$-test showed some statistically significant differences (Table 24) for items 5 and 10. For item 5 (local campus groups), males had a mean of 3.07 whiles females had a mean of 2.63, indicating that local campus groups were more helpful to males than females. For item 10 (staff), males had a mean of 3.88 whiles females had 3.55 showing that staff was a more helpful resources to males than females.

4.18 Years of Experience prior to WVU. The number of years of experience prior to being enrolled with WVU was analyzed with the resources. Students who had no experience prior to being enrolled at WVU had a highest mean of 3.98 for item 3 (other international students), followed by 3.63 for item 2 (academic advisor or major professor). Their lowest mean was 2.66 for item 6 (Office of Diversity, \& Inclusion). Students who had been enrolled in other institutions prior to being enrolled in WVU had a highest mean of 4.05 for item 3 (other international students) followed by 3.92 for item 11 (instructors). Their lowest mean was 2.82 for item 6 (Office of Diversity \& Inclusion). This infers that other international students are the most helpful resource for both students 
who have no prior experience before enrolling in WVU, and students who have some years of experience before enrolling at WVU. The Office of Diversity, \& Inclusion is the least helpful resource for both groups. The $t$-test showed some statistical differences (Table 25). Students who had no prior experience had a mean of 3.38 for item 10 (staff), and students with prior experience had 3.88 for the same item, signifying that staff was a helpful resource to students who had some years of prior experience compared to students who had no experience. For item 11 (instructors), students with no experience had a mean of 3.38 while students with some years of prior experience had 3.92, implying that instructors were a more helpful to students with some prior experience than students with no experience.

Table 25. Responses to WVU Resources by Years of Prior Experience in the U.S.

\begin{tabular}{clccc}
\hline & \multicolumn{1}{c}{ Resources } & $\begin{array}{c}\text { No } \\
\text { Experience } \\
\text { Mean }\end{array}$ & $\begin{array}{c}\text { Some yrs } \\
\text { experience } \\
\text { Mean }\end{array}$ & P \\
\hline \hline 1 & International Student Organizations & 3.29 & 3.55 & 0.19 \\
2 & Academic Advisor or Major Professor & 3.63 & 3.88 & 0.20 \\
3 & Other International Students & 3.98 & 4.05 & 0.70 \\
4 & American Students & 3.06 & 3.47 & 0.05 \\
5 & Local Campus Groups & 2.82 & 2.86 & 0.82 \\
6 & Office of Diversity \& Inclusion & 2.66 & 2.82 & 0.39 \\
& International Students \& Scholars & & & \\
7 & Services & 3.20 & 3.57 & 0.07 \\
8 & Writing Studio & 2.69 & 3.01 & 0.11 \\
9 & Student Orientation & 3.17 & 3.33 & 0.41 \\
10 & Staff & 3.38 & 3.88 & $0.01^{*}$ \\
11 & Instructors & 3.38 & 3.92 & $0.00^{*}$ \\
\hline
\end{tabular}

Note. * Significant at $p<.05$

4.19 Resources and Age. The age of students was analyzed with resources (Table 26). Students below the age of 20 years had a highest mean of 4.33 for item 3 (other international students). They 
had 3.88 for item 4 (American students) and 3.87 for item 10 (staff). Their least mean was 3.15 for both item 6 (Office of Diversity \& Inclusion), and item 8 (Writing Studio) signifying that the most helpful resource to them is their fellow international students and the least helpful resource to them is the Office of Diversity \& Inclusion, and the Writing Studio. Students within the age of 21- 25 years had a highest mean of 3.98 for item 3 (other international students) followed by 3.81 for academic advisor and major professor and 3.77 for item 11 (instructors). Their least mean was 2.60 for item 6 (Office of Diversity \& Inclusion) implying that the most helpful resource to them was other international students and their least helpful resource was the Office of Diversity \& Inclusion. Students above the age of 26 years had a highest mean of 3.94 for item 3 (other international students), 3.82 for item 2 (academic advisor and major professor), and 3.80 for item 10 (staff). Their least mean was 2.76 for item 5 (local campus groups) showing that the most helpful resource to them was other international students and the least helpful resource to them was local campus groups. The One Factor ANOVA analysis (Table 26) showed some statistical differences for item 4, American students $(d f=2, F=5.82, p<.05)$. Students below the age of 20 years had a mean of 3.88 for this item whiles students between the ages of 21 and 25 years had 3.33, and students above the age of 26 years had 3.00. This infers that American students are a helpful resource to students below the age of 20 years compared to students between the ages of 21 and 25 years and students above the age of 26 years. The detailed ANOVA analysis is attached as Appendix L 
Table 26. ANOVA Analysis of Responses to WVU Resources and Respondent Age

\begin{tabular}{|c|c|c|c|c|c|c|c|c|c|c|}
\hline \multirow[b]{2}{*}{ No. } & \multirow[b]{2}{*}{ Resource } & \multicolumn{2}{|c|}{ Below 20yrs } & \multicolumn{2}{|c|}{$\begin{array}{l}\text { Between 21- } \\
25 y r s\end{array}$} & \multicolumn{2}{|c|}{ 26yrs and above } & \multirow[b]{2}{*}{$d f$} & \multirow[b]{2}{*}{$\mathbf{F}$} & \multirow[b]{2}{*}{$\boldsymbol{P}$} \\
\hline & & Mean & Variance & Mean & Variance & Mean & Variance & & & \\
\hline 1 & International Student Organizations & 3.80 & 1.19 & 3.38 & 1.89 & 3.38 & 1.44 & 2 & 1.78 & 0.17 \\
\hline 2 & Academic Advisor or Major Professor & 3.70 & 1.21 & 3.81 & 1.59 & 3.82 & 1.90 & 2 & 0.11 & 0.90 \\
\hline 3 & Other International Students & 4.33 & 0.84 & 3.98 & 1.33 & 3.94 & 1.38 & 2 & 1.71 & 0.18 \\
\hline 4 & American Students & 3.88 & 1.24 & 3.33 & 1.77 & 3.00 & 1.69 & 2 & 5.82 & $0.00 *$ \\
\hline 5 & Local Campus Groups & 3.20 & 1.65 & 2.74 & 1.37 & 2.76 & 1.36 & 2 & 2.30 & 0.10 \\
\hline 6 & Office of Diversity \& Inclusion & 3.15 & 1.72 & 2.60 & 1.63 & 2.80 & 1.41 & 2 & 2.71 & 0.07 \\
\hline & International Students \& Scholars & & & & & & & & & \\
\hline 7 & Services & 3.43 & 1.64 & 3.46 & 1.75 & 3.44 & 1.48 & 2 & 0.01 & 0.99 \\
\hline 8 & Writing Studio & 3.15 & 2.03 & 2.71 & 1.62 & 3.02 & 1.40 & 2 & 2.10 & 0.13 \\
\hline 9 & Student Orientation & 3.38 & 1.57 & 3.12 & 1.62 & 3.44 & 1.39 & 2 & 1.40 & 0.25 \\
\hline 10 & Staff & 3.87 & 1.17 & 3.58 & 1.52 & 3.80 & 1.05 & 2 & 1.25 & 0.29 \\
\hline 11 & Instructors & 3.74 & 1.30 & 3.77 & 1.32 & 3.68 & 1.39 & 2 & 0.12 & 0.89 \\
\hline
\end{tabular}

Note. * Significant at $p<.05$

4.20 Level of Class. The resources utilized by students was analyzed with their level of class of (undergraduates/undergraduates).

The highest mean for undergraduate students was 4.01 for item 3 (other international students) followed by 3.71 for item 10 (staff) and 3.66 for item 11 (instructors). The lowest mean for undergraduate students was 2.90 for item 6 (office of Diversity \& Inclusion). The highest mean for graduate students was 4.06 for item 3 (other international students) and their least mean was 2.66 for item 6 (Office of Diversity \& Inclusion). This signifies that other international students are the most helpful resource for both graduate and undergraduate 
students, whiles the Office of Diversity \& Inclusion is the least helpful resource for both groups (Figure 15). However, the $t$-test computed no statistical differences between groups.

\section{Figure 15. Response Means for WVU Resources and Level of Class}

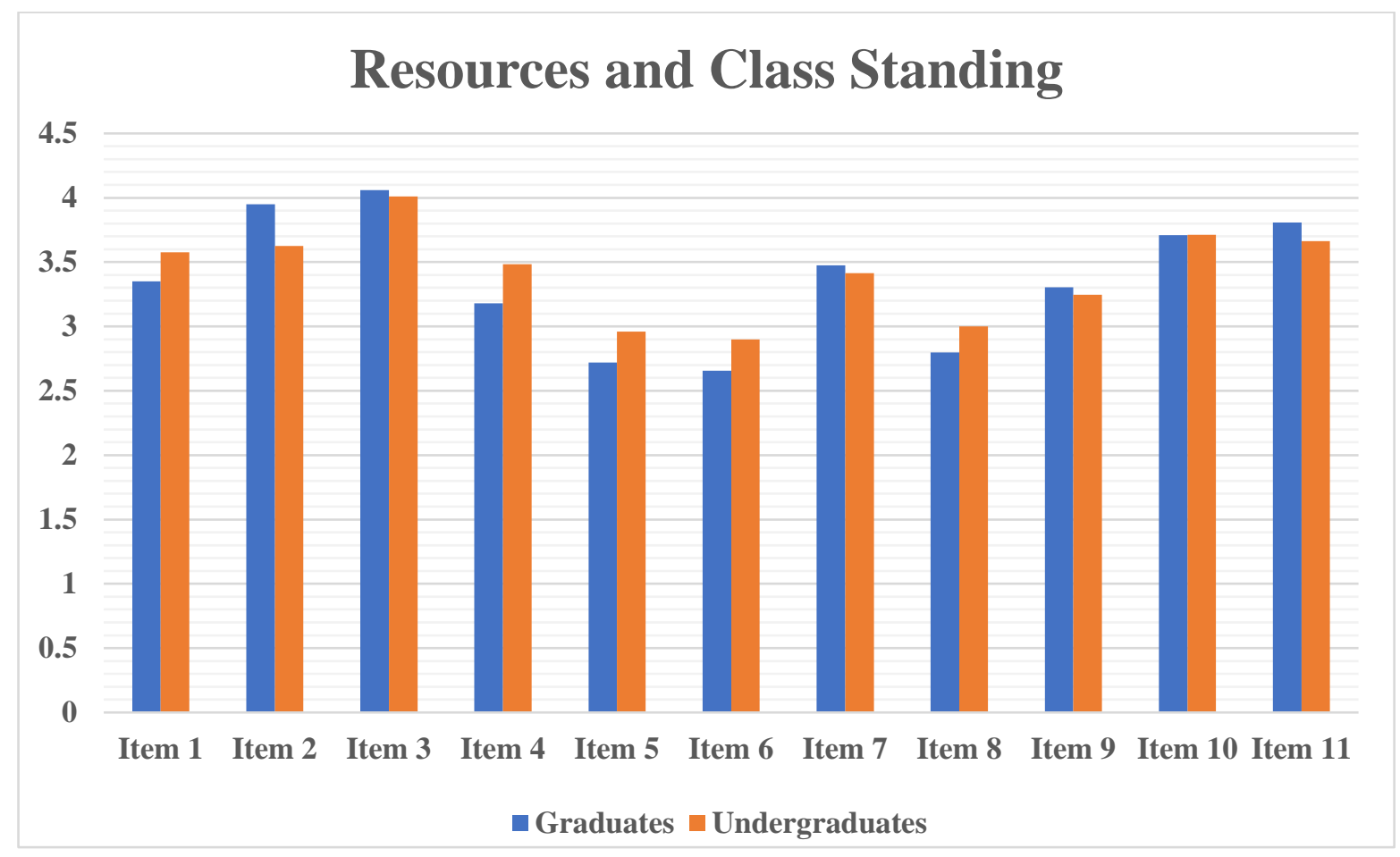

The $t$-test computed confirmed no statistical differences.

4.21 Number of Years Enrolled at WVU. The number of years a student has been enrolled at WVU was analyzed with the resources utilized by students. Students who had been enrolled for less than 1 year had a highest mean of 4.06 for item 3 (other international students) and a least mean of 2.85 for item 6 (Office of Diversity and Inclusion). Students who had been enrolled within 1 and 3 years had a highest mean of 3.88 for item 3 (other international students) and a least mean of 2.50 for item 5 (campus groups). 
Students who had been enrolled for 3 years and above had a highest mean of 4.21 for item 3 (other international students) and a lowest mean of 2.68 for item 6(Office of Diversity \& Inclusion). This analysis denotes that other international students is the most helpful resource for students in all the groups, and the least helpful resource for students enrolled less than 1 year, and 3 years and above is the Office of Diversity and Inclusion. For students enrolled within 1 and 3 years, local campus groups are the least helpful resource to them. The One Factor ANOVA test (Table 27) showed some statistical differences. Item 5, local campus groups had a statistical difference ( $d f=2, F=3.46, p<.05)$. The mean for students enrolled for less than 1 year for that item was 2.99, students enrolled within 1 and 3 years had a mean of 2.50, and students enrolled 3 years and above had a mean of 3.00. This implies that local campus groups were least helpful to students enrolled within 1 and 3 years as compared to students enrolled 3 years and above, and students enrolled less than 1 year. A complete ANOVA analysis is attached as Appendix M. 
Table 27. Responses to WVU Resources based upon the Number of Years Enrolled at WVU

\begin{tabular}{|c|c|c|c|c|c|c|c|c|c|c|}
\hline \multirow[b]{2}{*}{ No. } & \multirow[b]{2}{*}{ Resource } & \multicolumn{2}{|c|}{ Less than 1 yr } & \multicolumn{2}{|c|}{ 1-3 yrs } & \multicolumn{2}{|c|}{3 yrs and Above } & \multirow[b]{2}{*}{$d f$} & \multirow[b]{2}{*}{$\mathbf{f}$} & \multirow[b]{2}{*}{$p$} \\
\hline & & Mean & Variance & Mean & Variance & Mean & Variance & & & \\
\hline 1 & International Student Organizations & 3.63 & 1.59 & 3.38 & 1.51 & 3.23 & 1.71 & 2 & 1.70 & 0.18 \\
\hline 2 & Academic Advisor or Major Professor & 3.90 & 1.45 & 3.64 & 1.72 & 3.72 & 1.79 & 2 & 0.83 & 0.44 \\
\hline 3 & Other International Students & 4.06 & 1.22 & 3.88 & 1.60 & 4.21 & 0.90 & 2 & 1.04 & 0.36 \\
\hline 4 & American Students & 3.54 & 1.69 & 3.18 & 1.86 & 3.08 & 1.49 & 2 & 2.46 & 0.09 \\
\hline 5 & Local Campus Groups & 2.99 & 1.47 & 2.50 & 1.16 & 3.00 & 1.58 & 2 & 3.46 & $0.03 *$ \\
\hline 6 & $\begin{array}{l}\text { Office of Diversity \& Inclusion } \\
\text { International Students \& Scholars }\end{array}$ & 2.85 & 1.66 & 2.68 & 1.39 & 2.68 & 1.79 & 2 & 0.43 & 0.65 \\
\hline 7 & Services & 3.54 & 1.56 & 3.45 & 1.71 & 3.31 & 1.48 & 2 & 0.49 & 0.62 \\
\hline 8 & Writing Studio & 2.90 & 1.77 & 2.68 & 1.46 & 3.21 & 1.59 & 2 & 1.94 & 0.15 \\
\hline 9 & Student Orientation & 3.36 & 1.71 & 3.15 & 1.27 & 3.28 & 1.58 & 2 & 0.52 & 0.59 \\
\hline 10 & Staff & 3.84 & 1.27 & 3.44 & 1.19 & 3.85 & 1.34 & 2 & 2.44 & 0.09 \\
\hline 11 & Instructors & 3.88 & 1.17 & 3.63 & 1.29 & 3.62 & 1.72 & 2 & 1.23 & 0.30 \\
\hline
\end{tabular}

Note. * Significant at $p<.05$ 


\subsection{Other Resources}

From the international student survey, students were asked (question 4) if there were other resources that WVU provides which they utilize to cope or adjust as international students. Out of the total responses, $43(21 \%)$ responded Yes and 158(79\%) responded No. Out of those who responded Yes, $24(56 \%)$ were females, and 19 (44\%) were males, and out of those who responded No, 78 (51\%) were females, and 75 (49\%) were males (Figure 16). There were no statistical differences between males and females.

Other resources provided by WVU that students used to adjust as reported in question 4a. of the survey is presented below.

\section{Figure 16. Other Resources that Students Use to Adjust}

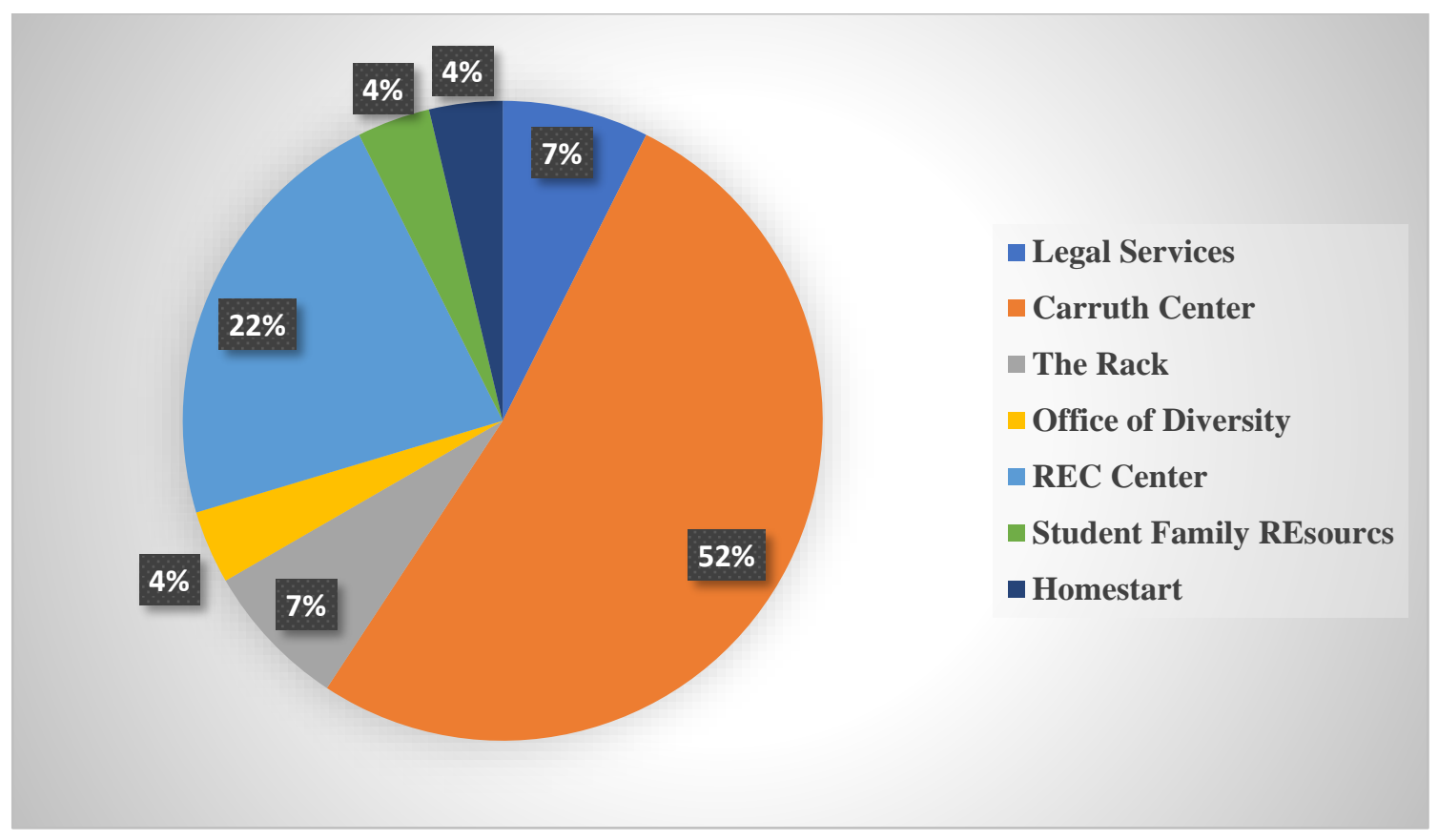

As indicated in Figure 17, the most utilized resource by students is the Carruth Center for Psychological and Psychiatric Services, the student recreation center is the second most utilized resource by students. The Rack Food Pantry, WVU Legal Services, the International Home-Start Closet, and WVU student's family resources are some of the resources students utilize to adjust. A complete list of resources 
utilized by students is attached as Appendix N. When asked in question 5a. if there were other resources outside WVU that students utilized to adjust, 128 (63\%) responded Yes, and 74 (34\%) responded No.

Students listed several resources outside WVU that they utilized to adjust. Most of the students (83\%) explained that family and friends were the most helpful and most utilized resources outside of WVU that helps them to adjust (Figure 18), church or religion was the second (10\%) most helpful resource. Other resources (7\%) students utilized to adjust were student groups such as Chi Alpha, Mocha Mama's of Morgantown group (Community group of women of color), and WVU athletics department. A complete list of the resources indicated by the students is attached in Appendix O. A summary of resources outside of WVU that students utilized to cope are presented in the figure below.

Figure 17. Resources Outside of WVU that Students Utilize to Adjust at WVU

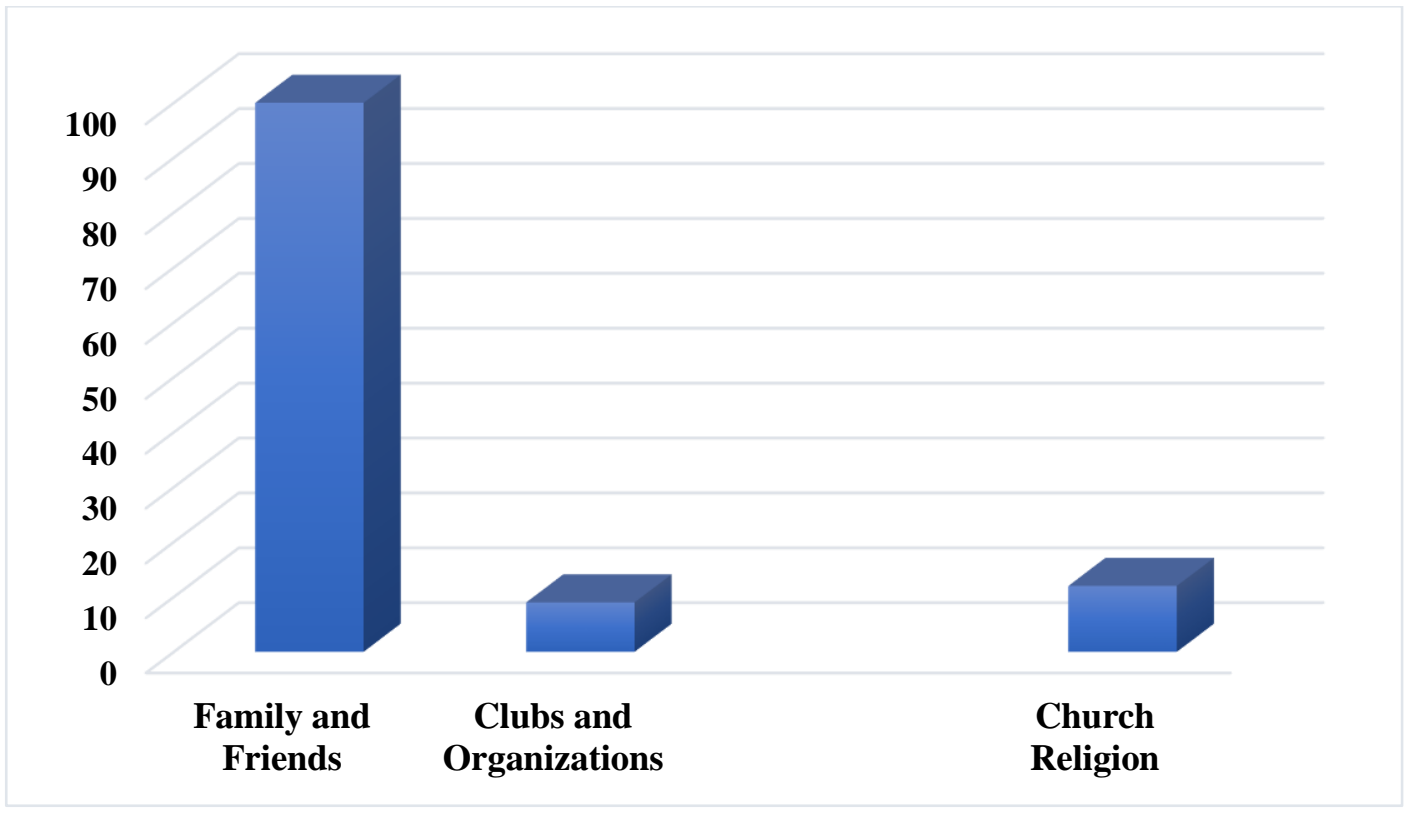

Question 6 of the survey asked if students had family or friends (or both) in the U.S. before enrolling at WVU. Of the 202 students who responded, 88 (44\%) said Yes, and 114(56\%) said No. When asked in question 7 if family/friends helped them adjust at WVU, 48 (43\%) responded No, and 63 (57\%) 
responded Yes. Students went further to explain how their engagement with available resources (family, church, friends, etc.) had helped them to cope or adjust.

\section{Table 28. Summary Responses of How Families/Friends Helped International Students to Adjust}

\begin{tabular}{|l|l|}
\hline General orientation to state and WVU & Finding a place to live \\
\hline Financial support and advice & Moral support \\
\hline $\begin{array}{l}\text { Finding accommodation, advisor choice, } \\
\text { linking to available resources, stress } \\
\text { management }\end{array}$ & $\begin{array}{l}\text { Explaining the condition of Morgantown and } \\
\text { the culture here to me before I came }\end{array}$ \\
\hline Home cooked food & $\begin{array}{l}\text { Gave me confidence and assurance every step } \\
\text { of the way }\end{array}$ \\
\hline $\begin{array}{l}\text { I am a graduate student here at WVU. I did } \\
\text { my undergrad at Purdue. Purdue made it } \\
\text { much easier to assimilate and build that } \\
\text { support system of friends. At WVU I haven't } \\
\text { seen much efforts to help international } \\
\text { students assimilate. I think there is a lot of } \\
\text { room for improvement }\end{array}$ & $\begin{array}{l}\text { Accommodated me and helped me find an } \\
\text { apartment }\end{array}$ \\
\hline $\begin{array}{l}\text { They helped me to adapt the new culture and } \\
\text { gave me tips to blend in }\end{array}$ & $\begin{array}{l}\text { Helping with the basics such as phone } \\
\text { number, apartment search, furniture, class } \\
\text { registration, etc. }\end{array}$ \\
\hline $\begin{array}{l}\text { Gave advice, helped me through rough times } \\
\text { Explain the culture of USA and bring me } \\
\text { around WVU }\end{array}$ \\
\hline $\begin{array}{l}\text { Guidance } \\
\text { Explaining to me the star system and credits, } \\
\text { helping me to enroll at first. }\end{array}$ & $\begin{array}{l}\text { Finding housing, explaining the system available for questions and } \\
\text { accommodation }\end{array}$ \\
\hline They made it feel like home & \begin{tabular}{l} 
Orientation and assistance with settling down \\
\hline
\end{tabular} \\
\hline
\end{tabular}

Most students explained that their families and friends helped them find accommodations and explained American culture to them which helped reduce culture shock. Some also explained that their 
families and friends gave them an orientation, provided emotional support and practical advice. Some of the responses are presented in Table 28 above. A complete table of responses is attached in Appendix P.

In question 8 , students were asked a single Likert-Scale question about how engaged they are with their families and friends. Most of the students (59-45\%) expressed that they were very engaged with their families and friends (Figure 18). Forty (31\%) were engaged and $26(20 \%)$ were neutral. Only a few (6-4\%) were rarely engaged with their families.

\section{Figure 18. International Students Engagement with Family and Fiends}

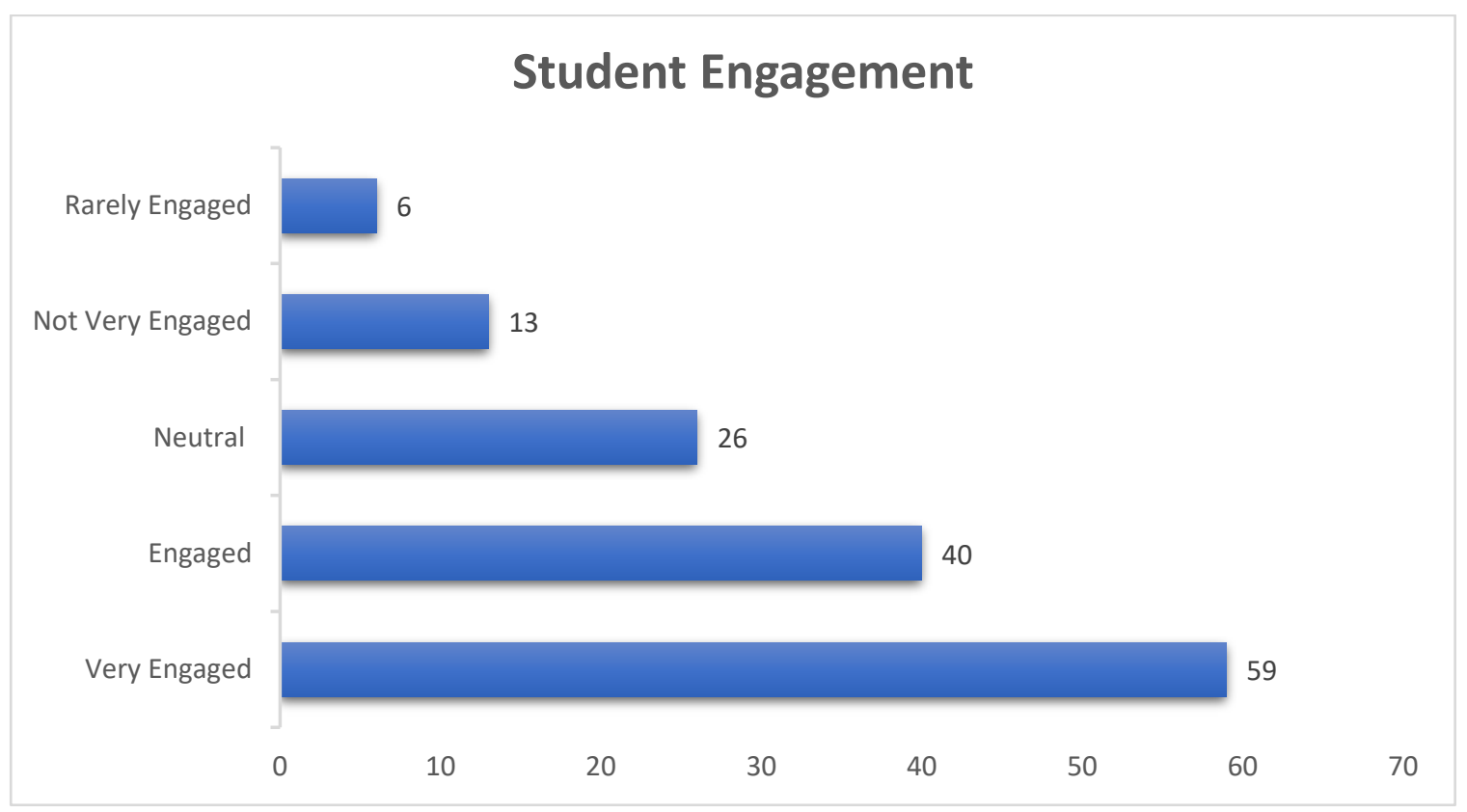

Student engagement with families and friends was also analyzed with gender (Figure 19). Males were very engaged (29) with their families and friends compared to females (27). Females were engaged (22) than males (18). Females were rarely engaged (4) as compared to males (2). 


\section{Figure 19. Engagement with Families/Friends by Gender}

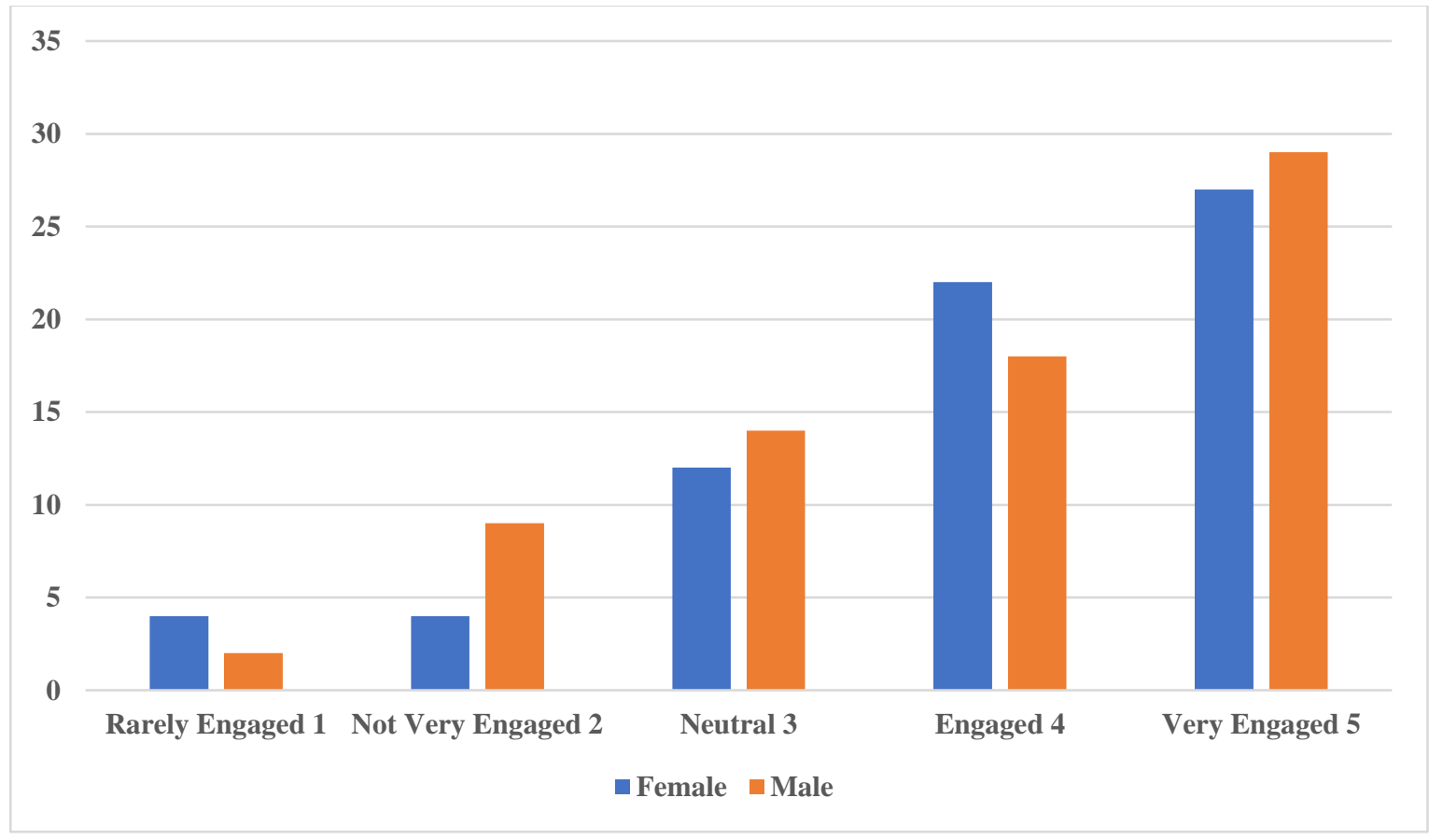

In investigating other resources apart from family and friends that students utilized to adjust, question 9 asked students to describe any other resources that helped them to cope. Students described other resources such as pets, work, sports and recreational activities. A summary of their responses is presented in table 29 and a complete list of their responses is attached as Appendix Q. 
Table 29. Other Resources Apart From family and Friends Used to Adjust

\begin{tabular}{|c|c|}
\hline $\begin{array}{l}\text { Sports and Recreation } \\
\text {-Swimming and go to sport events } \\
\text { •Extracurricular activities } \\
\text {-Hobbies! Sport } \\
\text {-Working out in the gym every night } \\
\text { - Going to the gym, being in WVU clubs }\end{array}$ & $\begin{array}{l}\text { Pets and Social Services } \\
\text { •Animals } \\
\text { •Music, books, and video games } \\
\text { • Volunteering } \\
\text { - Keeping in touch with some pets from other } \\
\text { students } \\
\text { •My dog } \\
\text { • Friendly community activities by the } \\
\text { university. }\end{array}$ \\
\hline $\begin{array}{l}\text {-Myself } \\
\text { • Endurance and focus } \\
\text { •Internet and physical activity } \\
\text {-Me time, my social environment } \\
\text { - Netflix } \\
\text { - My dreams and aspiration push me to do } \\
\text { more. } \\
\text { - My dedication towards getting the degree } \\
\text { and my parents } \\
\text {-Perseverance } \\
\text {-School work and goals } \\
\text {-Previous experience in international schools } \\
\text {-Strong will, determination } \\
\text { - Knowing that I came here for a dream to } \\
\text { seek my education } \\
\text { - The desire to graduate at USA university } \\
\text { - Breathing techniques } \\
\text { Think and analyze }\end{array}$ & $\begin{array}{l}\text {-Talking to family over FaceTime. Getting } \\
\text { help with tax, and people reaching out } \\
\text {-Phone calls with my family abroad. } \\
\text { • Church group, family friendly community } \\
\text { activities by the university. } \\
\text {-Spending time with friends from my same } \\
\text { country } \\
\text { - Other international students } \\
\text {-Playing video games with friends } \\
\text {-American people are the nicest people! I } \\
\text { wouldn't live without my friends here }\end{array}$ \\
\hline
\end{tabular}


A greater portion of the students $(27 \%)$ explained that the most useful resource that helped them to cope was themselves (Figure 20). Family and friends were the second most utilized resource (25\%) followed by sports and recreation (23\%). Nine percent used pets and social services and $5 \%$ used church and work.

Figure 20. Other Resources Used to Adjust

\section{Other Resources Used to Adjust}

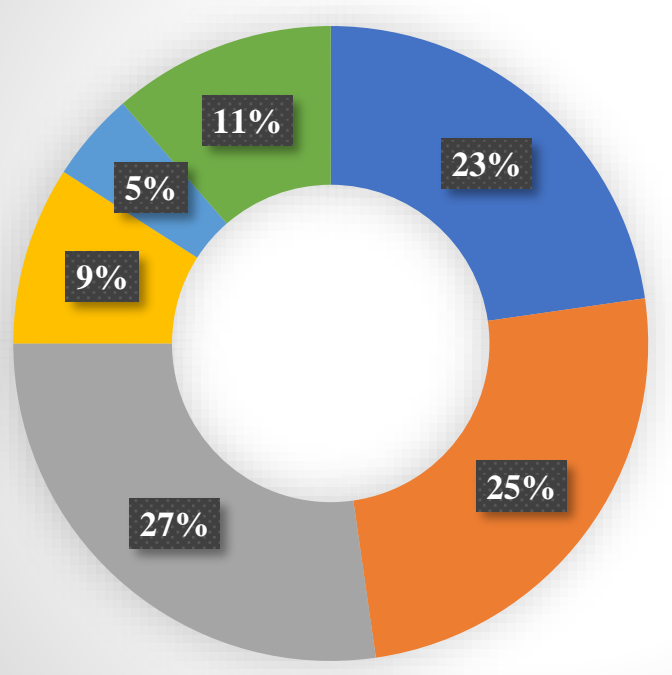

- Sports and Recreation

- Family and Friends

$\square$ Self

- Pets and Services

m Church and Work

nothers

\subsection{Informal Conversations.}

During the informal conversations, students described some resources that helped them to adjust.

Families and friends were the most helpful resource. Some students went further to explain that even though their families were thousands of miles away, social media platforms such as Facetime, and WhatsApp helped in communicating with their families at any time without incurring extra costs. Other international students who had been at WVU longer helped them significantly to adjust by showing them around campus and available resources. These students told them of the challenges they had encountered 
in the past helping them avoid or repeating the same challenges. Knowing that these students were there for them any time they encountered any challenge and practically helping them out was a tremendous help. Church family and friends, and other religious groups was another helpful resource to international students as these became their families here in Morgantown.

\subsection{Comparison of Challenges and Resources.}

After the statistical analysis of all the data, the results from the challenges were compared with that of the resources by $\mathrm{Chi}^{2}$ using Stata. The 24 challenges were categorized into 8 problem areas (category 1-admission selection problems, category 2-orientation service problems, category 3social/personal problems, category 4-financial aid problems, category 5-English language problems, category 6-immigration regulations, category 7-religious service problems, and category 8 - health service problems). The eleven resources were also put into 8 categories to correspond with the category of challenges (Table 30). $\mathrm{Chi}^{2}$ was used because we were comparing results in the eight categories of the resources and challenges and $\mathrm{Chi}^{2}$ is appropriate when you have two categorical variables. It is useful in determining whether there is a significant association or relationship between the two variables. It was important to test for independence between perception of students challenges and the ratings of the helpfulness of the resources because it will help in determining whether the resources available to students were unhelpful and probably lead to the challenges students encountered or the students encountered the challenges by chance. 
Table 30. Category of Challenges and Corresponding Resources

Admission Selection Problems (Cat.1)

1. Differences between U.S. and Home Country

Education System

\section{Orientation to WVU}

3. Relationship with international student advisor

\section{Orientation Service Problems (Cat.2)}

1. Attitude of some students towards international students

2. Attitude of some U.S. citizens to skin color

3. Relationship between faculty and students

\section{Social/Personal Problems (Cat.3)}

1.Treatment received at social functions

2. Being accepted in social groups

3. Insufficient personal- social counseling

Financial Aid problems (Cat.4)

1 Unexpected financial need.

2.Finding employment between semesters

3.Lack of money to meet expenses

\section{English Language Problems (Cat.5)}

1. Speaking English

2. Ability to write English

3. Understanding lectures in English

Immigration Regulations (Cat.6)

1. Immigration regulations

2. Immigration work restrictions

3. Finding part time work

\section{Religious Service Problems (Cat.7)}

1. Finding a worship group of own faith

2. Religion and morals in the U.S

3. Religious practices in U.S

\section{Health Service Problems (Cat 8)}

1. Finding adequate health services

2. Dietary problems

3. Feeling stressed

\section{Admission Selection Resources (Cat.1)}

Student Orientation

\section{Staff}

Instructors

Academic Advisor or Major Professor

\author{
Social/Personal Resources (Cat.3) \\ American Students \\ Other International Students
}

Financial Aid Resources (Cat. 4)

International Student Organizations

English Language Resources (Cat.5)

Writing Studio

Immigration Regulations Resources (Cat.6)

International Students \& Scholars Services

Religious Service Resource (Cat. 7)

Office of Diversity \& Inclusion

Health Service Resource (Cat.8)

Local Campus Groups 
The results of the eight categories of challenges and resources are compared and analyzed below.

The ratings of the perception of challenges, and the ratings of the helpfulness of the resources for the Chi ${ }^{2}$ analysis are;

\begin{tabular}{|l|l|}
\hline Ratings of the perception of challenges & Ratings of the helpfulness of the resources \\
\hline $1=$ No challenge/Much easier than expected & $1=$ Helpful \\
\hline $2=$ Neutral, & $2=$ Neutral \\
\hline $3=$ Greater than expected & $3=$ Not helpful \\
\hline
\end{tabular}

From Table 31, the Pearson $\mathrm{Chi}^{2}$ was 1.6180 with a statistically non-significant value of $\mathrm{p}=$ 0.806 indicating that there was no association between a student's perception of the admission selection challenge and the resource. The helpfulness of the resource had no impact on the challenges students encountered in this category.

Table 31. Chi ${ }^{2}$ Table of Challenges and Resources for Category 1- Admission Selection

\begin{tabular}{|c|c|c|c|c|}
\hline \multirow{2}{*}{$\begin{array}{l}\text { Perception of Challenge. } \\
\text { (Differences between U.S. } \\
\text { and Home Country } \\
\text { Education System, } \\
\text { Orientation to WVU, } \\
\text { Relationship with } \\
\text { international student } \\
\text { advisor) }\end{array}$} & \multicolumn{4}{|c|}{ Helpfulness of the Resource (Student Orientation) } \\
\hline & Helpful & Neutral & Not Helpful & Total \\
\hline $\begin{array}{l}\text { No Challenge } \\
\text { Neutral } \\
\text { Greater than Expect }\end{array}$ & $\begin{array}{c}19 \\
(17.7) \\
23 \\
(23.0) \\
40 \\
(41.2) \\
\end{array}$ & $\begin{array}{c}13 \\
(11.7) \\
13 \\
(15.2) \\
28 \\
(27.1) \\
\end{array}$ & $\begin{array}{c}8 \\
(10.6) \\
16 \\
(13.8) \\
25 \\
(24.6) \\
\end{array}$ & $\begin{array}{c}40 \\
(40.0) \\
52 \\
(52.0) \\
93 \\
(93.0) \\
\end{array}$ \\
\hline Total & $\begin{array}{c}82 \\
(82.0) \\
\end{array}$ & $\begin{array}{c}54 \\
(54.0)\end{array}$ & $\begin{array}{c}49 \\
(49.0) \\
\end{array}$ & $\begin{array}{c}185 \\
(185.0)\end{array}$ \\
\hline \multicolumn{5}{|c|}{$\begin{array}{l}\text { Expected Values in Parentheses } \\
\text { Pearson chi } 2(4)=1.6180 \\
\operatorname{Pr}=\mathbf{0 . 8 0 6}\end{array}$} \\
\hline
\end{tabular}


The Pearson $\mathrm{Chi}^{2}$ of 83.5141 with a statistically significant value of $\mathrm{p}=0.000$ shows that there is an association between the perception of orientation service challenges and the helpfulness of the resource (Staff, Instructors, Academic Advisor or Major Professor) (Table 32). The actual number of responses of students who experienced greater challenges with orientation service and yet found the orientation resource as helpful was 90 which is much higher than the expected responses (72.5). This suggests that the helpfulness of Staff, Instructors, Academic Advisor or Major Professor did not prevent students from experiencing challenges with Differences between U.S. and Home Country Education System, Orientation to WVU, and Relationship with international student advisor. It can again be observed from Table 32 that the number of actual students who had no challenges with orientation service and found the orientation service as not helpful was significantly higher (20) than the expected number of students (5.1). This reiterates the unhelpfulness of the resource.

Table 32. Chi ${ }^{2}$ Table of Challenges and Resources for Category 2- Orientation Service

\begin{tabular}{|c|c|c|c|c|}
\hline \multirow{2}{*}{$\begin{array}{l}\text { Perception of Challenge. } \\
\text { (Attitude of some students } \\
\text { towards international } \\
\text { students, } \\
\text { Attitude of some U.S. } \\
\text { citizens to skin color, } \\
\text { Relationship between } \\
\text { faculty and students) }\end{array}$} & \multicolumn{4}{|c|}{$\begin{array}{l}\text { Helpfulness of the Resource (Staff, Instructors, Academic } \\
\text { Advisor or Major Professor) }\end{array}$} \\
\hline & Helpful & Neutral & Not Helpful & Total \\
\hline No Challenge & $\begin{array}{c}16 \\
(23.9)\end{array}$ & $\begin{array}{c}0 \\
(6.9)\end{array}$ & $\begin{array}{c}20 \\
(5.1)\end{array}$ & $\begin{array}{c}36 \\
(36.0)\end{array}$ \\
\hline Neutral & $\begin{array}{c}25 \\
(34.6)\end{array}$ & $\begin{array}{c}19 \\
(10.0)\end{array}$ & $\begin{array}{c}8 \\
(7.4)\end{array}$ & $\begin{array}{c}52 \\
(52.0)\end{array}$ \\
\hline Greater than Expect & $\begin{array}{c}90 \\
(72.5)\end{array}$ & $\begin{array}{c}19 \\
(21.0)\end{array}$ & $\begin{array}{c}0 \\
(15.5)\end{array}$ & $\begin{array}{c}109 \\
(109.0)\end{array}$ \\
\hline Total & $\begin{array}{c}131 \\
(131.0)\end{array}$ & $\begin{array}{c}38 \\
(38.0)\end{array}$ & $\begin{array}{c}28 \\
(28.0)\end{array}$ & $\begin{array}{c}197 \\
(197.0)\end{array}$ \\
\hline \multicolumn{5}{|c|}{$\begin{array}{l}\text { Expected Values in Parentheses } \\
\text { Pearson chi2 } 2(4)=83.5141 \\
\operatorname{Pr}=\mathbf{0 . 0 0 0}\end{array}$} \\
\hline
\end{tabular}


From Table 33, there was a significant relationship between the perception of social/personal challenges (Treatment received at social functions, Being accepted in social groups, Insufficient personalsocial counseling) and the helpfulness of social/ personal resources (American Students, Other International Students) with a Pearson $\mathrm{chi}^{2}$ of 23.4283 and a statistically significant value of $\mathrm{p}=0.000$. The expected number of responses between the greater challenges that students experienced and helpfulness of the resource (67.7) was much lower than the actual number of responses (78). This shows that helpfulness of social/personal resources (American Students, Other International Students) was not enough to prevent students from experiencing greater challenges with Treatment received at social functions, being accepted in social groups, and insufficient personal- social counseling.

\section{Table 33. Chi ${ }^{2}$ Table of Challenges and Resources for Category 3-Social/personal}

\begin{tabular}{|c|c|c|c|c|}
\hline \multirow{2}{*}{$\begin{array}{l}\text { Perception of Challenge } \\
\text { (Treatment received at } \\
\text { social functions, being } \\
\text { accepted in social groups, } \\
\text { Insufficient personal- social } \\
\text { counseling) }\end{array}$} & \multicolumn{4}{|c|}{$\begin{array}{l}\text { Helpfulness of the Resource (American Students, Other } \\
\text { International Students) }\end{array}$} \\
\hline & Helpful & Neutral & Not Helpful & Total \\
\hline No Challenge & $\begin{array}{c}17 \\
(23.5)\end{array}$ & $\begin{array}{c}7 \\
(7.2)\end{array}$ & $\begin{array}{c}10 \\
(3.3)\end{array}$ & $\begin{array}{c}34 \\
(34.0)\end{array}$ \\
\hline Neutral & $\begin{array}{c}39 \\
(42.8)\end{array}$ & $\begin{array}{c}17 \\
(13.1)\end{array}$ & $\begin{array}{c}6 \\
(6.1)\end{array}$ & $\begin{array}{c}62 \\
(62.0)\end{array}$ \\
\hline Greater than Expect & $\begin{array}{c}78 \\
(67.7)\end{array}$ & $\begin{array}{c}17 \\
(20.7)\end{array}$ & $\begin{array}{c}3 \\
(9.6)\end{array}$ & $\begin{array}{c}98 \\
(98.0)\end{array}$ \\
\hline Total & $\begin{array}{c}134 \\
(134.0) \\
\end{array}$ & $\begin{array}{c}41 \\
(41.0) \\
\end{array}$ & $\begin{array}{c}19 \\
(19.0) \\
\end{array}$ & $\begin{array}{c}194 \\
(194.0) \\
\end{array}$ \\
\hline \multicolumn{5}{|l|}{$\begin{array}{l}\text { Expected Values in Parenthes } \\
\text { Pearson chi2 } 2(4)=23.4283 \\
\mathbf{P r}=\mathbf{0 . 0 0 0}\end{array}$} \\
\hline
\end{tabular}


Table 34 shows a Pearson chi $^{2}$ of 8.1254 and a non-statistically significant value of $\mathrm{p}=0.087$ which indicates that the perception of financial aid challenges was not dependent on the helpfulness of financial aid resources. Students expectations of the challenge may have been higher than their actual experience.

Table 34. $\mathrm{Chi}^{2}$ Table of Challenges and Resources for Category 4- Financial Aid

\begin{tabular}{|c|c|c|c|c|}
\hline \multirow{2}{*}{$\begin{array}{l}\text { Perception of Challenge } \\
\text { (Unexpected financial } \\
\text { need., Finding employment } \\
\text { between semesters, Lack of } \\
\text { money to meet expenses) }\end{array}$} & \multicolumn{4}{|c|}{$\begin{array}{l}\text { Helpfulness of the Resource (International Student } \\
\text { Organizations) }\end{array}$} \\
\hline & Helpful & Neutral & Not Helpful & Total \\
\hline No Challenge & $\begin{array}{c}24 \\
(32.0)\end{array}$ & $\begin{array}{c}15 \\
(14.0)\end{array}$ & $\begin{array}{c}21 \\
(14.0)\end{array}$ & $\begin{array}{c}60 \\
(60.0)\end{array}$ \\
\hline Neutral & $\begin{array}{c}42 \\
(37.9)\end{array}$ & $\begin{array}{c}16 \\
(16.6)\end{array}$ & $\begin{array}{c}13 \\
(16.6)\end{array}$ & $\begin{array}{c}71 \\
(71.0)\end{array}$ \\
\hline Greater than Expect & $\begin{array}{c}37 \\
(33.1)\end{array}$ & $\begin{array}{c}14 \\
(14.5)\end{array}$ & $\begin{array}{c}11 \\
(14.5)\end{array}$ & $\begin{array}{c}62 \\
(62.0)\end{array}$ \\
\hline Total & $\begin{array}{c}103 \\
(103.0)\end{array}$ & $\begin{array}{c}45 \\
(45.0)\end{array}$ & $\begin{array}{c}45 \\
(45.0)\end{array}$ & $\begin{array}{c}193 \\
(193.0)\end{array}$ \\
\hline \multicolumn{5}{|c|}{$\begin{array}{l}\text { Expected Values in Parentheses } \\
\text { Pearson chi2(4) = 8.1254 } \\
\mathbf{P r}=\mathbf{0 . 0 8 7}\end{array}$} \\
\hline
\end{tabular}

There was a non-significant relationship between the perception of English language problems and the helpfulness of the resource (Table 35) with a Pearson chi ${ }^{2}$ of 6.0172 and a statistically nonsignificant value of $p=0.198$. This signifies that there was no association between the perception of the English language challenges experienced by students and the helpfulness of the resource. 
Table 35. Chi $^{2}$ Table of Challenges and Resources for Category 5- English Language

\begin{tabular}{|l|c|c|c|c|}
\hline $\begin{array}{l}\text { Perception of Challenge. } \\
\text { (Speaking English, Ability to } \\
\text { write English, Understanding } \\
\text { lectures in English) }\end{array}$ & \multicolumn{5}{|l|}{ Helpfulness of the Resource (Writing Studio) } \\
\hline & Helpful & Neutral & Not Helpful & Total \\
\hline No Challenge & 7 & 15 & 12 & 34 \\
& $(11.3)$ & $(11.8)$ & $(10.9)$ & $(34.0)$ \\
Neutral & 15 & 14 & 20 & 49 \\
& $(16.2)$ & $(17.0)$ & $(15.7)$ & $(49.0)$ \\
Greater than Expect & 42 & 38 & 30 & 110 \\
& $(36.5)$ & $(38.2)$ & $(35.3)$ & $(110.0)$ \\
\hline Total & 64 & 67 & 62 & $(193.0)$ \\
\hline $\begin{array}{l}\text { Expected Values in Parentheses } \\
\text { Pearson chi2(4) = 6.0172 } \\
\text { Pr }=\mathbf{0 . 1 9 8}\end{array}$ & $(64.0)$ & $(67.0)$ & & \\
\hline
\end{tabular}

Table 36. $\mathrm{Chi}^{2}$ Table of Challenges and Resources for Category 6- Immigration Regulations

\begin{tabular}{|c|c|c|c|c|}
\hline \multirow{2}{*}{$\begin{array}{l}\text { Perception of Challenge } \\
\text { (Immigration regulations, } \\
\text { Immigration work } \\
\text { restrictions, Finding part time } \\
\text { work) }\end{array}$} & \multicolumn{4}{|c|}{$\begin{array}{l}\text { Helpfulness of the Resource (International Students \& Scholars } \\
\text { Services) }\end{array}$} \\
\hline & Helpful & Neutral & Not Helpful & Total \\
\hline No Challenge & $\begin{array}{c}30 \\
(33.9)\end{array}$ & $\begin{array}{c}16 \\
(15.5)\end{array}$ & $\begin{array}{c}17 \\
(13.6)\end{array}$ & $\begin{array}{c}63 \\
(63.0)\end{array}$ \\
\hline Neutral & $\begin{array}{c}28 \\
(32.8)\end{array}$ & $\begin{array}{c}19 \\
(15.0)\end{array}$ & $\begin{array}{c}14 \\
(13.1)\end{array}$ & $\begin{array}{c}61 \\
(61.0)\end{array}$ \\
\hline Greater than Expect & $\begin{array}{c}47 \\
(38.2)\end{array}$ & $\begin{array}{c}13 \\
(17.5)\end{array}$ & $\begin{array}{c}11 \\
(15.3)\end{array}$ & $\begin{array}{c}71 \\
(71.0)\end{array}$ \\
\hline Total & $\begin{array}{c}105 \\
(105.0)\end{array}$ & $\begin{array}{c}48 \\
(48.0)\end{array}$ & $\begin{array}{c}42 \\
(42.0)\end{array}$ & $\begin{array}{c}195 \\
(195.0)\end{array}$ \\
\hline \multicolumn{5}{|l|}{$\begin{array}{l}\text { Expected Values in Parentheses } \\
\text { Pearson chi2 }(4)=7.5287 \\
\operatorname{Pr}=0.110\end{array}$} \\
\hline
\end{tabular}


Based on Table 36, there is an insignificant relationship between the perception of immigration challenges and the helpfulness of immigration resources with a Pearson chi ${ }^{2}$ of 7.5287 and a statistically non-significant value of $p=0.110$. This suggests that the perception of immigration challenges is independent of the resources, indicating that students' challenges experienced with immigration had no association of the helpfulness of the resources.

\section{Table 37. Chi ${ }^{2}$ Table of Challenges and Resources for Category 7- Religious Services}

\begin{tabular}{|c|c|c|c|c|}
\hline \multirow{2}{*}{$\begin{array}{l}\text { Perception of Challenge } \\
\text { (Finding a worship group of } \\
\text { own faith, Religion and } \\
\text { morals in the U. S, Religious } \\
\text { practices in U.S) }\end{array}$} & \multicolumn{4}{|c|}{ Helpfulness of the Resource (Office of Diversity and Inclusion) } \\
\hline & Helpful & Neutral & Not Helpful & Total \\
\hline No Challenge & $\begin{array}{c}5 \\
(16.4)\end{array}$ & $\begin{array}{c}22 \\
(20.0)\end{array}$ & $\begin{array}{c}31 \\
(21.6)\end{array}$ & $\begin{array}{c}58 \\
(58.0)\end{array}$ \\
\hline Neutral & $\begin{array}{c}18 \\
(20.1)\end{array}$ & $\begin{array}{c}24 \\
(24.5)\end{array}$ & $\begin{array}{c}29 \\
(26.4)\end{array}$ & $\begin{array}{c}71 \\
(71.0)\end{array}$ \\
\hline Greater than Expect & $\begin{array}{c}31 \\
(17.5)\end{array}$ & $\begin{array}{c}20 \\
(21.4)\end{array}$ & $\begin{array}{c}11 \\
(23.0)\end{array}$ & $\begin{array}{c}62 \\
(62.0)\end{array}$ \\
\hline Total & $\begin{array}{c}54 \\
(54.0)\end{array}$ & $\begin{array}{c}66 \\
(66.0)\end{array}$ & $\begin{array}{c}71 \\
(71.0)\end{array}$ & $\begin{array}{c}191 \\
(191.0)\end{array}$ \\
\hline \multicolumn{5}{|l|}{$\begin{array}{l}\text { Expected Values in Parentheses } \\
\text { Pearson chi2(4) }=29.4750 \\
\mathbf{P r}=\mathbf{0 . 0 0 0}\end{array}$} \\
\hline
\end{tabular}

The Office of Diversity and Inclusion (Religious service resource) had a significant relationship with religious service challenge (Table 37) with a Pearson chi $^{2}$ of 29.4750 and a statistically significant value of $p=0.000$. This reveals that there is an association or relationship between the perception of the challenge (finding a worship group of own faith, religion and morals in the U. S, religious practices in U.S.) and the helpfulness of the resource (Office of Diversity and Inclusion). The actual number of students (5) who found the Office of Diversity and Inclusion helpful and had no challenges with religious service was significantly lower than the expected number of students (16.4). Thirty-one students 
experienced greater challenges with religious service which is much higher than the expected number

(31.5). This shows that the office of Diversity and Inclusion was not helpful enough in preventing students religious service challenges.

Table 38 shows a Pearson $\mathrm{Chi}^{2}$ of 11.3997 , with a statistically significant value of $\mathrm{p}=0.022$ which implies that there is a significant relationship between the perception of health challenges and the helpfulness of the resource, implying that the helpfulness of the resource and the perception of the challenge are dependent on each other. Twenty-six people who had no challenges with health services also found the health service resource as not helpful as compared to the number of expected of 18.9. Meanwhile 8 people who found the health service resource as helpful and yet had no challenges is lower than the expected (16.7) number of people.

\section{Table 38. Chi $^{2}$ Table of Challenges and Resources for Category 8- Health Services}

\begin{tabular}{|l|c|c|c|c|}
\hline $\begin{array}{l}\text { Perception of Challenge } \\
\text { (Finding adequate health } \\
\text { services, Dietary problems, } \\
\text { Feeling stressed) }\end{array}$ & \multicolumn{4}{|l|}{ Helpfulness of the Resource (Local Campus Groups) } \\
\hline & Helpful & Neutral & Not Helpful & Total \\
\hline No Challenges & 8 & 19 & 26 & 53 \\
& $(16.7)$ & $(17.5)$ & $(18.9)$ & $(53.0)$ \\
\hline Neutral & 19 & 21 & 18 & 58 \\
& $(18.2)$ & $(19.1)$ & $(20.6)$ & $(58.0)$ \\
\hline Greater than Expect & 34 & 24 & 25 & 83 \\
& $(26.1)$ & $(27.4)$ & $69.5)$ & $(83.0)$ \\
\hline Total & 61 & 64 & $(69.0)$ & 194 \\
& $(61.0)$ & $(64.0)$ & & \\
\hline $\begin{array}{l}\text { Expected Values in Parentheses } \\
\text { Pearson chi2(4) }=11.3997 \\
\text { Pr }=\mathbf{0 . 0 2 2}\end{array}$ & & & & \\
\end{tabular}




\section{Chapter 5}

5.0 Conclusions, Summary, and Recommendations

The results of the survey will enable the WVU Office of International Student and Scholars, and other offices to better provide appropriate and timely resources relevant to the challenges of international students. Provision of appropriate and timely resources will go a long way towards enhancing the efforts being made to recruit, retain, and build relationships among the diverse student populations. This will consequently increase international student enrollment and make the enrollment and transition process for international students less cumbersome.

The primary purpose of this study was to investigate international students' adjustment to challenges at West Virginia University and their perceptions of how the University assists them in meeting these challenges. The secondary purpose was to identify and analyze coping mechanisms and resources that international students at West Virginia University adopt to overcome their adjustment challenges. Identifying students' challenges and providing needed resources is necessary in ensuring successful retention of the students. Students have their expectations and unique challenges, however, Misra and McMahon (2006) posit that more often than not, they are inadequately prepared for the rigors and commitments of college life especially in an educational setting far away from their home. This study provides relevant information for incoming and currently enrolled international students at WVU on realistic college conditions and offer practical survival strategies useful for overcoming challenges as a student.

Other demographic data gathered from the survey of international students included student's gender, age, level of class (undergraduate/graduate), dependency status (students with dependents/students without dependents), number of years enrolled at WVU, number of years enrolled at other U.S. colleges prior to being enrolled at WVU, and country of origin. This survey was sent to all 
undergraduate and graduate international students at WVU via email. A total of 220 students responded to the survey on-line using the software Qualtrics.

\subsection{Summary}

Statistical analysis, $t$-tests, and One Factor ANOVA were utilized in this research and the results of students challenges and resources were compared using $\mathrm{Chi}^{2}$ to draw conclusions. The findings of the research are summarized below.

5.2 Research Question 1. What are the adjustment challenges facing international students at West Virginia University? From the analysis of question 1 of the survey, the challenge with the highest mean (4.88) was the relationship between faculty and students (Figure 22). The result contrasts with the findings of a study by Can (2015) which showed that $70 \%$ of the study participants recounted a positive relationship with their professors, academic advisors and faculty, while this research showed that students experienced their greatest challenges with their professors and faculty. Poyrazli and Graham (2007) established that a positive and healthy student- professor relationship was vital in the adjustment of international students which is what emerged in the findings of this study

Understanding lectures in English, and the ability to write in English was found to be the second greatest challenge with a mean of (4.87) for international students. Kuo (2011) posits that students have challenges understanding the accents of their professors making it difficult for them to fully understand their lectures which agrees with the literature of this study. Other reported key challenges were social /personal problems (treatment received at social functions (4.60), being accepted in social groups (4.75), insufficient personal- social counseling(4.20), and orientation service problems (attitude of some students towards international students (4.77), attitude of some U.S. citizens to skin color (4.45), relationship between faculty and students (4.88) which agrees to the literature of this study. The challenge with the lowest mean (3.72) was finding part time work. This implies that the greatest challenge for all international 
students is the relationship between students and faculty (item 6), and their least challenge is finding part time work (item 18) as shown in Figure 21 below. A list of item numbers and their names is presented in table 39 below.

Table 39. List of Item Numbers and Names

\begin{tabular}{|c|c|c|c|}
\hline $\begin{array}{l}\text { Item } \\
\text { no. }\end{array}$ & Item Name & $\begin{array}{l}\text { Item } \\
\text { no. }\end{array}$ & Item Name \\
\hline & Differences between U.S. and Home Country & & \\
\hline 1 & Education System & 13 & Speaking English \\
\hline 2 & Orientation to WVU & 14 & $\begin{array}{l}\text { Ability to write English } \\
\text { Understanding lectures in }\end{array}$ \\
\hline 3 & Relationship with international student advisor & 15 & English \\
\hline 4 & $\begin{array}{l}\text { Attitude of some students towards international } \\
\text { students }\end{array}$ & 16 & $\begin{array}{l}\text { Immigration regulations } \\
\text { Immigration work }\end{array}$ \\
\hline 5 & Attitude of some U.S. citizens to skin color & 17 & restrictions \\
\hline 6 & Relationship between faculty and students & 18 & $\begin{array}{l}\text { Finding part time work } \\
\text { Finding a worship group of }\end{array}$ \\
\hline 7 & Treatment received at social functions & 19 & $\begin{array}{l}\text { own faith } \\
\text { Religion and morals in the }\end{array}$ \\
\hline 8 & Being accepted in social groups & 20 & U.S \\
\hline 9 & Insufficient personal- social counseling & 21 & $\begin{array}{l}\text { Religious practices in U.S. } \\
\text { Finding adequate health }\end{array}$ \\
\hline 10 & Unexpected financial needs & 22 & services \\
\hline 11 & Finding employment between semesters & 23 & Dietary problems \\
\hline 12 & Lack of money to meet expenses & 24 & Feeling stressed \\
\hline
\end{tabular}


Figure 21. Mean of International Students Challenges.

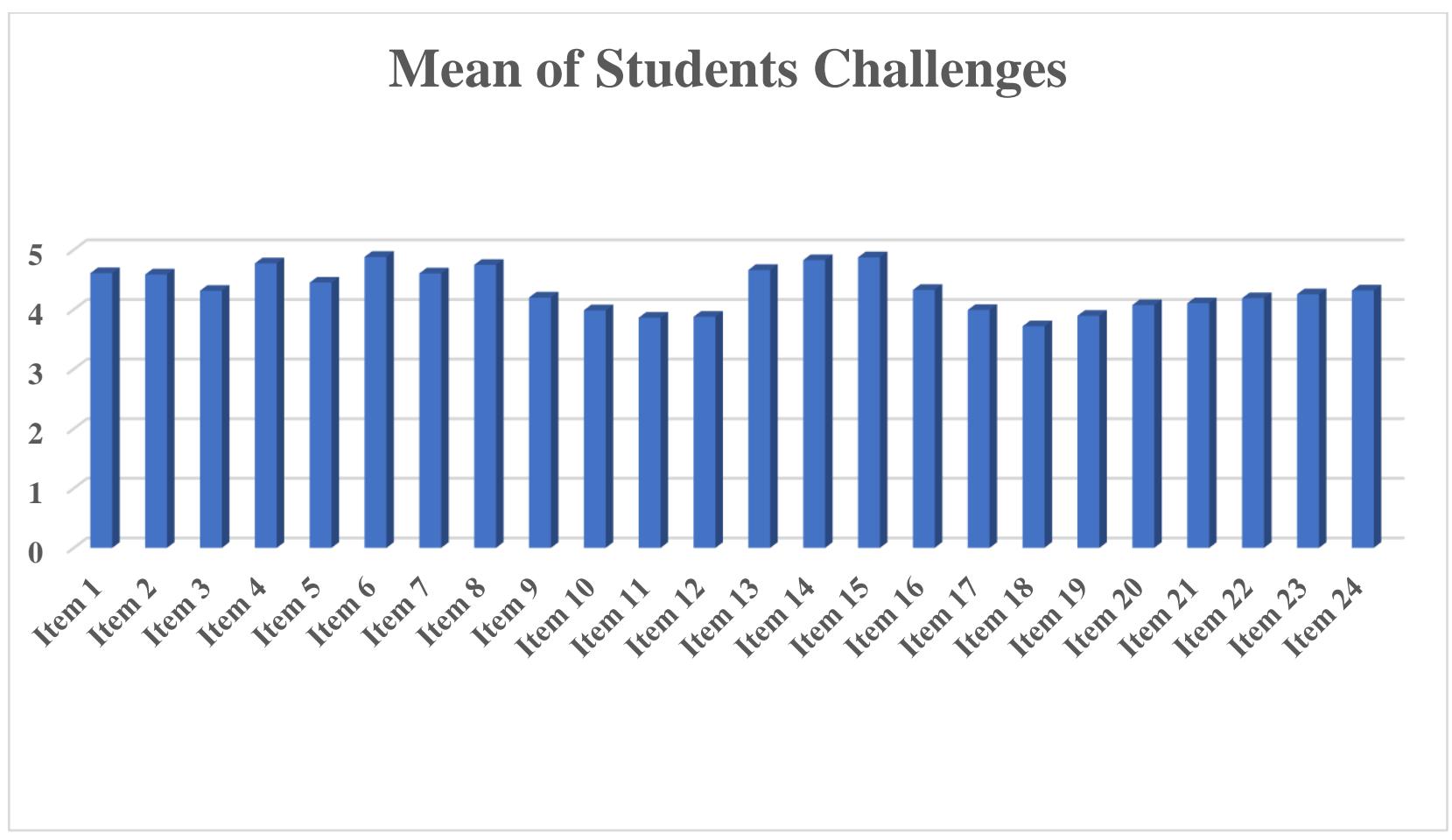

Challenges and Age. The age of the students was categorized into 3 groups (students below 20years, students between 21-25years, and students 26years and above). Students below the age of 20 years experienced more challenges than students within the other age groups as they had the highest mean in almost all the challenges (Figure 22). Their greatest challenge (5.19) was attitude of some students towards international students (item 4), and their least challenge (3.86) was finding adequate health service (item 22). The greatest challenge (4.87) for students between the ages of 21 and 25 was ability to write in English (item 14), and their least challenge (3.76) was finding a worship group of their own faith (item 19). Students 26 years and above had their greatest challenge (5.08) with relationship between faculty and students (item 6), and their least challenge (3.30) was finding part time work (item 18). The age of the students was used to test for any statistically significant differences in their perceived challenges (Table 10). There were statistical differences with item 18 (finding part time work) based on 
the students age. The results indicated that finding part time work was a much greater challenge to students below the age of 20 as compared to students within the other age groups.

\section{Figure 22. International Students Challenges with Age}

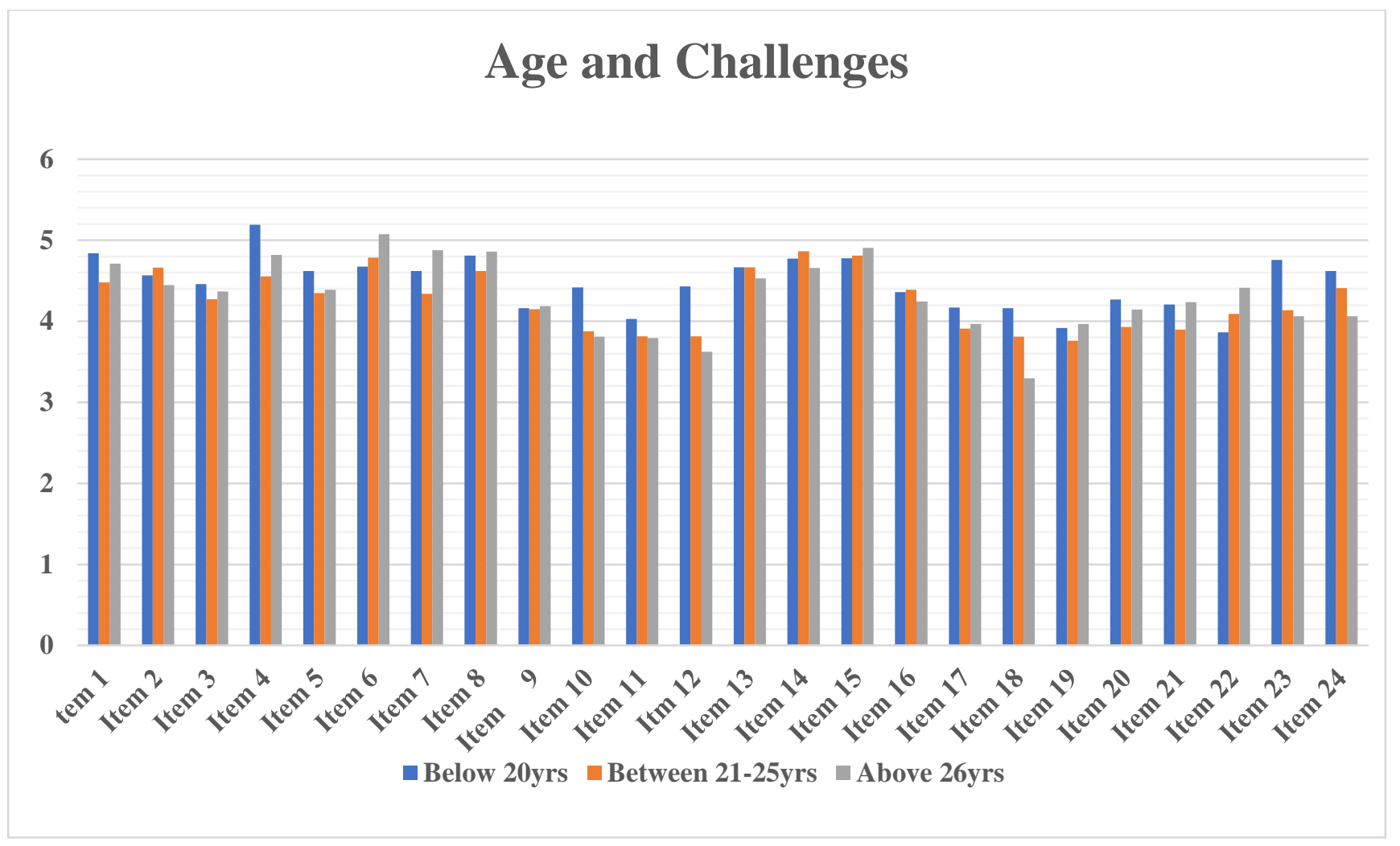

Challenges and Gender. There were no statistically significant differences in challenges based on gender even though males had higher means in almost all the problems (19) as compared to females. This finding contrasts with Wang's (2004) study that showed that females experienced more adjustment challenges than male students. It also conflicts with research by (Haynes et al., 2012) that females encountered more numerous role conflicts than males. Their study revealed further that females exclusively experienced major conflicts being between their academic and personal life as juxtaposed to males. The results of this study on the contrary reveals that there are no significant differences in challenges experienced by males and females. English language problems were the key challenges facing both males and females and finding part time work was the least challenge for both males and females. It 
disagrees again with (Stroebe, Van Vliet, Hewstone, \&Willis, 2002) that homesickness is more prevalent among female than male students. Whiles all these studies indicate females having more challenges than males, this study shows found no difference between the challenges faced by males and females. English language problems were the greatest challenge for females and males. The least challenge for both males (3.77) and females (3.64) was finding part time work (item 18).

Challenges and Class Level. There were no significant differences between the class level (undergraduates/graduates) of students and challenges. The greatest challenge (4.92) for undergraduate students was ability to write in English (item 14), and the greatest challenge (4.95) for graduate students was relationship between faculty and students (item 6). Finding part time work (item 18) was the least challenge for both graduate (3.58) and undergraduate students (3.83).

Challenges and Number of Years Enrolled at WVU. The number of years a student had been enrolled at WVU (Less than 1 year, 1 to 3 years, or 3 years and above) was analyzed with students' challenges (Figure 23). The greatest challenge (4.97) for students enrolled less than 1 year was attitude of some students towards international students (item 4) and their least challenge (3.96) was finding employment between semesters (item 11). The greatest challenge (5.35) for students enrolled between 1 and 3 years was speaking in English (item 13) and their least challenge (3.49) was finding part time work (item 18). Students enrolled for 3 years and above had their greatest challenge (5.00) as relationship between faculty and students (item 6) and their least challenge (3.25) was immigration work restrictions (item 17). Students who had been enrolled at WVU for less than 1 year had the highest mean in 16 of the challenges provided in the survey, implying that they experienced the challenges more than the other students. This harmonizes with Lysgaard's (1955) UCT where students experience the crisis stage (3-9 months) in the early part of their stay and experience the most challenges. Students who had been 
enrolled for 3 years and above had the least challenges probably because they had transitioned to the adjustment phase or even the adaptation phase as presented by Lysgaard's (1955) UCT.

Figure 23. International Students Challenges and Number of Years Enrolled at WVU

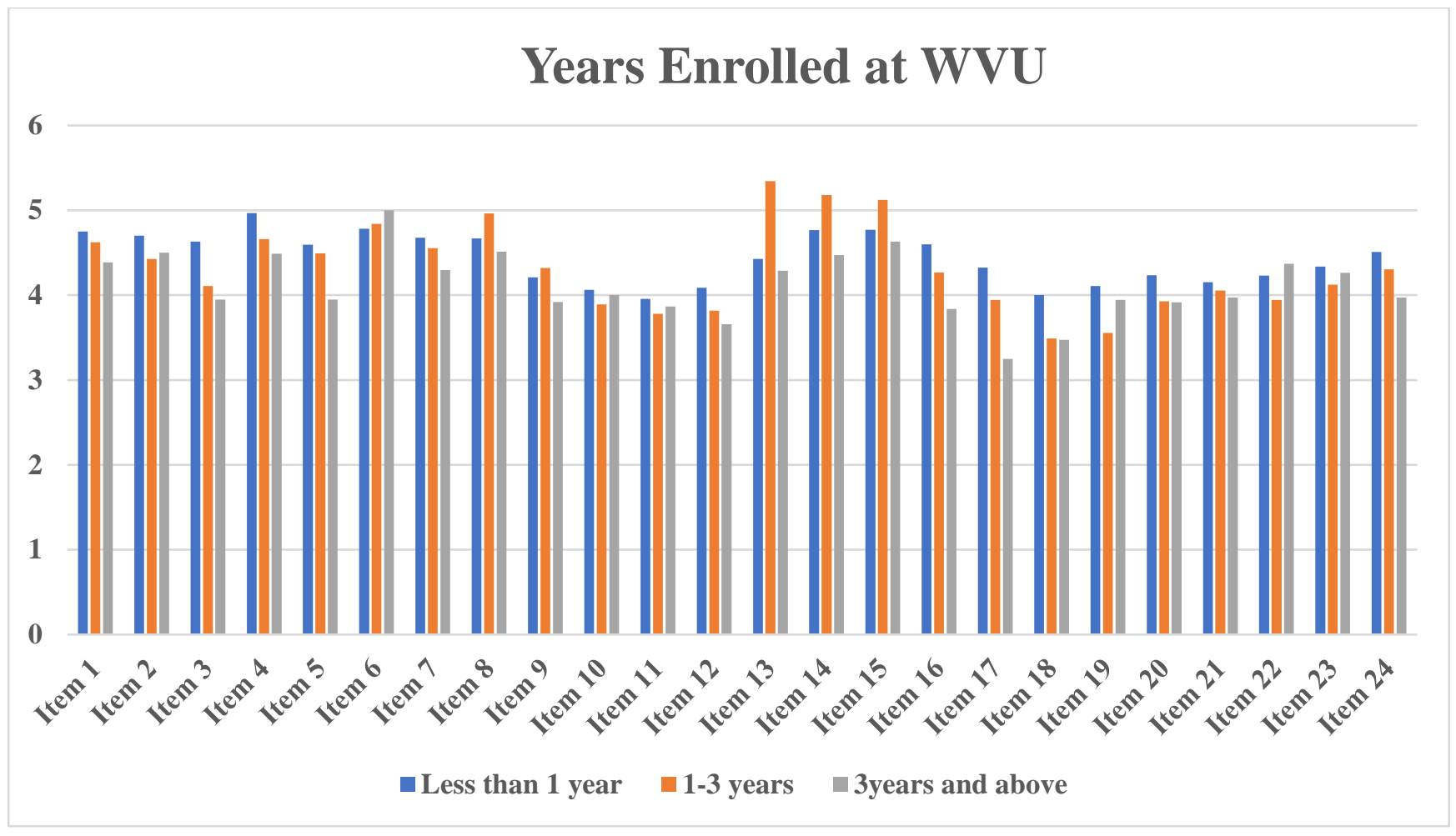

Challenges and Students Prior Experience Before Being Enrolled at WVU. The number of years a student had been enrolled in other U.S. colleges prior to being enrolled at WVU was analyzed with students' challenges. There were no statistical differences but students with no prior experience before being enrolled at WVU experienced the challenges greater in almost all the challenges (17 challenges) than students with some prior years of experience. This agrees with Lysgaard's (1955) UCT that students with no prior experience are in their early stage of their study (crisis stage) and students with some years of experience are in the adjustment stage. This analysis showed that relationship between faculty and students (4.90) and being accepted into social groups (4.90) were the greatest challenges facing students who had some years of prior experience in other universities before enrolling 
in WVU. Their least challenge (3.67) was finding employment between semesters (item 11). The greatest challenge (4.90) facing students with no prior experience to being enrolled at WVU was ability to write in English (item 14) and their least challenge (3.71) was finding part time work (item 18).

5.3 Other Challenges. Students reported several other challenges in question 2 of the survey which were not listed in the 24 Likert Scale questions from question 1. The greatest challenge students reported was racism and discrimination (53\%) from professors and faculty. The results disagree and differ from prior research conducted by Galloway and Jenkins (2005). The results disagree because whiles their research reveal financial aid as the key challenge and orientation service problems as the least challenges facing international students, this study shows that orientation service challenges (relationship between faculty and students) is the greatest challenge facing international students and finding part time work is the least challenge. Discrimination can be defined as an "[experience of] discrimination based on race or color, receiving mistreatment, and feeling socially isolated" (Poyrazli, Thukral, \& Duru, p. 26, 2010). All students (domestic and international) of different cultural and racial backgrounds experience discrimination however a study conducted by Poyrazli and Lopez (2007) among 439 students (241 domestic \&198 international) shows that international students experienced substantially greater discrimination (Poyrazli \& Lopez, 2007) than the domestic students. Transportation was the second greatest challenge (14\%), Health Insurance was 12\% and immigration issues was 11\%,

5.4 Informal Conversations. The greatest challenges recounted by students from the informal conversations were discrimination and racism especially from professors. This agrees with the findings and literature of this study. This was followed by transportation, not being able to access scholarships and funding due to 'international student status', and expensive health insurance making healthcare inaccessible. Other challenges narrated were difficulty finding grocery stores with ethnic food items in 
Morgantown, adjustment to American food, finding religious groups of own faith, the cumbersome and lengthy processes at the Office of International Students, and loneliness.

5.5 Research question 2. What are the students' perceptions of West Virginia University's role in addressing the adjustment challenges? From the analysis of data gathered from the international students' survey, the challenge that students perceived WVU as addressing the most was understanding lectures in English (item 15), it had the highest mean of 5.00 (Figure 24) followed by ability to write in English ( item 14-4.98). The challenge (3.55) that students perceived WVU as least addressing was finding part time work (item 18). A list of item numbers and their names is presented in table 40 below.

Table 40 List of Item Numbers and Corresponding Names

\begin{tabular}{|c|c|c|c|}
\hline $\begin{array}{l}\text { Item } \\
\text { no. }\end{array}$ & Item Name & $\begin{array}{l}\text { Item } \\
\text { no. }\end{array}$ & Item Name \\
\hline & Differences between U.S and Home Country & & \\
\hline 1 & Education System & 13 & Speaking English \\
\hline 2 & Orientation to WVU & 14 & $\begin{array}{l}\text { Ability to write English } \\
\text { Understanding lectures in }\end{array}$ \\
\hline 3 & $\begin{array}{l}\text { Relationship with international student advisor } \\
\text { Attitude of some students towards international }\end{array}$ & 15 & English \\
\hline 4 & students & 16 & $\begin{array}{l}\text { Immigration regulations } \\
\text { Immigration work }\end{array}$ \\
\hline 5 & Attitude of some U.S citizens to skin color & 17 & restrictions \\
\hline 6 & Relationship between faculty and students & 18 & $\begin{array}{l}\text { Finding part time work } \\
\text { Finding a worship group of }\end{array}$ \\
\hline 7 & Treatment received at social functions & 19 & $\begin{array}{l}\text { own faith } \\
\text { Religion and morals in the }\end{array}$ \\
\hline 8 & Being accepted in social groups & 20 & U.S. \\
\hline 9 & Insufficient personal- social counseling & 21 & $\begin{array}{l}\text { Religious practices in U.S. } \\
\text { Finding adequate health }\end{array}$ \\
\hline 10 & Unexpected financial needs & 22 & services \\
\hline 11 & Finding employment between semesters & 23 & Dietary problems \\
\hline 12 & Lack of money to meet expenses & 24 & Feeling stressed \\
\hline
\end{tabular}


Figure 24. International Students Perceptions of WVU Addressed Challenges

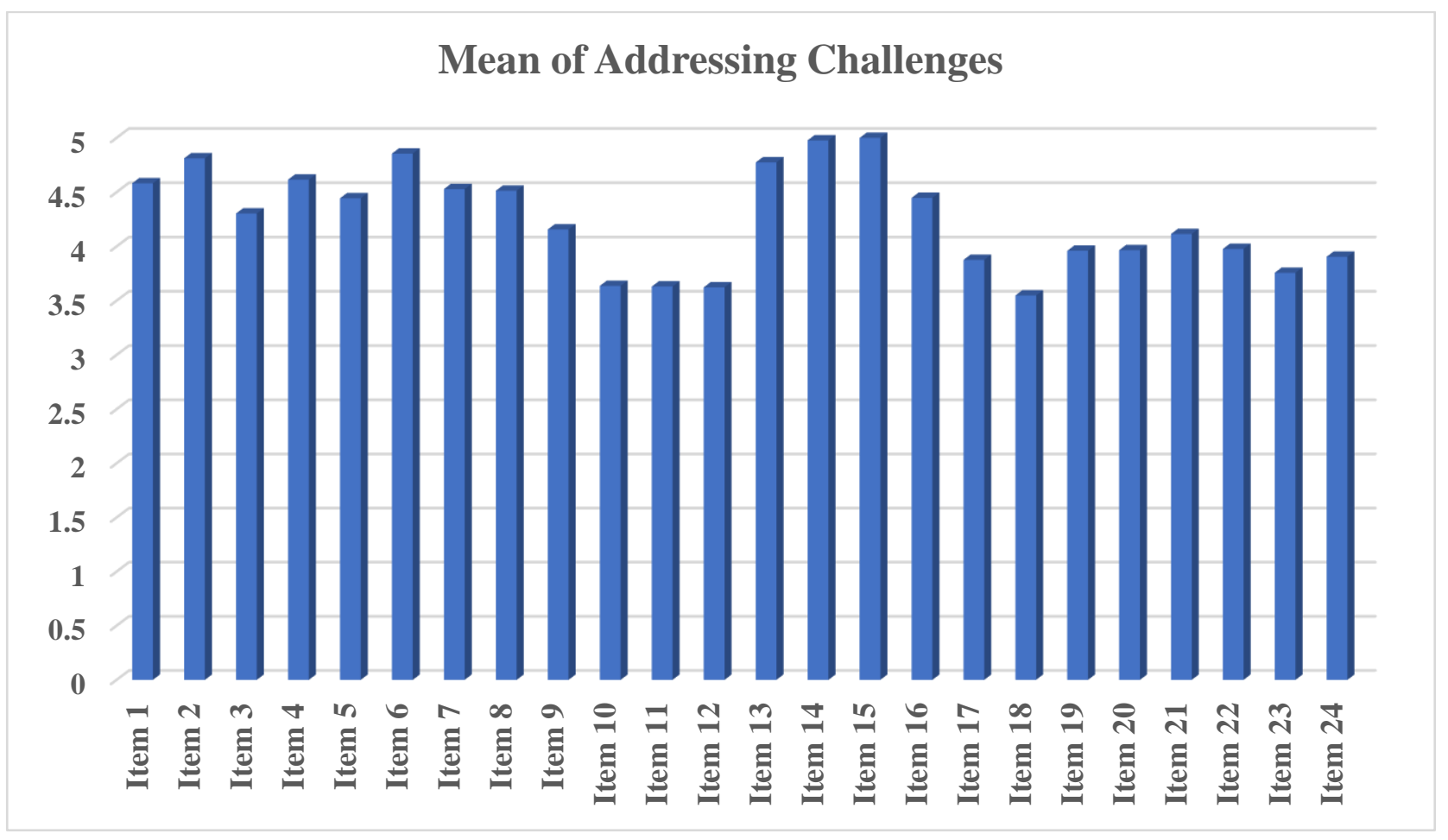

Addressed Challenges and Age. Age was analyzed with students' perception of challenges being addressed. Students who are 20 years old or less perceived WVU as addressing attitude of some students towards international students (item 4 -5.28) and being accepted into social groups (item 8-5.28) the most. The challenge they perceived WVU as addressing the least was finding employment between semesters (item 11-3.64). Students between the age of 21 and 25 years perceived WVU as assisting them the greatest with relationship between them and faculty (item 6-4.93) and assisting the least with lack of money to meet expenses (item 12-3.36). Students 26 years and above perceived WVU as addressing understanding lectures in English (item 15-5.17) the most and addressing finding part time work (item 18-2.91) the least. 
Addressed Challenges and Gender. From the analysis, males had a higher mean in all the challenges being addressed compared to females (Figure 25) except for insufficient personal-social counselling (item 9- 4.02). The challenge that males perceived WVU as addressing the most was ability to write English (item 14-5.24) and the challenge they perceived WVU as addressing the least was finding part time work (item 18-3.67). Females perceived WVU as addressing relationship between faculty and students (item 6-4.79) the most and addressing unexpected financial needs (item 10-3.31) the least.

Figure 25. Addressed Challenges and Gender

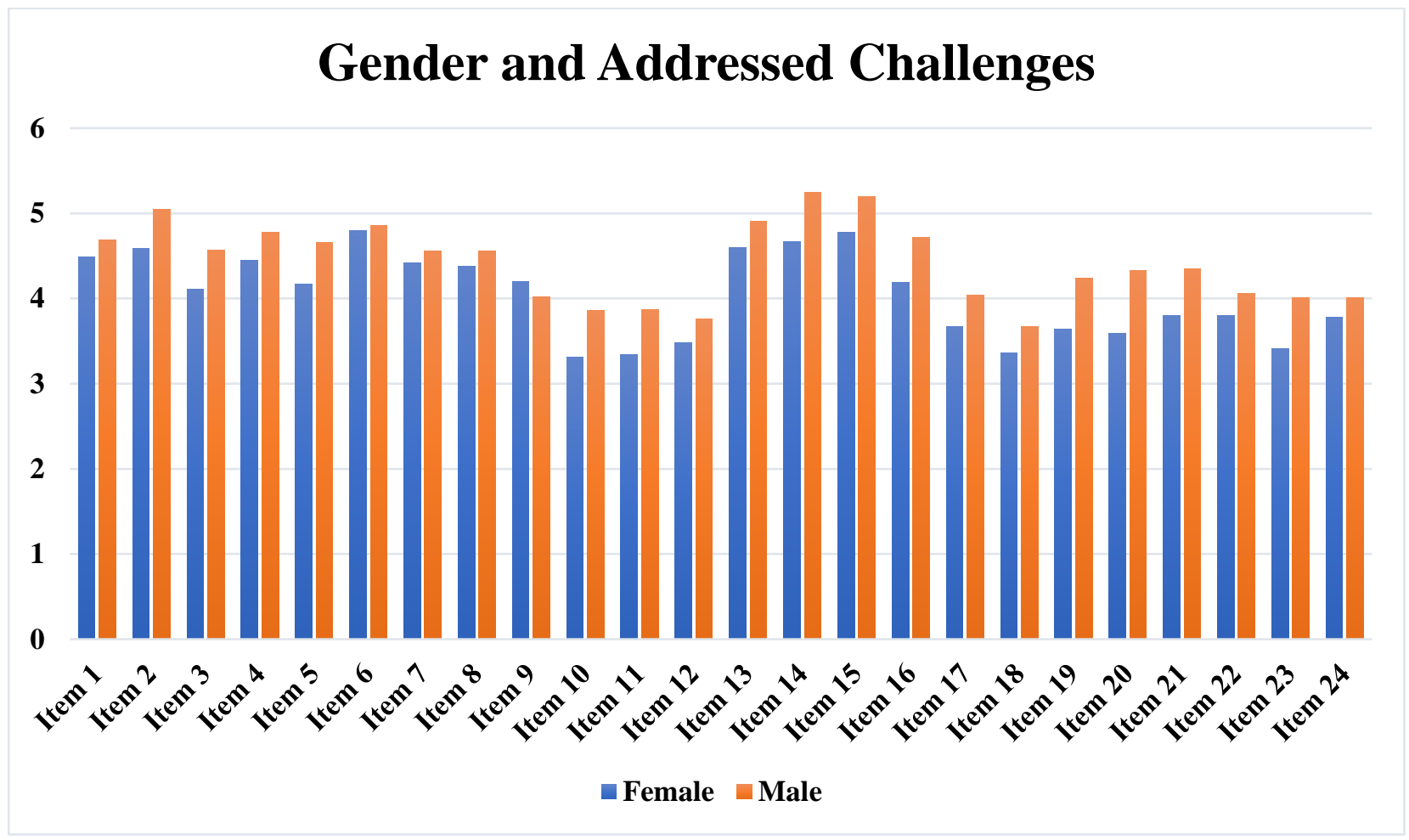

Addressed Challenges with Class Level. Students Perception of challenges being addressed was analyzed with their level of class (undergraduate/graduate). Undergraduate students perceived WVU as addressing ability to write in English (item 14 -5.06) the greatest, and the least addressed challenge as lack of money to meet expenses (item 12-3.68). The challenge perceived by graduate students as being 
addressed by WVU the most was understanding English (item 15-5.02) and the least addressed challenge was finding part time work (item 18-3.17).

Number of Years Being Enrolled at WVU. The number of years a student had been enrolled at WVU was analyzed with their perception of addressed challenges (Figure 26). Students who had been enrolled less than a year perceived WVU as assisting them the greatest with the relationship between faculty and students (item 6-5.09). The challenge that they perceived WVU as assisting them the least was lack of money to meet expenses (item 12-3.62). The challenge perceived to be addressed the greatest by students who had been enrolled between 1 to 3 years was ability to write in English (item 14-5.10) and the perception of their least addressed challenge was finding part time work (item 18-3.32). Students who had been enrolled for 3 years and above perceived WVU as addressing ability to write English (item 144.97) the greatest and immigration work restrictions (item 17-3.06) the least.

Figure 26. Addressed Challenges and Years Enrolled at WVU

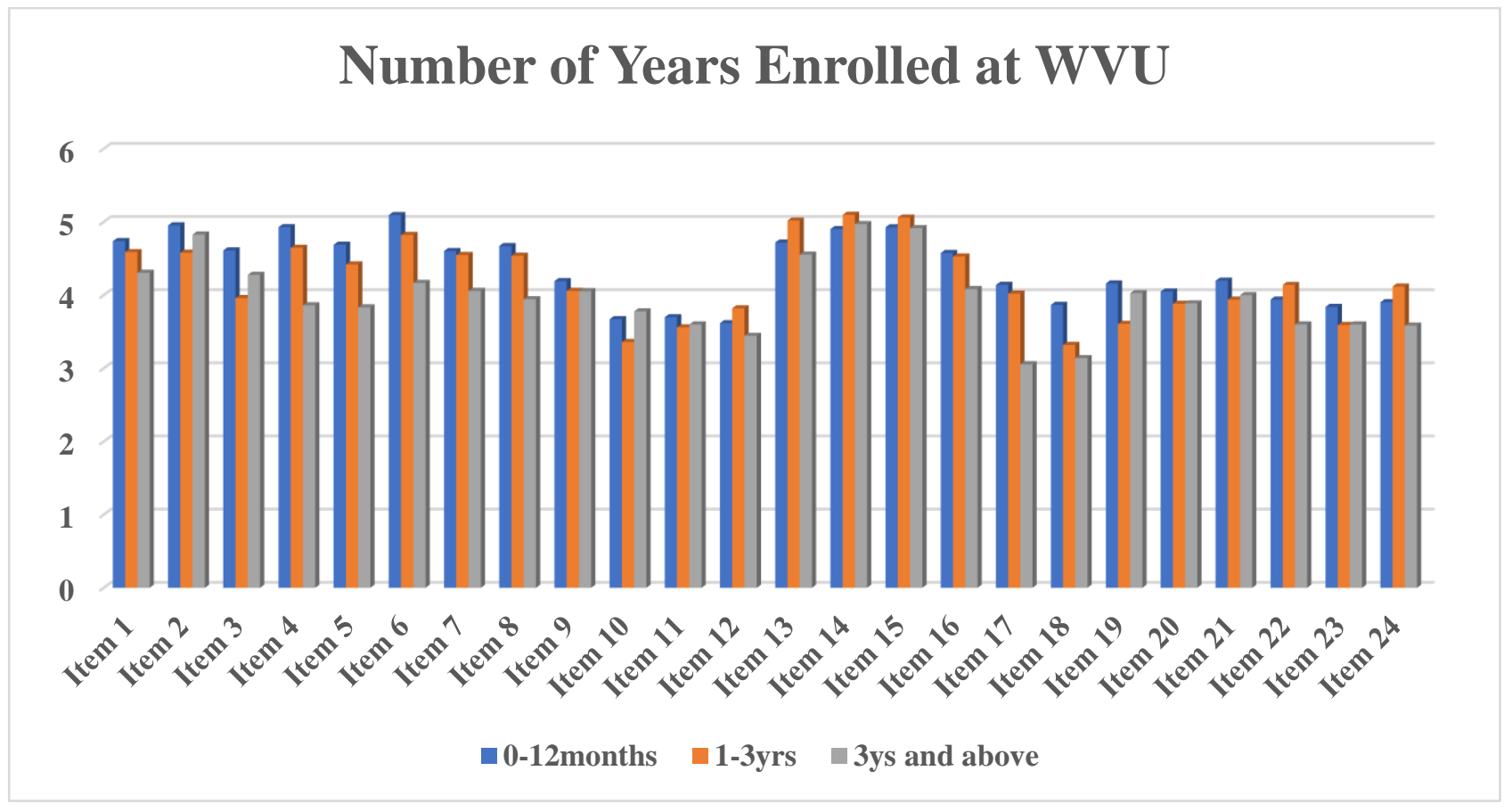


Years of Experience Before WVU. The years of experience a student has in other U.S. colleges before enrolling in WVU was analyzed with addressed challenges. The challenge perceived to be addressed the greatest by students with some years of experience in other colleges before being enrolled in WVU was understanding lectures in English (item 15-4.77) and the least addressed challenge was finding employment between semesters (item 11-3.25) and lack of money to meet expenses (item 123.25). Students with no prior experience in other schools before enrolling in WVU perceived WVU as addressing ability to write English (item 14-5.11) the greatest and unexpected financial needs (item 103.56) the least.

Research Question 3. What coping mechanisms or adaptation strategies do international students use to survive the adjustment challenges in West Virginia University? Responses to survey questions 3 to 6 helped in identifying the resources and coping mechanisms students utilized in surviving their adjustment challenges. For question 3, students rated the most helpful and least helpful resource that WVU provides them. The resource that students utilized the most to adjust was other international students (item 3-4.04). The shared experiences of international students create a sense of belonging which helps lessen the negative experiences and challenges they encounter whiles providing a strong academic and social network for them (Al-Sharideh \& Goe, 1998; Montgomery \& McDowell,2009; Urban, Orbe, Tavares, \& Alvarez, 2010). The least utilized resource was the Office of Diversity \& Inclusion (item 6- 2.81). Results from this study showed that racism and discrimination was the greatest challenge international students encountered at WVU, one would have assumed therefore that students would have utilized the Office of Diversity and Inclusion the most to help in addressing their challenge. The purpose of the Office of Diversity and Inclusion is to create a safe, welcoming, and inclusive community for all students at WVU. It does this by offering support, consultation, advocacy, and resources to students and community partners in addressing diversity related and issues of injustice. 
Ironically, the Office of Diversity and Inclusion was the least utilized resource considering that racism and discrimination was the greatest challenge reported by students in response to question 2 and that is the office that addresses this challenge. The Office of Diversity and Inclusion is rated the least utilized resource by students possibly because it is perceived to be just for students from the U.S.

Resources and Gender. Other international students (item 3) was the most utilized resource for both males (4.03) and females (4.04) in adjusting to their challenges. The least utilized resource for females was local campus groups (item 5-2.63) and the least utilized resource for males was Office of Diversity and Inclusion (item 6-.87).

Resources and Students with Prior Experience. Other international students (item 3-) was the most utilized resource by both students who had been enrolled in other U.S. colleges prior to being enrolled at WVU (4.05), and students with no experience before being enrolled at WVU (3.98). The Office of Diversity \& Inclusion (item 6) was the least utilized resource for students of both groups (Figure 27).

Figure 27. Resources and Years of Prior Experience

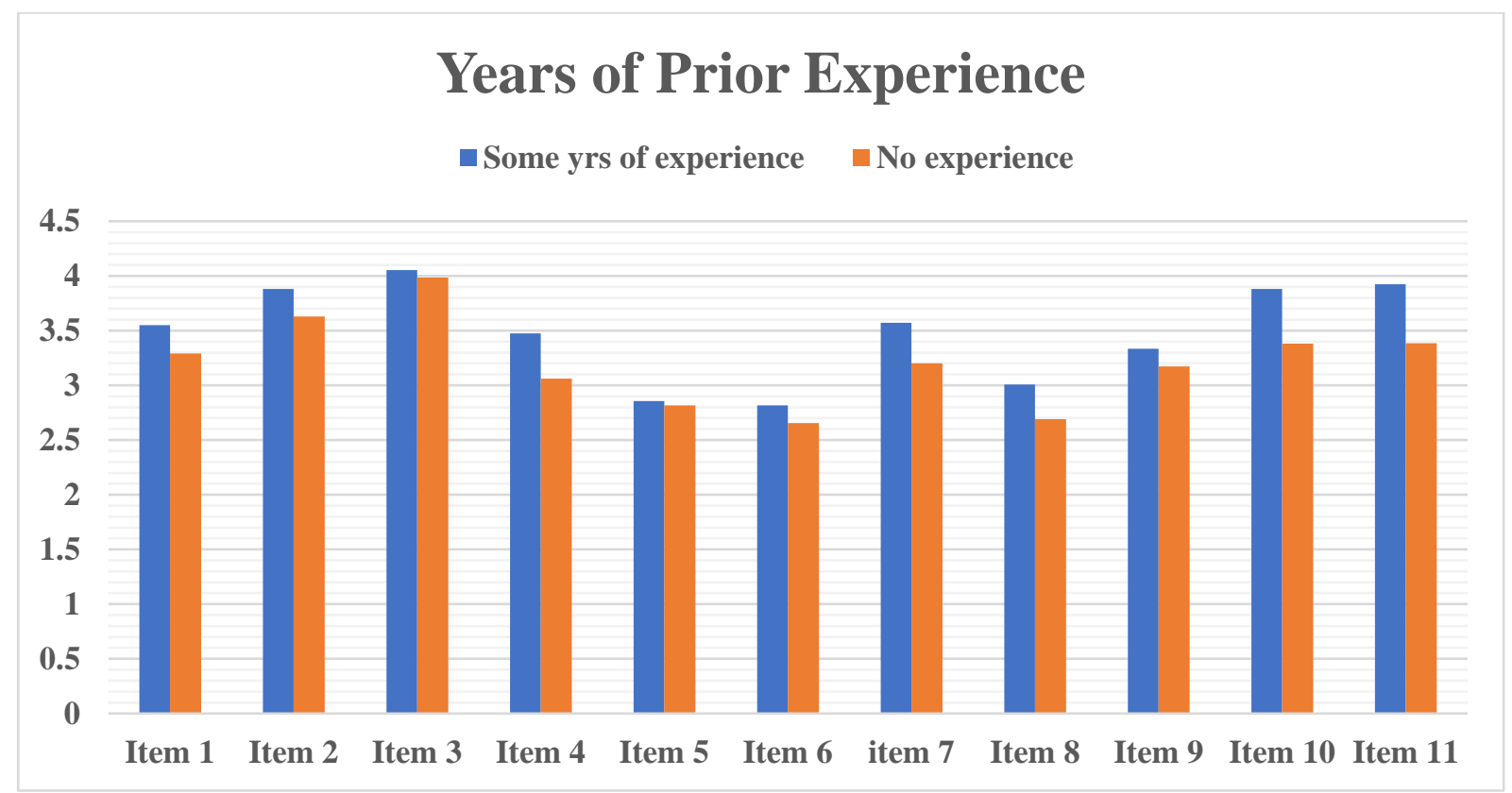


Resources and Age. The age of students was analyzed with resources. Other international students (item 3) was the most utilized resource for all category of age of students (students below the age of 20 years -4.33 , students between the age of 21 and 25 years-3.98, and students 26 years and above3.94). The least utilized resources for students below the age of 20 years were the Office of Diversity and Inclusion (item 6-3.15), and the writing studio (item 8-3.15). The least utilized resource for students between the ages of 21 and 25 years was the Office of Diversity and Inclusion (item 6-2.60). Local campus groups (item 5-2.76) was the least utilized resource for students above the age of 26 years.

Resource with Level of Class. Other international students (item 3) were the most utilized resource for both graduate (4.06) and undergraduate students (4.01). The office of Diversity and Inclusion (item 6) was the least utilized resource for both undergraduate (2.90) and graduate students (2.66).

Resources with Years Enrolled at WVU. The number of years a student has been enrolled at WVU was used to analyze utilized resources (Figure 28). Other international students (item 3) was the most utilized resource for students in all categories (students enrolled within less than 1 year- 4.06, students who had been enrolled within 1and 3 years -3.88 , and students enrolled 3 years and above-4.21). The Office of Diversity \& Inclusion (item 6-2.85) was the least utilized resource for students enrolled less than 1 year, and students enrolled 3 years and above (2.68). Local campus groups (item 5-3.00) was the least utilized resource for students enrolled within 1 and 3 years. 


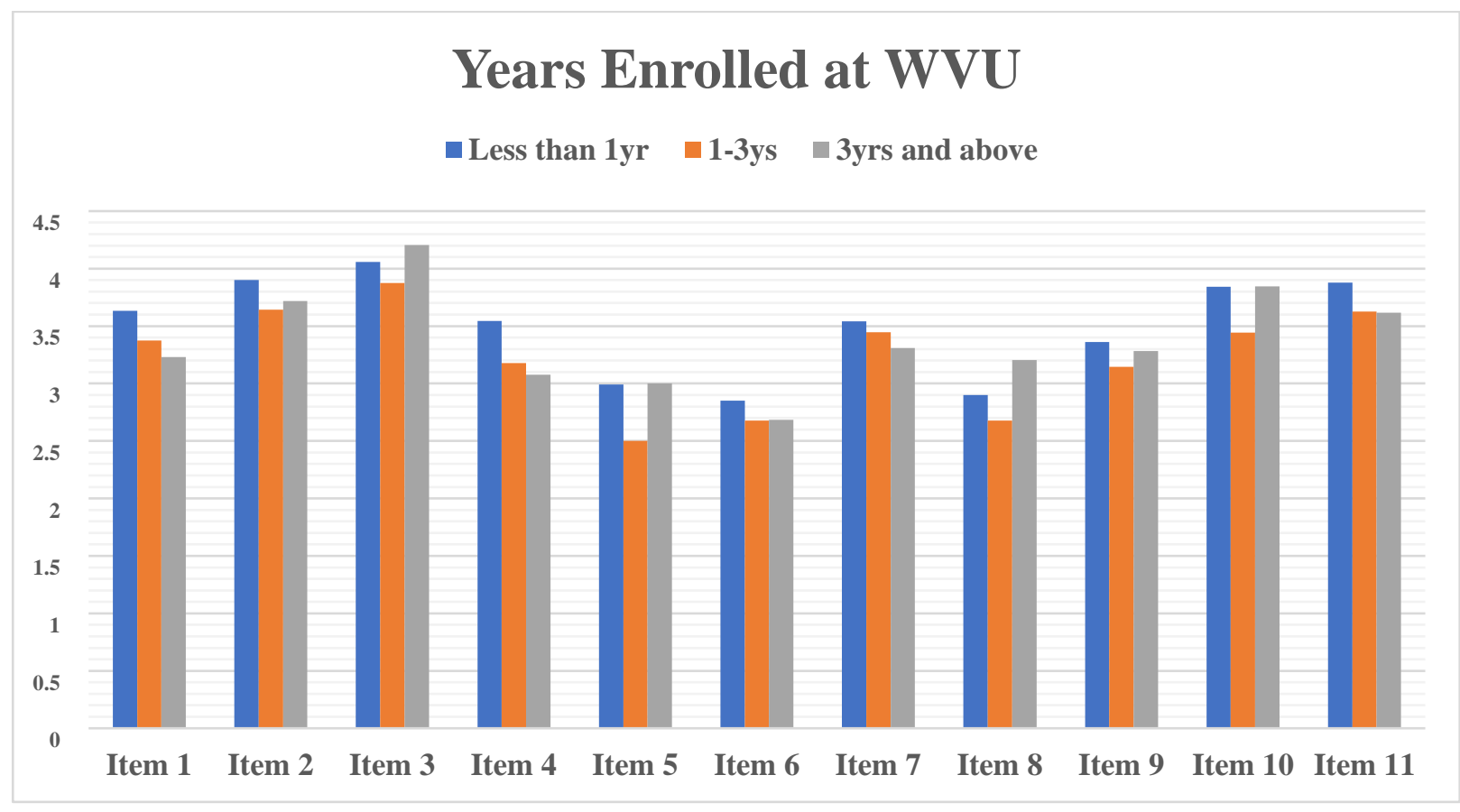

In response to question 4 of the international students' survey, students recounted several other resources WVU provides that helps them to adjust. The most utilized resource was the Carruth Center followed by the student recreation center. Some of the named resources were The Rack food bank, WVU Legal Services, and International Home-Start Closet.

Students described in response to question 5 other resources outside WVU that they used to adjust. The most helpful resource outside WVU that students used the most was family and friends. Church/ religion was the second most helpful. Clubs and organizations such as the Mocha Mama's of Morgantown group (Community group of women of color), and Chi Alpha were other named resources. Eighty-eight people stated in response to question 6 that, that they had family or friends in the U.S. before enrolling at WVU and 63 out of the 88 asserted that their family/friends helped them to adjust by helping them find appropriate housing, explaining the star system to them, providing emotional and practical support, general orientation to WVU and many more. Students described how engaged they 
were with family/friends in response to question 8. Most of the students (59) were very engaged with their families and friends. Only a few (6) were rarely engaged with their families. Other resources apart from family/friends that students mentioned were pets, volunteering, sports and recreational activities, church family, American students, and many others. The most helpful and utilized resource was the individual self (endurance, focus, strong will and determination, dedication, perseverance, etc.).

Comparison of Challenges and Resources. The results from the challenges were compared with that of the resources using $\mathrm{chi}^{2}$. The 24 challenges were put into 8 categories and the eleven resources were also grouped into 8 corresponding categories. The chi ${ }^{2}$ test showed significant relationships in four categories (orientation services, social/personal, religious services, and health services). This suggested that student challenges in these categories had an association with the unhelpfulness with the corresponding resources. The four remaining categories (admission selection, financial aid, English language, and immigration regulations) showed no significant relationships.

\subsection{Conclusions}

This research revealed the key challenges experienced by international students at West Virginia University and the coping mechanisms and resources used in adjusting to their challenges. It also revealed the importance of resources provided by WVU to assist international students. During the process of this research, acknowledging and recognizing the challenges of international students at WVU was both beneficial to the students and WVU. Students during the face to face interview expressed delight, gratitude and a sigh of relief that finally their interest and their challenges were being heard for the first time by the institution. International students in WVU perceived that their key challenges are social /personal problems (treatment received at social functions, being accepted in social groups, insufficient personal- social counseling), English language problems (understanding, writing, and speaking English), transportation problems, health insurance problems, and orientation service problems 
(attitude of some students towards international students, attitude of some U.S. citizens to skin color, relationship between faculty and students). The greatest above all is racism, discrimination and relationship between faculty and students.

Discrimination negatively impacts student's psychological well-being (Cokley, Hall-Clark, \& Hicks, 2011; Donovan, Huynh, Park, Kim, Lee, \& Robertson, 2012) and contributes significantly to the adjustment challenges experienced by students (Duru \& Poyrazli, 2011). These challenges may be partially due to the academic and socio-cultural differences between students' country of origin and host country. Parr, Bradley, and Bingi (1992) concurs and posits that the academic and socio-cultural challenges experienced by international students may be due to individualism, assertiveness, and the culture of competitiveness of the U.S. The least challenges experienced by students were finding part time work, finding employment between semesters, and lack of money to meet expenses. This finding is contrary to previous research by (Kwon 2009; Abdul -Jalal, Ariff, \& Ling,2014) that financial difficulties are the key challenges facing international students.

Students up to 20 years of age experienced the challenges as greater in many categories than older students with their greatest challenge being attitude of some students toward international students. There were no significant differences in challenges based on students gender even though males had a higher mean for most of the challenges than females. The class level (undergraduate and graduate) did not have any significance on students' perceived challenges. Graduate students' greatest challenges were orientation service problems while undergraduate students' greatest challenges were English language problems. Among all the categories, students who are 20 years or less, males, and students enrolled in less than 1 year experienced the most challenges.

When asked to report challenges not listed in question 1 , racism and discrimination were the most commonly reported challenges $(52 \%)$ by students in question 2 of the international student survey. 
Attitude of some students towards international students was the greatest challenge facing students who have been enrolled for less than 1 year while relationship between faculty and students was the greatest challenge facing students enrolled 3 years and above, and students who have some experience in other U.S. colleges prior to being enrolled at WVU. English language problems were the greatest challenge facing students who had been enrolled between 1 and 3 years and those without prior experience at other U.S. colleges. Students with prior experience in other U.S. colleges, and number of years a student has been enrolled at WVU did not have any significant differences in the challenges they experienced which supports the study conducted by Wang (2003).

Even though students perceive WVU's greatest assistance to be with English language problems, students still experience significant difficulties with English language. This supports earlier research (Sue \& Sue, 2013; Bista, 2015) which revealed that English language was the major challenge facing international students. Ching, Renes, McMurro, Simpson, and Strange (2017) explain further that international students usually do not realize their English language challenges until they arrive on campuses and have difficulties communicating with domestic students and faculty. This is confirmed in Sue \& Sue's (2013) research where students expressed confidence in their communication skills in their home country only to experience difficulties once they arrived on campuses and had to communicate with domestic faculty and students.

Males perceive WVU as assisting them address most challenges compared to females except for insufficient personal-social counselling. The challenge that students perceived WVU as addressing the least was finding part time employment. The most helpful and utilized resource for students is their fellow international students. Schmitt, Spears, and Branscombe (2003) explain that international students easily identify with their fellow international students as they realize they belong to the same outgroup. The Carruth center is the second most helpful resource in WVU followed by student recreation center. 
Outside of WVU, family and friends are a valuable resource in helping students overcome challenges and students are very engaged with them. The greatest resource outside WVU according to the survey results that students use to adjust is "themselves"; the student's perseverance, strong will, determination, endurance, dreams and aspirations among several others.

\subsection{Recommendations for Host Institutions}

International students experience the most stress during their first month of arriving in their host country (Brown \& Halloway, 2008). In addition to hosting orientation sessions and handing out brochures about the various programs, and departments to new international students during the first week of arrival on campus as is currently being done at WVU, the orientation materials and brochures can be mailed to students together with admission materials before they arrive on campus. This will give students enough time to acquaint themselves and prepare mentally and psychologically before they arrive. This study revealed that international students' greatest challenges were with faculty and staff. Students further revealed through the online survey the challenges they encountered with course registration, the star system, and general orientation. It is therefore recommended that host institutions, international student advisors, faculty, and staff, offer more support services to international students as they transition to their new environment (Abarbanel, 2009; Brown \& Holloway, 2008 Chapdelaine \& Alexitch 2004; Pantelidou \& Craig, 2006). Institutions can support international students to overcome their challenges in the following ways:

\subsection{Effective Facilitation}

Some students reported during the face to face interviews that they became aware of some available resources only towards the end of their studies. According to Chen and Yang (2014), effective facilitation is key in assisting international students adjust to their new environment. It is important that host institutions not only provide services to ensure the students smooth transition but also make 
international students aware of the existence of those support services and support them to navigate those services as they adjust to their new environment. Universities should endeavor to create awareness of existing resources and assist students in the engagement of these resources. Communication of resources should include community resources outside the University (legal aid, healthcare resources, childcare, after school programs, etc.) to help students better integrate with the community as the university does not exist in isolation but exists within the community.

Most international students become aware of existing resources only towards the end of their studies (Chen \& Yang, 2014). Many of the student challenges could have been avoided if those services had been known from the beginning. A study by Sherry, Bhat, Beaver, and Ling (2004) of international students at a New Zealand university revealed that students were "not confident that they are getting value for money, or that the skills they are being taught will get them good results both academically and for future employment" (p. 9). The survey also revealed that students were dissatisfied with support services provided by their institutions and felt that faculty and staff did not understand their needs (Sherry et al., 2004). This supports the findings of this study where students recounted that they got to know of some existing resources in WVU such as the WVU Legal services, International Home-Start Closet, and the Students Family Resources in the later stages of their studies where they had already encountered challenges and needed these resources but were not aware of them. Urban et al. (2010) however counter this argument and posit that the support international students received depended highly on the institutions they enrolled in.

\subsection{Effective Communication}

Effective communication between the host institution and students is key in ensuring student success. Information, no matter how little, should be shared with international students and open dialogues encouraged. Universities should go beyond formal means of communication such as emails 
and mails to informal meetings, and face-to-face communications, where students can freely discuss any sensitive challenges (Palmer \& Koenig Lewis, 2009). The WVU office of Diversity and Inclusion, and the WVU International Students and Scholars Office should host informal meetings, and open dialogues regularly where they can share information and students can freely share their opinion. It is important for colleges to offer orientation, cultural events and other social programs to enhance language skills and offer support for international students to help them adjust and enhance their psychological well-being (Mallinckrodt \& Leong, 1992). Orientation should include the university's academic culture and the general culture of the U.S.; it should also involve international students enrolled in the college for some years to easily connect with new international students.

\subsection{Orientation for Faculty and Staff}

It is important for universities to offer training and continuous orientation to faculty and staff to better orient them on international students' learning and thinking styles. WVU should offer orientation to faculty and staff maybe bi-yearly to educate them to understand the unique challenges that international students encounter. This will not merely inform them but increase their cultural awareness, sensitivity, and diversity. A participant of the informal conversation suggested formal mentoring with international faculty, and international students who have been enrolled for some years and fresh incoming students. This could be helpful in understanding challenges and communicating solutions.

\subsection{Community Relationship}

Schools are not islands, they operate within a community. Students through the online survey recounted how volunteering opportunities, resources (e.g., Salvation Army, and Christian Help) and recreational facilities within the community such as the Morgantown biking and walking trails had helped them to cope with some challenges they encountered. Programs and dialogues in West Virginia such as the Monongalia County Starting Points Resource Center, and Community Action that involve the 
community where WVU is located is necessary in providing a positive and friendly environment for international students to thrive (Grayson, 2008). A good and cordial relationship among the students, university, and community increases social support, giving international students a sense of security and belonging. Businesses and individuals within the community become more accepting of international students which reflects positively on the students and goes a long way in improving the performance of the student (Crossley, 2007). A supportive community helps students overcome culture shock and loneliness as they are able to adjust with minimum challenges. Yang, Salzman, and Yang (2015) echo that social support systems are important in making international students feel secure as they realize they are not alone in the challenges they face.

\subsection{Language and Writing Centers}

English language problems were one of the key challenges facing international students at WVU which concurs with the findings of Akanwa's (2015) research that language is a major challenge for most international students, especially international students from China (Perkins, 1977). Universities should have language centers to assist their students. Akanwa (2015) explains that language centers help boost the confidence of international students and enhance their interaction with others. He reiterates the importance of colleges and universities in assisting international students improve their skills in speaking, writing, and understanding the English Language. WVU has a writing studio which provides students the opportunity to work directly with peer trained consultants to assist them with note taking, editing, presentation techniques, among others. Even though findings from this research shows that the writing studio is much utilized by students, results from the study showed that the writing studio was inadequate in assisting students with their language difficulties and students had significant challenges with the English language. This is probably because the writing studio offers little support for speaking and understanding English, the main English language challenges faced by international students. The writing 
studio can do more "by organizing English language workshops, writing seminars, having informal conversations partners, and institutions can integrate more English speaking and writing assignments in course syllabi” (Akanwa, 2015 p. 1281).

\subsection{Student Counselling Centers}

The WVU Carruth center was a highly rated and utilized resource by students at WVU. However, students reported challenges with insufficient personal-social counseling. The Carruth Center creates a safe space for students to freely share challenges and experiences. The center provides a variety of services to students such as individual, group, couples, drug or alcohol counselling, assessment services, cognitive enhancement services, etc. It offers treatment and consultation for emotional health issues such as depression, psychosis, anxiety, and others. Universities need such centers in addition to existing support systems which will enhance mentoring and encourage open and confidential conversations with students. According to Arthur (1997), however, some international students usually deny the fact that they need help and others are also embarrassed to seek counselling. Many authors (Constantine, Anderson, Berkel, Caldwell, \& Utsey, 2005; Mori 2000; Warren \& Constantine 2007; Yakushko, Davidson, \& Sanford-Martens, 2008) confirm that international students do not usually seek counselling for adjustment challenges. This research however reveals the opposite as the results of this study showed that students utilized the counselling center (Carruth Center) the most among resources provided by WVU. Group counselling is both beneficial and effective in addressing the adjustment challenges of international students as it provides international students, especially students from Africa, a sense of comfort which is not always available with individualized counselling (Carr, Koyama, \& Thiagarajan,.2003; Dipeolu, Kang, \& Cooper, 2007; Johnson \& Sandhu 2007; Mori 2000; Walker and Conyne 2007). The Carruth Center should create "action-oriented" groups to "address racism and racial inequality within the university system" as suggested by Gordon Gee (President of WVU). These groups 
should incorporate race issues or create the opportunity for international students to meet other students from similar cultural and social backgrounds, to openly discuss their challenges which will help in reducing the feeling of loneliness and create a sense of community.

\subsection{Student Inclusion and Diversity Programs}

The WVU Office of Diversity and Inclusion exists to create an all-inclusive campus community by offering support and education on diversity issues through advocacy and consultations along with resolving impacts of inequality on WVU campus (https://diversity.wvu.edu). This is done through hosting programs, presentations, training, and facilitated dialogues that are focused on contemporary issues of injustice along with creating diversity committees. Some resources available at the Office of Diversity and Inclusion are; 1 . student diversity ambassadors- these are students who value and respect diversity and different ethnic cultures, represent the Office of Diversity and Inclusion by creating awareness of the Office's mission and services among students. 2. Peer Advocates- students who are trained to work to help end sexual assault on campus. 3. Equity Assurance, Title X and ADA- a unit that handles inquiries and queries of discrimination, harassment, and ensuring support for persons with disabilities. 4. Diversity Week- an annual celebration to promote the understanding of different cultures on campus, and create an atmosphere for staff, faculty, and students to explore the different cultures and contributions of the diverse people on campus.

It is ironic to note that in spite of the above services and more offered by the WVU Office of Diversity and Inclusion, it was rated as the least helpful and utilized resource by students. It is suggested for the office to conduct surveys to evaluate and measure the impact of their programs. International students should be included in the peer advocates, and other programs by the office to make them feel a part of the university. Knight (2004) proposes that certain days and programs can be earmarked for some traditions and culture that are important to allow students to connect and feel at home at the university. 
Multi-cultural programs should be encouraged to integrate and enhance socialization between international and domestic students (Mamiseishvili, 2012). The Office of Diversity and Inclusion should develop ways through research to identify the peculiar needs of students and offer solutions or services that are relevant to the needs of international students. Constantine et al. (2005) suggest that adjustment strategies for international students should be relevant to the cultural background of the student and not merely emphasize coping mechanisms that temporarily relieve the student of discomfort of being in a new environment.

\subsection{Additional Institutional Resources}

Ramsey et al. (2007) suggest four types of support systems for international students which are practical support systems to offer material and physical assistance. The International Home-Start Closet

at WVU, informational support systems to offer cognitive guidance and counsel such as the WVU Legal Services, emotional support systems to provide a sense of belonging and value, and social support systems to offer companionship. Olivas and Li (2006) suggest that support and quality relationships between international students, faculty or staff helps in reducing the adjustment related problems that international students face. Less social support from host institutions and domestic students on the other hand results in increased levels of depression and anxiety among international students (Sumer, Poyrazli, \& Grahame, 2008).

\subsection{For Faculty}

The greatest challenge noted in question one by students was relationship between faculty and students. Students also noted in question two and the face to face interviews the challenges they have with their professors and academic advisors. A study conducted by Zhou, Frey and Bang (2011) to understand international students' needs and adjustment showed that a positive relationship between 
international students, faculty and staff was key in the successful adjustment of students. To help address this issue therefore;

1. Professors should be friendly and make students feel welcome. They should let them know of their willingness to assist students with challenges they encounter. Wan (2001) suggests that efforts should be made to create positive relationships between professors and international students.

2. Professors should understand that international students are coming from a different cultural and educational background and may need time to adjust to their new environment and match up to the academic expectations. It is therefore important for professors to be patient with students, while inspiring, encouraging, and offering guidance to them.

3. Professors/academic advisors should let students know that they are willing to assist students in articulating their ideas across to other students.

\subsection{For International Students.}

1. Students explained in their responses to question seven some of the ways their families helped them, which included explaining the culture of the U.S. to them and a general orientation to Morgantown upon their arrival here. The adjustment process should not begin only when students arrive on their campuses, students can begin orienting themselves in their home country by learning about the culture (general, and academic) of U.S. before they arrive to reduce culture shock. A lack of knowledge in the culture of the U.S. causes challenges for students in their classroom participation, course selection, and social interaction (Caplan \& Stevens, 2017). A lack of knowledge in the culture of the host country contributes significantly to students' difficulty in interacting socially and making friends (Bista, 2015). 
2. Students who had been enrolled at WVU for less than one-year experienced greater challenges than students enrolled 1- 3yrs or those at WVU for 3 years or more. Students should know that adjustment occurs over time and is not instant, it is a growth process. Just as challenges are part of every academic journey, students should know that challenges are inevitable whether studying at home or abroad. Students should anticipate challenges and be prepared emotionally and mentally. Lick and Kauffman (2000) call this "learning before change" which is key in the change process.

3. English language problems were some of the key challenges facing international students and understanding English was the greatest challenge for females. Speaking English was the greatest challenge for students enrolled between 1 and 3 years. International students should be bold in making contributions in class and express themselves freely as this will help them in their language articulation and thereby assist in overcoming their language difficulties. They should freely contribute their ideas knowing that professors understand, appreciate their views, and are willing to help. He (2013) claims that students were hesitant in expressing themselves in and out of the classroom for fear of being misunderstood, making mistakes, and poor pronunciation.

4. From the responses gathered in question three, other international students were the most utilized resource for international students. Students again expressed in response to question six how friends they knew in the U.S. and at WVU before enrolling, helped them to adjust. While all that is good, international students should feel free and take a step further to make new friends and interact with other students. Domestic students should also be encouraged to interact and socialize with international students. Social interaction between domestic and international students enhances communication skills of international students and increases the cultural and general knowledge of both student groups. Social interaction, according to Park, Lee, Choi, and 
Zepernick (2016), enhances and increases the communication skills and confidence of international students. Social interaction enhances students' general wellbeing, increases their academic ability, and gives them a sense of belonging (Bista, 2015).

5. International students should seek help immediately when the need arises, in or out of the classroom. Rather than trying to figure things out on their own which leaves them feeling lonely as expressed in the informal conversations, they should be willing to ask for help.

6. From this study, students rated local campus groups at WVU as not very helpful which indicates the need for follow up study to ascertain the cause and make these groups helpful to students. It would be beneficial if International students' network and get involved in groups, clubs, and organizations on campus. Tsevi (2018); Reinties and Nolan (2014) postulate that participating in social groups, events and clubs give students a sense of belonging that helps them to better face their challenges which has a positive effect on their cultural adjustment and academic performance.

7. Students should be open minded and appreciate the different cultures. They should learn to focus on the brighter side of things than the negative. Challenges are inevitable and it is important for students to be optimistic and hopeful. With perseverance, determination, focus, and strong will, they will succeed and become who they aspire to be.

\subsection{9}

\section{Closing Note}

International students encounter several challenges; however, some challenges are unique to certain groups. From this research for example, undergraduate students greatest challenge was ability to write in English whiles the greatest challenge for graduate students was relationship between faculty and students. Students who are 20 years or younger experienced more challenges than students within the 
other age groups, and their greatest challenge was attitude of some students towards international students. It is therefore important for the university to provide resources that correspond to the specific needs of each group and not simply provide a 'one size fits all' resource. This will ensure the provision of precise and practical resources that will be beneficial for each student and ensure the effectiveness of the resources in helping students overcome their adjustment challenges. Finally, efforts should be made to address racism and discrimination. It was heartbreaking to see some students tearing up during the face to face interviews as they narrated the bitter experiences they had especially from staff and faculty.

\subsection{Limitations and Recommendation for Further Study}

1. A series of surveys conducted over the span of international students stay at WVU would have been ideal for this study considering the fact that students encounter a range of adjustment challenges at different stages or periods. Newly enrolled international students for example may be at the honeymoon stage as suggested by the U Curve Adjustment theory whiles this survey is being conducted and may not have experienced any adjustment challenges yet. However, time and resources will allow only for a one-time survey.

2. The desired sample size for this study was 350 to 400 , however only 220 responses were gathered which does not adequately reflect the population of international students at WVU. A wider sample size would have been ideal to reflect the challenges of all international students.

3. This research could be expanded be to other universities within the entire nation, to include both public and private universities making the results more generalizable.

4. Considering that the key challenges international students encountered were with faculty, staff, and students, it would be ideal to conduct further studies on challenges faculty and domestic students encounter with international students to gain a balanced perspective. This will ensure a holistic view 
of challenges students encounter and provide strategies that enhances the creation of a positive and all-inclusive environment. 


\section{References}

Abdul- Jalal, T. S. B.T., Ariff, R. B., Ling, L. A. (2014). Do adjustment problems hamper international students' academic achievement? International Journal of the Computer, the Internet and Management, 22(1), 36-41.

Admission and Aid (2018), University of Minnesota. Retrieved January 7, 2019 from https://twincities.umn.edu/admissions-aid

Akanwa, E. M. (2015). International students in western developed countries: History, challenges, and promises. Journal of International Students, 5, 271-284.

Al-Sharideh, K., \& Goe, W. R. (1998). Ethnic communities within the university: An examination of factors influencing the personal adjustment of international students. Research in Higher Education, 39(6), 699-725.

Anderson, R. E. (1976). Determinants of institutional attractiveness to bright, prospective college students. Research in Higher Education, 4, 361-371.

Anderson, N., \& Svriuga, S. (2020, July 14). Trump Administration Backs off Plan Requiring International Students to take Face-to-Face Classes. Retrieved from https://www.washingtonpost.com/local/education/ice-rule-harvard-international-studentsrescinded/2020/07/14/319fdae0-c607-11ea-a99f-3bbdffb1af38_story.

Ang, R. \& Huan, V. (2006). Academic Expectations Stress Inventory Development, Factor Analysis, Reliability, and Validity. Educational and Psychological Measurement, 66, 522-539. Retrieved from http://epm.sagepub.com.libproxy.nie.edU.S.g/content /66/3/522.full.pdf+html.

Arthur, N. (1997). Counselling issues with international students. Canadian Journal of Counselling, 31, 259-274. 
Arthur, N., \& Flynn, S. (2011). Career development influences of international students who pursue permanent immigration to Canada. International Journal for Education and Vocational Guidance, 11,221-237.

Ashley, S. (2019). What community college students say impede their progress. Retrieved September 1, 2019 from https://www.insidehighered.com/news/2019/02/12/survey-asks-community-collegestudents-detail-their-challenges.

Atebe, G. M. (2011). An Exploratory Study on International Students' Adjustment to American Universities. Doctoral Dissertation, West Virginia University.

Aubrey, R. (1991). International students on campus: A challenge for counselors, medical providers, and clinician. Smith College Studies in Social Work, 62, 20-33.

Baer, J. (2017). International Student Enrollment Hot Topics Survey. Washington, DC: Institute of International Education (IIE).

Baker, M., Robertson, F., Taylor, A., Doube, L., \& Rhall, T. (1996). The Labour Market Effects of Overseas Students. Canberra: AGPS.

Baker, M., Creedy, J., \& Johnson, D. (1996). Financing and Effects of Internationalization in Higher Education: An Australian Country Study. Canberra: AGPS

Becker, T. (1968). Patterns of attitudinal changes among foreign students. American Journal of Sociology, 73, 431-442.

Bista, K. (2015). Asian international students' college experience: Relationship between quality of personal contact and gains in learning. Journal of International and Global Studies, 6(2), 38-54.

Black, J. \& Mendenhall, M. (1991). The U-Curve Adjustment Hypothesis Revisited: A Review and Theoretical Framework. Journal of International Business Studies, 22, 225-247. Retrieved May 29, 2019 from https://doi.org/10.1057/palgrave.jibs.8490301. 
Bonazzo, C., \& Wong, Y. J. (2007). Japanese international female students' experience of discrimination, prejudice, and stereotypes. College Student Journal, 41, 631-639.

Bourke, A. (2000). "A Model of the determinants of International Trade in Higher Education,” The Service Industries Journal, 20, 110-138.

Brader, T., Valentino, N.A., \& Suhay, E. (2008). What triggers public opposition to immigration? Anxiety, group cues, and immigration threat. American Journal of Political Science, 52, 959978.

Can, A. (2015). An Examination of the Relationship Between Adjustment Problems, Homesickness, Perceived Discrimination and Psychological Wellbeing among International Students. Doctoral Dissertation, Ohio University.

Cain, P. P., \& McClintock, J. (1984). “The ABC's of Choice," Journal of College Admissions, 105, 1521.

Caplan, N.A. \& Stevens, S.G. (2017). "Step out of the cycle": Needs, challenges and successes of international undergraduates at a U.S.. university. English for Specific Purposes, 47, 15-28.

Carr, J. L., Koyama, M., \& Thiagarajan, M. (2003). A women's support group for Asian international students. Journal of American College Health, 52, 131-134.

Challenge (n.d). In Collins Dictionaries.com. Retrieved September 1, 2019 from https://www.collinsdictionary.com/us/dictionary/english/challenge

Chapdelaine, R., \& Alexitch, L. (2004). Social skills difficulty: Model of culture shock for international graduate students. Journal of College Student Development, 45, 167.

Charles-Toussaint, G., \& Crowson, H. (2010). Prejudice against international students: The role of threat perceptions and authoritarian dispositions in U.S. students. The Journal of Psychology, 144, 413428. 
Chellaraj, G., Maskus, K., \& Mattoo, A. (2008). The contribution of international graduate students to US innovation. Review of International Economics, 16, 444-462. doi:10.1111/j.1467-9396.2007. 00714.X

Chen, L. H. (2007). Choosing Canadian graduate schools from afar: East Asian students' perspectives. Higher Education, 54, 759-780.

Chen, C. P. (1999). Common stressors among international college students: Research and counseling implications. Journal of College Counseling, 2, 49-65.

Chen, L.H. (2008). Internationalization or international marketing? Two frameworks for understanding international students' choice of Canadian universities. Journal of Marketing for Higher Education, 18, 1-33.

Chen, D., \&Yang, X. (2014). Striving and thriving in a foreign culture: A mixed approach on adult international students' experience in U.S.A. Journal of Education and Training Studies, 2, 16-25.

Ching, Y., Renes, S. L., McMurro, S., Simpson, J. \& Strange, A. T. (2017, April). Challenges facing Chinese international students studying in the United States. Educational Research and Reviews, 12(8), 473-482. Doi: 10.5897/ERR 2016.3206

Cho, J., \& Morris, M. W. (2015). Cultural study and problem-solving gains: Effects of study abroad, openness, and choice. Journal of Organizational Behavior, 36, 944-966. Retrieved from https://doi-org.www.libproxy.wvu.edu/10.1002/job.2028.

Church, J., \& Gillingham, D. (1985). "Situational Position and Student Choice Criteria," The Canadian Journal of Higher Education, 15, 31-51.

Church, A. T. (1982). Sojourner adjustment. Psychological Bulletin, 91, 540-572. doi:10.1037//00332909.91.3.540 
Conard, M. J., \& Conard, M. A. (2001). “Actors that predict academic reputation don't always predict desire to attend." Journal of Marketing for Higher Education, 11, 1-18.

Copelanda, A. P., \& Norell, S. K. (2002). Spousal adjustment on international assignments: The role of social support. International Journal of Intercultural Relations, 26,255-272.

Constantine, M. G., Anderson, G. M., Berkel, L. A., Caldwell, L. D., \& Utsey, S. O. (2005). Examining the cultural adjustment experiences of African international college students: a qualitative analysis. Journal of Counseling Psychology, 52(1), 57-66.

Davis, F. J. (1963). The two-way mirror and the U-curve: Americans as seen by Turkish students returned home. Sociology and Social Research, 56, 49-43

de Wit, H. (2011). Internationalization of higher education in Europe and its assessment. In H. de Wit (Ed.), Trends, Issues, and Challenges in Internationalization of Higher Education, 39-43. Amsterdam, The Netherlands: Centre for Applied Research on Economics and Management, School of Economics and Management of the Hoge school van Amsterdam, and Hans de Wit. Dickerson, C. (2020, April 25). 'My World Is Shattering”: Foreign Students Stranded by Coronavirus. Retrieved from https://www.nytimes.com/2020/04/25/us/coronavirus- international-foreignstudents-universities.

Dipeolu, A., Kang, J., \& Cooper, C. (2007). Support group for international students: a counseling center's experience. Journal of College Student Psychotherapy, 22, 63-74.

Doherty, W. T., \& Summers. F. P. (1982). West Virginia University: Symbol of Unity in a Sectionalized State. West Virginia University Press.

Donovan, R. A., Huynh, Q., Park, I. J., Kim, S. Y., Lee, R. M., \& Robertson, E. (2012). Relationships among identity, perceived discrimination, and depressive symptoms in eight ethnic-generational groups. Journal of Clinical Psychology, 69(4), 397-414. 
Douglass, J. A., \& Edelstein, R. (2009). The global competition for talent: The rapidly changing market for international students and the need for a strategic approach in the US. University of California Berkeley, Goldman School of Public Policy, Research Paper. Retrieved from http://cshe.berkeley.edu/publications/docs/ROPS.JD.RE.GlobalTalent.9.25.09.pdf.

Duru, E., \& Poyrazli, S. (2011). Perceived discrimination, social connectedness, and other predictors of adjustment difficulties among Turkish international students. International Journal of Psychology, 46(6), 446-454.

Essandoh, P. K. (1995). Counseling issues with African college students in U.S. colleges and universities. The Counseling Psychologist, 23, 348-360.

Fischer, K. (2019, October 8). An Iranian student's visa was voided in his way to America. He still doesn't know why. Chronicle of Higher Education.

Fong, S.L., \& Peskin, H. (1969). Sex-role strain and personality adjustment of China-born students in America: A Pilot Study. Journal of Abnormal Psychology, 74, 563-568. doi:10.1037/h0028068

Frey, L. L., \& Roysircar, G. (2006). South Asian and East Asian international students' perceived prejudice, acculturation, and frequency of help resource utilization. Multicultural Counseling and Development, 34, 208-222.

Galloway, F. J., \& Jenkins, J. R. (2005). The adjustment problems faced by international students in the United States: A comparison of international students and administrative perceptions at two private, religiously affiliated universities. NASPA Journal, 42(2), 175-187.

Galloway, F., \& Jenkins, J. (2009). The adjustment problems faced by international students in the United States: A comparison of international students and administrative perceptions at two private, religiously affiliated universities. NASPA Journal, 46. doi:10.2202/0027-6014.1471. 
Gay, L.R., \& Airasian, P. (2000). Education research: Competencies for Analysis and Application. Upper Saddle River, New Jersey: Pearson Education.

Gay, L. R., Mills, G. E., \& Airasian, P. (2006). Educational Research: Competencies for Analysis and Applications. New Jersey: Pearson.

Glass, C., Buus, S., \& Braskamp, L. (2013). Uneven experiences: What's missing and what matters for today's international students. Chicago, IL: Global Perspective Institute. Retrieved from https://www.gpi.hs.iastate.edu/documents/Report-on-International-Students.pdf

Government Accounting Office (2005). Higher Education: Federal science, technology, engineering, and mathematics programs and related trends. Retrieved November 15, 2018, from http://www.gao.gov/new.items/d06114.pdf

Grayson, J. P. (2008). The experiences and outcomes of domestic students at four Canadian universities. Higher Educational Research \& Development, 27, 215-230.

Gudykunst, W., \& Ting-Toomey, S. (1998). Culture and interpersonal communication. Newbury Park, CA: Sage.

Gullahorn, J. T., \& Gullahorn, J. E. (1966). American students abroad: Professional versus personal development. Annals of the American Academy of Political and Social Science, 368, 43-59.

Guttman, H. M. (2009). Crisis management as a core competency for HR professionals. People and Strategy, 21, 32-39.

Hanassab, S. (2006). Diversity, international students, and perceived discrimination: Implications for educators and counselors. Journal of Studies in International Education, 10, 157-172.

Haynes, C., Bulosan, M., Citty, J., Grant-Harris, M., Hudson, J., \& Koro-Ljungber, M. (2012). My world is not my doctoral program...or is it? Female students' perceptions of well-being. International Journal of Doctoral Studies, 7, 1-17. 
He, D. (2013). What makes learners anxious while speaking English: A comparative study of the perceptions held by university students and teachers in China. Educational Studies, 39(3), 338350. Doi: 10.1080/03055698.2013.764819.

Higgenbotham, E. L., "Attachment, Coping Style, and Perceived Stress in University Students" (2016). Morgantown, WV: West Virginia University, College of Education and Human Services, Ph.D. Dissertation. https://researchrepository.wvu.edu/etd/5800

Ho, E., Bulman-Fleming, B., \& Mitchell, B. (2003). Course Internationalization: Engaging Students as Learning Resources. University of Waterloo, Ontario: Canadian Bureau for International Education.

Howell, D. C. (2002). Statistical Methods for Psychology. Pacific Grove, CA: Duxbury/Thomson Learning

Hull, W.F. (1978). Foreign Students in the United States: Coping Behavior within the Educational Environment. New York: Praeger.

Institute of International Education (2017). A Quick Look at Global Mobility Trends. Washington, DC: IIE.

Institute of International Education (2018a), Open Doors. Retrieved December 3, 2018, from https://www.iie.org/Open-Doors/Data/International-Students/Enrollment.

Institute of International Education (2018b), Open Doors. Retrieved December 3, 2018, from https://www.iie.org/Open-Doors/Data/International-Students/Places-of-Orgin

International Organization for Migration (2018). Migration Data Portal. Berlin, Germany: International Organization for Migration, Global Migration Data Analysis Centre Retrieved December 17, 2018, from https://migrationdataportal.org/themes/international-students 
Jacob, E.J. (2001). Using counselor training and collaborative programming strategies in working with international students. Journal of Multicultural Counseling and Development, 29, 73-88.

Jiani, M. (2017). Why and how international students choose mainland China as a higher education study abroad destination. Higher Education: The International Journal of Higher Education Research,74, 563-579.

Johnson, J. M. (2002). The reverse brain drain and the global diffusion of knowledge. Georgetown Journal of International Affairs, 3, 125- 131.

Johnson, L. R., \& Sandhu, D. S. (2007). Isolation, adjustment, and acculturation issues of international students: Intervention strategies for counselors. In H. D. Singarevelu \& M. Pope (Eds.), A Handbook for Counseling International Students in the US (pp. 3-36). Alexandria, VA: American Counseling Association

Johnston, D., Baker, M., \& Creedy, J. (1997). The cost and benefit of international students. Economic Papers: A Journal of Applied Economics and Policy, 16, 44-54. doi:10.1111/j.17593441.1997.tb00153.x

Johnson, R. B., \& Christensen, L. (2014). Educational research: Quantitative, Qualitative, and Mixed Methods Approaches. Los Angeles, CA: SAGE Publications.

Jung, E., Hecht, M. L., \& Wadsworth, B. C. (2007). The role of identity in international students' psychological well-being in the United States: A model of depression level, identity gaps, discrimination, and acculturation. International Journal of Intercultural Relations, 31, 605-624.

Kapur, M. (2017). Overcoming Challenges for International Student. Education New Zealand: Retrieved December 3, 2018, from https://www.studyinnewzealand.govt.nz/blog/challenges-internationalstudents-and-how-overcome-them 
Kashima, E. S., \& Loh, E. (2006). International students' acculturation: Effects of international, conational, and local ties and need for closure. International Journal of Intercultural Relations, 30, 471-485.

Kim, S. (2015). The influence of social relationships on international students' intentions to remain abroad: Multi-group analysis by marital status. The International Journal of Human Resource Management, 26, 1848-1848.

Knight, J. (2004). Internationalization remodeled: Definition, approaches, and rationales. Journal of Studies in International Education, 8, 5-31.

Kuo, Y. H. (2011). Language challenges faced by international graduate students in the U.S.A. Journal of International Students, 1, 38-42.

Kwon, Y. (2009, December). Factors affecting international students' transition to higher education institutions in the United States: From the perspective of the Office of International Students. College Student Journal, 43(4), 1020-1036

Lee, J. (2007). Neo-racism toward international students. About Campus, 11, 28-30.

Lee, J., \& Rice, C. (2007). Welcome to America? International student perceptions of discrimination. Higher Education,53, 381-409.

Leikvold, D. M. (1997). German and American Perceptions of a Short-term Secondary School Exchange Program. Doctoral dissertation, University of South Dakota.

Leong, F., \& Chou, E. (1996). Counselling international students. In P. B. Pedersen, J. G. Draguns, et al. Counselling across cultures. Newbury Park, CA: Sage

Liberman, K. (1994). Asian student perspectives on American university instruction. International Journal of Intercultural Relations, 18, 173-192 
Li, M., \& Bray, M. (2007). Cross-border flows of students for higher education: Push-pull factors and motivations of Mainland Chinese students in Hong Kong and Macau. Higher Education, 53, 791818.

Li, R. Y. \& Kaye, M. (1998). Understanding overseas students' concerns and problems. Journal of Higher Education Policy and Management, 20, 41-50.

Lick, D. W., \& Kaufman, R. (2000). Change creation: The rest of the planning story. In J. V. Boettcher, M.M. Doyle, \& R. W. Jensen (Eds.) Technology-driven Planning: Principles to Practice. Ann Arbor, MI : Society for College and University Planning.

Liu, C., Stevens, C., Wong, S., Yasui, M., \& Chen, J. (2019). The prevalence and predictors of mental health diagnoses and suicide among U.S. college students: Implications for addressing disparities in service use. Depression and Anxiety, 36, 8-17. doi:10.1002/da.22830

Lysgaard, S. (1955). Adjustment in a foreign society: Norwegian Fulbright grantees visiting the United States. International Social Science Bulletin, 7, 45-51.

Mamiseishvili, K. (2012). International students’ persistence in U.S. postsecondary institutions. Higher Education, 64, 1-17.

Mallinckrodt, B., \& Leong, F. T. L. (1992). International graduate students, stress, and social support. Journal of College Student Development, 33, 71-78.

Marginson, S., \& van der Wende, M. (2007). To rank or to be ranked: The impact of global rankings in higher education. Journal of Studies in International Education, 11, 306-329.

Mazzarol, T., \& Soutar, G.N. (2002). Push-pull factors influencing international student destination choice. International Journal of Education Management, 16, 82-90.

Miller, R. (1990). Major American Higher Education Issues and Challenges in the 1990s. London: Kingsley. 
Minsky, C. (2016, January 28). The soaring cost of student living. Retrieved from https://www.timeshighereducation.com/student/news/soaring-cost-student-living

Misra, R., Crist, M., \& Burant, C. J. (2003). Relationships among life stress, social support, academic stressors and reactions to stressors of international students in the United States. International Journal of Stress Management. 10, 137-157. doi:10.1037/1072-5245.10.2.137

Misra, S., and McMahon, G. (2006). Diversity in higher education: The three R's. Journal of Education for Business, 82, 40-43.

Montgomery, C., \& McDowell, L. (2009). Social networks and the international student experience: An international community of practice? Journal of Studies in International Education, 13(4), 455466.

Montgomery, D. C. (2001). Design and Analysis of Experiments. New York: Wiley.

Moogan, Y. J., Baron, S., \& Kim, H. (1999). Decision-Making Behavior of Potential Higher Education Students, Higher Education Quarterly, 53, 211-228.

Mori, S. (2000). Addressing the mental health concerns of international students. Journal of Counseling and Development, 78, 137-144.

Murphy, D., Sahakyan, N., Yong-Yi, D., \& Magnan, S. S. (2014). The impact of study abroad on the global engagement of university graduates. Frontiers: The Interdisciplinary Journal of Study Abroad, 24, 1-24.

Musumba, M., Jin. Y. H., \& Mjelde, J. W. (2009). Factors influencing career location preferences of international graduate students in the United States. Education Economics, 19,501517.

Norris, E. M., \& Gillespie, J. (2009). How study abroad shapes global careers evidence from the United States. Journal of Studies in International Education, 13, 382-397. 
Olivas, M., \& Li, C. (2006). Understanding stressors of international students in higher education: What college counselors and personnel need to know. Journal of Instructional Psychology, 33, 217222.

Osei-Owusu, B., \& Awunyo-Vitor, D. (2012). Teacher's perception on sustainability of distance education in Ghana: Evidence from Ashanti-Region. International Education Studies, 5, 222-227. doi:10.5539/ies.v5n4p222

Owens, D., Srivastava, P., \& Feerasta, A. (2011). Viewing international students as state stimulus potential: Current perceptions and future possibilities. Journal of Marketing for Higher Education, 21, 157-179.

Owens, Y. O. (2003). Adjusting but not Assimilating: International Students at East Tennessee State University. Unpublished Master's Thesis, East Tennessee State University, Department of Sociology and Anthropology. https://dc.etsu.edu/cgi/viewcontent.cgi?article=1994\&context=etd

Pang, B. (2001). Higher Education: A new immigrant path to Chinese students and scholars. Unpublished doctoral dissertation, Arizona State University

Park, H., Lee, M.J., Choi, G.Y., \& Zepernick, J.S. (2016). Challenges and coping strategies of East Asian graduate students in the United States. International Social Work, 60(3), 733-749. Doi: $10.1177 / 00208728816655864$.

Parr, G., Bradley and Bingi, R. (1992). Concerns and feelings of international students. Journal of College Student Development, 33, 20-25.

Pedersen, P. B. (1991). Counseling international students. The Counseling Psychologist, 19, 10-58.

Peng, S. Y. (2006). A comparative perspective of intercultural sensitivity between college students and multinational employees in China. Multicultural Perspectives, 8, 38-45. 
Perkins, C. (1977). A comparison of the adjustment problems of three international groups. Journal of College Student Personnel, 18, 382-388.

Perna, L. W. (2002). Financing higher education at selective private institutions: Implications for college access and choice. Review of Higher Education, 25, 225-235.

Porter, J. (1966). The Manual of Michigan International Student Problem Inventory. Unpublished Report by Urban Education Alliance, Inc. at Ann Arbor, MI.

Poyrazli, S. \& Rajat, T., \& Duru, E. (2010). International students' race-ethnicity, personality and acculturative stress. Journal of Psychology and Counseling, 2, 25-32.

Poyrazli, S., Arbona, C., Bullington, R. \& Pisecco, S. (2001). Adjustment issues of Turkish college students studying in the United States. College Student Journal, 35, 52-63.

Poyrazli, S. \& Grahame, K. M. (2007). Barriers to adjustment: Needs of international students within a semi-urban campus community. Journal of Instructional Psychology, 34, 28-45.

Poyrazli, S., \& Lopez, M.Z. (2007). An exploratory study of perceived discrimination and homesickness: A comparison of international students and American students. Journal of Psychology, 141(3), 263-280.

Rahman, O., \& Rollock, D. (2004). Acculturation, competence, and mental health among South Asian students in the United States. Multicultural Counseling and Development, 32, 130-142.

Ramsey, S., Jones, E., \& Barker, M. (2007). Relationship between adjustment and support types: Young and mature-aged local and international first year university students. Higher Education. 54(2), 247-265. doi.10.1007/s10734-006-90010

Reed, J. G., Lahey, M. A, \& Downey, R. G. (1984). "Development of the College Descriptive Index: A Measure of Student Satisfaction," Measurement and Evaluation in Counseling and Development, 67-82. 
Rhea, D. (1997). A Post-Departure Study of International Faculty, Scholars, and Doctoral Students of the University of Virginia, (Ph.D. Dissertation) Charlottesville, VA: University of Virginia.(AAT 9724726) Retrieved June 29, 2020, from ProQuest Dissertations \& Theses Full Text

Rhee, J., \& Sagaria, M. A. D. (2004). International students: Constructions of imperialism in the Chronicle of Higher Education. Review of Higher Education, 28, 77-96.

Rienties, B., \& Nolan, E.M. (2014). Understanding friendship and learning networks of international and host students using longitudinal social network analysis. International Journal of Intercultural Relations, 41, 165-180. Doi:10.1016/j.ijntrel.2013.12.003.

Roberts, R., Golding, J., Towell, T. \& Weinreib, I. (1999). The effects of economic circumstances on British students' mental and physical health. Journal of American College Health, 48, 103-109.

Roberts, C. (2010). The Dissertation Journey. Thousand Oaks, CA: SAGE Publications.

Schaeffer, P. (2005). Human Capital, Migration Strategy, and the Brain Drain. Journal of International Trade and Economic Development 14(3): 319-335

Schaeffer, P. V. (1983). Immigration into the United States: An Important Issue for State and Local Governments. Planning and Public Policy, 9, 1-3.

Schmitt, M. T., Spears, R., \& Branscombe, N. R. (2003). Constructing a minority group identity out of shared rejection: The case of international students. European Journal of Social Psychology, 33, $1-12$.

Schmidt, S., \& Pardo, M. (2017). The Contribution of Study Abroad to Human Capital Formation. Journal of Higher Education, 88, 135-157. Retrieved from http://www.libproxy.wvu.edu/login?url=http://search.ebscohost.com/login.aspx?direct=true\&db= eric\&AN=EJ1189434 
Scott, J. C. (2006). The mission of the university: Medieval to postmodern transformations. Journal of Higher Education, 77, 1- 39. doi:10.1353/jhe.2006.0007.

Schmitt, M. T., Spears, R., \& Branscombe, N. R. (2003). Constructing a minority group identity out of shared rejection: The case of international students. European Journal of Social Psychology, 33, $1-12$.

Selby, H.A., and Woods, C.M. (1966). Foreign students at a high-pressure university. Sociology of Education, 39, 138-154. doi:10.2307/2111864.

Sharma, M. P, \& Mulka, J.S. (1993). The impact of international education upon United States students in comparative perspective. A paper presented at the annual conference of the Comparative and International Education Society. Kingston, Jamaica.

Sheehan, O. T. O., \& Pearson, F. (1995). Asian International and American students' psychosocial development. Journal of College Student Development, 36. 522-530.

Shenoy, U. A. (2001). College-stress and symptom expression in international students: A comparative study. Unpublished doctoral dissertation, Virginia Polytechnic Institute and State University, Blacksburg, Virginia

Sherry, C., Bhat, R., Beaver, B., \& Ling, A. (2004). Students as customers: The expectations and perceptions of local and international students. Paper presented at the HERDSA 2004.

Conference, Sarawak comparative and international education society. Kingston, Jamaica.

Smith, H. A. (1989). The Socio-Economic Importance of Links between Campuses, Communities, and International Students and Alumni: Perceptions of Collegiate and Community Leaders. Mississippi State University, Mississippi State 
Sodowsky, G. R., and Plake, B.S. (1992). A study of acculturation differences among international people and suggestions for sensitivity to within-group differences. Journal of Counseling and Development, 71, 53-59.

Spaulding, S. \& Flack, M. (1976). The World's Students in the United States. New York: Praeger.

Spencer-Rodgers, J. (2000). The vocational situation and country of orientation of international students. Journal of Multicultural Counseling and Development, 28, 32-49.

Spencer-Rodgers, J. (2001). Consensual and individual stereotypic beliefs about international students among American host nationals. International Journal of Intercultural Relations, 25, 639-657.

Stewart, B. J., \& Mendenhall. (1991). The U-Curve Adjustment Hypothesis Revisited: A Review and Theoretical Framework. Journal of International Business Studies. 22. 22

Stoynoff, S. (1997). Factors associated with international student's academic achievement. Journal of Instructional Psychology, 24, 56-68

Stroebe, M., Van Vliet, T., Hewstone, M., \& Willis, H. (2002). Homesickness among students in two cultures: Antecedents and consequences. British Journal of Psychology, 93, 147-168.

Sue, D. W. \& Sue, D. (2013). Counseling the culturally diverse: Theory and practice. Hoboken, NJ: Wiley.

Sue, S., \& Zane, N. S. (1985). Academic achievement and socio-emotional adjustment among Chinese University students. Journal of Counseling Psychology, 32(4), 570-579.

Sumer, S., Poyrazli, S., \& Grahame, K. (2008). Predictors of depression and anxiety among international students. Journal of Counseling and Development, 86, 429-437.

Thomas, R. (2006). International students. International Journal of Learning, 13, 113-122. 
Thurber, C., \& Walton, E. (2012). Homesickness and Adjustment in University Students. Journal of American College Health: 60, 415-419. 10.1080/07448481.2. Retrieved from https://www.healthcare.gov/young-adults/college-students.

Townsend, P., \& Lee, C. (2004). Cultural adaptation: A comparative analysis of tertiary students' international education experience. Tourism Review International, 8, 143-152.

Townsend, P. \& Poh, H. J. (2008). An exploratory study of international students studying and living in a regional area. Journal of Marketing for Higher Education, 18, 240-263.

Triandis, H. C. (1999). Cross-cultural psychology. Asian Journal of Social Psychology, 2, 127-143.

Tseng, W. C., and Newton, F. B. (2002). International students' strategies for well- being. College Student Journal, 36, 591-597

Tsevi, L. (2018). Survival strategies of international undergraduate students at a public research Midwestern university in the United States: A case study. Journal of International Student, 8 (2), 1034-1058. Doi: 10.55281/zendo.1250404.

U.K. Department of Education (2017), Research Report. Retrieved January 3, 2019, from https://www.gov.uk/government/publications

Urban, E., \& Orbe, M. P. (2007). “The syndrome of the boiled frog:” Exploring international students on U.S. campuses as co-cultural group members. Journal of Intercultural Communication Research, $36,117-138$.

Urban, E., Orbe, M. P., Tavares, N. A., \& Alvarez, W. (2010). Exploration of Dominican international students' experiences. Journal of Student Affairs Research and Practice, 47, 233-250.

Usunier, J. (1998). Oral pleasure and expatriate satisfaction: An empirical approach. International Business Review, 7, 89-110. 
U.S. Immigration and Customs Enforcement (ICE). 2018. SEVIS by the Numbers: Biannual Report on International Student Trends. Washington, DC: ICE.

U.S. Department of Homeland Security (2013). "What is the I-901 SEVIS Fee?" https://studyinthestates.dhs.gov/2013/01/what-is-the-i-901-sevis-fee

Vickers, P., \& Bekhradnia B. (2007). The economic costs and benefits of international students. Oxford, UK: Higher Education Policy Institute (HEPI) Report. https://www.hepi.ac.uk/wpcontent/uploads/2014/02/32Economiceffectsofinternationalstudents. pdf

Wadsworth, B. C., Hecht, M. L., \& Jung, E. (2008). The role of identity gaps, discrimination, and acculturation in international students' educational satisfaction in American classrooms. Communication Education, 57, 64-87.

Wan, G. (2001). The learning experience of Chinese students in American universities: a cross-cultural perspective. College Student Journal, 35(1), 28 - 44.

Wang, J. (2004). A Study of the adjustment of international graduate students at American universities, including both resilience characteristics and traditional background factors (Doctoral Dissertation, Florida State University, 2004). Dissertation Abstracts International, 64, 10-A.

Walker, L. A., \& Conyne, R. K. (2007). Group work with international students. In H. D. Singarevelu \& M. Pope (Eds.), A Handbook for Counseling International Students in the United States (pp. 336). Alexandria, VA: American Counseling Association.

Warren, K. A., \& Constantine, G. M. (2007). Counseling African international students. In D. H. Singaravelu \& M. Pope (Eds.), A Handbook for Counseling International Students in the United States (pp. 211-222). Alexandria, VA: American Counseling Association. 
Wei, M., Ku, T., Russell, D.W., Mallinctrodt, B., \& Liao, K. Y. (2008). Moderating effects of three coping strategies and self-esteem on perceived discrimination and depressive symptoms: A minatory stress model for Asian international students. Journal of Counseling Psychology, 55, 451-462.

White, W.A., \& Rosado, C. (2014). How can international students overcome their biggest obstacle in an American university? Journal of International Education Research, 10(3), 241-248.

WVU Student Government (2007). “8”. Dream Big, Dream Here. Tapestry Press.

Yang, S., Salzman, M., \& Yang, C. (2015). Exploring adjustment problems among international graduate students in Hawaii. . Universal Journal of Educational Research 3(3), 214-219.

http://www.hrpub.org/journals/article_info.php?aid=2393

Yao, E. L. (1983). Chinese students in American universities. Texas Tech Journal of Education, 10, 3542

Yakushko, O., Davidson, M. M., \& Sanford-Maartens, T. C. (2008). Seeking help in a foreign land: International students' use patterns for a U.S. university counseling center. Journal of College Counseling, 11, 6-18.

Yang, M. (2007). What attracts mainland Chinese students to Australian Higher Education? Studies in learning, evaluation, innovation and development, 4, 1-2.

Yeh, C. J. \& Inose, M. (2003). International students' reported English fluency, social support satisfaction, and social connectedness as predictors of acculturative stress. Counselling Psychology Quarterly, 2003, 15-28.

Yeoh, J.S., \& Terry, D.R. (2013). International research students' experience in academic success. Universal Journal of Educational Research, 1(3), 275-280. Doi:10.13189/ujer.2014.010319. 
Zhang, Z. \& Brunton, M. (2007). Differences in living and learning: Chinese international students in New Zealand. Journal of Studies in International Education, 11, 124-140.

Zhou, Y., Frey, C., \& Bang, H. (2011). Understanding of international graduate students' academic adaptation to a U.S. graduate school. International Education, 41(1), 76-94.

Zimmermann, S. (1995). Perceptions of intercultural communication competence and international student adaptation to an American Campus. Communication Education, 44, 321-335. 
Appendices 
Appendix A: Institutional Review Board Approval Letter 


\section{Acknowledgement of Exemption}

$07 / 03 / 2019$

To: Peter Schaeffer

From: WVU Office of Research Integrity \& Compliance

Protocol Type: Exempt

Approval Date: 07/03/2019

Submission Type: Initial

Expiration Date: 07/02/2022

Funding: N/A

WVU Protocol \#: 1906605405

Protocol Title: International Students Adjustment Challenges in The United States: A Case

Study of West Virginia University

The West Virginia University Institutional Review Board has reviewed your submission of Exempt protocol 1906605405. Additional details regarding the review are below:

- This research study was granted an exemption because the Research involves educational tests, survey procedures, interview procedures or observation of public behavior and (i) information obtained is recorded in such a manner that human subjects cannot be identified, directly or through identifiers linked to the subjects; and (ii) any disclosure of the human subjects responses outside the research could not reasonably place the subjects at risk of criminal or civil liability or be damaging to the subjects financial standing, employability, or reputation [45 CFR 46.101(2)]. All exemptions are only good for three years. If this research extends more than three years beyond the approved date, then the researcher will have to request another exemption. The following documents have been acknowledged for use in this study and are available in the WVU+kc system:

The following documents were reviewed and approved for use as part of this submission. Only the documents listed below may be used in the research. Please access and print the files in the Notes \& Attachments section of your approved protocol.

- International Students Survey for WVU.docx

Protocol \#: 1906605405

FWA: 00005078

IORG: 0000194

- Cover letter for Lawrencia Okai.pdf
Phone: 304-293-7073

Fax: 304-293-3098

Email: IRB@mail.wvu.edu 


\section{WVU IRB acknowledgement of protocol 1906605405 will expire on 07/02/2022.}

If the study is to continue beyond the expiration date, a renewal application must be submitted no later than two (2) weeks prior to expiration date. It is your responsibility to submit your protocol for renewal. Once you begin your human subjects research, the following regulations apply:

1. Unanticipated or serious adverse events and/or side effects encountered in this research study must be reported to the IRB within five (5) days, using the Notify IRB action in the electronic protocol.

2. Any modifications to the study protocol should be submitted only if there will be an increase in risk to subjects accompanying the proposed change(s).

3. You may not use a modified information sheet until it has been reviewed and acknowledged by the WVU IRB prior to implementation.

The Office of Research Integrity and Compliance will be glad to provide assistance to you throughout the research process. Please feel free to contact us by phone, at 304.293 .7073 or by email at IRB@mail.wvu.edu. 
Appendix B: Cover Letter for International Student Survey 
October 29, 2019

Dear Participant,

This letter is a request for you to take part in a research project "International Students Adjustment Challenges at West Virginia University". This project is being conducted by Lawrencia Baaba Okai in the Division of Design and Community Development at WVU under the supervision of Peter Schaeffer, Ph.D., professor of Resource Economics and Management, to fulfil requirements for the degree of Doctor of Philosophy in Human and Community Development.

If you decide to participate, you will be asked to complete an online survey, which will take approximately fifteen minutes. All international students enrolled in the 2019/2020 academic year at WVU are being asked to participate in this research. International students who graduated in the Spring 2019 semester will be excluded. You must be 18 years of age or older to participate. Two participants of this survey will be randomly selected to receive a $\$ 25$ gift card. We request your email address so that we can enter your name in the drawing for the gift card. Your email address will be stored separately from the data collected in this study.

This project will respect your privacy and no identifiable data will be collected from you. Data will only be reported in the aggregate and you will not be asked questions that could lead back to your identity. Participation is voluntary. You may skip questions that you do not wish to answer, and you discontinue at any time. Your class standing will not be affected by your participation decision or withdrawal. The project has been cleared by West Virginia University's Institutional Review Board (IRB Protocol Number: 1906605405).

If you have any questions about this project, please contact me at 304-502-2317 or by e-mail at lbokai@mix.wvu.edu or you may contact Dr. Peter Schaeffer at 304-293-5572 or by email at Peter.Schaeffer@mail.wvu.edu. If you have any questions about your rights as a research participant, please contact the WVU Office of Human Research Protection at 304-293-7073 or by email at IRB@mail.wvu.edu.

I hope that you will participate in this research project to help us better understand the adjustment challenges of international students at WVU. Please click on the survey link below or copy and paste into your internet browser to take the survey.

https://wvu.qualtrics.com/jfe/form/SV_5nZXiUoEHIoseMt

Thank you for your time and consideration!

Sincerely,

Lawrencia Okai. 
Appendix C: International Student Survey 


\section{International Students Survey}

This survey seeks to improve our understanding of the experiences of international students at WVU. Answers to the questions will identify adjustment challenges they encounter. This information will help us design policies to better support international students.

1. Please carefully read each question before answering. We are interested in knowing two aspects of how each item below describes your perception of challenges. First, challenges are to be judged by considering what your expectations were before enrolling at WVU versus what you are experiencing now at WVU. If what you are experiencing exceeds your expectations, then that would be perceived as a challenge to you as an international student. The second aspect is to what extent does WVU assist you in meeting your challenges.

For each statement below, please make two ratings: First, by selecting the appropriate rating number, rate your perception of the item being a challenge to you. Second, rate your perception on the extent to which West Virginia University assists you in meeting this challenge.

\begin{tabular}{|l|l|}
\hline Ratings of Your Perception of the & $\begin{array}{l}\text { Ratings of WVU's Assistance Dealing with } \\
\text { the Challenge: }\end{array}$ \\
Challenge: & $7=$ Much better than expected \\
7= Much greater challenge than expected & $6=$ Better than expected \\
6= Greater challenge than expected & $5=$ Somewhat better than expected \\
$5=$ Somewhat expected & $4=$ Neutral-Exactly as I expected \\
$4=$ Neutral-Exactly what I expected & $3=$ Less than expected \\
$3=$ Easier than expected & $2=$ Much less than expected \\
$2=$ Much easier than expected & $1=$ No assistance at all \\
$1=$ No challenge at all & \\
&
\end{tabular}


Items

Your Perception of the Challenge

Admission Selection Problems

1. Differences between U.S. and Home Country Education System

2. Orientation to WVU

3. Relationship with international student advisor

\section{Orientation Service Problems}

4. Attitude of some students towards international students

5. Attitude of some U.S. citizens to skin color

6. Relationship between faculty and students

\section{Social/Personal Problems}

7. Treatment received at social functions

8. Being accepted in social groups

9. Insufficient personal- social counseling

\section{Financial Aid problems}

10. Unexpected financial needs

11.Finding employment between semesters

12.Lack of money to meet expenses

\section{English Language Problems}

13. Speaking English

14. Ability to write English

15. Understanding lectures in English

\section{Immigration Regulations}

16. Immigration regulations

17. Immigration work restrictions

18. Finding part time work

\section{Religious Service Problems}

19. Finding a worship group of own faith

20. Religion and morals in the U.S

21. Religious practices in U.S

\section{Health Service Problems}

22. Finding adequate health services

23. Dietary problems

24. Feeling stressed
How Did WVU Assist

You Meeting the

Challenge?

$\begin{array}{llllllllllllll}7 & 6 & 5 & 4 & 3 & 2 & 1 & 7 & 6 & 5 & 4 & 3 & 2 & 1 \\ 7 & 6 & 5 & 4 & 3 & 2 & 1 & 7 & 6 & 5 & 4 & 3 & 2 & 1 \\ 7 & 6 & 5 & 4 & 3 & 2 & 1 & 7 & 6 & 5 & 4 & 3 & 2 & 1\end{array}$

$\begin{array}{lllllll}7 & 6 & 5 & 4 & 3 & 2 & 1\end{array}$

$\begin{array}{lllllll}7 & 6 & 5 & 4 & 3 & 2 & 1\end{array}$

$\begin{array}{llllllllllllll}7 & 6 & 5 & 4 & 3 & 2 & 1 & 7 & 6 & 5 & 4 & 3 & 2 & 1\end{array}$

$\begin{array}{llllllllllllll}7 & 6 & 5 & 4 & 3 & 2 & 1 & 7 & 6 & 5 & 4 & 3 & 2 & 1\end{array}$

$\begin{array}{llllllllllllll}7 & 6 & 5 & 4 & 3 & 2 & 1 & 7 & 6 & 5 & 4 & 3 & 2 & 1\end{array}$

$\begin{array}{llllllllllllll}7 & 6 & 5 & 4 & 3 & 2 & 1 & 7 & 6 & 5 & 4 & 3 & 2 & 1\end{array}$

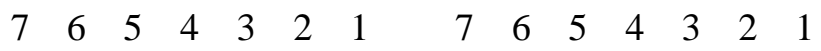

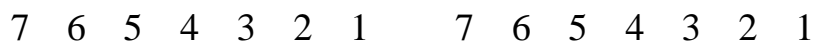

$\begin{array}{llllllllllllll}7 & 6 & 5 & 4 & 3 & 2 & 1 & 7 & 6 & 5 & 4 & 3 & 2 & 1\end{array}$

$\begin{array}{llllllllllllll}7 & 6 & 5 & 4 & 3 & 2 & 1 & 7 & 6 & 5 & 4 & 3 & 2 & 1\end{array}$

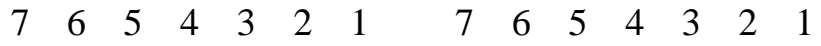

$\begin{array}{llllllllllllll}7 & 6 & 5 & 4 & 3 & 2 & 1 & 7 & 6 & 5 & 4 & 3 & 2 & 1\end{array}$

$\begin{array}{llllllllllllll}7 & 6 & 5 & 4 & 3 & 2 & 1 & 7 & 6 & 5 & 4 & 3 & 2 & 1\end{array}$

$\begin{array}{llllllllllllll}7 & 6 & 5 & 4 & 3 & 2 & 1 & 7 & 6 & 5 & 4 & 3 & 2 & 1\end{array}$

$\begin{array}{llllllllllllll}7 & 6 & 5 & 4 & 3 & 2 & 1 & 7 & 6 & 5 & 4 & 3 & 2 & 1\end{array}$

$\begin{array}{llllllllllllll}7 & 6 & 5 & 4 & 3 & 2 & 1 & 7 & 6 & 5 & 4 & 3 & 2 & 1\end{array}$

$\begin{array}{llllllllllllll}7 & 6 & 5 & 4 & 3 & 2 & 1 & 7 & 6 & 5 & 4 & 3 & 2 & 1\end{array}$

$\begin{array}{llllllllllllll}7 & 6 & 5 & 4 & 3 & 2 & 1 & 7 & 6 & 5 & 4 & 3 & 2 & 1\end{array}$

$\begin{array}{llllllllllllll}7 & 6 & 5 & 4 & 3 & 2 & 1 & 7 & 6 & 5 & 4 & 3 & 2 & 1\end{array}$

$\begin{array}{llllllllllllll}7 & 6 & 5 & 4 & 3 & 2 & 1 & 7 & 6 & 5 & 4 & 3 & 2 & 1\end{array}$

$\begin{array}{llllllllllllll}7 & 6 & 5 & 4 & 3 & 2 & 1 & 7 & 6 & 5 & 4 & 3 & 2 & 1\end{array}$

$\begin{array}{llllllllllllll}7 & 6 & 5 & 4 & 3 & 2 & 1 & 7 & 6 & 5 & 4 & 3 & 2 & 1\end{array}$ 
2. Please indicate below any additional situations that pose a challenge to you that are not listed in the previous question. Indicate their importance to you and the extent to which West Virginia University helps you meet them.

3. How have the following resources helped you overcome challenges faced here at West

Virginia University?

\section{Ratings}

$$
\begin{aligned}
& 5=\text { Very Helpful } \\
& 4=\text { Somewhat Helpful } \\
& 3=\text { Neutral } \\
& 2=\text { Very Little } \\
& 1=\text { Not at all }
\end{aligned}
$$

\begin{tabular}{|c|c|c|c|c|c|}
\hline & $\begin{array}{c}\text { Very } \\
\text { Helpful }\end{array}$ & & Neutral & & $\begin{array}{c}\text { Not at } \\
\text { All }\end{array}$ \\
\hline $\begin{array}{l}\text { International Student } \\
\text { Organizations }\end{array}$ & 5 & 4 & 3 & 2 & 1 \\
\hline $\begin{array}{l}\text { Academic Advisor or Major } \\
\text { Professor }\end{array}$ & 5 & 4 & 3 & 2 & 1 \\
\hline Other International Students & 5 & 4 & 3 & 2 & 1 \\
\hline American Students & 5 & 4 & 3 & 2 & 1 \\
\hline Local Campus Groups & 5 & 4 & 3 & 2 & 1 \\
\hline $\begin{array}{l}\text { Office of Diversity \& } \\
\text { Inclusion }\end{array}$ & 5 & 4 & 3 & 2 & 1 \\
\hline $\begin{array}{l}\text { International Students \& } \\
\text { Scholars Services }\end{array}$ & 5 & 4 & 3 & 2 & 1 \\
\hline Writing Studio & 5 & 4 & 3 & 2 & 1 \\
\hline Student Orientation & 5 & 4 & 3 & 2 & 1 \\
\hline Staff & 5 & 4 & 3 & 2 & 1 \\
\hline Instructors & 5 & 4 & 3 & 2 & 1 \\
\hline
\end{tabular}

4. Are there other resources that West Virginia University provides to you which you have utilized to cope or adjust as an international student? 
YES/NO

If YES, please explain.

5. Are there resources outside WVU (e.g. friends, church, family, etc.) that have helped you cope or adjust?

YES/NO

If YES, please specify.

6. Did you have family or friends (or both) in the U.S. before enrolling at WVU?

YES/NO.

If no please proceed to question 9.

7. If you answered YES to question 6, did your family/friends help you adjust to live at WVU? YES/NO.

If no proceed to question 9.

If YES, how did they help you adjust?

8. On a scale of 1-5, how engaged are you with your family/friends living in the US?

5=Very Engaged (Communicate Everyday)

$4=$ Engaged (Communicate every week)

$3=$ Neutral 
2= Not Very Engaged (Communicate once a month)

$1=$ Rarely Engaged (Communicate once a year)

\begin{tabular}{|c|c|c|c|c|}
\hline & & & Not Very & Rarely \\
Very Engaged & Engaged & Neutral & Engaged & Engaged \\
$\mathbf{5}$ & $\mathbf{4}$ & $\mathbf{3}$ & $\mathbf{2}$ & $\mathbf{1}$ \\
\hline & & & & \\
\hline
\end{tabular}

9. In addition to the above, what helps you cope?

This section seeks to know and understand who you are. This will help improve our interpretation of the study results in order to improve international students experiences at WVU.

10. Respondent's Age

Below 20 years Between 21 to 25 Between 26 to 30 Above 30

11. Respondent's Gender

Male

Female

12. Country/ Countries of Citizenship

13. Class in College

Undergraduate

Graduate

14. Marital Status

Married with

dependents

Single with
dependents

$\circ$ Single

15. Respondent's Department/Division at WVU 
16. Current Major/Discipline

17. Number of years at U.S. College(s) prior to WVU
0
$\mathrm{C}$
$\mathrm{C}$
$0 \mathrm{yrs} \quad$ Less than $2 \mathrm{yrs}$
$2-5$ yrs

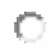
More than 5 yrs

18. How long have you been at WVU?
○ $0-6$
○ 6-12
months
$\circ \quad 1-3 \mathrm{yrs}$
○ 3 to 5
$\circ 5$ years and above months

\begin{abstract}
tions
\end{abstract}

years

19. Language you speak most fluently

Thank you very much for completing this survey. Hopefully this will eventually benefit international students and West Virginia University. 
Appendix D: Descriptive Analysis for Challenges 
Table of Descriptive for Individual Challenges

\begin{tabular}{|c|c|c|c|c|c|}
\hline \multicolumn{2}{|l|}{ Q1\#1 } & \multicolumn{2}{|l|}{ Q1\#2 } & \multicolumn{2}{|l|}{ Q1\#3 } \\
\hline Mean & 4.607843 & Mean & 4.586207 & Mean & 4.311881 \\
\hline Standard & & Standard & & Standard & \\
\hline Error & 0.110388 & Error & 0.106973 & Error & 0.12782 \\
\hline Median & 4 & Median & 5 & Median & 4 \\
\hline Mode & 4 & Mode & 4 & Mode & 4 \\
\hline Standard & & Standard & & Standard & \\
\hline Deviation & 1.576658 & Deviation & 1.524132 & Deviation & 1.816661 \\
\hline Sample & & Sample & & Sample & \\
\hline Variance & 2.48585 & Variance & 2.322977 & Variance & 3.300256 \\
\hline Kurtosis & -0.49964 & Kurtosis & -0.2724 & Kurtosis & -0.84459 \\
\hline Skewness & -0.25389 & Skewness & -0.3772 & Skewness & -0.1708 \\
\hline Range & 6 & Range & 6 & Range & 6 \\
\hline Minimum & 1 & Minimum & 1 & Minimum & 1 \\
\hline Maximum & 7 & Maximum & 7 & Maximum & 7 \\
\hline Sum & 940 & Sum & 931 & Sum & 871 \\
\hline Count & 204 & Count & 203 & Count & 202 \\
\hline Confidence & & Confidence & & Confidence & \\
\hline Level $(95.0 \%)$ & 0.217654 & Level $(95.0 \%)$ & 0.210927 & Level $(95.0 \%)$ & 0.25204 \\
\hline Q1\#4 & & Q1\#5 & & Q1\#6 & \\
\hline Mean & 4.772277 & Mean & 4.449495 & Mean & 4.879397 \\
\hline Standard Error & 0.11506 & Standard Error & 0.134058 & Standard Error & 0.116318 \\
\hline Median & 5 & Median & 4 & Median & 5 \\
\hline Mode & 4 & Mode & 4 & Mode & 5 \\
\hline Standard & & Standard & & Standard & \\
\hline Deviation & 1.635314 & Deviation & 1.886359 & Deviation & 1.640869 \\
\hline Sample Variance & 2.674252 & Sample Variance & 3.55835 & Sample Variance & 2.692452 \\
\hline Kurtosis & -0.74042 & Kurtosis & -0.94758 & Kurtosis & -0.38508 \\
\hline Skewness & -0.28311 & Skewness & -0.21869 & Skewness & -0.54594 \\
\hline Range & 6 & Range & 6 & Range & 6 \\
\hline Minimum & 1 & Minimum & 1 & Minimum & 1 \\
\hline Maximum & 7 & Maximum & 7 & Maximum & 7 \\
\hline Sum & 964 & Sum & 881 & Sum & 971 \\
\hline Count & 202 & Count & 198 & Count & 199 \\
\hline Confidence & & Confidence & & Confidence & \\
\hline Level(95.0\%) & 0.22688 & Level(95.0\%) & 0.264372 & Level(95.0\%) & 0.229381 \\
\hline
\end{tabular}




\begin{tabular}{lrlrlr}
\hline Q1\#7 & & Q1\#8 & & Q1\#9 & \\
& & & & & \\
Mean & 4.604061 & Mean & 4.746193 & Mean & 4.19898 \\
Standard Error & 0.106885 & Standard Error & 0.115524 & Standard Error & 0.106222 \\
Median & 4 & Median & 5 & Median & 4 \\
Mode & 4 & Mode & 4 & Mode & 4 \\
Standard & & Standard & & Standard & \\
Deviation & 1.500199 & Deviation & 1.621459 & Deviation & 1.487107 \\
Sample Variance & 2.250596 & Sample Variance & 2.629131 & Sample Variance & 2.211486 \\
Kurtosis & -0.29196 & Kurtosis & -0.59588 & Kurtosis & -0.09734 \\
Skewness & -0.189 & Skewness & -0.28584 & Skewness & 0.041011 \\
Range & 6 & Range & 6 & Range & 6 \\
Minimum & 1 & Minimum & 1 & Minimum & 1 \\
Maximum & 7 & Maximum & 7 & Maximum & 7 \\
Sum & 907 & Sum & 935 & Sum & 823 \\
Count & 197 & Count & 197 & Count & 196 \\
\hline Confidence & & Confidence & & Confidence & \\
Level(95.0\%) & 0.210792 & Level(95.0\%) & 0.22783 & Level(95.0\%) & 0.209491 \\
\hline \hline
\end{tabular}

\begin{tabular}{lrlrlr}
\hline Q1\#10 & & Q1\#11 & & Q1\#12 & \\
\hline & & & & \\
Mean & 3.98461 & Mean & 3.860825 & Mean & 3.876289 \\
Standard & & Standard & & Standard & \\
Error & 0.126457 & Error & 0.12672 & Error & 0.120429 \\
Median & 4 & Median & 4 & Median & 4 \\
Mode & 4 & Mode & 4 & Mode & 4 \\
Standard & & Standard & & Standard & \\
Deviation & 1.765876 & Deviation & 1.765006 & Deviation & 1.677388 \\
Sample & & Sample & & Sample & \\
Variance & 3.118319 & Variance & 3.115245 & Variance & 2.813632 \\
Kurtosis & -0.75628 & Kurtosis & -0.5182 & Kurtosis & -0.50922 \\
Skewness & -0.03885 & Skewness & 0.042425 & Skewness & -0.00232 \\
Range & 6 & Range & 6 & Range & 6 \\
Minimum & 1 & Minimum & 1 & Minimum & 1 \\
Maximum & 7 & Maximum & 7 & Maximum & 7 \\
Sum & 777 & Sum & 749 & Sum & 752 \\
Count & 195 & Count & 194 & Count & 194 \\
\hline Confidence & & Confidence & Confidence \\
Level (95.0\%) & 0.249407 & Level (95.0\%) & 0.249934 & Level (95.0\%) & 0.237527 \\
\hline & & & & \\
\hline
\end{tabular}




\begin{tabular}{lrlrlr}
\hline Q1\#13 & & Q1\#14 & & Q1\#15 \\
\hline & & & & \\
Mean & 4.661538 & Mean & 4.826531 & Mean & 4.873737 \\
& & Standard & & Standard & \\
Standard Error & 0.136384 & Error & 0.134762 & Error & 0.136976 \\
Median & 5 & Median & 5 & Median & 5 \\
Mode & 4 & Mode & 4 & Mode & 7 \\
Standard & & Standard & & Standard & \\
Deviation & 1.9045 & Deviation & 1.886663 & Deviation & 1.927418 \\
Sample & & Sample & & Sample & \\
Variance & 3.627121 & Variance & 3.559498 & Variance & 3.714941 \\
Kurtosis & -0.77976 & Kurtosis & -0.53804 & Kurtosis & -0.60928 \\
Skewness & -0.45082 & Skewness & -0.65405 & Skewness & -0.64411 \\
Range & 6 & Range & 6 & Range & 6 \\
Minimum & 1 & Minimum & 1 & Minimum & 1 \\
Maximum & 7 & Maximum & 7 & Maximum & 7 \\
Sum & 909 & Sum & 946 & Sum & 965 \\
Count & 195 & Count & 196 & Count & 198 \\
\hline Confidence & & Confidence & & Confidence & \\
Level (95.0\%) & 0.268986 & Level (95.0\%) & 0.265777 & Level (95.0\%) & 0.270127 \\
\hline \hline
\end{tabular}

\begin{tabular}{|c|c|c|c|c|c|}
\hline Q1\#16 & & Q1\#17 & & Q1\#18 & \\
\hline Mean & 4.326531 & $\begin{array}{l}\text { Mean } \\
\text { Standard }\end{array}$ & 3.989744 & $\begin{array}{l}\text { Mean } \\
\text { Standard }\end{array}$ & 3.716495 \\
\hline Standard Error & 0.120732 & Error & 0.138339 & Error & 0.125679 \\
\hline Median & 4 & Median & 4 & Median & 4 \\
\hline Mode & 4 & Mode & 4 & Mode & 4 \\
\hline Standard & & Standard & & Standard & \\
\hline Deviation & 1.690247 & Deviation & 1.9318 & Deviation & 1.75051 \\
\hline Sample & & Sample & & Sample & \\
\hline Variance & 2.856934 & Variance & 3.731853 & Variance & 3.064286 \\
\hline Kurtosis & -0.44086 & Kurtosis & -0.94307 & Kurtosis & -0.61742 \\
\hline Skewness & -0.19587 & Skewness & -0.00702 & Skewness & 0.113627 \\
\hline Range & 6 & Range & 6 & Range & 6 \\
\hline Minimum & 1 & Minimum & 1 & Minimum & 1 \\
\hline Maximum & 7 & Maximum & 7 & Maximum & 7 \\
\hline Sum & 848 & Sum & 778 & Sum & 721 \\
\hline Count & 196 & Count & 195 & Count & 194 \\
\hline Confidence & & Confidence & & Confidence & \\
\hline Level (95.0\%) & 0.238108 & Level (95.0\%) & 0.272842 & Level (95.0\%) & 0.247881 \\
\hline
\end{tabular}




\begin{tabular}{lrlrlr}
\hline Q1\#19 & & Q1\#20 & & Q1\#21 & \\
& & & & \\
Mean & 3.892308 & Mean & 4.072165 & Mean & 4.104167 \\
Standard & & Standard & & Standard & \\
Error & 0.124113 & Error & 0.127952 & Error & 0.123785 \\
Median & 4 & Median & 4 & Median & 4 \\
Mode & 4 & Mode & 4 & Mode & 4 \\
Standard & & Standard & & Standard & \\
Deviation & 1.733149 & Deviation & 1.782165 & Deviation & 1.715218 \\
Sample & & Sample & & Sample & \\
Variance & 3.003807 & Variance & 3.176112 & Variance & 2.941972 \\
Kurtosis & -0.47832 & Kurtosis & -0.53398 & Kurtosis & -0.428 \\
Skewness & -0.0305 & Skewness & -0.06547 & Skewness & -0.1445 \\
Range & 6 & Range & 6 & Range & 6 \\
Minimum & 1 & Minimum & 1 & Minimum & 1 \\
Maximum & 7 & Maximum & 7 & Maximum & 7 \\
Sum & 759 & Sum & 790 & Sum & 788 \\
Count & 195 & Count & 194 & Count & 192 \\
\hline Confidence & & Confidence & & Confidence & \\
Level (95.0\%) & 0.244785 & Level (95.0\%) & 0.252364 & Level (95.0\%) & 0.244162 \\
\hline \hline
\end{tabular}

\begin{tabular}{lrlrlr}
\hline Q1\#22 & & Q1\#23 & & Q1\#24 \\
\hline Mean & 4.188776 & Mean & 4.253807 & Mean & 4.318182 \\
Standard & & Standard & & Standard & \\
Error & 0.129607 & Error & 0.12291 & Error & 0.132515 \\
Median & 4 & Median & 4 & Median & 4 \\
Mode & 4 & Mode & 4 & Mode & 4 \\
Standard & & Standard & & Standard & \\
Deviation & 1.814493 & Deviation & 1.725129 & Deviation & 1.864652 \\
Sample & & Sample & & Sample & \\
Variance & 3.292386 & Variance & 2.97607 & Variance & 3.476927 \\
Kurtosis & -0.85778 & Kurtosis & -0.5593 & Kurtosis & -0.93075 \\
Skewness & -0.04502 & Skewness & -0.02547 & Skewness & -0.15914 \\
Range & 6 & Range & 6 & Range & 6 \\
Minimum & 1 & Minimum & 1 & Minimum & 1 \\
Maximum & 7 & Maximum & 7 & Maximum & 7 \\
Sum & 821 & Sum & 838 & Sum & 855 \\
Count & 196 & Count & 197 & Count & 198 \\
\hline & & & Confidence & \\
Confidence & & Confidence & & Level & \\
Level (95.0\%) & 0.255611 & Level (95.0\%) & 0.242397 & (95.0\%) & 0.26133 \\
\hline
\end{tabular}


Appendix E: One Factor ANOVA Analysis for Challenges with Age 


\begin{tabular}{lcrrrrr} 
ANOVA & \multicolumn{8}{c}{ Q1 } \\
\hline \multicolumn{1}{c}{$\begin{array}{l}\text { Source of } \\
\text { Variation }\end{array}$} & \multicolumn{1}{c}{$S S$} & $d f$ & $M S$ & \multicolumn{1}{c}{ M } & P-value & F crit \\
\hline Between Groups & 4.157943 & 2 & 2.078972 & 0.832432 & 0.436554 & 3.042964 \\
Within Groups & 479.5139 & 192 & 2.497468 & & & \\
& & & & & & \\
Total & 483.6718 & 194 & & & & \\
\hline
\end{tabular}

ANOVA

Q2

\begin{tabular}{lrrrrrr}
\hline \multicolumn{1}{c}{$\begin{array}{l}\text { Source of } \\
\text { Variation }\end{array}$} & \multicolumn{1}{c}{$S S$} & \multicolumn{1}{c}{ df } & MS & \multicolumn{1}{c}{ F } & P-value & F crit \\
\hline Between Groups & 1.792723 & 2 & 0.896362 & 0.382413 & 0.682734 & 3.043214 \\
Within Groups & 447.697 & 191 & 2.343963 & & & \\
& & & & & & \\
Total & 449.4897 & 193 & & & & \\
\hline
\end{tabular}

ANOVA

Q3

\begin{tabular}{lrrrrrr}
\hline \multicolumn{1}{c}{$\begin{array}{c}\text { Source of } \\
\text { Variation }\end{array}$} & \multicolumn{1}{c}{ SS } & df & MS & \multicolumn{1}{c}{ F } & P-value & F crit \\
\hline Between Groups & 0.970533 & 2 & 0.485266 & 0.150052 & 0.860765 & 3.043466 \\
Within Groups & 614.4595 & 190 & 3.233997 & & & \\
& & & & & & \\
Total & 615.4301 & 192 & & & & \\
\hline
\end{tabular}

\begin{tabular}{lcrrrrr} 
ANOVA & \multicolumn{8}{c}{ Q4 } \\
\hline \multicolumn{1}{c}{$\begin{array}{l}\text { Source of } \\
\text { Variation }\end{array}$} & \multicolumn{1}{c}{ SS } & $d f$ & $M S$ & \multicolumn{1}{c}{ M } & P-value & F crit \\
\hline Between Groups & 10.79169 & 2 & 5.395846 & 2.059831 & 0.130313 & 3.043466 \\
Within Groups & 497.7161 & 190 & 2.619558 & & & \\
& & & & & & \\
Total & 508.5078 & 192 & & & & \\
\hline
\end{tabular}

\begin{tabular}{lcrrrrr} 
ANOVA & \multicolumn{8}{c}{ Q5 } \\
\hline \multicolumn{1}{c}{$\begin{array}{l}\text { Source of } \\
\text { Variation }\end{array}$} & \multicolumn{1}{c}{$S S$} & $d f$ & $M S$ & \multicolumn{1}{c}{$F$} & P-value & F crit \\
\hline Between Groups & 2.013307 & 2 & 1.006653 & 0.286897 & 0.750919 & 3.04424 \\
Within Groups & 656.1393 & 187 & 3.508766 & & & \\
& & & & & & \\
Total & 658.1526 & 189 & & & & \\
\hline
\end{tabular}




\begin{tabular}{lrrrrrr} 
ANOVA & \multicolumn{8}{c}{ Q6 } \\
\hline \multicolumn{1}{c}{$\begin{array}{l}\text { Source of } \\
\text { Variation }\end{array}$} & \multicolumn{1}{c}{$S S$} & \multicolumn{1}{c}{ D f } & \multicolumn{1}{c}{$M S$} & \multicolumn{1}{c}{ F } & P-value & F crit \\
\hline Between Groups & 4.79342 & 2 & 2.39671 & 0.905387 & 0.406141 & 3.04398 \\
Within Groups & 497.6673 & 188 & 2.647167 & & & \\
& & & & & & \\
Total & 502.4607 & 190 & & & & \\
\hline
\end{tabular}

\begin{tabular}{lcrrrrr} 
ANOVA & \multicolumn{8}{c}{ Q7 } \\
\hline \multicolumn{1}{c}{$\begin{array}{l}\text { Source of } \\
\text { Variation }\end{array}$} & \multicolumn{1}{c}{ SS } & Df & MS & \multicolumn{1}{c}{$F$} & P-value & F crit \\
\hline Between Groups & 10.66214 & 2 & 5.331068 & 2.421583 & 0.091575 & 3.044504 \\
Within Groups & 409.4754 & 186 & 2.201481 & & & \\
& & & & & & \\
Total & 420.1376 & 188 & & & & \\
\hline
\end{tabular}

\begin{tabular}{lcrrrrr} 
ANOVA & \multicolumn{8}{c}{ Q8 } \\
\hline \multicolumn{1}{c}{$\begin{array}{l}\text { Source of } \\
\text { Variation }\end{array}$} & \multicolumn{1}{c}{$S S$} & Df & $M S$ & \multicolumn{1}{c}{ M } & P-value & F crit \\
\hline Between Groups & 2.384016 & 2 & 1.192008 & 0.469819 & 0.625855 & 3.044504 \\
Within Groups & 471.9123 & 186 & 2.537163 & & & \\
& & & & & & \\
Total & 474.2963 & 188 & & & & \\
\hline
\end{tabular}

\begin{tabular}{|c|c|c|c|c|c|c|}
\hline ANOVA & & & Q9 & & & \\
\hline $\begin{array}{l}\text { Source of } \\
\text { Variation }\end{array}$ & $S S$ & $D f$ & $M S$ & $F$ & P-value & $F$ crit \\
\hline Between Groups & 0.0538 & 2 & 0.0269 & 0.012202 & 0.987873 & 3.044771 \\
\hline Within Groups & 407.8345 & 185 & 2.204511 & & & \\
\hline Total & 407.8883 & 187 & & & & \\
\hline ANOVA & & & Q10 & & & \\
\hline $\begin{array}{l}\text { Source of } \\
\text { Variation } \\
\end{array}$ & $S S$ & $D f$ & $M S$ & $F$ & P-value & $F$ crit \\
\hline Between Groups & 9.568468 & 2 & 4.784234 & 1.571712 & 0.210465 & 3.04504 \\
\hline Within Groups & 560.0893 & 184 & 3.043964 & & & \\
\hline Total & 569.6578 & 186 & & & & \\
\hline
\end{tabular}


ANOVA

Q11

\begin{tabular}{lcrrrrr}
\hline \multicolumn{1}{c}{$\begin{array}{l}\text { Source of } \\
\text { Variation }\end{array}$} & \multicolumn{1}{c}{ SS } & \multicolumn{1}{c}{ df } & \multicolumn{1}{c}{ MS } & \multicolumn{1}{c}{ F } & P-value & F crit \\
\hline Between Groups & 1.437792 & 2 & 0.718896 & 0.23818 & 0.788305 & 3.045312 \\
Within Groups & 552.3472 & 183 & 3.01829 & & & \\
& & & & & & \\
Total & 553.7849 & 185 & & & & \\
\hline
\end{tabular}

ANOVA

Q12

\begin{tabular}{lcrcccc}
\hline \multicolumn{1}{c}{$\begin{array}{l}\text { Source of } \\
\text { Variation }\end{array}$} & \multicolumn{1}{c}{ SS } & df & MS & \multicolumn{1}{c}{ F } & P-value & F crit \\
\hline Between Groups & 15.01089 & 2 & 7.505443 & 2.79946 & 0.063451 & 3.045312 \\
Within Groups & 490.6289 & 183 & 2.681032 & & & \\
& & & & & & \\
Total & 505.6398 & 185 & & & & \\
\hline
\end{tabular}

ANOVA

Q13

\begin{tabular}{lrrrrrr}
\multicolumn{1}{c}{$\begin{array}{l}\text { Source of } \\
\text { Variation }\end{array}$} & \multicolumn{1}{c}{ QS } & df & MS & \multicolumn{1}{c}{ F } & P-value & F crit \\
\hline Between Groups & 0.771947 & 2 & 0.385974 & 0.105484 & 0.899943 & 3.04504 \\
Within Groups & 673.2708 & 184 & 3.659081 & & & \\
& & & & & & \\
Total & 674.0428 & 186 & & & & \\
\hline
\end{tabular}

ANOVA

Q14

\begin{tabular}{lcrcccc}
\hline \multicolumn{1}{c}{$\begin{array}{l}\text { Source of } \\
\text { Variation }\end{array}$} & \multicolumn{1}{c}{ SS } & $d f$ & $M S$ & \multicolumn{1}{c}{ F } & P-value & F crit \\
\hline Between Groups & 1.62607 & 2 & 0.813035 & 0.225508 & 0.79833 & 3.044771 \\
Within Groups & 666.991 & 185 & 3.605356 & & & \\
& & & & & & \\
Total & 668.617 & 187 & & & & \\
\hline
\end{tabular}

ANOVA

Q15

\begin{tabular}{lcrrrrr}
\hline \multicolumn{1}{c}{$\begin{array}{l}\text { Source of } \\
\text { Variation }\end{array}$} & \multicolumn{1}{c}{ SS } & \multicolumn{1}{c}{ df } & \multicolumn{1}{c}{ MS } & \multicolumn{1}{c}{ F } & P-value & F crit \\
\hline Between Groups & 0.493494 & 2 & 0.246747 & 0.065969 & 0.936182 & 3.04424 \\
Within Groups & 699.4486 & 187 & 3.740367 & & & \\
& & & & & & \\
Total & 699.9421 & 189 & & & & \\
\hline
\end{tabular}


ANOVA

\begin{tabular}{|c|c|c|c|c|c|c|}
\hline $\begin{array}{l}\text { Source of } \\
\text { Variation }\end{array}$ & $S S$ & $D f$ & $M S$ & $F$ & $P$-value & $F$ crit \\
\hline Between Groups & 0.80856 & 2 & 0.40428 & 0.145204 & 0.864944 & 3.044771 \\
\hline Within Groups & 515.0797 & 185 & 2.784215 & & & \\
\hline Total & 515.8883 & 187 & & & & \\
\hline ANOVA & & & Q17 & & & \\
\hline $\begin{array}{l}\text { Source of } \\
\text { Variation } \\
\end{array}$ & $S S$ & $D f$ & $M S$ & $F$ & $P$-value & $F$ crit \\
\hline Between Groups & 1.732783 & 2 & 0.866391 & 0.233002 & 0.792385 & 3.04504 \\
\hline Within Groups & 684.1817 & 184 & 3.718379 & & & \\
\hline Total & 685.9144 & 186 & & & & \\
\hline ANOVA & & & Q18 & & & \\
\hline $\begin{array}{l}\text { Source of } \\
\text { Variation }\end{array}$ & $S S$ & $D f$ & $M S$ & $F$ & $P$-value & $F$ crit \\
\hline Between Groups & 19.36192 & 2 & 9.680961 & 3.334024 & 0.037828 & 3.045312 \\
\hline Within Groups & 531.3746 & 183 & 2.903687 & & & \\
\hline Total & 550.7366 & 185 & & & & \\
\hline
\end{tabular}

ANOVA

Q19

\begin{tabular}{lcrrcrc}
\hline \multicolumn{1}{c}{$\begin{array}{l}\text { Source of } \\
\text { Variation }\end{array}$} & \multicolumn{1}{c}{ SS } & \multicolumn{1}{c}{ Df } & MS & \multicolumn{1}{c}{ F } & P-value & F crit \\
\hline Between Groups & 1.760728 & 2 & 0.880364 & 0.298525 & 0.74227 & 3.04504 \\
Within Groups & 542.6243 & 184 & 2.949045 & & & \\
& & & & & & \\
Total & 544.385 & 186 & & & & \\
\hline
\end{tabular}

ANOVA

Q20

\begin{tabular}{lrrrrrr}
\hline \multicolumn{1}{c}{$\begin{array}{l}\text { Source of } \\
\text { Variation }\end{array}$} & \multicolumn{1}{c}{ SS } & \multicolumn{1}{c}{ Df } & \multicolumn{1}{c}{ MS } & \multicolumn{1}{c}{ F } & P-value & F crit \\
\hline Between Groups & 3.498419 & 2 & 1.74921 & 0.568982 & 0.5671 & 3.045312 \\
Within Groups & 562.593 & 183 & 3.074279 & & & \\
& & & & & & \\
Total & 566.0914 & 185 & & & & \\
\hline
\end{tabular}




\begin{tabular}{lcrrrrr} 
ANOVA & \multicolumn{8}{c}{ Q21 } \\
\hline \multicolumn{1}{c}{$\begin{array}{l}\text { Source of } \\
\text { Variation }\end{array}$} & \multicolumn{1}{c}{ SS } & \multicolumn{1}{c}{ df } & \multicolumn{1}{c}{$M S$} & \multicolumn{1}{c}{ F } & P-value & F crit \\
\hline Between Groups & 4.980184 & 2 & 2.490092 & 0.871602 & 0.420029 & 3.045866 \\
Within Groups & 517.1013 & 181 & 2.856913 & & & \\
& & & & & & \\
Total & 522.0815 & 183 & & & & \\
\hline
\end{tabular}

ANOVA

Q22

\begin{tabular}{lcrcccc}
\hline \multicolumn{1}{c}{$\begin{array}{c}\text { Source of } \\
\text { Variation }\end{array}$} & \multicolumn{1}{c}{ SS } & \multicolumn{1}{c}{ df } & MS & \multicolumn{1}{c}{ F } & P-value & F crit \\
\hline Between Groups & 7.848012 & 2 & 3.924006 & 1.235929 & 0.292952 & 3.044771 \\
Within Groups & 587.3648 & 185 & 3.174945 & & & \\
& & & & & & \\
Total & 595.2128 & 187 & & & & \\
\hline
\end{tabular}

ANOVA

Q23

\begin{tabular}{lcrrrrr}
\hline \multicolumn{1}{c}{$\begin{array}{c}\text { Source of } \\
\text { Variation }\end{array}$} & \multicolumn{1}{c}{ SS } & $d f$ & \multicolumn{1}{c}{ MS } & \multicolumn{1}{c}{ F } & P-value & F crit \\
\hline Between Groups & 12.83217 & 2 & 6.416083 & 2.256261 & 0.107601 & 3.044504 \\
Within Groups & 528.9244 & 186 & 2.84368 & & & \\
& & & & & & \\
Total & 541.7566 & 188 & & & & \\
\hline
\end{tabular}

ANOVA

\begin{tabular}{lrrrrrr} 
ANOVA & \multicolumn{8}{c}{ Q24 } \\
\hline \multicolumn{1}{c}{$\begin{array}{c}\text { Source of } \\
\text { Variation }\end{array}$} & \multicolumn{1}{c}{$S S$} & \multicolumn{1}{c}{ Sf } & \multicolumn{1}{c}{ MS } & \multicolumn{1}{c}{$F$} & P-value & F crit \\
\hline Between Groups & 8.38125 & 2 & 4.190625 & 1.228808 & 0.294993 & 3.04424 \\
Within Groups & 637.7293 & 187 & 3.410317 & & & \\
& & & & & & \\
Total & 646.1105 & 189 & & & & \\
\hline
\end{tabular}


Appendix F: One Factor ANOVA Analysis for Challenges and Years Enrolled at WVU 
ANOVA

Q1

Source of

Variation

Between Groups

Within Groups

$S S$

$M S$

\begin{tabular}{ccccc}
$d f$ & $M S$ & $F$ & $P$-value & $F$ crit \\
\hline 2 & 1.883013 & 0.757774 & 0.470105 & 3.042964
\end{tabular}

477.1058

$192 \quad 2.484926$

Total

480.8718

194

ANOVA

Q2

Source of

Variation

Between Groups 2.966127

Within Groups $\quad 440.2143$

\begin{tabular}{ccccc}
$d f$ & $M S$ & $F$ & $P$-value & $F$ crit \\
\hline 2 & 1.483063 & 0.643471 & 0.526601 & 3.043214
\end{tabular}

$191 \quad 2.304787$

Total

443.1804

193

ANOVA

Q3

Source of

Variation

Between Groups 17.39996

Within Groups $\quad 610.0301$

df $\quad M S$

F P-value $\quad F$ crit

$\begin{array}{llllll}2 & 8.699981 & 2.709697 & 0.06913 & 3.043466\end{array}$

$190 \quad 3.210685$

Total

627.4301

192

\begin{tabular}{lcrrrrr} 
ANOVA & \multicolumn{8}{c}{ Q4 } \\
\hline \multicolumn{1}{c}{$\begin{array}{l}\text { Source of } \\
\text { Variation }\end{array}$} & \multicolumn{1}{c}{$S S$} & $d f$ & \multicolumn{1}{c}{$M S$} & \multicolumn{1}{c}{$F$} & P-value & F crit \\
\hline Between Groups & 7.654779 & 2 & 3.82739 & 1.45091 & 0.236941 & 3.043466 \\
Within Groups & 501.2053 & 190 & 2.637923 & & & \\
& & & & & & \\
Total & 508.8601 & 192 & & & & \\
\hline
\end{tabular}

ANOVA

Q5

\begin{tabular}{lcrcccc}
\hline \multicolumn{1}{c}{$\begin{array}{c}\text { Source of } \\
\text { Variation }\end{array}$} & \multicolumn{1}{c}{ SS } & \multicolumn{1}{c}{ df } & MS & \multicolumn{1}{c}{ F } & P-value & F crit \\
\hline Between Groups & 11.81139 & 2 & 5.905693 & 1.691737 & 0.187006 & 3.04424 \\
Within Groups & 652.7991 & 187 & 3.490904 & & & \\
& & & & & & \\
Total & 664.6105 & 189 & & & & \\
\hline
\end{tabular}




\begin{tabular}{|c|c|c|c|c|c|c|}
\hline ANOVA & & & Q6 & & & \\
\hline $\begin{array}{l}\text { Source of } \\
\text { Variation } \\
\end{array}$ & $S S$ & $D f$ & $M S$ & $F$ & P-value & $F$ crit \\
\hline Between Groups & 1.280778 & 2 & 0.640389 & 0.23514 & 0.790693 & 3.04398 \\
\hline Within Groups & 512.0072 & 188 & 2.723442 & & & \\
\hline Total & 513.288 & 190 & & & & \\
\hline ANOVA & & & Q7 & & & \\
\hline $\begin{array}{l}\text { Source of } \\
\text { Variation }\end{array}$ & $S S$ & $D f$ & $M S$ & $F$ & P-value & $F$ crit \\
\hline Between Groups & 3.864682 & 2 & 1.932341 & 0.862821 & 0.423652 & 3.044504 \\
\hline Within Groups & 416.5586 & 186 & 2.239562 & & & \\
\hline Total & 420.4233 & 188 & & & & \\
\hline
\end{tabular}

\begin{tabular}{lcrcccc} 
ANOVA & \multicolumn{8}{c}{ Q8 } \\
\hline \multicolumn{1}{c}{$\begin{array}{l}\text { Source of } \\
\text { Variation }\end{array}$} & \multicolumn{1}{c}{ SS } & Df & MS & \multicolumn{1}{c}{ F } & P-value & F crit \\
\hline Between Groups & 5.079307 & 2 & 2.539653 & 0.978786 & 0.377694 & 3.044504 \\
Within Groups & 482.6138 & 186 & 2.594698 & & & \\
& & & & & & \\
Total & 487.6931 & 188 & & & & \\
\hline
\end{tabular}

\begin{tabular}{lcrcccc} 
ANOVA & \multicolumn{8}{c}{ Q9 } \\
\hline \multicolumn{1}{c}{$\begin{array}{l}\text { Source of } \\
\text { Variation }\end{array}$} & \multicolumn{1}{c}{ SS } & Df & MS & \multicolumn{1}{c}{ F } & P-value & F crit \\
\hline Between Groups & 3.723526 & 2 & 1.861763 & 0.872494 & 0.41962 & 3.044771 \\
Within Groups & 394.7605 & 185 & 2.133841 & & & \\
& & & & & & \\
Total & 398.484 & 187 & & & & \\
\hline
\end{tabular}

\begin{tabular}{lrrrrrr} 
ANOVA & \multicolumn{7}{c}{ Q10 } \\
\hline \multicolumn{1}{c}{$\begin{array}{l}\text { Source of } \\
\text { Variation }\end{array}$} & \multicolumn{1}{c}{$S S$} & Df & MS & \multicolumn{1}{c}{$F$} & P-value & F crit \\
\hline Between Groups & 1.029954 & 2 & 0.514977 & 0.167718 & 0.845721 & 3.04504 \\
Within Groups & 564.97 & 184 & 3.070489 & & & \\
& & & & & & \\
Total & 566 & 186 & & & & \\
\hline
\end{tabular}


ANOVA

Q11

Source of

Variation

Between Groups 1.093103

Within Groups $\quad 551.5359$

df $\quad M S \quad F \quad P$-value $F$ crit

$\begin{array}{llllll}2 & 0.546551 & 0.181346 & 0.834296 & 3.045312\end{array}$

$183 \quad 3.013858$

Total

552.629

185

ANOVA

Q12

Source of

Variation

Between Groups 5.744045

Within Groups $\quad 498.0463$

\begin{tabular}{ccccc}
$d f$ & $M S$ & $F$ & $P$-value & $F$ crit \\
\hline 2 & 2.872022 & 1.055284 & 0.350202 & 3.045312
\end{tabular}

$183 \quad 2.721564$

Total

503.7903

185

ANOVA

Q13

\begin{tabular}{lcrcccc}
\hline \multicolumn{1}{c}{$\begin{array}{c}\text { Source of } \\
\text { Variation }\end{array}$} & \multicolumn{1}{c}{ SS } & \multicolumn{1}{c}{ df } & \multicolumn{1}{c}{ MS } & \multicolumn{1}{c}{ P } & P-value & F crit \\
\hline Between Groups & 36.21297 & 2 & 18.10649 & 5.244697 & 0.006093 & 3.04504 \\
Within Groups & 635.2309 & 184 & 3.452342 & & & \\
& & & & & & \\
Total & 671.4439 & 186 & & & & \\
\hline
\end{tabular}

ANOVA

Q14

\begin{tabular}{lcrcccc}
\hline \multicolumn{1}{c}{$\begin{array}{c}\text { Source of } \\
\text { Variation }\end{array}$} & \multicolumn{1}{c}{ SS } & \multicolumn{1}{c}{ df } & MS & \multicolumn{1}{c}{ F } & P-value & F crit \\
\hline Between Groups & 11.99243 & 2 & 5.996213 & 1.710402 & 0.18364 & 3.044771 \\
Within Groups & 648.5608 & 185 & 3.505734 & & & \\
& & & & & & \\
Total & 660.5532 & 187 & & & & \\
\hline
\end{tabular}

ANOVA

Q15

\begin{tabular}{lcrcccc}
\hline \multicolumn{1}{c}{$\begin{array}{c}\text { Source of } \\
\text { Variation }\end{array}$} & \multicolumn{1}{c}{ SS } & \multicolumn{1}{c}{ df } & \multicolumn{1}{c}{$M S$} & \multicolumn{1}{c}{$F$} & P-value & F crit \\
\hline Between Groups & 6.648246 & 2 & 3.324123 & 0.893215 & 0.411077 & 3.04424 \\
Within Groups & 695.9254 & 187 & 3.721526 & & & \\
& & & & & & \\
Total & 702.5737 & 189 & & & & \\
\hline
\end{tabular}


ANOVA

Q16

\begin{tabular}{lcrcccc}
\hline \multicolumn{1}{c}{$\begin{array}{c}\text { Source of } \\
\text { Variation }\end{array}$} & \multicolumn{1}{c}{ SS } & \multicolumn{1}{c}{ Df } & MS & \multicolumn{1}{c}{ F } & P-value & F crit \\
\hline Between Groups & 16.02062 & 2 & 8.010309 & 2.98285 & 0.05309 & 3.044771 \\
Within Groups & 496.8092 & 185 & 2.685455 & & & \\
& & & & & & \\
Total & 512.8298 & 187 & & & & \\
\hline
\end{tabular}

ANOVA

Q17

\begin{tabular}{lcrrrrr}
\hline \multicolumn{1}{c}{$\begin{array}{c}\text { Source of } \\
\text { Variation }\end{array}$} & \multicolumn{1}{c}{ SS } & Df & \multicolumn{1}{c}{$M S$} & \multicolumn{1}{c}{ F } & P-value & F crit \\
\hline Between Groups & 30.41871 & 2 & 15.20935 & 4.328217 & 0.01456 & 3.04504 \\
Within Groups & 646.5759 & 184 & 3.514 & & & \\
& & & & & & \\
Total & 676.9947 & 186 & & & & \\
\hline
\end{tabular}

ANOVA

Q18

Source of

Variation

Between Groups 12.39376

Within Groups $\quad 529.2191$

MS $\quad F \quad P$-value $\quad F$ crit

$\begin{array}{lllll}2 & 6.196882 & 2.142835 & 0.120256 & 3.045312\end{array}$

$\begin{array}{ll}183 & 2.891908\end{array}$

Total

541.6129

185

\begin{tabular}{lrrrrrr} 
ANOVA & \multicolumn{7}{c}{ Q19 } \\
\hline \multicolumn{1}{c}{$\begin{array}{l}\text { Source of } \\
\text { Variation }\end{array}$} & \multicolumn{1}{c}{$S S$} & \multicolumn{1}{c}{ Df } & MS & \multicolumn{1}{c}{ F } & P-value & F crit \\
\hline Between Groups & 10.7872 & 2 & 5.393599 & 1.884343 & 0.154849 & 3.04504 \\
Within Groups & 526.6673 & 184 & 2.862323 & & & \\
& & & & & & \\
Total & 537.4545 & 186 & & & & \\
\hline
\end{tabular}

\begin{tabular}{lcrrrrr} 
ANOVA & \multicolumn{8}{c}{ Q20 } \\
\hline \multicolumn{1}{c}{$\begin{array}{l}\text { Source of } \\
\text { Variation }\end{array}$} & \multicolumn{1}{c}{ SS } & Df & MS & \multicolumn{1}{c}{ F } & P-value & F crit \\
\hline Between Groups & 4.474973 & 2 & 2.237487 & 0.716697 & 0.489728 & 3.045312 \\
Within Groups & 571.3153 & 183 & 3.121942 & & & \\
& & & & & & \\
Total & 575.7903 & 185 & & & & \\
\hline
\end{tabular}


ANOVA

Source of

Variation

Between Groups 0.929794

Within Groups $\quad 529.6789$

Total

530.6087

Q21

\begin{tabular}{rcccc} 
df & $M S$ & $F$ & $P$-value & $F$ crit \\
\hline 2 & 0.464897 & 0.158863 & 0.853232 & 3.045866 \\
181 & 2.926403 & & &
\end{tabular}

$181-2.926403$

ANOVA

Q22

\begin{tabular}{lcrrrrr}
\hline \multicolumn{1}{c}{$\begin{array}{l}\text { Source of } \\
\text { Variation }\end{array}$} & \multicolumn{1}{c}{ SS } & df & \multicolumn{1}{c}{ MS } & \multicolumn{1}{c}{ F } & P-value & F crit \\
\hline Between Groups & 4.623715 & 2 & 2.311857 & 0.736661 & 0.480108 & 3.044771 \\
Within Groups & 580.5837 & 185 & 3.13829 & & & \\
& & & & & & \\
Total & 585.2074 & 187 & & & & \\
\hline
\end{tabular}

ANOVA

Q23

\section{Source of}

Variation

Between Groups 1.581823

Within Groups

532.7145

183

Total

534.2963

df 2

\begin{tabular}{cccc}
$M S$ & $F$ & $P$-value & $F$ crit \\
\hline .790911 & 0.276151 & 0.759009 & 3.044504
\end{tabular}

$186 \quad 2.864056$

188

ANOVA

Q24

Source of

Variation

Between Groups 7.960605

Within Groups $\quad 636.8026$

\begin{tabular}{ccccc}
$d f$ & $M S$ & $F$ & $P$-value & $F$ crit \\
\hline 2 & 3.980302 & 1.168834 & 0.312989 & 3.04424
\end{tabular}

$187 \quad 3.405361$

Total

644.7632

189 
Appendix G: Responses to Survey Question 2- Other Challenges 


\section{Question 2}

Please indicate below any additional situations that pose as a challenge to you that are not listed in the previous section, indicate their importance to you and the extent to which West Virginia University helps you meets them.

\begin{tabular}{|c|c|}
\hline $\begin{array}{l}\text { NUMBER } \\
\text { OF } \\
\text { RESPONSES }\end{array}$ & RESPONSE \\
\hline 1 & $\begin{array}{l}\text { Being an English as a second language student and the fact that WVU doesn't care } \\
\text { about our education, they just care about the money. }\end{array}$ \\
\hline 1 & $\begin{array}{l}\text { I'm used to having pets but while being at WVU I can't have any and I feel very lonely } \\
\text { sometimes. I wish WVU could provide any services so that we can play with dogs, } \\
\text { walk them or like that. I will be much happier. }\end{array}$ \\
\hline 1 & Some students are friendly to others. \\
\hline 1 & Priority to state residents and higher tuition. \\
\hline 1 & Visa issues. Very stressful process, took a long time. \\
\hline 13 & $\begin{array}{l}\text { The health insurance and health services are too expensive, there are better and } \\
\text { cheaper options of health insurance. }\end{array}$ \\
\hline 1 & I am a single parent. This category of students is invisible at WVU. \\
\hline 1 & $\begin{array}{l}\text { Renting a house here being from another country is hard and necessary, also taking } \\
\text { the buses here, since I don't have a car. Maybe help getting a loan as an international } \\
\text { student as well. }\end{array}$ \\
\hline & Transportation to major cities/airports, Roads in Morgantown. \\
\hline 1 & Teaching as a Graduate Assistant. \\
\hline 1 & The lack of activity to Morgantown. \\
\hline 1 & Conversation etiquette, accent. \\
\hline 1 & $\begin{array}{l}\text { Getting a U.S. driving license. I have never heard WVU even talk about it or never } \\
\text { seen a flyer on it. }\end{array}$ \\
\hline 1 & Less learning support for non-English native students. \\
\hline 1 & $\begin{array}{l}\text { Public transportation. As international students we don't have cars so moving around } \\
\text { is difficult, we always need to rely on others to do grocery shopping for example. }\end{array}$ \\
\hline 1 & $\begin{array}{l}\text { Graduate international students orientation. WVU put us together with young one } \\
\text { semester exchange students. It would have been good to have been put together for } \\
\text { socialization appropriateness. }\end{array}$ \\
\hline 1 & $\begin{array}{l}\text { Off-campus student housing roommates, roommates crossing boundaries in } \\
\text { work/school. }\end{array}$ \\
\hline 11 & Transportation. \\
\hline 1 & This university are bunch of racists. \\
\hline
\end{tabular}




\begin{tabular}{|c|c|}
\hline 2 & $\begin{array}{l}\text { Setting up bank account was difficult without a social security number and generally } \\
\text { accessing money from home was quite hard. }\end{array}$ \\
\hline 5 & Transportation upon arrival. \\
\hline 1 & $\begin{array}{l}\text { Put student into a situation that he or she have to take extra course during summer and } \\
\text { waste his or her time and money. }\end{array}$ \\
\hline 7 & Getting a driver's license. No help from university. \\
\hline 1 & Financial support. \\
\hline 1 & $\begin{array}{l}\text { No opportunity for international students. No assistance for first generation of } \\
\text { international students. }\end{array}$ \\
\hline 1 & $\begin{array}{l}\text { Friends and getting jobs out of school. WVU does not help in any way because I } \\
\text { believe this is an American problem all together. }\end{array}$ \\
\hline 1 & $\begin{array}{l}\text { Student and advisor relationship. I had a bitter experience with my advisor which has } \\
\text { taken a toll on me. }\end{array}$ \\
\hline 1 & $\begin{array}{l}\text { The problem which I am facing currently is change of I- } 20 \text { from one major to other } \\
\text { major. It is taking a very long time. Actually, to say they are not responding. And also } \\
\text { food in Hatfield's is also not good, there is no vast varieties of food. All the time the } \\
\text { menu is same, as I'm from India at least once in a week I feel like to eat Indian } \\
\text { cuisine. But it is not happening. }\end{array}$ \\
\hline 1 & PRT doesn't run during the break. \\
\hline 1 & Include time management in orientation class. \\
\hline 6 & $\begin{array}{l}\text { Finding ways to travel out of Morgantown without having a car (assistance could be } \\
\text { better). }\end{array}$ \\
\hline 27 & Professors are racist. \\
\hline 2 & Mental health as an international student. \\
\hline 3 & Better Health Insurance needed urgently. \\
\hline 1 & Rent laws is a major challenge and we find little help from WVU to the problem. \\
\hline 1 & Healthcare is a joke and poses so much trouble, let alone stress! \\
\hline 1 & Knowing my way around campus is a challenge to me. \\
\hline 1 & $\begin{array}{l}\text { Immigration and Financial assistance can be better to benefit the international students } \\
\text { from getting into situations due to lack of information. }\end{array}$ \\
\hline 1 & $\begin{array}{l}\text { Acquiring a driver license. It is of high importance and WVU offers no help. A system } \\
\text { to help international students find a car to take the practical driving test should be } \\
\text { established. }\end{array}$ \\
\hline 1 & Finding social groups from similar situation. \\
\hline 1 & $\begin{array}{l}\text { This survey posed really a big challenge in how it is organized !! what do you mean } \\
\text { No:4 as expected do you know the expectation of each student?! strange survey I have } \\
\text { to look at the numbers and go up for each question I think this survey is a reflection of } \\
\text { how much do you care about the opinion of international students. }\end{array}$ \\
\hline 41 & Racism \\
\hline 1 & Tutors for higher level classes - WVU does not meet them much. \\
\hline
\end{tabular}




\begin{tabular}{|c|l|}
\hline 1 & $\begin{array}{l}\text { Health insurance. I had to pay a lot of money and being in debt for a year and a half } \\
\text { just because I went to the ER. }\end{array}$ \\
\hline 14 & Discrimination by faculty. \\
\hline 1 & Students and professors being racist toward me. \\
\hline 3 & $\begin{array}{l}\text { I faced so many racisms with the prof toward Middle Eastern students. } \\
\text { Some professors do not care about our feelings or emotions. They do not even care } \\
\text { about our medical situation such as being pregnant, and they do not give extensions to } \\
\text { help keeping my grades still. Sometimes they do not really respect that we are far } \\
\text { away from home with different culture and they do not help in motivating us to } \\
\text { accomplish what we are here for. They do not really care when a close family member } \\
\text { passes away and they do not help us to avoid being depressed. }\end{array}$ \\
\hline 1 & $\begin{array}{l}\text { Course registration until the end of the first week is very dangerous for students that } \\
\text { could not arrive before the first day of classes and because of professors do not reply } \\
\text { to students mail, that is why is very difficult to have an idea of which course fits with } \\
\text { our home country study plan. }\end{array}$ \\
\hline 2 & $\begin{array}{l}\text { Part time job. } \\
\text { The public transportation was a challenge, it's so important to know how it works and } \\
\text { the bus stops. Maybe if they implement a guided tour but in public transportation } \\
\text { instead the WVU buses. }\end{array}$ \\
\hline 1
\end{tabular}


Appendix H: Descriptive Analysis and Distribution of Responses for Addressed Challenges by WVU 
Ratings/Responses of WVU's Assistance Dealing with the Challenge:

7= Much better than expected

$6=$ Better than expected

5 = Somewhat better than expected

4 = Neutral-Exactly as I expected

$3=$ Less than expected

2 = Much less than expected

$1=$ No assistance at all

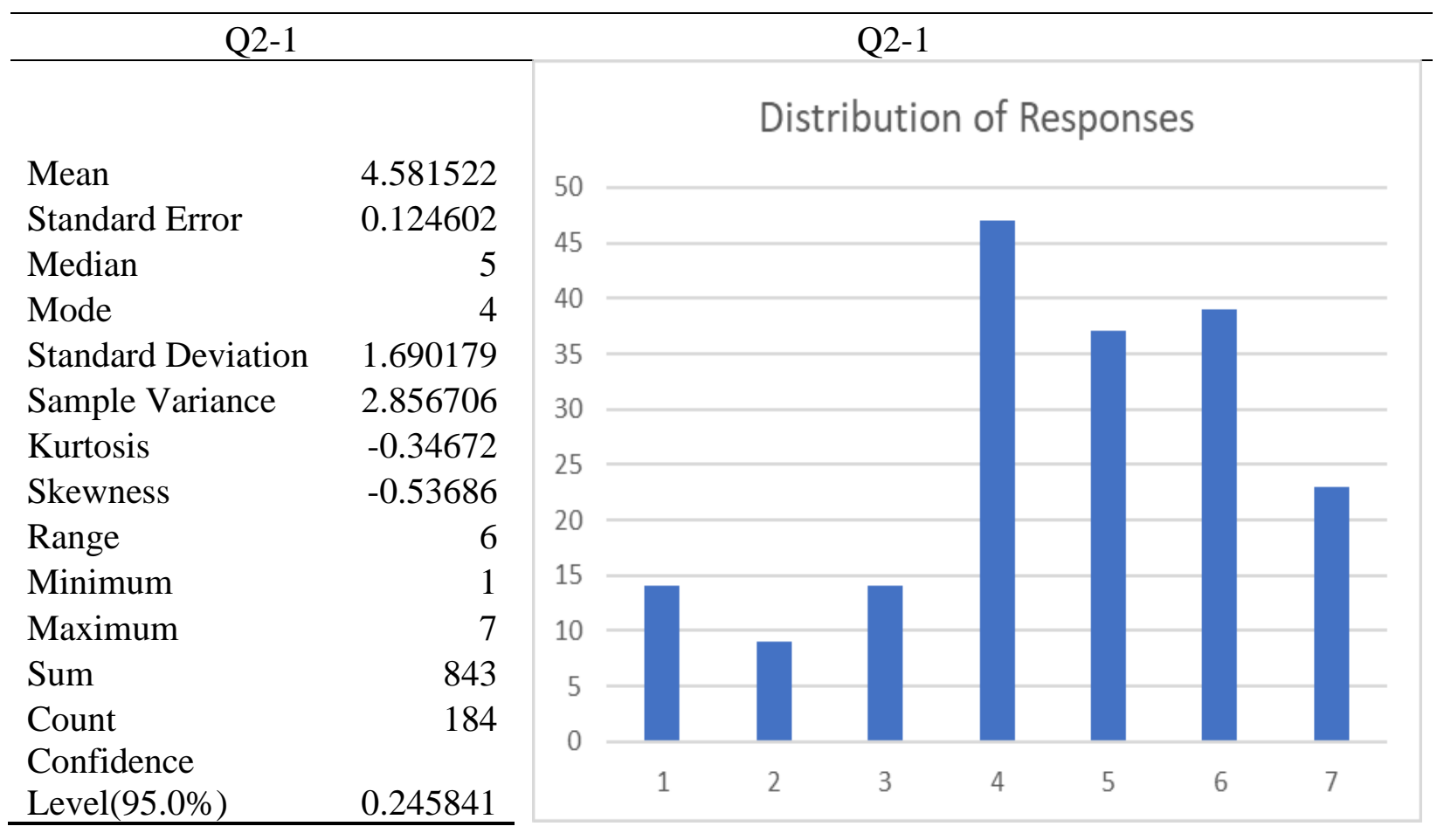




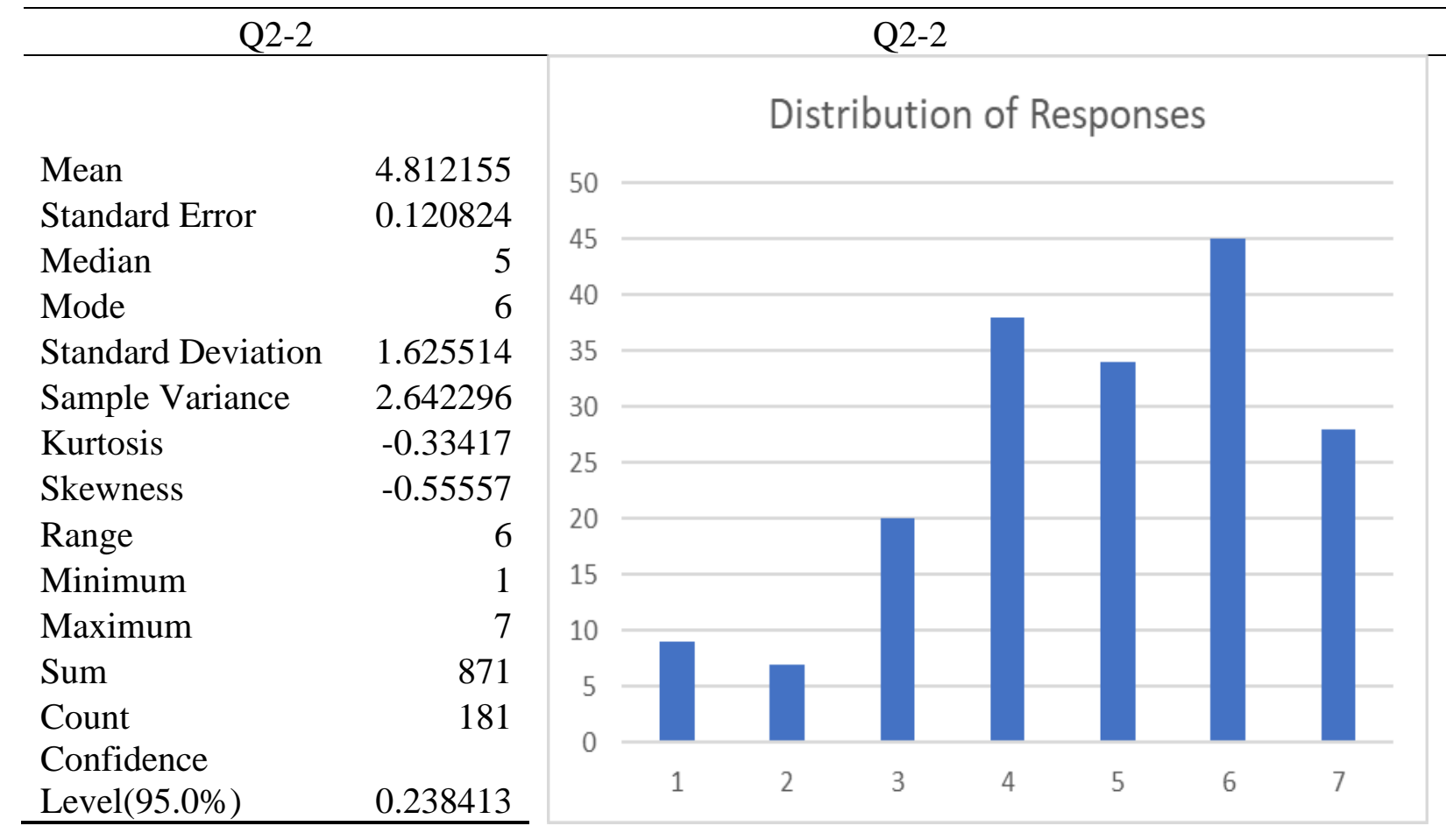

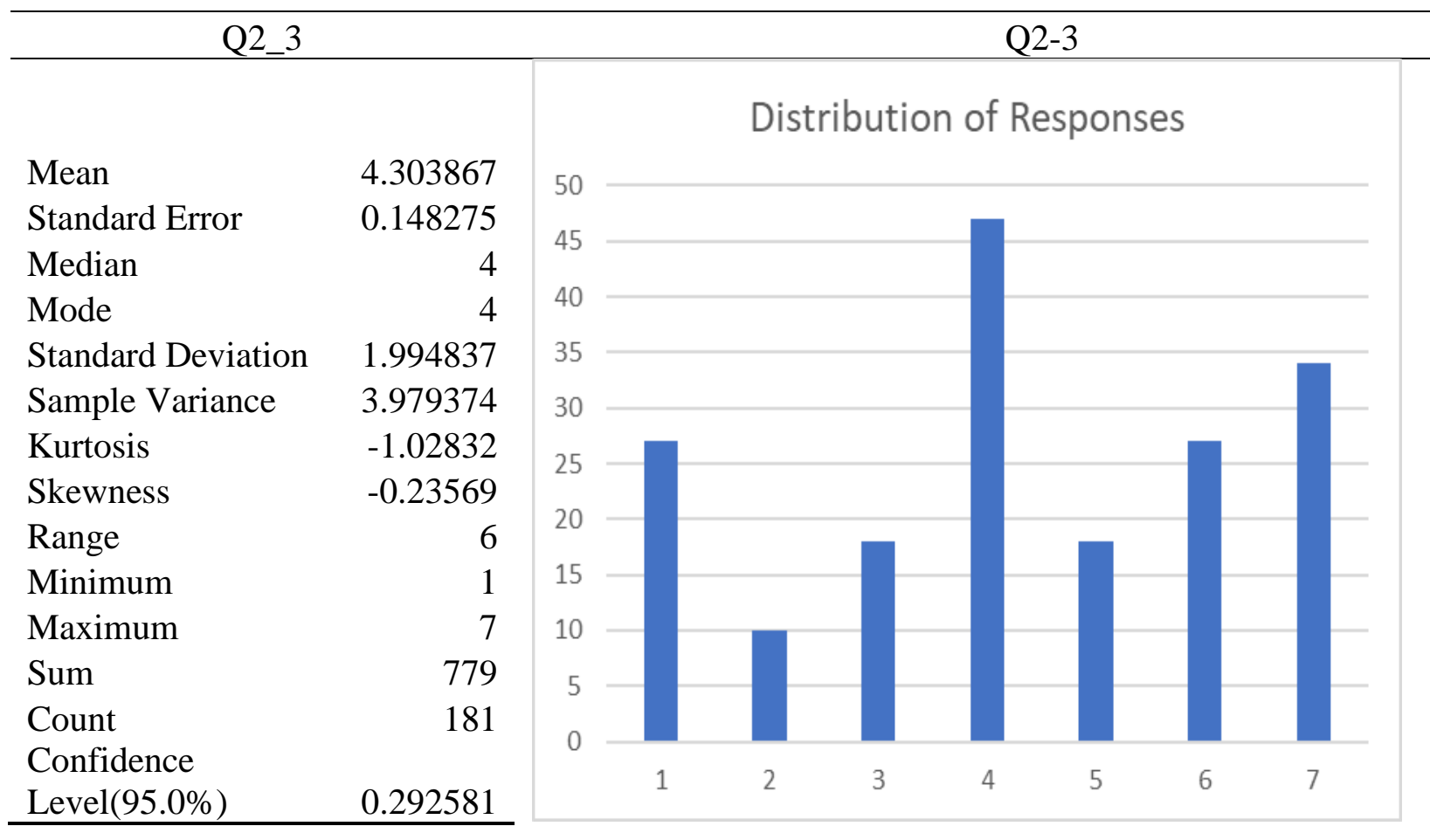




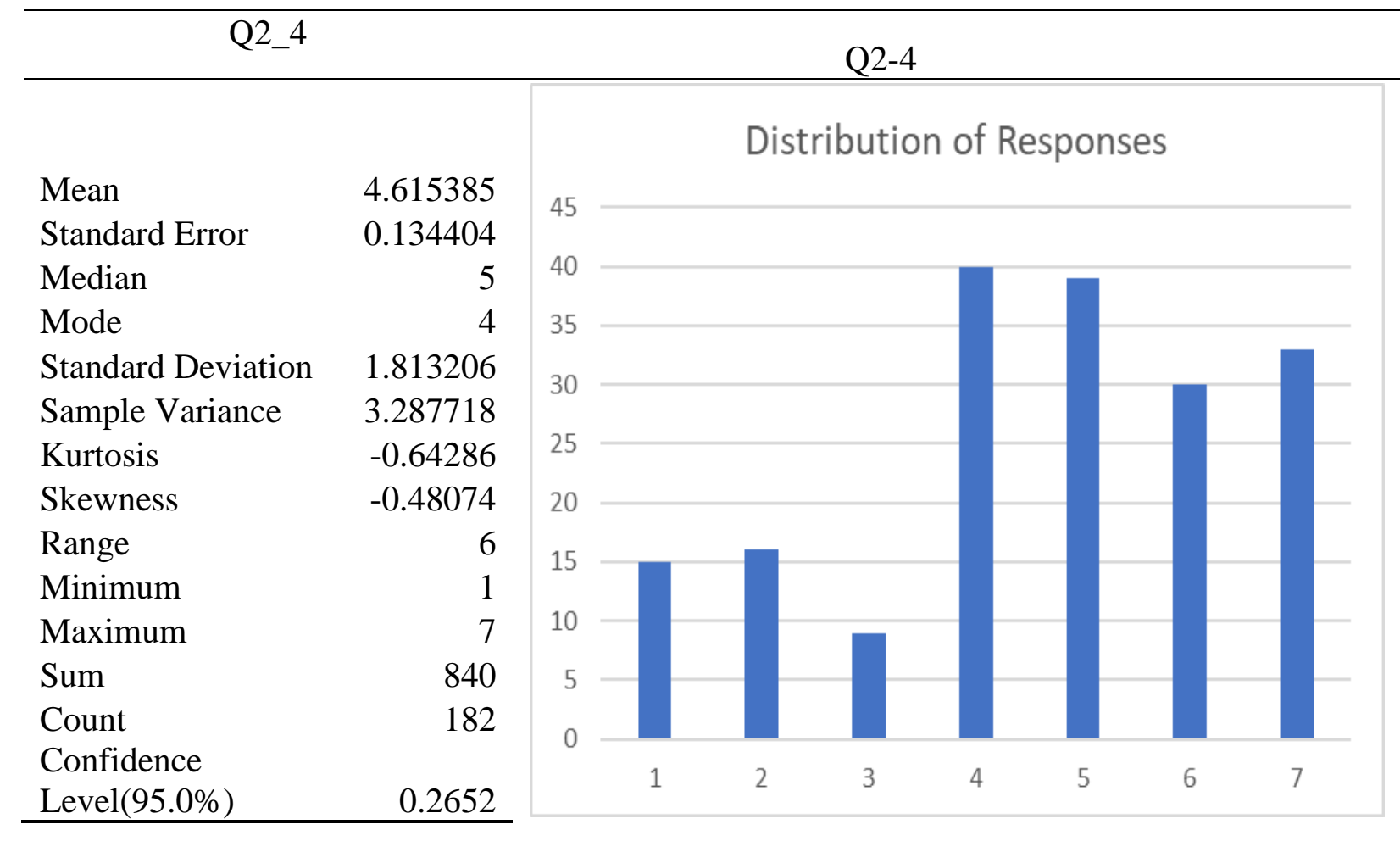

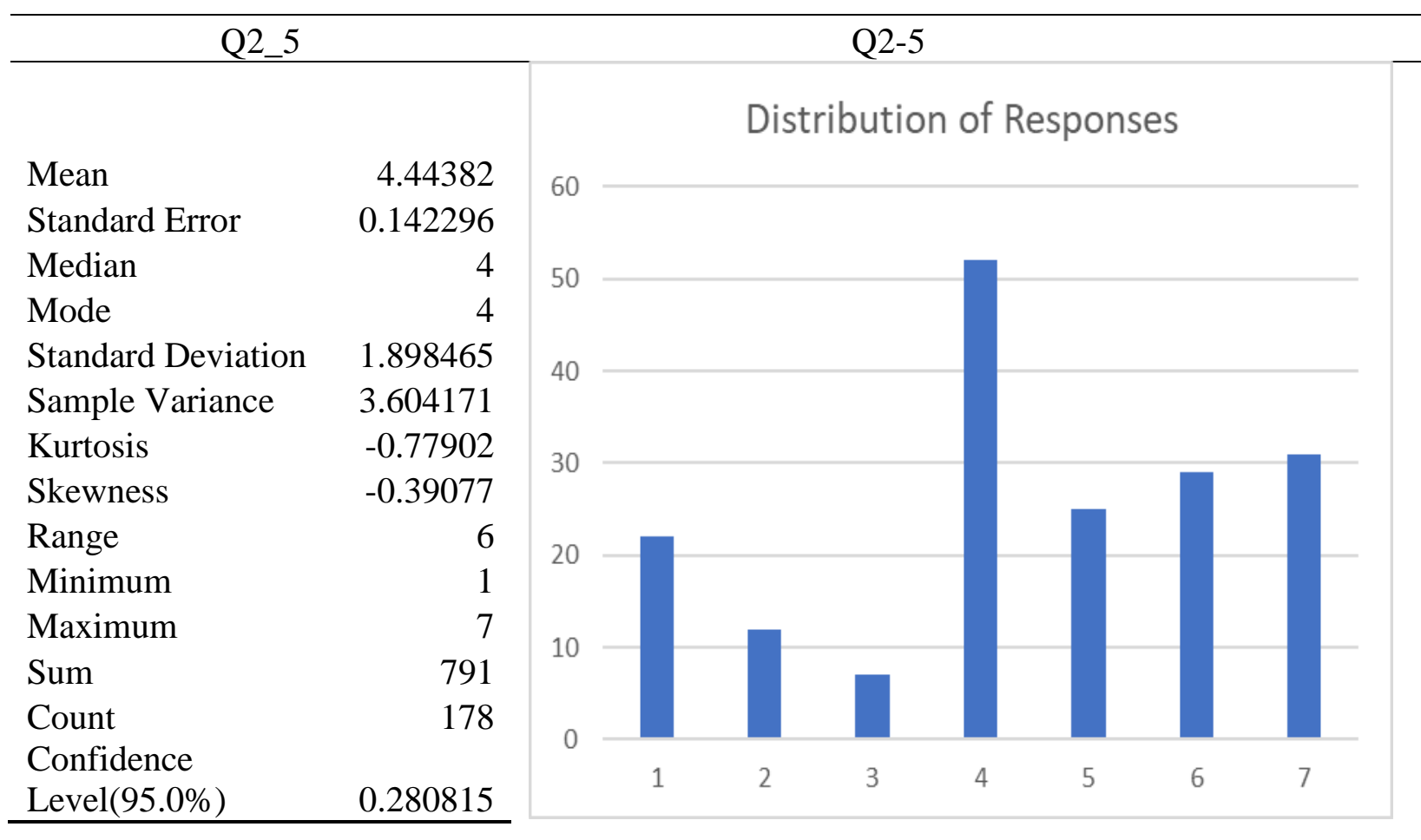




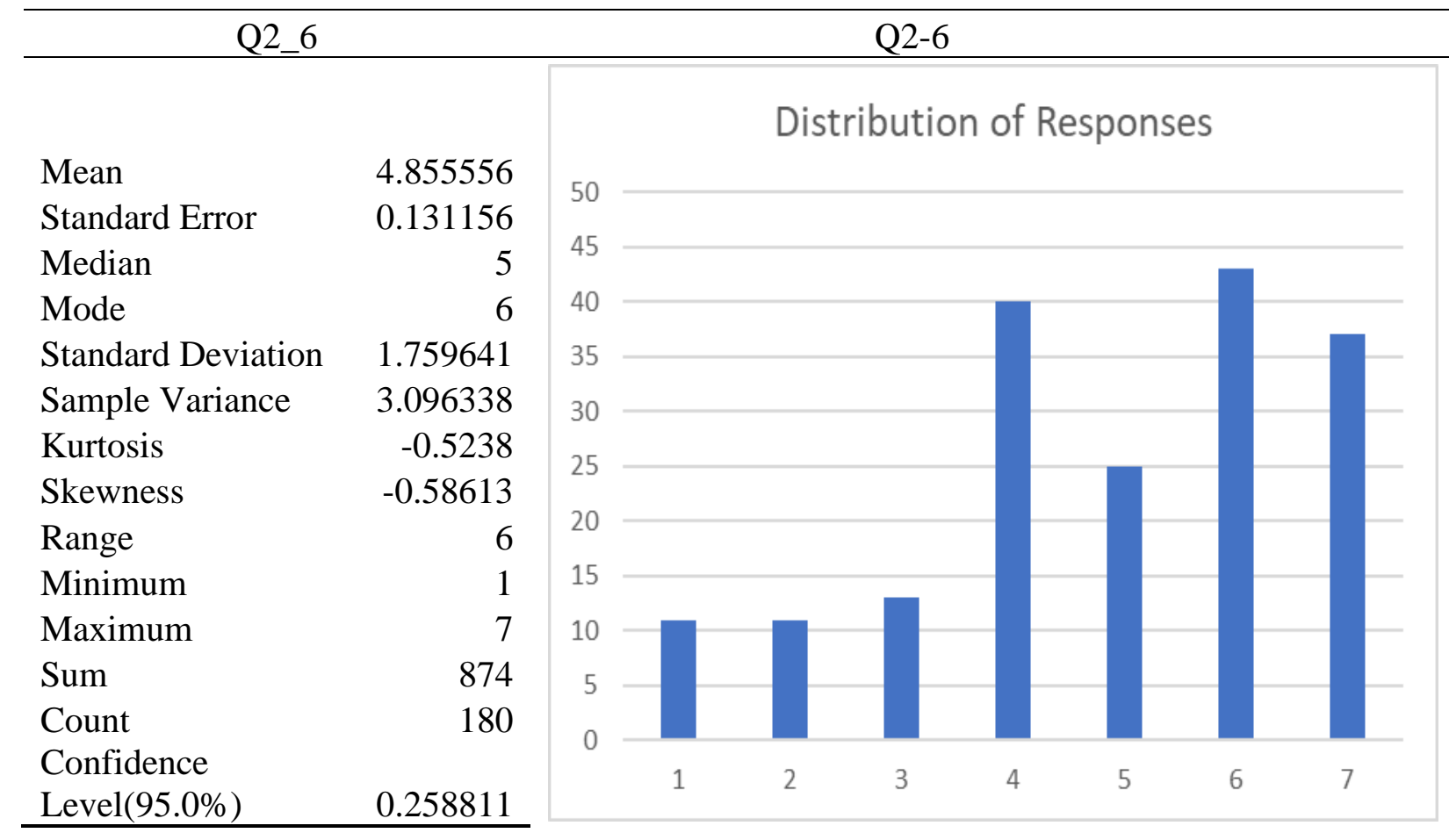

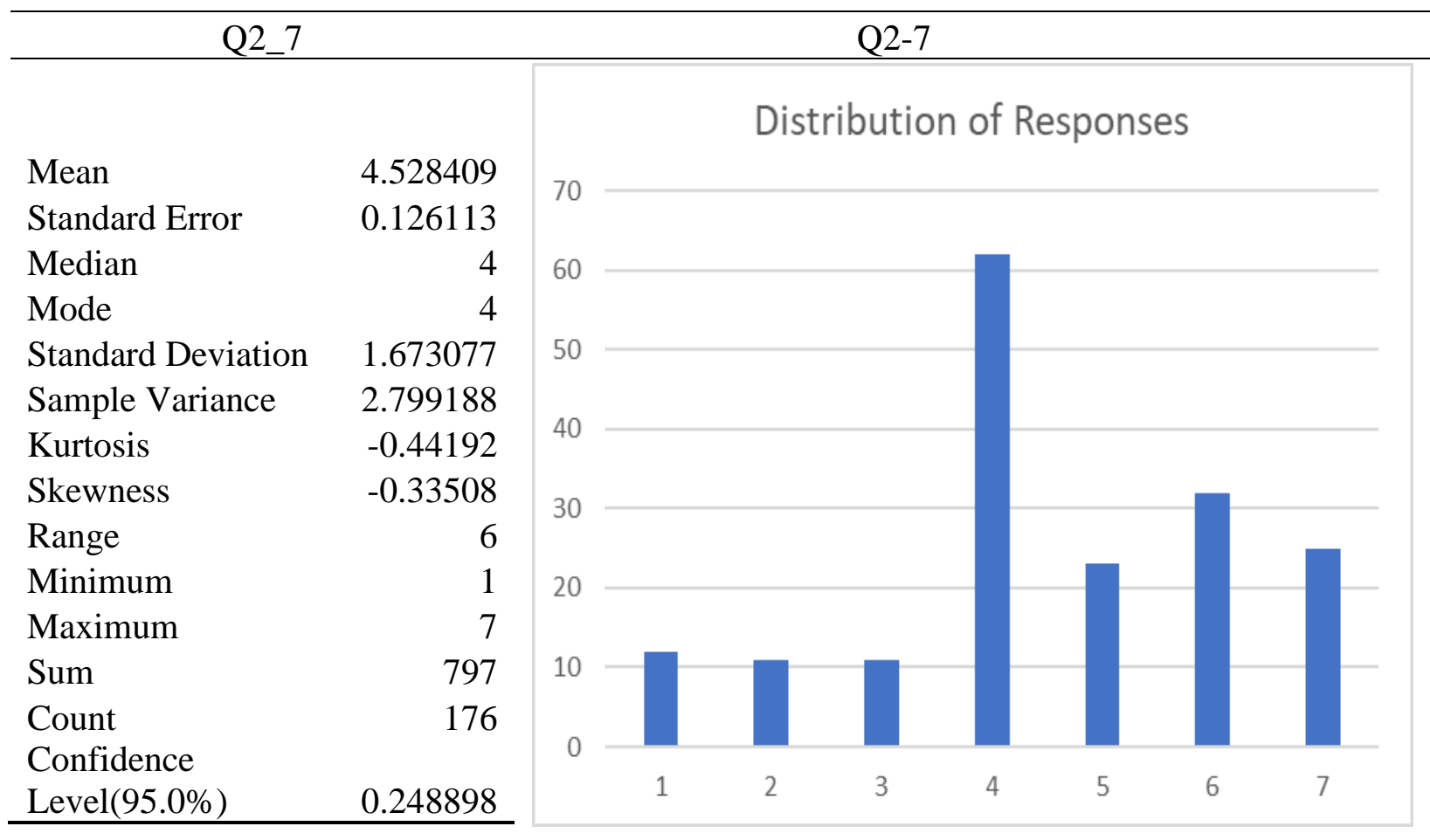




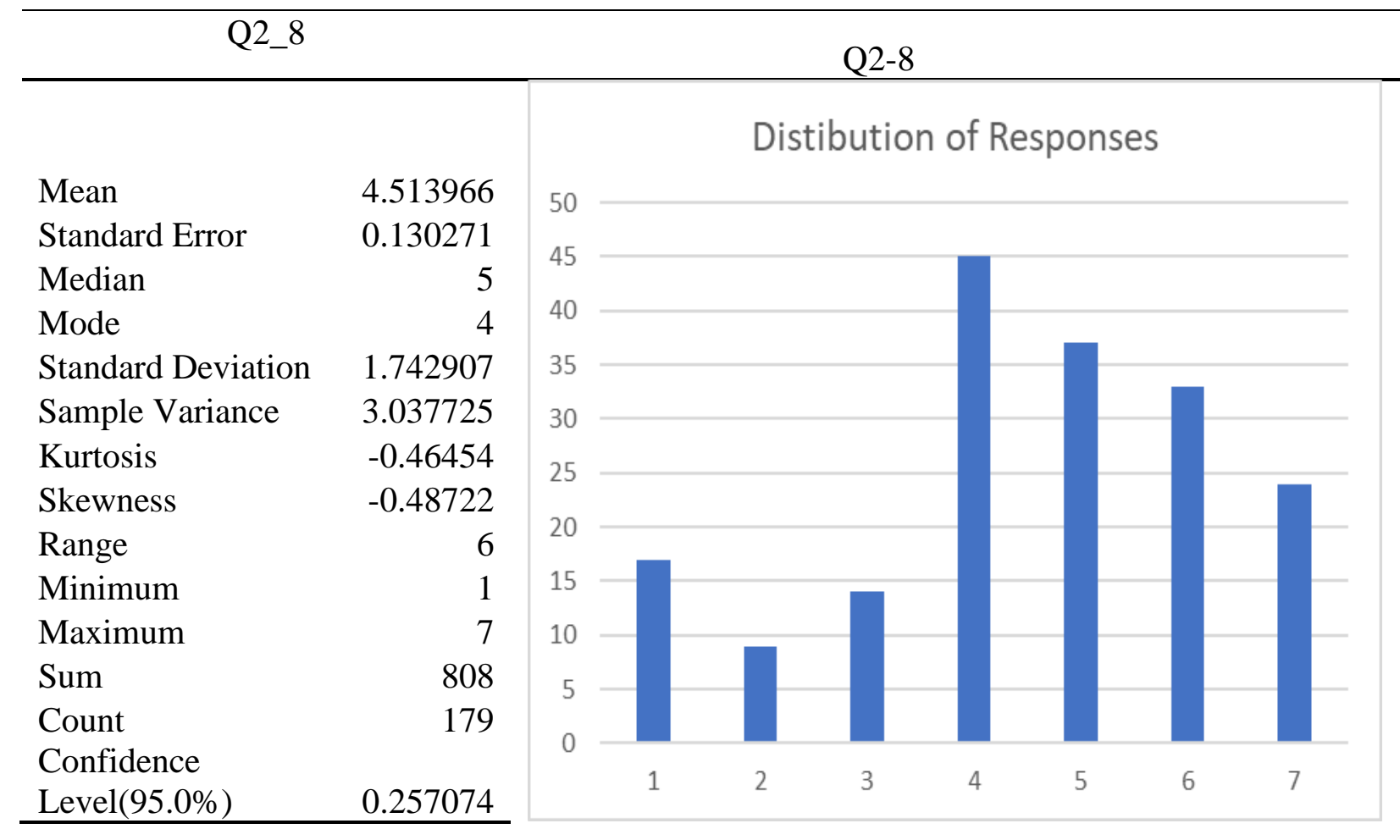

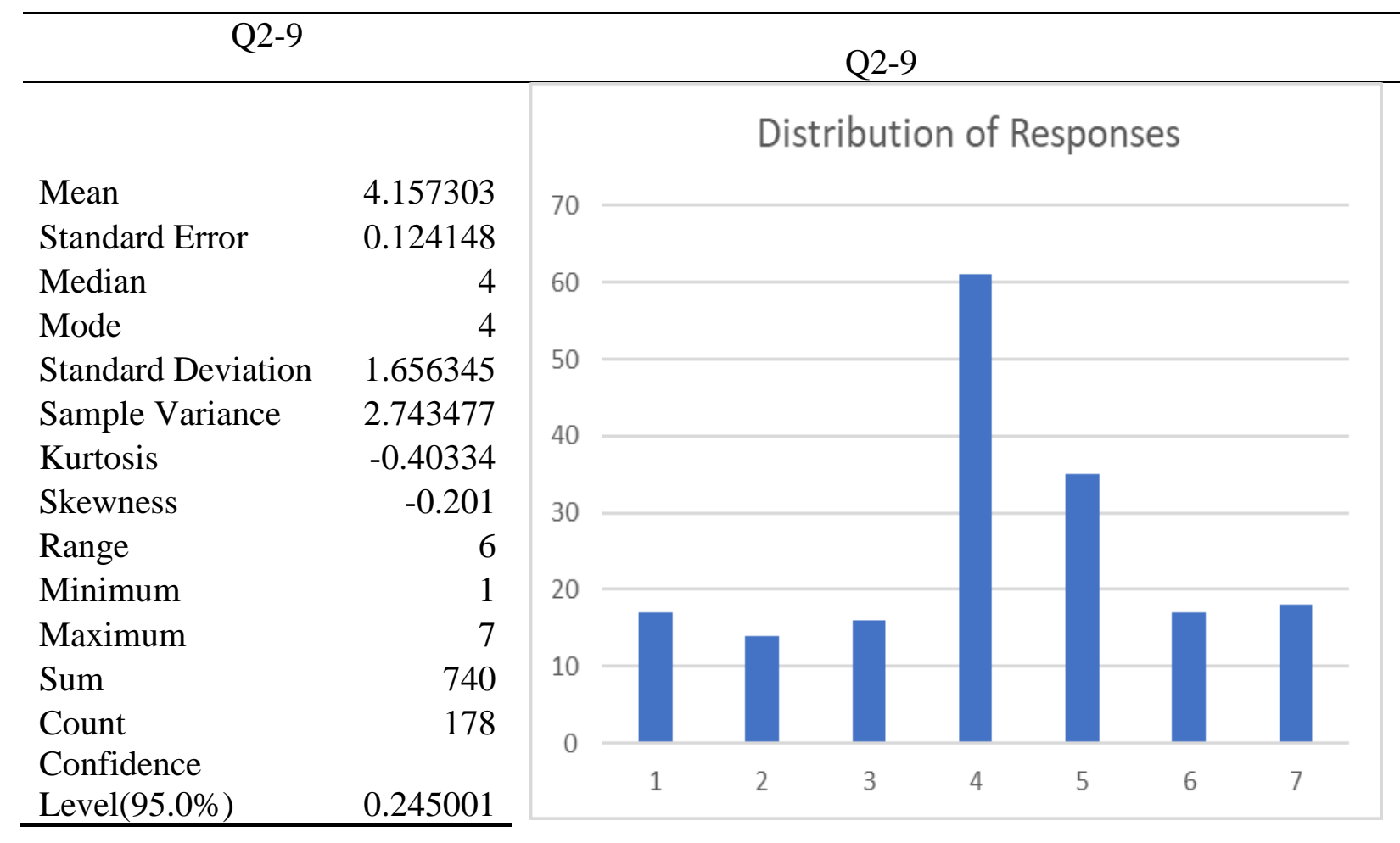




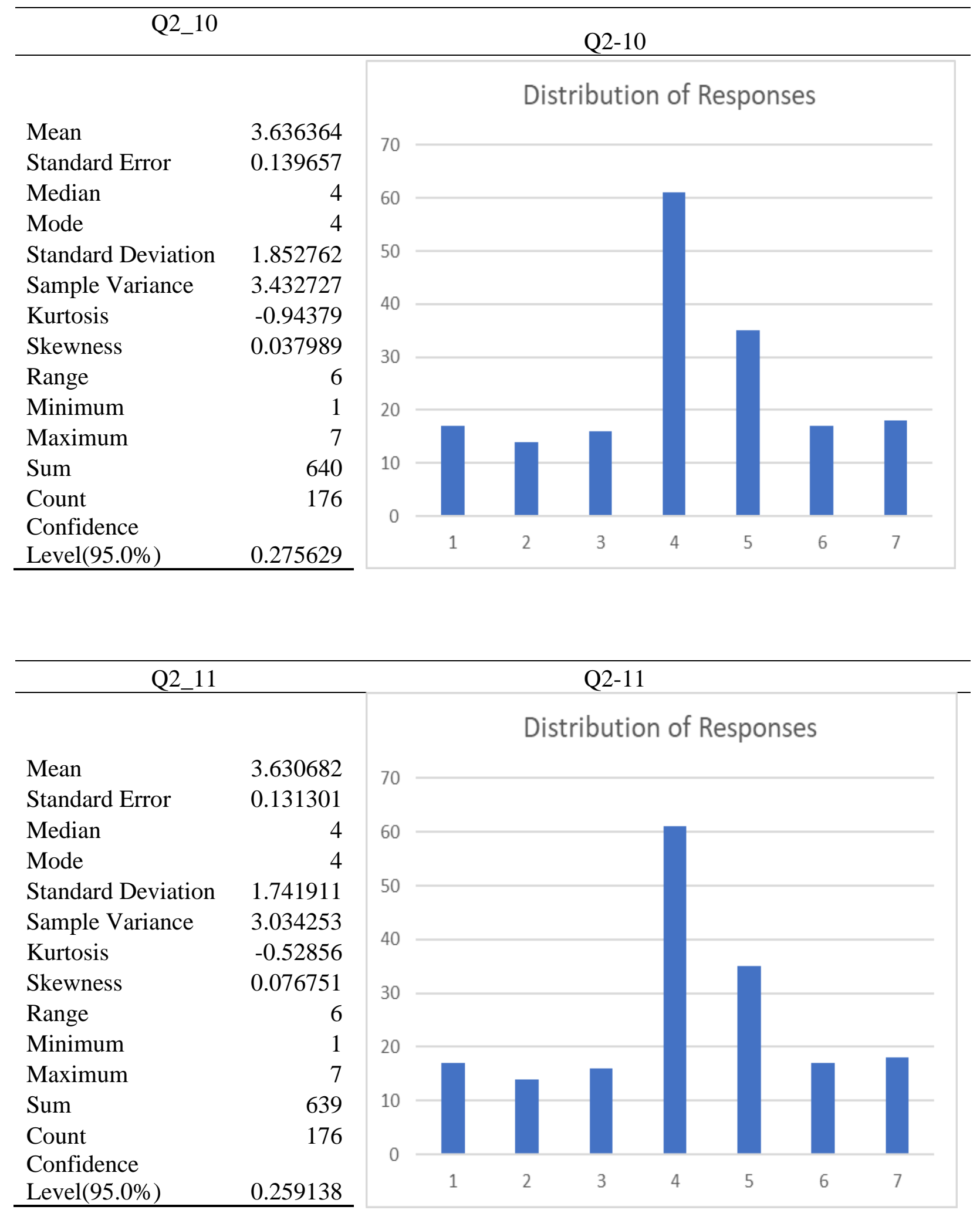




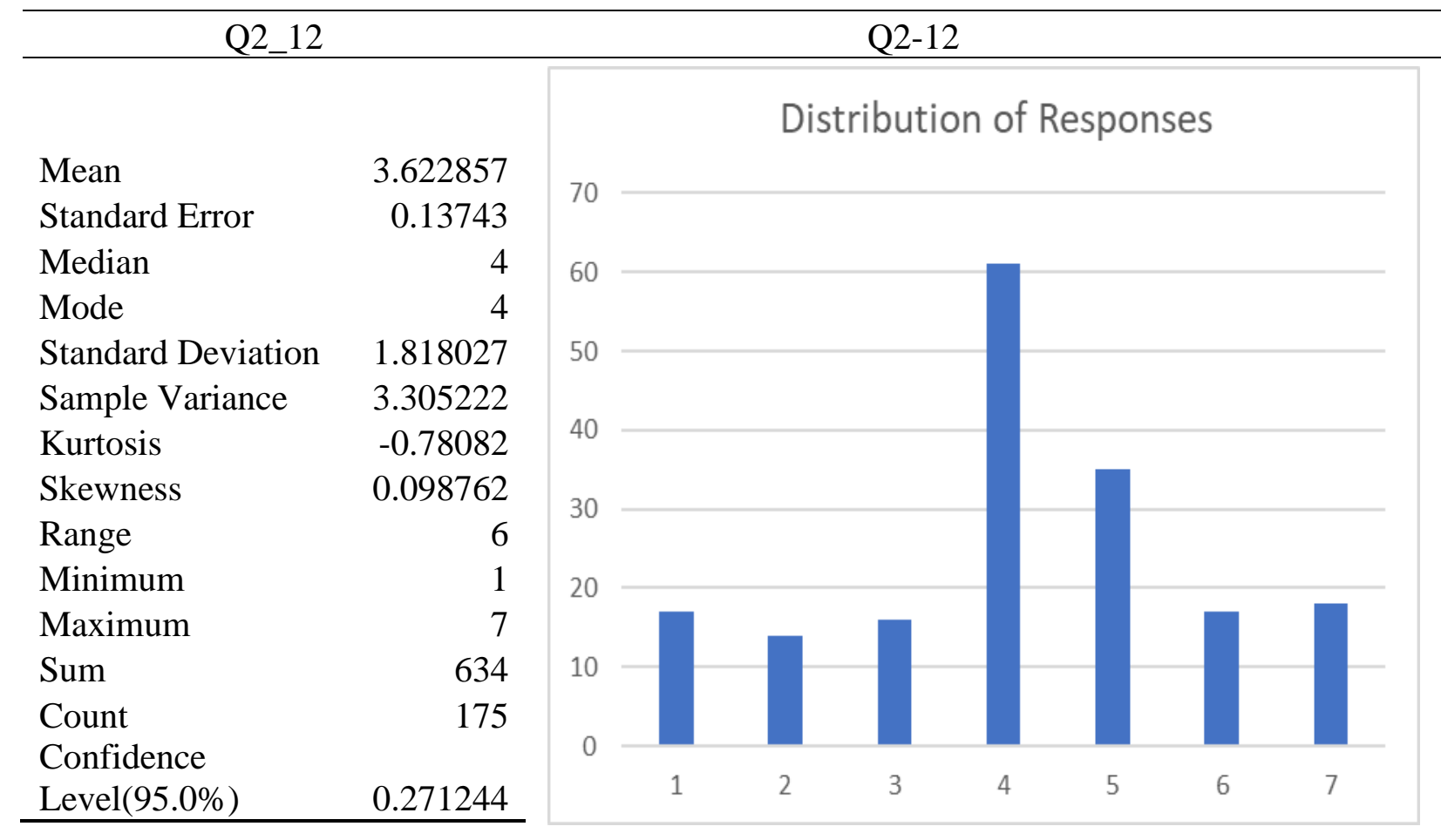

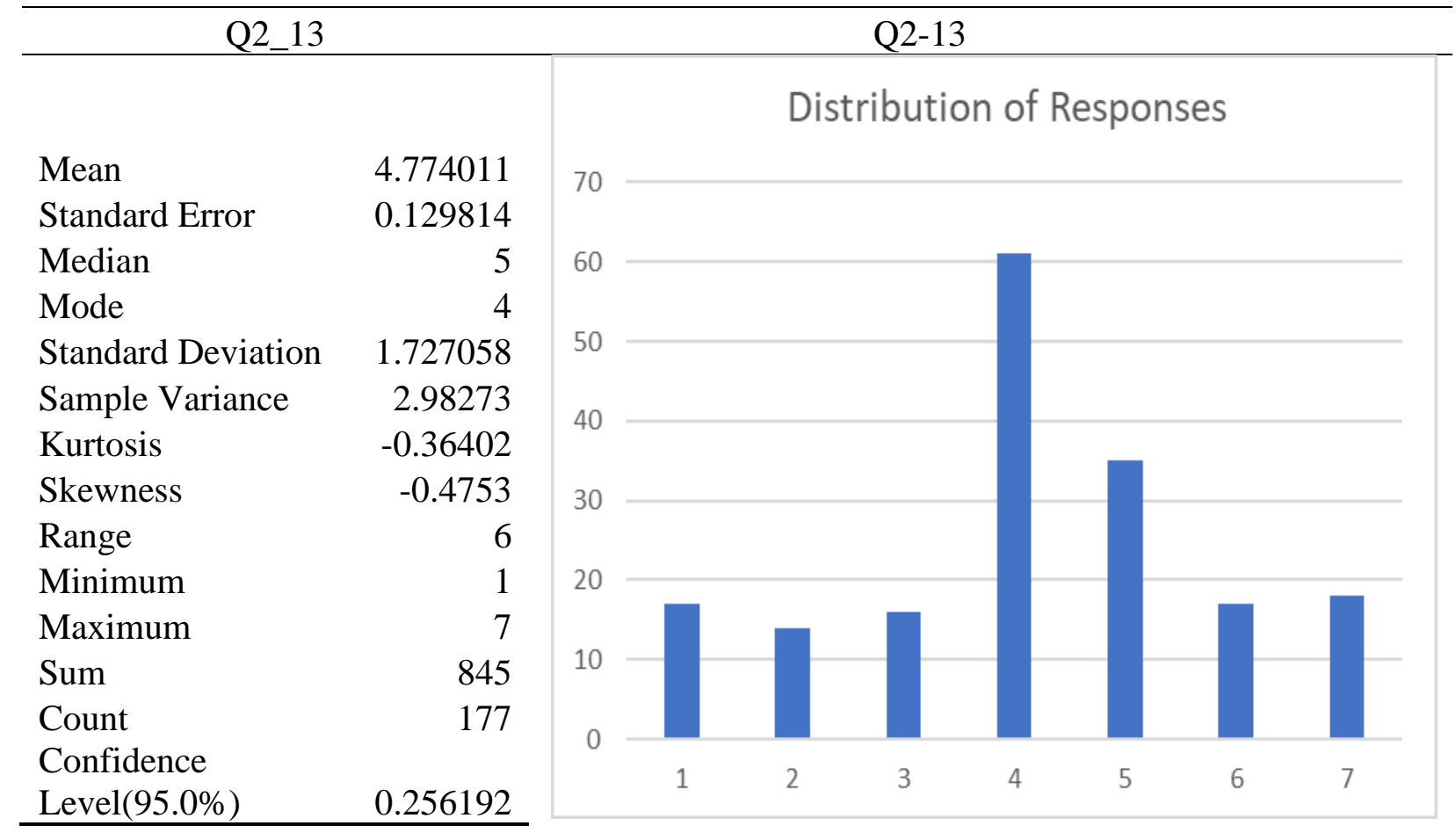




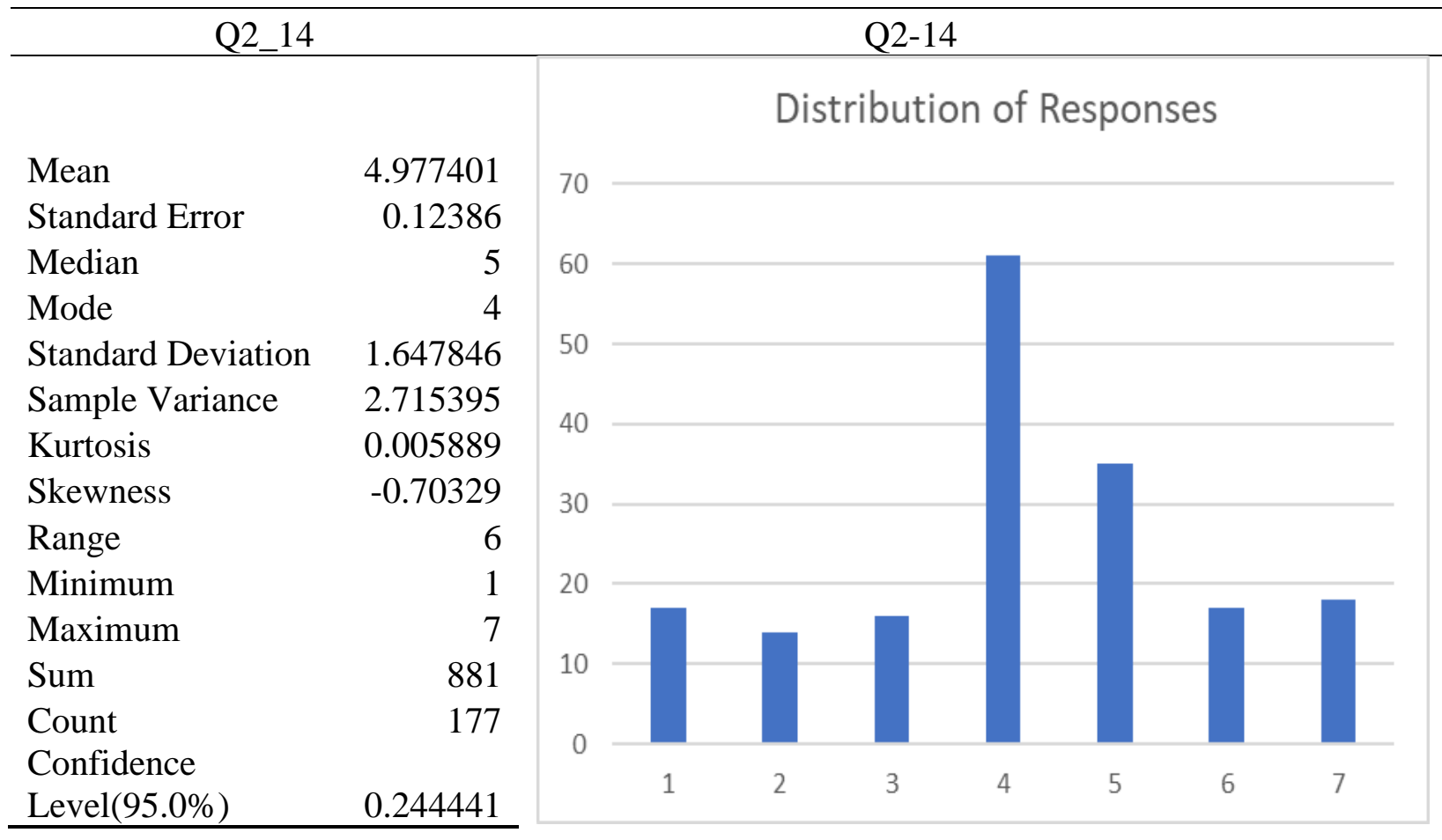

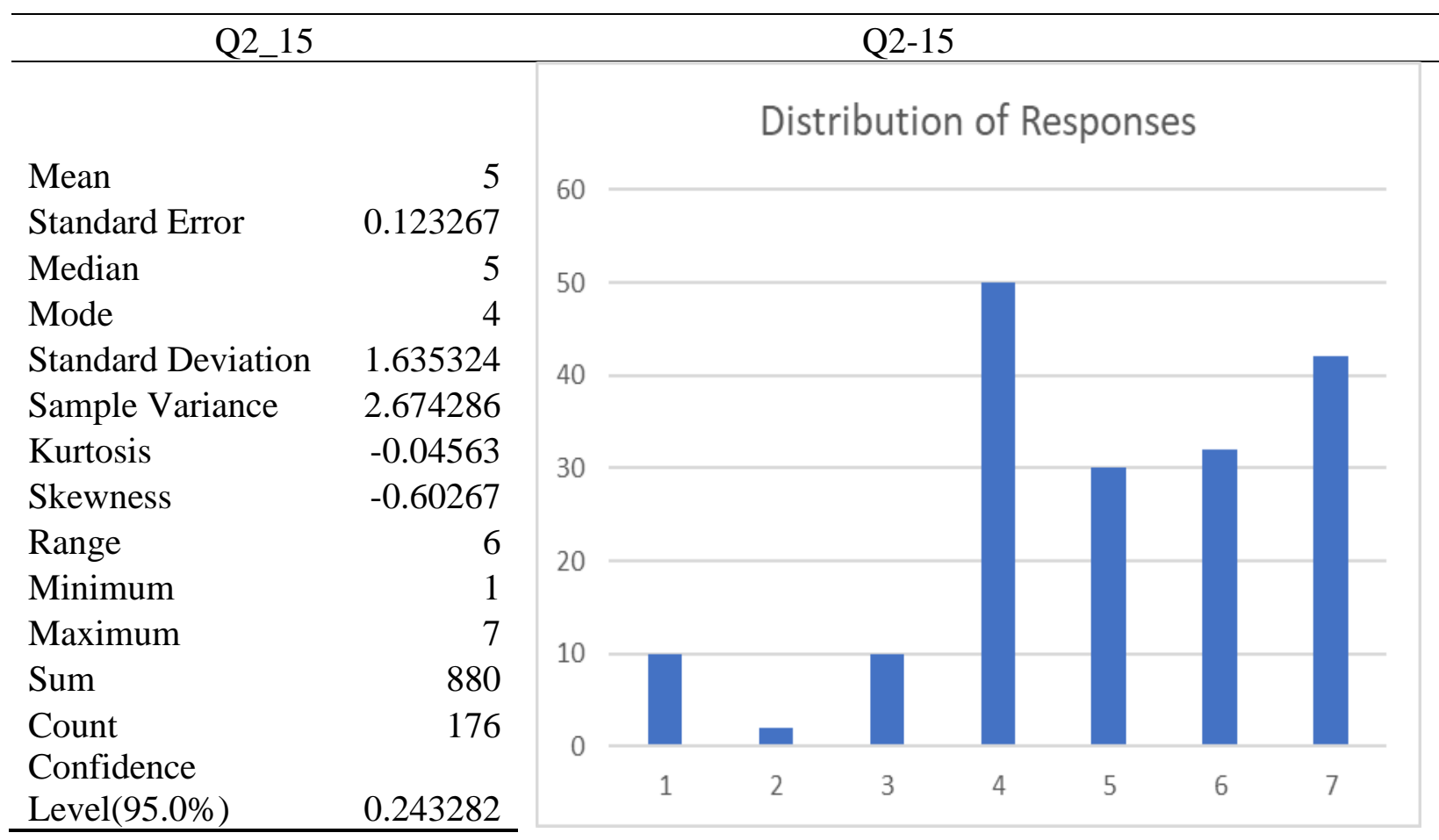




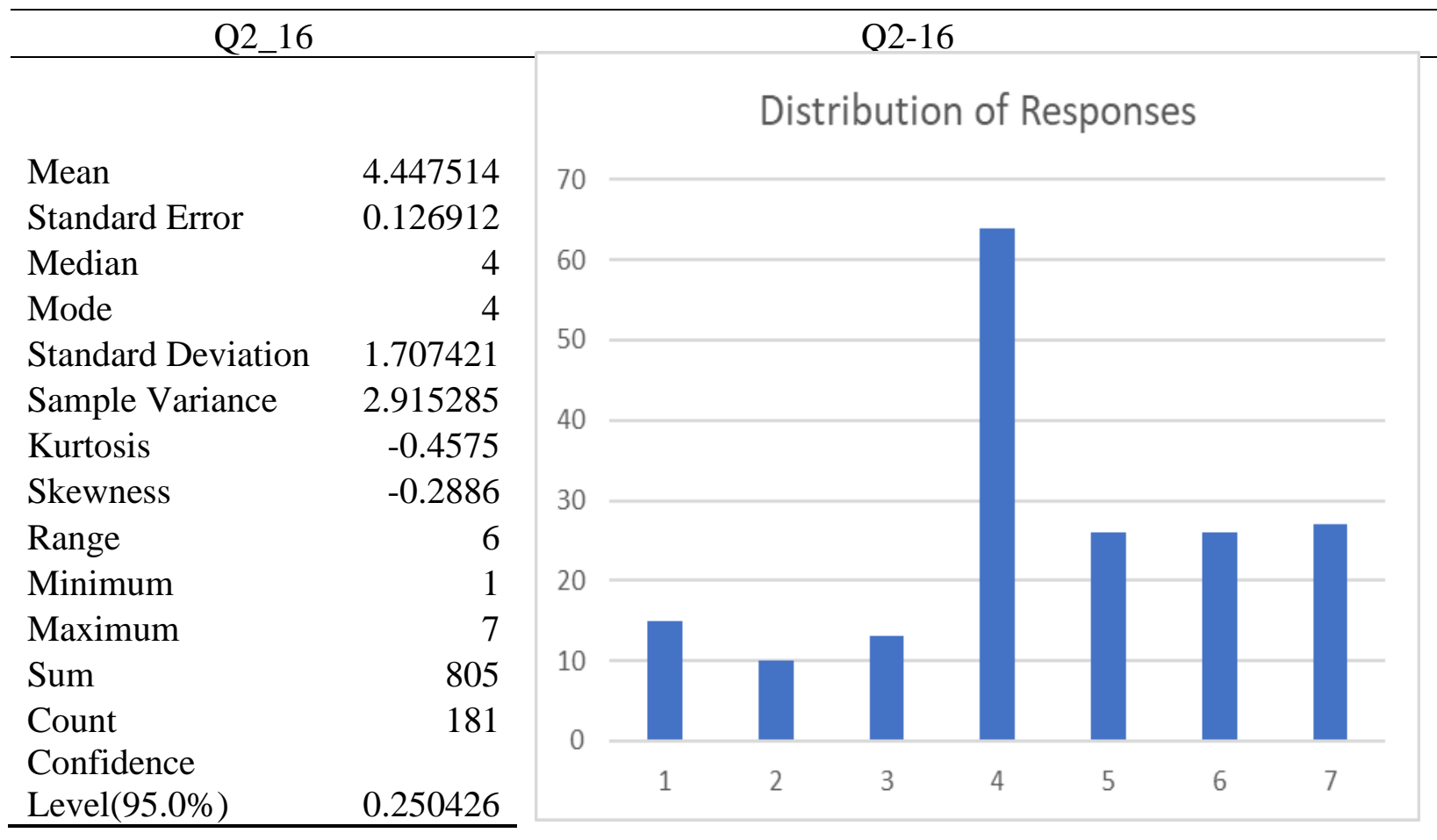

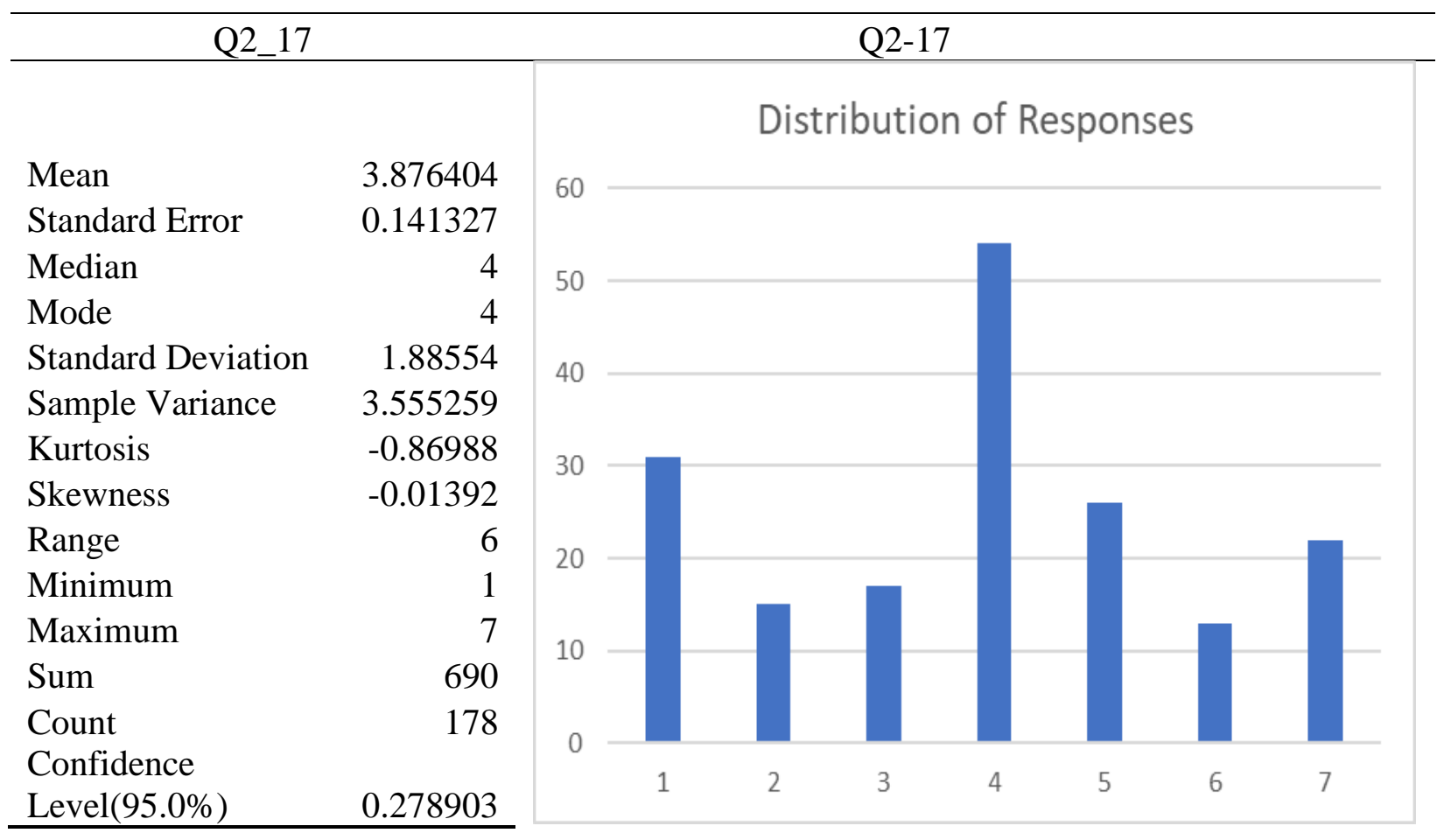




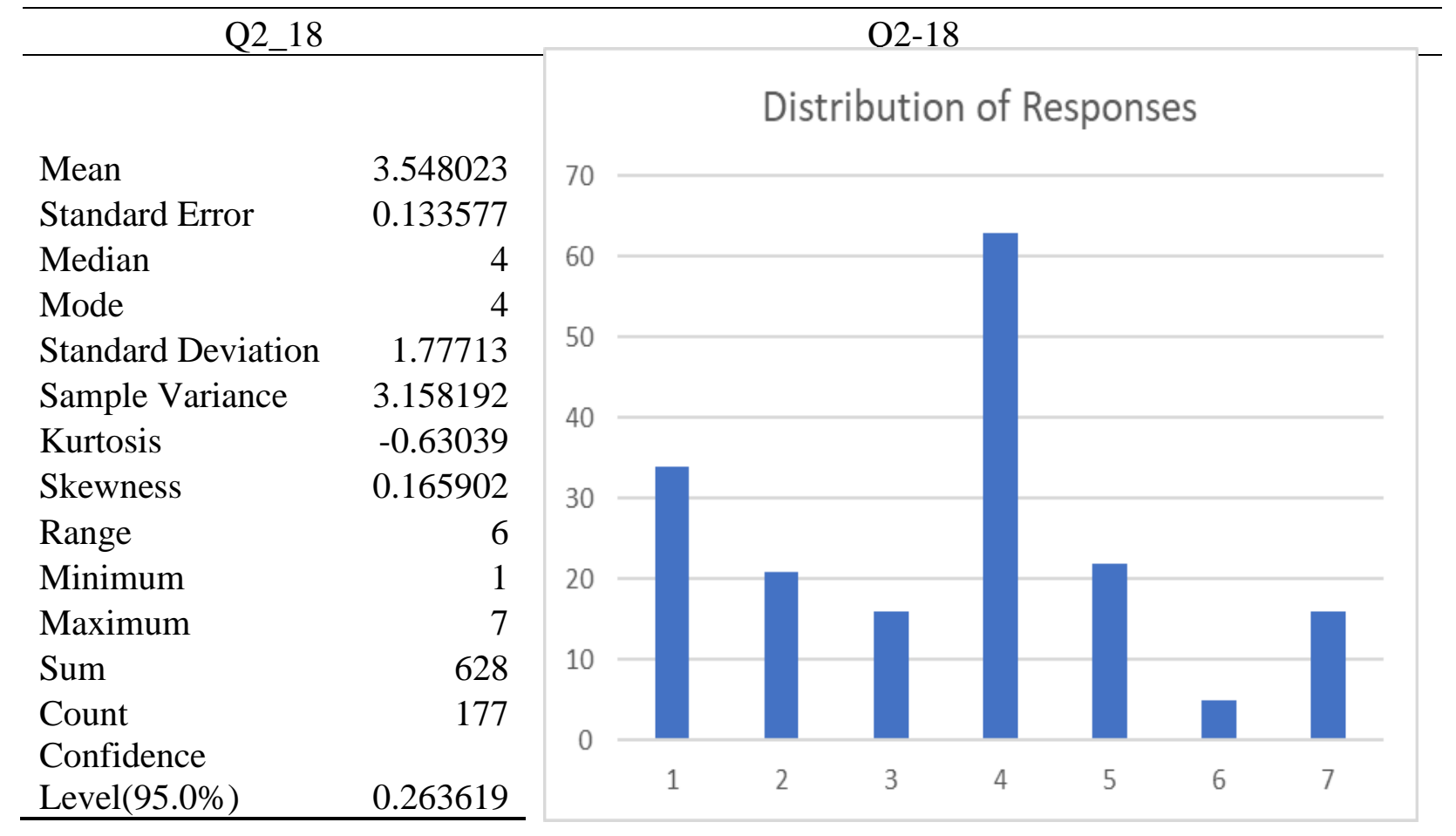

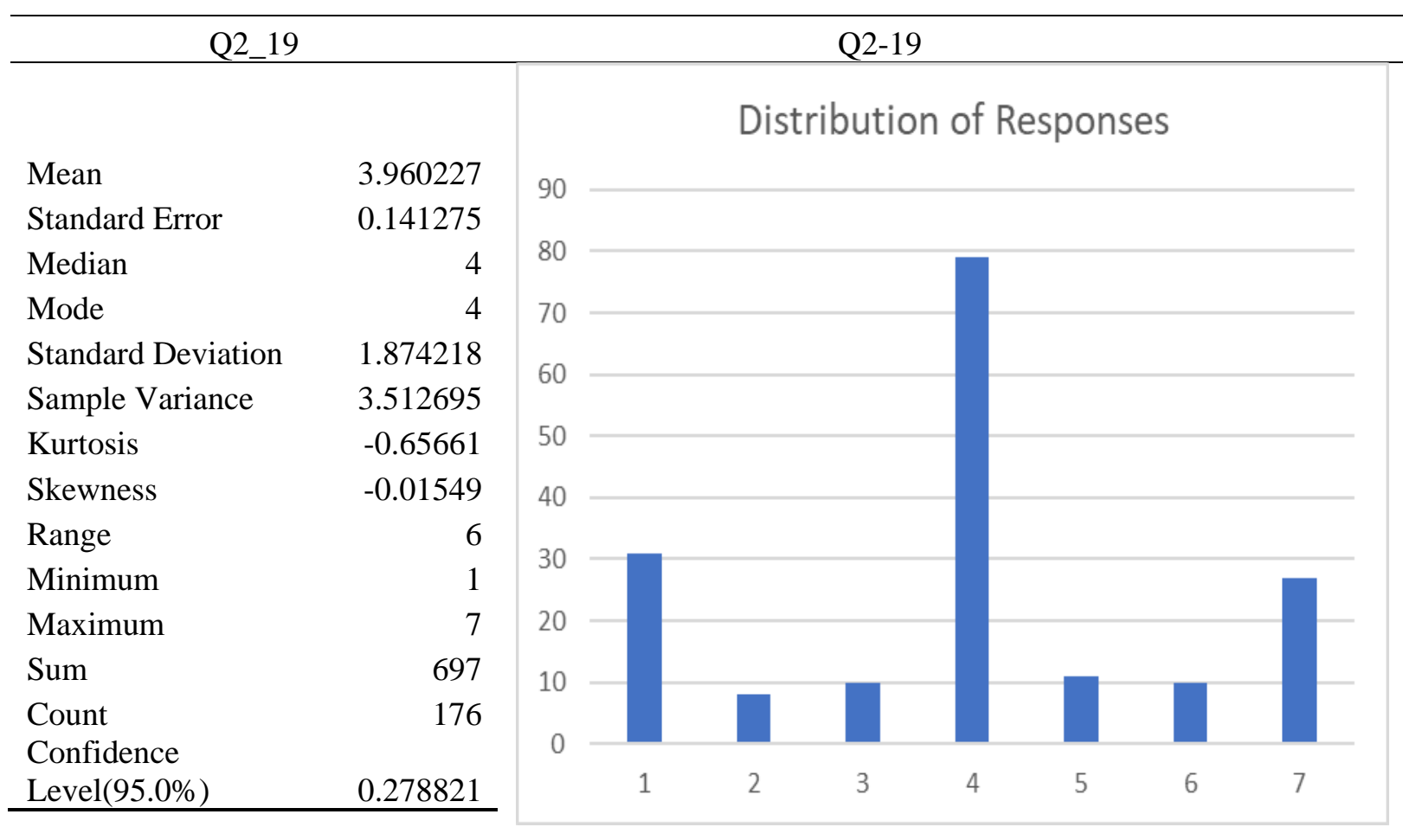




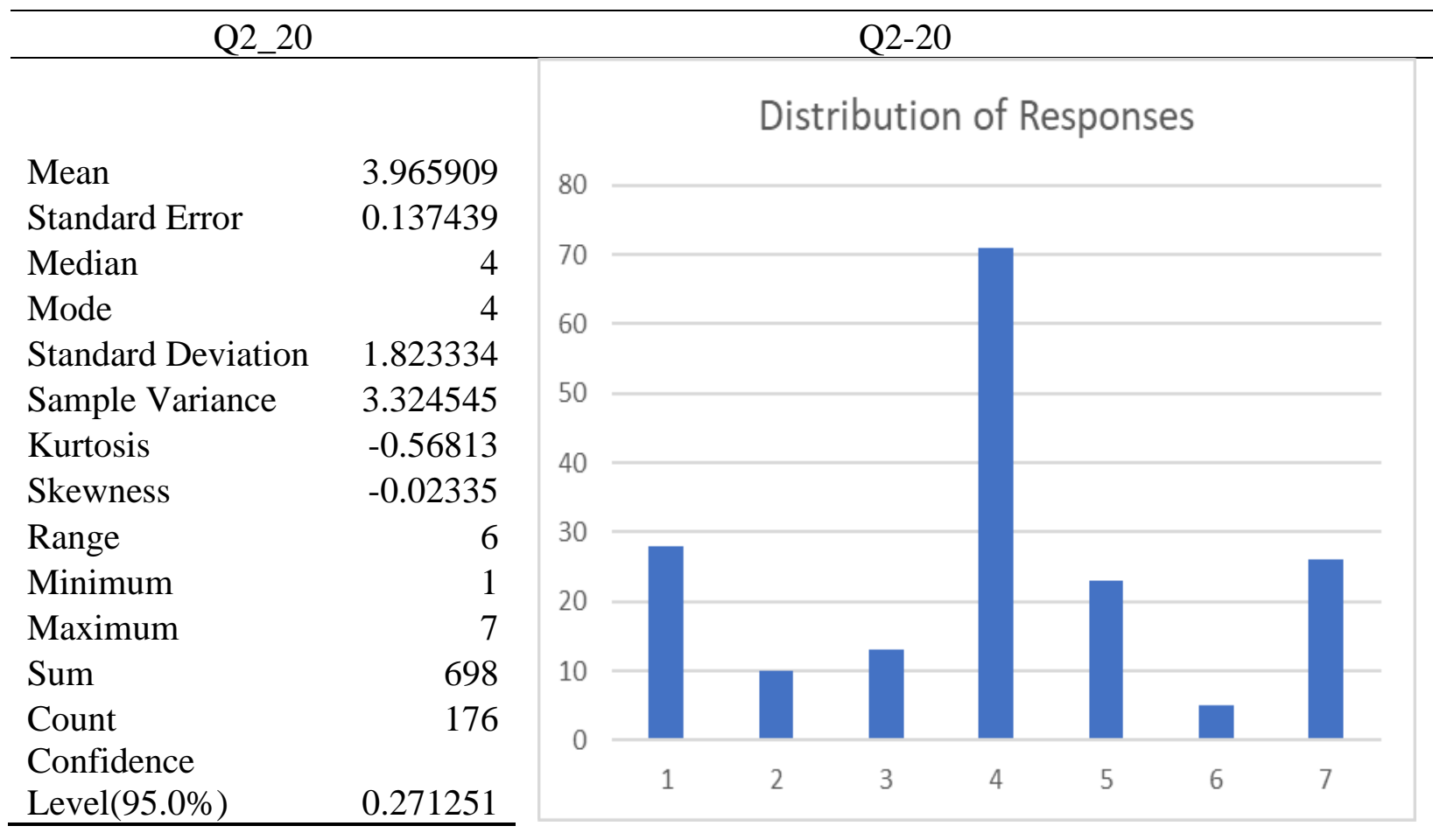

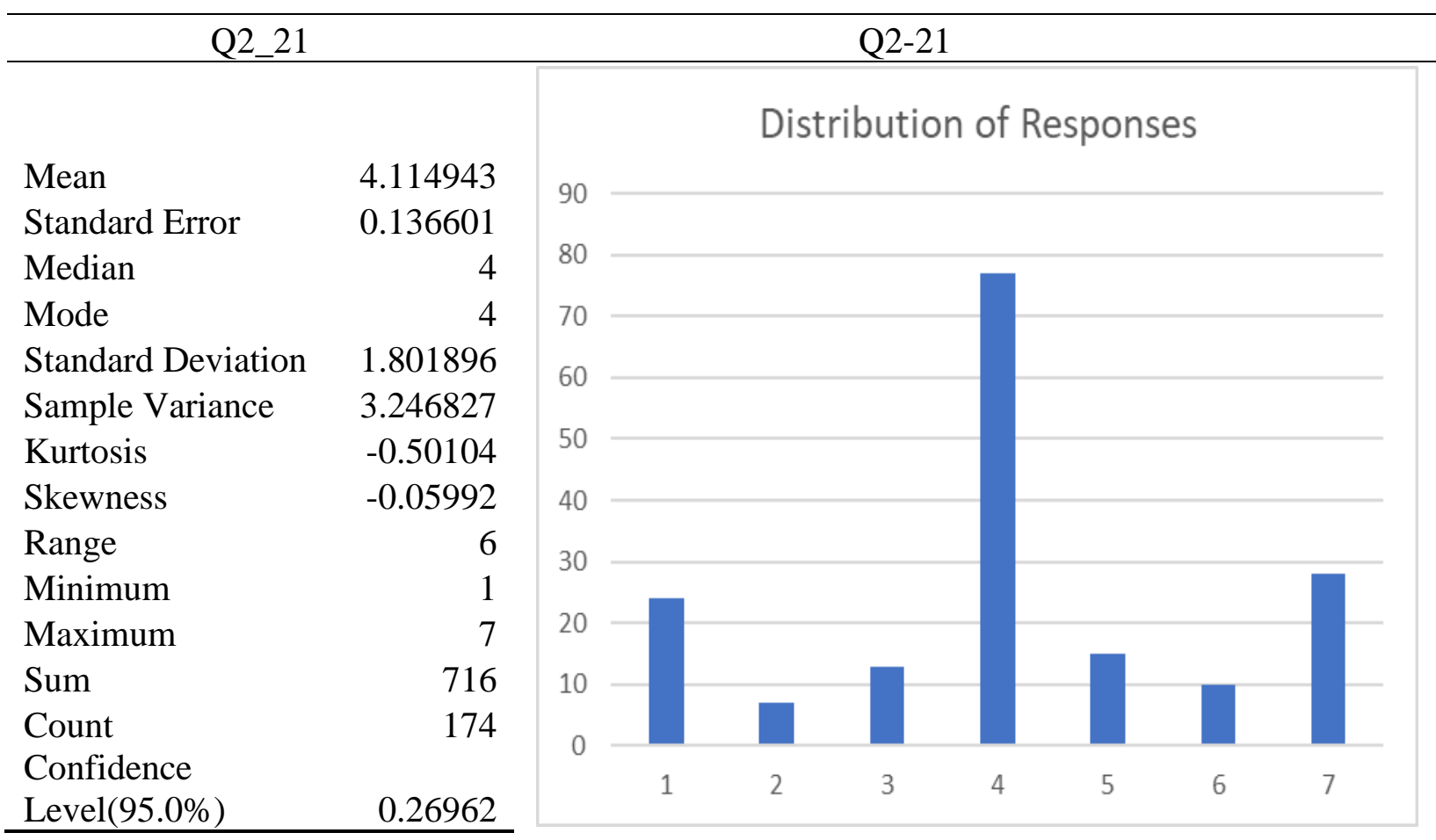




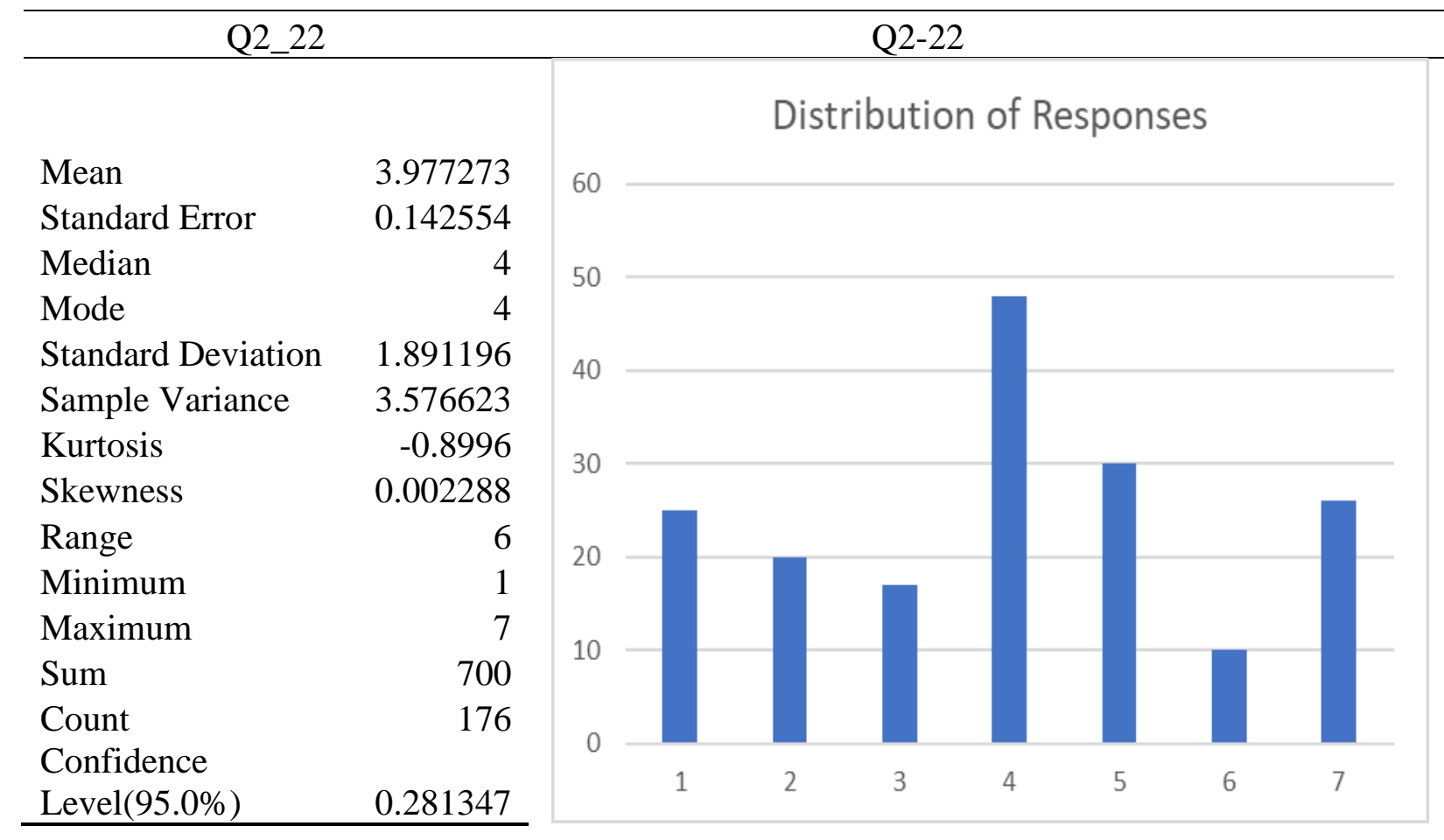

\section{Q2_23}

Q2-23

Mean

3.757225

Distribution of Responses

Standard Error

0.139107

Median

Mode

Standard Deviation

Sample Variance

Kurtosis

4
4

1.829671

3.347695

Skewness

Range

Minimum

Maximum

Sum

Count $-0.66687$

0.12277

Confidence

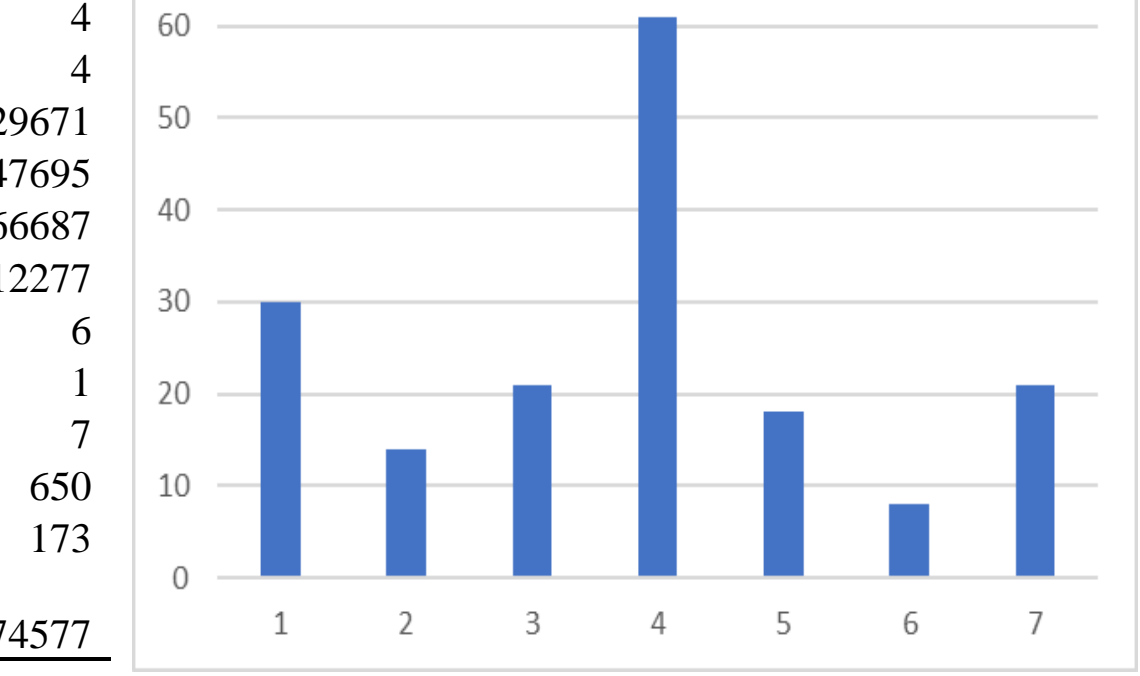

Level(95.0\%)

0.274577 


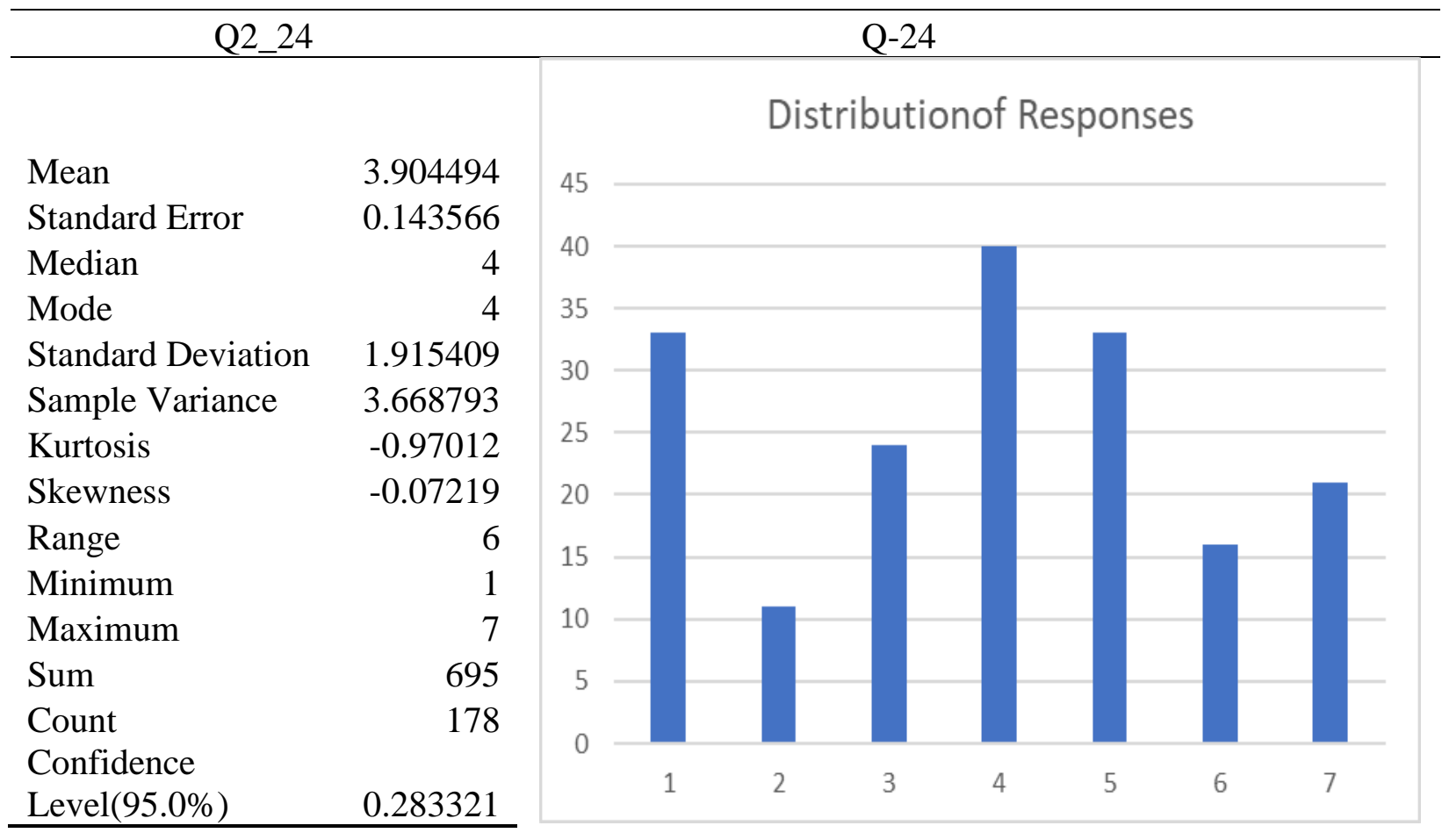


Appendix I: One Factor ANOVA Analysis of Challenges Addressed and Age 
ANOVA

Q\#1

\begin{tabular}{lcrrrrr}
\hline \multicolumn{1}{c}{$\begin{array}{l}\text { Source of } \\
\text { Variation }\end{array}$} & \multicolumn{1}{c}{ SS } & \multicolumn{1}{c}{ df } & MS & \multicolumn{1}{c}{ F } & P-value & F crit \\
\hline Between Groups & 1.569412 & 2 & 0.784706 & 0.268572 & 0.7648 & 3.05012 \\
Within Groups & 487.9365 & 167 & 2.921775 & & & \\
& & & & & & \\
Total & 489.5059 & 169 & & & & \\
\hline
\end{tabular}

ANOVA

Q2\#2

\begin{tabular}{lcrcccc}
\hline \multicolumn{1}{c}{$\begin{array}{l}\text { Source of } \\
\text { Variation }\end{array}$} & \multicolumn{1}{c}{ SS } & \multicolumn{1}{c}{ df } & MS & \multicolumn{1}{c}{ F } & P-value & F crit \\
\hline Between Groups & 0.18179 & 2 & 0.090895 & 0.034312 & 0.966277 & 3.050787 \\
Within Groups & 437.098 & 165 & 2.649079 & & & \\
& & & & & & \\
Total & 437.2798 & 167 & & & & \\
\hline
\end{tabular}

ANOVA

Q2\#3

Source of

Variation

Between Groups 3.908969

Within Groups

$\begin{array}{lll}660.63 \quad 164 & 4.028231\end{array}$

Total

$664.5389 \quad 166$

\begin{tabular}{lrrrrrr} 
ANOVA & \multicolumn{7}{c}{ Q2\#4 } \\
\hline \multicolumn{1}{c}{$\begin{array}{l}\text { Source of } \\
\text { Variation }\end{array}$} & \multicolumn{1}{c}{ SS } & \multicolumn{1}{c}{ df } & \multicolumn{1}{c}{$M S$} & \multicolumn{1}{c}{ F } & P-value & F crit \\
\hline Between Groups & 21.32031 & 2 & 10.66015 & 3.301823 & 0.039249 & 3.050451 \\
Within Groups & 535.942 & 166 & 3.228566 & & & \\
& & & & & & \\
Total & 557.2623 & 168 & & & & \\
\hline
\end{tabular}

\begin{tabular}{lrrrrrr} 
ANOVA & \multicolumn{8}{c}{ Q2\#5 } \\
\hline \multicolumn{1}{c}{$\begin{array}{l}\text { Source of } \\
\text { Variation }\end{array}$} & \multicolumn{1}{c}{$S S$} & $d f$ & \multicolumn{1}{c}{ MS } & \multicolumn{1}{c}{ F } & P-value & F crit \\
\hline Between Groups & 14.3664 & 2 & 7.183201 & 2.121775 & 0.123137 & 3.051819 \\
Within Groups & 548.4457 & 162 & 3.385467 & & & \\
& & & & & & \\
Total & 562.8121 & 164 & & & & \\
\hline
\end{tabular}


ANOVA

Source of

Variation

Between Groups 9.095056

Within Groups

Total

507.3054

Q2\#6

\begin{tabular}{rcccc} 
df & $M S$ & $F$ & $P$-value & $F$ crit \\
\hline 2 & 4.547528 & 1.496947 & 0.226854 & 3.051127 \\
164 & 3.037868 & & &
\end{tabular}

ANOVA

Q2\#7

\begin{tabular}{lrrrrrr}
\hline \multicolumn{1}{c}{$\begin{array}{c}\text { Source of } \\
\text { Variation }\end{array}$} & \multicolumn{1}{c}{ SS } & df & MS & \multicolumn{1}{c}{ F } & P-value & F crit \\
\hline Between Groups & 4.382763 & 2 & 2.191381 & 0.771734 & 0.463924 & 3.052529 \\
Within Groups & 454.3289 & 160 & 2.839556 & & & \\
& & & & & & \\
Total & 458.7117 & 162 & & & & \\
\hline
\end{tabular}

ANOVA

Q2\#8

Source of

Variation

Between Groups 28.73055

Within Groups $\quad 462.4743$

166

Total

491.2048

165

ANOVA

Q2\#9

Source of

Variation

Between Groups 3.053313

Within Groups $\quad 444.9831$

\begin{tabular}{ccccc}
$d f$ & $M S$ & $F$ & $P$-value & $F$ crit \\
\hline 2 & 14.36527 & 5.06307 & 0.007358 & 3.051471
\end{tabular}

$\begin{array}{ll}163 & 2.837265\end{array}$

Total

448.0364

164

\begin{tabular}{lcrrrrr} 
ANOVA & \multicolumn{7}{c}{ Q2\#10 } \\
\hline \multicolumn{1}{c}{$\begin{array}{l}\text { Source of } \\
\text { Variation }\end{array}$} & \multicolumn{1}{c}{$S S$} & $d f$ & $M S$ & \multicolumn{1}{c}{ M } & P-value & F crit \\
\hline Between Groups & 1.439729 & 2 & 0.719864 & 0.213096 & 0.808307 & 3.052529 \\
Within Groups & 540.4989 & 160 & 3.378118 & & & \\
& & & & & & \\
Total & 541.9387 & 162 & & & & \\
\hline
\end{tabular}


ANOVA

Source of

Variation

\begin{tabular}{lcrcccc}
\multicolumn{1}{c}{ Variation } & \multicolumn{1}{c}{$S S$} & $d f$ & $M S$ & $F$ & $P$-value & $F$ crit \\
\hline Between Groups & 1.526279 & 2 & 0.763139 & 0.264055 & 0.768265 & 3.052529 \\
Within Groups & 462.4124 & 160 & 2.890077 & & &
\end{tabular}

Total

463.9387
162

ANOVA

Q2\#12

\begin{tabular}{lcrrrrr}
\hline \multicolumn{1}{c}{$\begin{array}{c}\text { Source of } \\
\text { Variation }\end{array}$} & \multicolumn{1}{c}{ SS } & df & MS & \multicolumn{1}{c}{ F } & P-value & F crit \\
\hline Between Groups & 3.673367 & 2 & 1.836684 & 0.565179 & 0.569389 & 3.052529 \\
Within Groups & 519.9585 & 160 & 3.249741 & & & \\
& & & & & & \\
Total & 523.6319 & 162 & & & & \\
\hline
\end{tabular}

ANOVA

Q2\#13

Source of

Variation

Between Groups $\quad 5.875035$

Within Groups $\quad 473.6555$

MS $\quad F \quad P$-value $F$ crit

\begin{tabular}{ccccc} 
& $M S$ & $F$ & $P$-value & $F$ crit \\
\hline 2 & 2.937518 & 0.99849 & 0.370705 & 3.052172
\end{tabular}

$\begin{array}{ll}161 & 2.941959\end{array}$

Total

479.5305

163

ANOVA

Q2\#14

\begin{tabular}{lcrcccc}
\hline \multicolumn{1}{c}{$\begin{array}{c}\text { Source of } \\
\text { Variation }\end{array}$} & \multicolumn{1}{c}{ SS } & $d f$ & $M S$ & \multicolumn{1}{c}{ M } & P-value & F crit \\
\hline Between Groups & 3.521026 & 2 & 1.760513 & 0.665982 & 0.515178 & 3.052172 \\
Within Groups & 425.6009 & 161 & 2.643484 & & & \\
& & & & & & \\
Total & 429.122 & 163 & & & & \\
\hline
\end{tabular}

\begin{tabular}{lcrrrrr} 
ANOVA & \multicolumn{7}{c}{ Q2\#15 } \\
\hline \multicolumn{1}{c}{$\begin{array}{l}\text { Source of } \\
\text { Variation }\end{array}$} & \multicolumn{1}{c}{$S S$} & $d f$ & \multicolumn{1}{c}{$M S$} & \multicolumn{1}{c}{$F$} & P-value & F crit \\
\hline Between Groups & 6.616749 & 2 & 3.308374 & 1.255562 & 0.28769 & 3.052172 \\
Within Groups & 424.2308 & 161 & 2.634974 & & & \\
& & & & & & \\
Total & 430.8476 & 163 & & & & \\
\hline
\end{tabular}


ANOVA

\begin{tabular}{lcrrrrr}
\hline \multicolumn{1}{c}{$\begin{array}{c}\text { Source of } \\
\text { Variation }\end{array}$} & \multicolumn{1}{c}{ SS } & $d f$ & $M S$ & \multicolumn{1}{c}{ M } & P-value & F crit \\
\hline Between Groups & 3.696429 & 2 & 1.848214 & 0.643932 & 0.526538 & 3.050787 \\
Within Groups & 473.5833 & 165 & 2.870202 & & & \\
& & & & & & \\
Total & 477.2798 & 167 & & & & \\
\hline
\end{tabular}

ANOVA

\begin{tabular}{lrrrrrr}
\hline \multicolumn{1}{c}{$\begin{array}{c}\text { Source of } \\
\text { Variation }\end{array}$} & \multicolumn{1}{c}{ SS } & $d f$ & MS & \multicolumn{1}{c}{ F } & P-value & F crit \\
\hline Between Groups & 3.338407 & 2 & 1.669203 & 0.484181 & 0.617085 & 3.051471 \\
Within Groups & 561.9387 & 163 & 3.447477 & & & \\
& & & & & & \\
Total & 565.2771 & 165 & & & & \\
\hline
\end{tabular}

ANOVA

Q2\#18

\begin{tabular}{lrrrrrc}
\hline \multicolumn{1}{c}{$\begin{array}{c}\text { Source of } \\
\text { Variation }\end{array}$} & \multicolumn{1}{c}{ SS } & $d f$ & \multicolumn{1}{c}{ MS } & \multicolumn{1}{c}{ F } & P-value & F crit \\
\hline Between Groups & 36.96386 & 2 & 18.48193 & 6.797662 & 0.001465 & 3.052172 \\
Within Groups & 437.7374 & 161 & 2.718866 & & & \\
& & & & & & \\
Total & 474.7012 & 163 & & & & \\
\hline
\end{tabular}

ANOVA

Q2\#19

\begin{tabular}{lcrrrrr}
\hline \multicolumn{1}{c}{$\begin{array}{l}\text { Source of } \\
\text { Variation }\end{array}$} & \multicolumn{1}{c}{ SS } & \multicolumn{1}{c}{ df } & \multicolumn{1}{c}{ MS } & \multicolumn{1}{c}{ F } & P-value & F crit \\
\hline Between Groups & 8.352681 & 2 & 4.17634 & 1.228615 & 0.295427 & 3.052172 \\
Within Groups & 547.2754 & 161 & 3.399226 & & & \\
& & & & & & \\
Total & 555.628 & 163 & & & & \\
\hline
\end{tabular}

ANOVA

Q2\#20

\begin{tabular}{lcrcccc}
\hline \multicolumn{1}{c}{$\begin{array}{l}\text { Source of } \\
\text { Variation }\end{array}$} & \multicolumn{1}{c}{ SS } & \multicolumn{1}{c}{ df } & \multicolumn{1}{c}{$M S$} & \multicolumn{1}{c}{ P } & P-value & F crit \\
\hline Between Groups & 2.884953 & 2 & 1.442476 & 0.444285 & 0.642067 & 3.052172 \\
Within Groups & 522.7248 & 161 & 3.246738 & & & \\
& & & & & & \\
Total & 525.6098 & 163 & & & & \\
\hline
\end{tabular}


ANOVA

Source of

Variation

Between Groups

Within Groups

Total

ANOVA

Source of

\begin{tabular}{cc} 
Variation & $S S$ \\
\hline Between Groups & 7.294282
\end{tabular}

Within Groups $\quad 567.491$

0.1725

489.4471

499.6196

162

Q2\#21

Total

574.7853

162

ANOVA

Q2\#23

Source of

Variation

Between Groups 0.569486

Within Groups

525.4926

$d f$

MS

$2 \quad 0.284743$

$158 \quad 3.325903$

Total

526.0621

160

ANOVA

Q2\#24

Source of

Variation

Between Groups

Within Groups

609.563

$S S \quad d f$

df $\quad$ MS

$2 \quad 0.624574$

$\begin{array}{cc}F & P \text {-value }\end{array}$

F crit

$162 \quad 3.762734$

Total

610.8121

164 
Appendix J: One Factor ANOVA Analysis for Addressed Challenges with Number of Years Enrolled at WVU 
ANOVA

Q2 \#1

Source of

Variation

Between Groups 4.813819

Within Groups $\quad 474.9805$

\begin{tabular}{ccccc}
$d f$ & $M S$ & $F$ & $P$-value & $F$ crit \\
\hline 2 & 2.40691 & 0.87159 & 0.420125 & 3.04852
\end{tabular}

$172 \quad 2.761514$

Total

479.7943

174

ANOVA

Q2 \#2

\begin{tabular}{lrrrrrr}
\hline \multicolumn{1}{c}{$\begin{array}{c}\text { Source of } \\
\text { Variation }\end{array}$} & \multicolumn{1}{c}{ SS } & \multicolumn{1}{c}{ df } & MS & \multicolumn{1}{c}{ P } & P-value & F crit \\
\hline Between Groups & 4.475476 & 2 & 2.237738 & 0.870577 & 0.420568 & 3.049149 \\
Within Groups & 436.9696 & 170 & 2.570409 & & & \\
& & & & & & \\
Total & 441.4451 & 172 & & & & \\
\hline
\end{tabular}

ANOVA

Q2\#3

\begin{tabular}{lrrrrrr}
\hline \multicolumn{1}{c}{$\begin{array}{l}\text { Source of } \\
\text { Variation }\end{array}$} & \multicolumn{1}{c}{ SS } & \multicolumn{1}{c}{ df } & \multicolumn{1}{c}{ MS } & \multicolumn{1}{c}{ F } & P-value & F crit \\
\hline Between Groups & 13.73774 & 2 & 6.868871 & 1.744752 & 0.17782 & 3.049468 \\
Within Groups & 665.332 & 169 & 3.936876 & & & \\
& & & & & & \\
Total & 679.0698 & 171 & & & & \\
\hline
\end{tabular}

ANOVA

Q2\#4

\begin{tabular}{lrrrrrr}
\hline \multicolumn{1}{c}{$\begin{array}{l}\text { Source of } \\
\text { Variation }\end{array}$} & \multicolumn{1}{c}{ SS } & \multicolumn{1}{c}{ df } & MS & \multicolumn{1}{c}{ F } & P-value & F crit \\
\hline Between Groups & 29.04402 & 2 & 14.52201 & 4.592718 & 0.011414 & 3.049149 \\
Within Groups & 537.534 & 170 & 3.161965 & & & \\
& & & & & & \\
Total & 566.578 & 172 & & & & \\
\hline
\end{tabular}

ANOVA

Q2\#5

\begin{tabular}{lcrcccc}
\hline \multicolumn{1}{c}{$\begin{array}{c}\text { Source of } \\
\text { Variation }\end{array}$} & \multicolumn{1}{c}{ SS } & \multicolumn{1}{c}{ df } & \multicolumn{1}{c}{ MS } & \multicolumn{1}{c}{ F } & P-value & F crit \\
\hline Between Groups & 18.52056 & 2 & 9.26028 & 2.698272 & 0.070257 & 3.05012 \\
Within Groups & 573.1324 & 167 & 3.43193 & & & \\
& & & & & & \\
Total & 591.6529 & 169 & & & & \\
\hline
\end{tabular}




\begin{tabular}{|c|c|c|c|c|c|c|}
\hline ANOVA & & & Q2 \#6 & & & \\
\hline $\begin{array}{l}\text { Source of } \\
\text { Variation } \\
\end{array}$ & $S S$ & $d f$ & $M S$ & $F$ & $P$-value & $F$ crit \\
\hline Between Groups & 21.75397 & 2 & 10.87698 & 3.693716 & 0.02691 & 3.049468 \\
\hline Within Groups & 497.6588 & 169 & 2.944727 & & & \\
\hline Total & 519.4128 & 171 & & & & \\
\hline ANOVA & & & Q2\#7 & & & \\
\hline $\begin{array}{l}\text { Source of } \\
\text { Variation }\end{array}$ & $S S$ & $d f$ & $M S$ & $F$ & $P$-value & $F$ crit \\
\hline Between Groups & 7.51544 & 2 & 3.75772 & 1.370554 & 0.256842 & 3.050787 \\
\hline Within Groups & 452.3893 & 165 & 2.741753 & & & \\
\hline Total & 459.9048 & 167 & & & & \\
\hline ANOVA & & & Q2\#8 & & & \\
\hline $\begin{array}{l}\text { Source of } \\
\text { Variation } \\
\end{array}$ & $S S$ & $d f$ & $M S$ & $F$ & $P$-value & $F$ crit \\
\hline Between Groups & 13.593 & 2 & 6.796502 & 2.297014 & 0.103709 & 3.049792 \\
\hline Within Groups & 497.0854 & 168 & 2.958841 & & & \\
\hline Total & 510.6784 & 170 & & & & \\
\hline ANOVA & & & Q2\#9 & & & \\
\hline $\begin{array}{l}\text { Source of } \\
\text { Variation } \\
\end{array}$ & $S S$ & $d f$ & $M S$ & $F$ & $P$-value & $F$ crit \\
\hline Between Groups & 0.777801 & 2 & 0.388901 & 0.144445 & 0.865611 & 3.05012 \\
\hline Within Groups & 449.6281 & 167 & 2.692384 & & & \\
\hline Total & 450.4059 & 169 & & & & \\
\hline
\end{tabular}

\begin{tabular}{lrrrrrr} 
ANOVA & \multicolumn{7}{c}{ Q2\#10 } \\
\hline \multicolumn{1}{c}{$\begin{array}{l}\text { Source of } \\
\text { Variation }\end{array}$} & \multicolumn{1}{c}{$S S$} & $d f$ & \multicolumn{1}{c}{$M S$} & \multicolumn{1}{c}{ F } & P-value & F crit \\
\hline Between Groups & 4.427784 & 2 & 2.213892 & 0.661939 & 0.517215 & 3.050787 \\
Within Groups & 551.852 & 165 & 3.344557 & & & \\
& & & & & & \\
Total & 556.2798 & 167 & & & & \\
\hline
\end{tabular}




\begin{tabular}{|c|c|c|c|c|c|c|}
\hline ANOVA & & & Q2\#11 & & & \\
\hline $\begin{array}{l}\text { Source of } \\
\text { Variation } \\
\end{array}$ & $S S$ & $d f$ & $M S$ & $F$ & P-value & $F$ crit \\
\hline Between Groups & 0.661311 & 2 & 0.330655 & 0.113147 & 0.893089 & 3.050787 \\
\hline Within Groups & 482.1899 & 165 & 2.922363 & & & \\
\hline Total & 482.8512 & 167 & & & & \\
\hline ANOVA & & & Q2\#12 & & & \\
\hline $\begin{array}{l}\text { Source of } \\
\text { Variation }\end{array}$ & $S S$ & $d f$ & $M S$ & $F$ & $P$-value & $F$ crit \\
\hline Between Groups & 3.038422 & 2 & 1.519211 & 0.463618 & 0.629825 & 3.051127 \\
\hline Within Groups & 537.4047 & 164 & 3.276858 & & & \\
\hline Total & 540.4431 & 166 & & & & \\
\hline ANOVA & & & Q2\#13 & & & \\
\hline $\begin{array}{l}\text { Source of } \\
\text { Variation }\end{array}$ & $S S$ & $d f$ & $M S$ & $F$ & P-value & F crit \\
\hline Between Groups & 5.03756 & 2 & 2.51878 & 0.842269 & 0.432564 & 3.050451 \\
\hline Within Groups & 496.4181 & 166 & 2.99047 & & & \\
\hline Total & 501.4556 & 168 & & & & \\
\hline ANOVA & & & Q2\#14 & & & \\
\hline $\begin{array}{l}\text { Source of } \\
\text { Variation } \\
\end{array}$ & $S S$ & $d f$ & $M S$ & $F$ & $P$-value & $F$ crit \\
\hline Between Groups & 1.194941 & 2 & 0.59747 & 0.225379 & 0.798456 & 3.05012 \\
\hline Within Groups & 442.7109 & 167 & 2.650964 & & & \\
\hline Total & 443.9059 & 169 & & & & \\
\hline
\end{tabular}

\begin{tabular}{lcrrrrr} 
ANOVA & \multicolumn{7}{c}{ Q2\#15 } \\
\hline \multicolumn{1}{c}{$\begin{array}{l}\text { Source of } \\
\text { Variation }\end{array}$} & \multicolumn{1}{c}{$S S$} & $d f$ & $M S$ & \multicolumn{1}{c}{ M } & P-value & F crit \\
\hline Between Groups & 0.653123 & 2 & 0.326561 & 0.118911 & 0.887962 & 3.050787 \\
Within Groups & 453.1326 & 165 & 2.746258 & & & \\
& & & & & & \\
Total & 453.7857 & 167 & & & & \\
\hline
\end{tabular}


ANOVA

Q2\#16

\begin{tabular}{lrrrrrr}
\hline \multicolumn{1}{c}{$\begin{array}{l}\text { Source of } \\
\text { Variation }\end{array}$} & \multicolumn{1}{c}{ SS } & $d f$ & \multicolumn{1}{c}{ MS } & \multicolumn{1}{c}{ F } & P-value & F crit \\
\hline Between Groups & 6.863448 & 2 & 3.431724 & 1.219947 & 0.297817 & 3.049149 \\
Within Groups & 478.2117 & 170 & 2.81301 & & & \\
& & & & & & \\
Total & 485.0751 & 172 & & & & \\
\hline
\end{tabular}

ANOVA

Q2\#17

\begin{tabular}{lcrrrrr}
\hline \multicolumn{1}{c}{$\begin{array}{l}\text { Source of } \\
\text { Variation }\end{array}$} & \multicolumn{1}{c}{ SS } & \multicolumn{1}{c}{ df } & MS & \multicolumn{1}{c}{ F } & P-value & F crit \\
\hline Between Groups & 31.23152 & 2 & 15.61576 & 4.73141 & 0.01003 & 3.05012 \\
Within Groups & 551.1744 & 167 & 3.300445 & & & \\
& & & & & & \\
Total & 582.4059 & 169 & & & & \\
\hline
\end{tabular}

ANOVA

Q2\#18

\begin{tabular}{lcrrrrr}
\hline \multicolumn{1}{c}{$\begin{array}{c}\text { Source of } \\
\text { Variation }\end{array}$} & \multicolumn{1}{c}{ SS } & $d f$ & \multicolumn{1}{c}{$M S$} & \multicolumn{1}{c}{ F } & P-value & F crit \\
\hline Between Groups & 17.09476 & 2 & 8.54738 & 2.891349 & 0.058301 & 3.050451 \\
Within Groups & 490.7277 & 166 & 2.956191 & & & \\
& & & & & & \\
Total & 507.8225 & 168 & & & & \\
\hline
\end{tabular}

ANOVA

Q2\#19

Source of

Variation

Between Groups

Within Groups

556.0427

$M S$

\begin{tabular}{ccccc}
$d f$ & $M S$ & $F$ & $P$-value & $F$ crit \\
\hline 2 & 4.871525 & 1.445575 & 0.238579 & 3.050787
\end{tabular}

$\begin{array}{ccc}S S & d f & M S \\ 9.743049 & 2 & 4.871525\end{array}$

$165 \quad 3.369956$

Total

565.7857

167

\begin{tabular}{lrrrrrr} 
ANOVA & \multicolumn{7}{c}{ Q2\#20 } \\
\hline \multicolumn{1}{c}{$\begin{array}{l}\text { Source of } \\
\text { Variation }\end{array}$} & \multicolumn{1}{c}{$S S$} & $d f$ & $M S$ & \multicolumn{1}{c}{ M } & P-value & F crit \\
\hline Between Groups & 1.133572 & 2 & 0.566786 & 0.171705 & 0.842378 & 3.050787 \\
Within Groups & 544.6521 & 165 & 3.300922 & & & \\
& & & & & & \\
Total & 545.7857 & 167 & & & & \\
\hline
\end{tabular}


ANOVA

Source of

Variation

Between Groups

Within Groups

Total

521.9819

2.322422

Q2\#21

\begin{tabular}{lccccc}
$S S$ & $d f$ & $M S$ & $F$ & $P$-value & $F$ crit \\
\hline 322422 & 2 & 1.161211 & 0.364233 & 0.695293 & 3.051471
\end{tabular}

$\begin{array}{ll}163 & 3.188095\end{array}$

\section{ANOVA}

Q2\#22

\begin{tabular}{lcrrrrr}
\hline \multicolumn{1}{c}{$\begin{array}{c}\text { Source of } \\
\text { Variation }\end{array}$} & \multicolumn{1}{c}{ SS } & \multicolumn{1}{c}{ df } & \multicolumn{1}{c}{ MS } & \multicolumn{1}{c}{ F } & P-value & F crit \\
\hline Between Groups & 6.093196 & 2 & 3.046598 & 0.889224 & 0.412935 & 3.050787 \\
Within Groups & 565.3116 & 165 & 3.426131 & & & \\
& & & & & & \\
Total & 571.4048 & 167 & & & & \\
\hline
\end{tabular}

ANOVA

Q2\#23

\begin{tabular}{|c|c|c|c|c|c|c|}
\hline $\begin{array}{l}\text { Source of } \\
\text { Variation }\end{array}$ & $S S$ & $d f$ & $M S$ & $F$ & $P$-value & $F$ crit \\
\hline Between Groups & 2.461806 & 2 & 1.230903 & 0.387084 & 0.679661 & 3.051819 \\
\hline Within Groups & 515.1503 & 162 & 3.17994 & & & \\
\hline Total & 517.6121 & 164 & & & & \\
\hline ANOVA & & & & Q2\#24 & & \\
\hline $\begin{array}{l}\text { Source of } \\
\text { Variation }\end{array}$ & $S S$ & $d f$ & $M S$ & $F$ & P-value & $F$ crit \\
\hline Between Groups & 6.026967 & 2 & 3.013483 & 0.825987 & 0.439583 & 3.05012 \\
\hline Within Groups & 609.273 & 167 & 3.648342 & & & \\
\hline Total & 615.3 & 169 & & & & \\
\hline
\end{tabular}


Appendix K: Descriptive Analysis for Resources Used by students to Adjust 


\begin{tabular}{lrlrlr}
\hline Q3_1 & & Q3_2 & & Q3_3 & \\
\hline \hline & 3.48039 & & 3.79411 & & 4.03921 \\
Mean & 2 & Mean & 8 & Mean & 6 \\
& 0.08993 & & 0.08890 & & 0.07857 \\
Standard Error & 1 & Standard Error & 9 & Standard Error & 6 \\
Median & 4 & Median & 4 & Median & 4 \\
Mode & 4 & Mode & 5 & Mode & 5 \\
Standard & 1.28446 & Standard & 1.26987 & Standard & 1.12229 \\
Deviation & 9 & Deviation & 2 & Deviation & 2 \\
Sample & & Sample & 1.61257 & Sample & 1.25953 \\
Variance & 1.64986 & Variance & 6 & Variance & 8 \\
& & & & & 0.33683 \\
Kurtosis & -0.83321 & Kurtosis & -0.39972 & Kurtosis & 3 \\
Skewness & -0.46316 & Skewness & -0.81636 & Skewness & -1.07022 \\
Range & 4 & Range & 4 & Range & 4 \\
Minimum & 1 & Minimum & 1 & Minimum & 1 \\
Maximum & 5 & Maximum & 5 & Maximum & 5 \\
Sum & 710 & Sum & 774 & Sum & 824 \\
Count & 204 & Count & 204 & Count & 204 \\
\hline Confidence & 0.17731 & Confidence & 0.17530 & Confidence & \\
Level(95.0\%) & 8 & Level(95.0\%) & 3 & Level(95.0\%) & 0.15493 \\
\hline \hline
\end{tabular}

\begin{tabular}{lrlrlr}
\hline Q3_4 & & Q3_5 & & Q3_6 & \\
\hline Mean & 3.35294 & & 2.86274 & & 2.81188 \\
& 1 & Mean & 5 & Mean & 1 \\
Standard Error & 0.09174 & & 0.08541 & & 0.09108 \\
Median & 7 & Standard Error & 9 & Standard Error & 5 \\
Mode & 4 & Median & 3 & Median & 3 \\
Standard & 4 & Mode & 3 & Mode & 3 \\
Deviation & 1.31041 & Standard & 1.22002 & Standard & 1.29455 \\
Sample & 3 & Deviation & 4 & Deviation & 7 \\
Variance & 1.71718 & Sample & 1.48845 & Sample & 1.67587 \\
Kurtosis & 3 & Variance & 7 & Variance & 8 \\
& -0.91638 & Kurtosis & -0.91244 & Kurtosis & -0.96946 \\
Skewness & -0.41135 & Skewness & -0.06316 & Skewness & 0.07747 \\
Range & 4 & Range & 4 & Range & 2 \\
Minimum & 1 & Minimum & 1 & Minimum & 4 \\
Maximum & 5 & Maximum & 5 & Maximum & 1 \\
Sum & 684 & Sum & 584 & Sum & 5 \\
Count & 204 & Count & 204 & Count & 568 \\
Confidence & & Confidence & 0.16842 & Confidence & 0.17960 \\
Level(95.0\%) & 0.1809 & Level(95.0\%) & 2 & Level(95.0\%) & 4 \\
\hline \hline
\end{tabular}




\begin{tabular}{lrlrlr}
\hline Q3_7 & & Q3_8 & & Q3_9 & \\
\hline & 3.46305 & & 2.92118 & & 3.28855 \\
Mean & 4 & Mean & 2 & Mean & 7 \\
& 0.08977 & & 0.09115 & & 0.08855 \\
Standard Error & 3 & Standard Error & 6 & Standard Error & 7 \\
Median & 4 & Median & 3 & Median & 3 \\
Mode & 4 & Mode & 3 & Mode & 3 \\
Standard & 1.27906 & Standard & 1.29877 & Standard & 1.25551 \\
Deviation & 4 & Deviation & 9 & Deviation & 5 \\
Sample & 1.63600 & Sample & 1.68682 & Sample & 1.57631 \\
Variance & 4 & Variance & 6 & Variance & 8 \\
Kurtosis & -0.74574 & Kurtosis & -0.97385 & Kurtosis & -0.87644 \\
Skewness & -0.50471 & Skewness & -0.09889 & Skewness & -0.28515 \\
Range & 4 & Range & 4 & Range & 4 \\
Minimum & 1 & Minimum & 1 & Minimum & 1 \\
Maximum & 5 & Maximum & 5 & Maximum & 5 \\
Sum & 703 & Sum & 593 & Sum & 661 \\
Count & 203 & Count & 203 & Count & 201 \\
\hline Confidence & 0.17701 & Confidence & & Confidence & 0.17462 \\
Level(95.0\%) & 2 & Level(95.0\%) & 0.17974 & Level(95.0\%) & 6 \\
\hline \hline
\end{tabular}

\begin{tabular}{lrlr}
\hline Q3_10 & & Q3_11 & \\
\hline Mean & 3.727723 & Mean & 3.757426 \\
Standard Error & 0.080026 & Standard Error & 0.080806 \\
Median & 4 & Median & 4 \\
Mode & 4 & Mode & 4 \\
Standard Deviation & 1.13739 & Standard Deviation & 1.148466 \\
Sample Variance & 1.293655 & Sample Variance & 1.318974 \\
Kurtosis & -0.15881 & Kurtosis & -0.34041 \\
Skewness & -0.73945 & Skewness & -0.72709 \\
Range & 4 & Range & 4 \\
Minimum & 1 & Minimum & 1 \\
Maximum & 5 & Maximum & 5 \\
Sum & 753 & Sum & 759 \\
Count & 202 & Count & 202 \\
\hline Confidence & & Confidence & \\
Level(95.0\%) & 0.157799 & Level(95.0\%) & 0.159336 \\
\hline \hline
\end{tabular}


Appendix L: One Factor ANOVA Analysis of Resources Utilized by Students and Age 
ANOVA

Q3\#1

Source of

Variation

Between Groups 5.709077

Within Groups

313.7583

22.854538

\begin{tabular}{ccc}
$F$ & $P$-value & $F$ crit \\
\hline 1.783187 & 0.170818 & 3.04199
\end{tabular}

$196 \quad 1.600807$

Total

319.4673

198

ANOVA

Q3\#2

\begin{tabular}{lrrrrrr}
\hline \multicolumn{1}{c}{$\begin{array}{l}\text { Source of } \\
\text { Variation }\end{array}$} & \multicolumn{1}{c}{ SS } & \multicolumn{1}{c}{ df } & MS & \multicolumn{1}{c}{ F } & P-value & F crit \\
\hline Between Groups & 0.359429 & 2 & 0.179714 & 0.110439 & 0.895498 & 3.042717 \\
Within Groups & 314.064 & 193 & 1.627275 & & & \\
& & & & & & \\
Total & 314.4235 & 195 & & & & \\
\hline
\end{tabular}

ANOVA

Q3\#3

\begin{tabular}{lcrcccc}
\hline \multicolumn{1}{c}{$\begin{array}{l}\text { Source of } \\
\text { Variation }\end{array}$} & \multicolumn{1}{c}{ SS } & \multicolumn{1}{c}{ df } & MS & \multicolumn{1}{c}{ F } & P-value & F crit \\
\hline Between Groups & 4.264204 & 2 & 2.132102 & 1.709243 & 0.18369 & 3.04199 \\
Within Groups & 244.4896 & 196 & 1.247396 & & & \\
& & & & & & \\
Total & 248.7538 & 198 & & & & \\
\hline
\end{tabular}

ANOVA

Q3\#4

\begin{tabular}{lcrcccc}
\hline \multicolumn{1}{c}{$\begin{array}{l}\text { Source of } \\
\text { Variation }\end{array}$} & \multicolumn{1}{c}{ SS } & \multicolumn{1}{c}{ df } & MS & \multicolumn{1}{c}{ F } & P-value & F crit \\
\hline Between Groups & 19.06889 & 2 & 9.534443 & 5.820898 & 0.003501 & 3.04199 \\
Within Groups & 321.0417 & 196 & 1.637968 & & & \\
& & & & & & \\
Total & 340.1106 & 198 & & & & \\
\hline
\end{tabular}

ANOVA

Q3\#5

\begin{tabular}{lrrrrrr}
\hline \multicolumn{1}{c}{$\begin{array}{l}\text { Source of } \\
\text { Variation }\end{array}$} & \multicolumn{1}{c}{ SS } & \multicolumn{1}{c}{ df } & MS & \multicolumn{1}{c}{ F } & P-value & F crit \\
\hline Between Groups & 6.526608 & 2 & 3.263304 & 2.298038 & 0.103156 & 3.04199 \\
Within Groups & 278.3277 & 196 & 1.420039 & & & \\
& & & & & & \\
Total & 284.8543 & 198 & & & & \\
\hline
\end{tabular}




\begin{tabular}{lcrrrrr} 
ANOVA & \multicolumn{7}{c}{ Q3\#6 } \\
\hline \multicolumn{1}{c}{$\begin{array}{l}\text { Source of } \\
\text { Variation }\end{array}$} & \multicolumn{1}{c}{ SS } & \multicolumn{1}{c}{ df } & \multicolumn{1}{c}{ MS } & \multicolumn{1}{c}{ F } & P-value & F crit \\
\hline Between Groups & 8.553024 & 2 & 4.276512 & 2.714628 & 0.068746 & 3.042472 \\
Within Groups & 305.6196 & 194 & 1.575359 & & & \\
& & & & & & \\
Total & 314.1726 & 196 & & & & \\
\hline
\end{tabular}

\begin{tabular}{lcrrrrr} 
ANOVA & \multicolumn{8}{c}{ Q3\#7 } \\
\hline \multicolumn{1}{c}{$\begin{array}{l}\text { Source of } \\
\text { Variation }\end{array}$} & \multicolumn{1}{c}{ SS } & $d f$ & MS & \multicolumn{1}{c}{$F$} & P-value & F crit \\
\hline Between Groups & 0.019872 & 2 & 0.009936 & 0.006072 & 0.993946 & 3.042964 \\
Within Groups & 314.1647 & 192 & 1.636275 & & & \\
& & & & & & \\
Total & 314.1846 & 194 & & & & \\
\hline
\end{tabular}

ANOVA

Q3\#8

\begin{tabular}{lcrcccc}
\hline \multicolumn{1}{c}{$\begin{array}{l}\text { Source of } \\
\text { Variation }\end{array}$} & \multicolumn{1}{c}{ SS } & \multicolumn{1}{c}{ df } & MS & \multicolumn{1}{c}{ F } & P-value & F crit \\
\hline Between Groups & 6.818863 & 2 & 3.409431 & 2.09622 & 0.125682 & 3.04223 \\
Within Groups & 317.1609 & 195 & 1.626466 & & & \\
& & & & & & \\
Total & 323.9798 & 197 & & & & \\
\hline
\end{tabular}

ANOVA

Q3\#9

\begin{tabular}{lcrcccc}
\hline \multicolumn{1}{c}{$\begin{array}{l}\text { Source of } \\
\text { Variation }\end{array}$} & \multicolumn{1}{c}{ SS } & $d f$ & \multicolumn{1}{c}{ MS } & \multicolumn{1}{c}{ F } & P-value & F crit \\
\hline Between Groups & 4.312666 & 2 & 2.156333 & 1.402152 & 0.248562 & 3.042717 \\
Within Groups & 296.8098 & 193 & 1.537875 & & & \\
& & & & & & \\
Total & 301.1224 & 195 & & & & \\
\hline
\end{tabular}

ANOVA

Q3\#10

\begin{tabular}{lcrcccc}
\hline \multicolumn{1}{c}{$\begin{array}{c}\text { Source of } \\
\text { Variation }\end{array}$} & \multicolumn{1}{c}{ SS } & df & MS & \multicolumn{1}{c}{ F } & P-value & F crit \\
\hline Between Groups & 3.241855 & 2 & 1.620927 & 1.251503 & 0.288374 & 3.042472 \\
Within Groups & 251.2658 & 194 & 1.295184 & & & \\
& & & & & & \\
Total & 254.5076 & 196 & & & & \\
\hline
\end{tabular}




\begin{tabular}{lcrrrrr} 
ANOVA & \multicolumn{7}{c}{ Q3\#11 } \\
\hline \multicolumn{1}{c}{$\begin{array}{l}\text { Source of } \\
\text { Variation }\end{array}$} & \multicolumn{1}{c}{ SS } & \multicolumn{1}{c}{ df } & MS & \multicolumn{1}{c}{ F } & P-value & F crit \\
\hline Between Groups & 0.313511 & 2 & 0.156755 & 0.116981 & 0.889665 & 3.042472 \\
Within Groups & 259.9606 & 194 & 1.340003 & & & \\
& & & & & & \\
Total & 260.2741 & 196 & & & & \\
\hline
\end{tabular}


Appendix M: One Factor ANOVA Analysis of Resources Utilized by Students with Years Enrolled at WVU 
ANOVA

Q3\#1

Source of

Variation

Between Groups 5.424746

Within Groups 307.4936

\begin{tabular}{ccccc}
$d f$ & $M S$ & $F$ & $P$-value & $F$ crit \\
\hline 2 & 2.712373 & 1.702435 & 0.184964 & 3.042717
\end{tabular}

$193 \quad 1.593231$

Total

312.9184

195

ANOVA

Q3\#2

\begin{tabular}{lrrrrrr}
\hline \multicolumn{1}{c}{$\begin{array}{l}\text { Source of } \\
\text { Variation }\end{array}$} & \multicolumn{1}{c}{ SS } & \multicolumn{1}{c}{ df } & MS & \multicolumn{1}{c}{ F } & P-value & F crit \\
\hline Between Groups & 2.65899 & 2 & 1.329495 & 0.83373 & 0.435984 & 3.042717 \\
Within Groups & 307.7645 & 193 & 1.594635 & & & \\
& & & & & & \\
Total & 310.4235 & 195 & & & & \\
\hline
\end{tabular}

ANOVA

Q3\#3

\begin{tabular}{lrrrrrr}
\hline \multicolumn{1}{c}{$\begin{array}{l}\text { Source of } \\
\text { Variation }\end{array}$} & \multicolumn{1}{c}{ SS } & \multicolumn{1}{c}{ df } & \multicolumn{1}{c}{ MS } & \multicolumn{1}{c}{ F } & P-value & F crit \\
\hline Between Groups & 2.622461 & 2 & 1.311231 & 1.03662 & 0.356617 & 3.042717 \\
Within Groups & 244.1275 & 193 & 1.26491 & & & \\
& & & & & & \\
Total & 246.75 & 195 & & & & \\
\hline
\end{tabular}

ANOVA

Q3\#4

\begin{tabular}{lrrrrrr}
\hline \multicolumn{1}{c}{$\begin{array}{l}\text { Source of } \\
\text { Variation }\end{array}$} & \multicolumn{1}{c}{ SS } & \multicolumn{1}{c}{ df } & MS & \multicolumn{1}{c}{ F } & P-value & F crit \\
\hline Between Groups & 8.375142 & 2 & 4.187571 & 2.46378 & 0.087786 & 3.042717 \\
Within Groups & 328.033 & 193 & 1.699653 & & & \\
& & & & & & \\
Total & 336.4082 & 195 & & & & \\
\hline
\end{tabular}

ANOVA

Q3\#5

\begin{tabular}{lcrcccc}
\hline \multicolumn{1}{c}{$\begin{array}{l}\text { Source of } \\
\text { Variation }\end{array}$} & \multicolumn{1}{c}{ SS } & \multicolumn{1}{c}{ df } & MS & \multicolumn{1}{c}{ F } & P-value & F crit \\
\hline Between Groups & 9.719085 & 2 & 4.859542 & 3.460981 & 0.033361 & 3.042717 \\
Within Groups & 270.9901 & 193 & 1.404094 & & & \\
& & & & & & \\
Total & 280.7092 & 195 & & & & \\
\hline
\end{tabular}




\begin{tabular}{lcrrrrr} 
ANOVA & \multicolumn{8}{c}{ Q3\#6 } \\
\hline \multicolumn{1}{c}{$\begin{array}{l}\text { Source of } \\
\text { Variation }\end{array}$} & \multicolumn{1}{c}{ SS } & \multicolumn{1}{c}{ df } & \multicolumn{1}{c}{$M S$} & \multicolumn{1}{c}{ F } & P-value & F crit \\
\hline Between Groups & 1.387044 & 2 & 0.693522 & 0.431229 & 0.650341 & 3.043214 \\
Within Groups & 307.1748 & 191 & 1.608245 & & & \\
& & & & & & \\
Total & 308.5619 & 193 & & & & \\
\hline
\end{tabular}

\begin{tabular}{lrrrrrr} 
ANOVA & \multicolumn{8}{c}{ Q2\#7 } \\
\hline \multicolumn{1}{c}{$\begin{array}{l}\text { Source of } \\
\text { Variation }\end{array}$} & \multicolumn{1}{c}{ SS } & df & MS & \multicolumn{1}{c}{$F$} & P-value & F crit \\
\hline Between Groups & 1.546355 & 2 & 0.773178 & 0.486742 & 0.615382 & 3.042964 \\
Within Groups & 304.987 & 192 & 1.588474 & & & \\
& & & & & & \\
Total & 306.5333 & 194 & & & & \\
\hline
\end{tabular}

\begin{tabular}{lrrrrrr} 
ANOVA & \multicolumn{7}{c}{ Q3\#8 } \\
\hline \multicolumn{1}{c}{$\begin{array}{l}\text { Source of } \\
\text { Variation }\end{array}$} & \multicolumn{1}{c}{ SS } & $d f$ & $M S$ & \multicolumn{1}{c}{ M } & P-value & F crit \\
\hline Between Groups & 6.375458 & 2 & 3.187729 & 1.939467 & 0.146587 & 3.042964 \\
Within Groups & 315.5733 & 192 & 1.643611 & & & \\
& & & & & & \\
Total & 321.9487 & 194 & & & & \\
\hline
\end{tabular}

\begin{tabular}{lcrrrrr} 
ANOVA & \multicolumn{7}{c}{ Q3\#9 } \\
\hline \multicolumn{1}{c}{$\begin{array}{l}\text { Source of } \\
\text { Variation }\end{array}$} & \multicolumn{1}{c}{ SS } & df & \multicolumn{1}{c}{$M S$} & \multicolumn{1}{c}{ F } & P-value & F crit \\
\hline Between Groups & 1.633417 & 2 & 0.816708 & 0.523858 & 0.593079 & 3.043214 \\
Within Groups & 297.7738 & 191 & 1.559025 & & & \\
& & & & & & \\
Total & 299.4072 & 193 & & & & \\
\hline
\end{tabular}

\begin{tabular}{lcrrrrr} 
ANOVA & \multicolumn{7}{c}{ Q3\#10 } \\
\hline \multicolumn{1}{c}{$\begin{array}{l}\text { Source of } \\
\text { Variation }\end{array}$} & \multicolumn{1}{c}{ SS } & $d f$ & $M S$ & \multicolumn{1}{c}{ M } & P-value & F crit \\
\hline Between Groups & 6.186253 & 2 & 3.093126 & 2.442525 & 0.089653 & 3.043214 \\
Within Groups & 241.8756 & 191 & 1.266364 & & & \\
& & & & & & \\
Total & 248.0619 & 193 & & & & \\
\hline
\end{tabular}




\begin{tabular}{lcrrrrr} 
ANOVA & \multicolumn{7}{c}{ Q3\#11 } \\
\hline \multicolumn{1}{c}{$\begin{array}{l}\text { Source of } \\
\text { Variation }\end{array}$} & \multicolumn{1}{c}{ SS } & \multicolumn{1}{c}{ df } & MS & \multicolumn{1}{c}{ F } & P-value & F crit \\
\hline Between Groups & 3.222488 & 2 & 1.611244 & 1.226569 & 0.295597 & 3.043214 \\
Within Groups & 250.9012 & 191 & 1.313619 & & & \\
& & & & & & \\
Total & 254.1237 & 193 & & & & \\
\hline
\end{tabular}


Appendix N: Responses to Survey Question 4 


\section{Question 4}

Are there other resources that West Virginia University provides to you which you have utilized to cope or adjust as an international student? If YES, please explain.

\begin{tabular}{|c|c|}
\hline Legal services & The Diversity Office \\
\hline $\begin{array}{l}\text { The RACK is very helpful because many times I } \\
\text { don't have money to buy food and the food bank } \\
\text { has saved me on many occasions. }\end{array}$ & $\begin{array}{l}\text { Access to the REC center and Kidzone } \\
\text { support for children, also the Student } \\
\text { Family childcare support program. }\end{array}$ \\
\hline Conversation Partner assign & Carruth Center \\
\hline $\begin{array}{l}\text { Email regarding events that are going to happen } \\
\text { in WVU. }\end{array}$ & $\begin{array}{l}\text { RAC service plays a key role for } \\
\text { international students }\end{array}$ \\
\hline $\begin{array}{l}\text { The people who I can ask my English such as } \\
\text { paper. }\end{array}$ & $\begin{array}{l}\text { We need more sports event for } \\
\text { international students }\end{array}$ \\
\hline Just google & Carruth center \\
\hline Residence life & Rec center, events like fall fest. \\
\hline $\begin{array}{l}\text { Carruth Center, I took counseling there and hope } \\
\text { to take again. }\end{array}$ & Clubs and organizations. \\
\hline Rec Sports & The REC \& Homestart office. \\
\hline $\begin{array}{l}\text { I really don't know what in particular but they } \\
\text { can try and be more out there because we really } \\
\text { see them around apart from when someone visits } \\
\text { the office. }\end{array}$ & $\begin{array}{l}\text { The use of the book of the library, so that } \\
\text { you don't have to buy them but just ask to } \\
\text { borrow them from there. }\end{array}$ \\
\hline Transfer scholarship & International Student Organizations \\
\hline Webinars & Carruth Center \\
\hline Students & Rec Center and Mountain lair \\
\hline
\end{tabular}


Appendix O: Responses to Survey Question 5 


\section{Question 5}

Are there resources outside WVU (e.g. friends, church, family, etc.) that have helped you cope or adjust? If YES, please specify.

\begin{tabular}{|c|c|}
\hline Family & Wife \\
\hline Church & Tinder helped me find friends here \\
\hline HRCC & Rccg Morgantown \\
\hline My landlord and friends & Friends in the community and church \\
\hline Friends & Extended family and very few friends \\
\hline Friends, family & $\begin{array}{l}\text { Friends from my country who came here } \\
\text { before me and my spouse. }\end{array}$ \\
\hline Small talk group & friends, family, boyfriend \\
\hline Family and friends at home. & Church members \\
\hline $\begin{array}{l}\text { Dating apps help find people with similar } \\
\text { interests. }\end{array}$ & $\begin{array}{l}\text { Having extended family in USA and back } \\
\text { home, old friends etc. always helps }\end{array}$ \\
\hline Church and friends & Highschool friends \\
\hline American Friends & Partner \\
\hline MT Pocket Theater, I go there for learning acting & Religious groups outside of WVU \\
\hline International students & Teammates \\
\hline $\begin{array}{l}\text { American friends have invited me to join them on } \\
\text { family celebrations or trips to feel more like } \\
\text { home }\end{array}$ & $\begin{array}{l}\text { REDEEM CHRISTIAN CHURCH OF } \\
\text { GOD }\end{array}$ \\
\hline $\begin{array}{l}\text { Friends who arrived here before I did are very } \\
\text { helpful, this is because they know how we } \\
\text { struggle and feel lost at the beginning }\end{array}$ & $\begin{array}{l}\text { Mocha Mama's of Morgantown group. } \\
\text { Community group of women of color. I } \\
\text { have received a lot of guidance from } \\
\text { women in this group some of whom work } \\
\text { for the university and some who do not. }\end{array}$ \\
\hline $\begin{array}{l}\text { Friends and previous students really help you fit } \\
\text { into your community }\end{array}$ & $\begin{array}{l}\text { Making friends is extremely important no } \\
\text { matter where you are at }\end{array}$ \\
\hline Host family & Classmates \\
\hline
\end{tabular}




\begin{tabular}{|c|c|}
\hline Friend from same country & WVU athletics department \\
\hline My family and boyfriend & Friends of my parents \\
\hline family members & Chi Alpha \\
\hline I found a group of students from my country here. & $\begin{array}{l}\text { Other international students that arrived } \\
\text { before I did }\end{array}$ \\
\hline My uncle in Ohio and my cousin in Virginia & Roommates \\
\hline $\begin{array}{l}\text { keeping in contact with family and friends back } \\
\text { home }\end{array}$ & Latin community and organizations. \\
\hline $\begin{array}{l}\text { Hanging out with friends, going to the church and } \\
\text { spending the whole week of thanksgiving with } \\
\text { my friends, American family. }\end{array}$ & $\begin{array}{l}\text { I've made some friends in each class and } \\
\text { some of them have helped me to } \\
\text { understand better the professors and also } \\
\text { to get some stuff from stores or locate } \\
\text { important places, also some of them are so } \\
\text { friendly, which helps because of that you } \\
\text { don't feel so alone }\end{array}$ \\
\hline Friends, sport club & A community church \\
\hline Pittsburg Buddhist temple & Yea, nice friends \\
\hline International students & Friends studying at WVU \\
\hline International meeting & Older international students \\
\hline Only friends and mosque & $\begin{array}{l}\text { Morgantown Korean Church, West } \\
\text { Virginia Korean Society. }\end{array}$ \\
\hline Friends at my hall have proved incredibly helpful. & Close friends \\
\hline Friends/Morgantown Local Community. & $\begin{array}{l}\text { Friends who live in the US for a long } \\
\text { time. }\end{array}$ \\
\hline $\begin{array}{l}\text { Friends from the same ARAMCO scholarship all } \\
\text { over the US. }\end{array}$ & $\begin{array}{l}\text { My friends helped to get on track and } \\
\text { understand the culture more }\end{array}$ \\
\hline $\begin{array}{l}\text { Meeting my partner and his family who supported } \\
\text { me }\end{array}$ & $\begin{array}{l}\text { Friends, people who have been here } \\
\text { before }\end{array}$ \\
\hline
\end{tabular}


Appendix P: Responses to Survey Question 7 


\section{Question 7.}

Did your family/friends help you adjust to live at WVU? If YES, how did they help you adjust?

\begin{tabular}{|c|c|}
\hline General orientation to state and WVU & Home cooked food \\
\hline $\begin{array}{l}\text { Explain the culture in the USA and bring me } \\
\text { around WVU. }\end{array}$ & $\begin{array}{l}\text { Accommodate me and help me find an } \\
\text { apartment }\end{array}$ \\
\hline $\begin{array}{l}\text { Provided me information about their } \\
\text { experience and tips on what to bring, e.g. } \\
\text { bringing a certified copy of passport }\end{array}$ & $\begin{array}{l}\text { Gave me confidence and assurance every step } \\
\text { of the way }\end{array}$ \\
\hline Trusting friend I could talk to & They gave me suggestions \\
\hline Orientation & Find place to live, introduced town \\
\hline $\begin{array}{l}\text { Buy something, introduce the West Virginia } \\
\text { and Morgantown }\end{array}$ & $\begin{array}{l}\text { My friend from California came over when I } \\
\text { got here and helped me shop and taught me a } \\
\text { bit about how things work }\end{array}$ \\
\hline $\begin{array}{l}\text { Finding accommodation, advisor choice, } \\
\text { linking to available resources, stress } \\
\text { management }\end{array}$ & $\begin{array}{l}\text { Reducing cultural shock. I already knew what } \\
\text { to expect }\end{array}$ \\
\hline $\begin{array}{l}\text { Explaining to me the star system and credits, } \\
\text { helping me to enroll at first. }\end{array}$ & $\begin{array}{l}\text { By introducing me to others with the same } \\
\text { situation }\end{array}$ \\
\hline Moral support & I live with them \\
\hline Talk about the problem & Being nice \\
\hline Finding place to live & Supported Financially and advice. \\
\hline They helped me to get used to it & By providing support \\
\hline $\begin{array}{l}\text { I lived with my parents friends for the first } \\
\text { year }\end{array}$ & We room together \\
\hline $\begin{array}{l}\text { I am a graduate student here at WVU. I did } \\
\text { my undergrad at Purdue. Purdue made it } \\
\text { much easier to assimilate and build that } \\
\text { support system of friends. At WVU I haven't } \\
\text { seen much efforts to help international } \\
\text { students assimilate. I think there is a lot of } \\
\text { room for improvement. }\end{array}$ & $\begin{array}{l}\text { Explaining the condition of Morgantown and } \\
\text { the cultures here to me before I came. }\end{array}$ \\
\hline Visiting me & Emotional support \\
\hline Gave advice, helped me through rough times & Time to visit when I wasn't able to go home. \\
\hline $\begin{array}{l}\text { How to handle situations in university life and } \\
\text { also how to mingle with Americans }\end{array}$ & $\begin{array}{l}\text { Invited me to stay in their home during the } \\
\text { break. }\end{array}$ \\
\hline They let me stay at their home for awhile & $\begin{array}{l}\text { Being available for questions and } \\
\text { accommodation. }\end{array}$ \\
\hline They made it feel like home & \\
\hline
\end{tabular}




\begin{tabular}{|l|l|}
\hline $\begin{array}{l}\text { Suggestions and ideas on how to treat } \\
\text { American students. }\end{array}$ & $\begin{array}{l}\text { Helping with the basics such as phone } \\
\text { number, apartment search, furniture, class } \\
\text { registration, etc. }\end{array}$ \\
\hline Showed me around, told me how things work. & Finding housing, explaining the system. \\
\hline Sharing apartments. & Emotional support \\
\hline They explained any expected issue. & $\begin{array}{l}\text { They provide me with what I need to be } \\
\text { happy. }\end{array}$ \\
\hline Orientation and assistance with settling down. & By visiting me. \\
\hline $\begin{array}{l}\text { They help me to adapt the new culture and } \\
\text { gave me tips to blend in. }\end{array}$ & I stayed with my cousins for winter break. \\
\hline Guidance & He came with me for the first time. \\
\hline
\end{tabular}


Appendix Q: Responses to Survey Question 9 


\section{Question 9.}

In addition to the above, what helps you cope?

\begin{tabular}{|c|c|}
\hline Myself & $\begin{array}{l}\text { My dreams and aspiration push me to do } \\
\text { more. }\end{array}$ \\
\hline Hobbies! sport & Meeting my family \\
\hline $\begin{array}{l}\text { Talking to family over FaceTime. Getting } \\
\text { help with tax, and people reaching out. }\end{array}$ & $\begin{array}{l}\text { My dedication towards getting the degree and } \\
\text { my parents. }\end{array}$ \\
\hline $\begin{array}{l}\text { My husband came with me and that helped } \\
\text { me a lot. I also live with a Chinese student, } \\
\text { who faces similar problems to mine so we } \\
\text { help each other. }\end{array}$ & Perseverance and department funding as GA \\
\hline Endurance and focus. & School work and goals \\
\hline $\begin{array}{l}\text { Church group, rec center access, family } \\
\text { friendly community activities by the } \\
\text { university. }\end{array}$ & $\begin{array}{l}\text { My husband came with me and he is of great } \\
\text { help }\end{array}$ \\
\hline Me time, my social environment. & Working out in the gym every night. \\
\hline Internet and physical activity & $\begin{array}{l}\text { Spending time with friends from my same } \\
\text { country. }\end{array}$ \\
\hline Netflix & Netflix \\
\hline $\begin{array}{l}\text { Having restaurants that serve food from } \\
\text { home, going to the gym, being in WVU clubs. }\end{array}$ & $\begin{array}{l}\text { Knowing that I can always have someone to } \\
\text { talk to. }\end{array}$ \\
\hline Work & Other international students. \\
\hline Phone calls with my family abroad. & Other international students \\
\hline Church & Do exercise \\
\hline Previous experience in international schools. & Playing video games with friends \\
\hline Keeping in touch with my family back home. & Animals \\
\hline Gym & Meditation \\
\hline $\begin{array}{l}\text { If people were more open minded toward } \\
\text { international students/Arab. }\end{array}$ & The desire to graduate at USA university. \\
\hline $\begin{array}{l}\text { Nothing has aided my worries and frustration. } \\
\text { I feel like I am alone here, and nobody cares } \\
\text { if I will succeed or not. }\end{array}$ & $\begin{array}{l}\text { I typically figure most things out myself and } \\
\text { as a result I've learnt to adjust quickly. I trust } \\
\text { my adaptability very much. }\end{array}$ \\
\hline Strong will, determination & Communication and visiting \\
\hline $\begin{array}{l}\text { The environment in the city, travelling and a } \\
\text { solid community of people from my country. }\end{array}$ & Music, books, and video games. \\
\hline Social media & Running \\
\hline
\end{tabular}




\begin{tabular}{|l|l|}
\hline $\begin{array}{l}\text { The amount of free time I have, especially } \\
\text { during the weekends. }\end{array}$ & $\begin{array}{l}\text { Knowing that I'll be leaving soon. I love } \\
\text { WVU but the healthcare as well as how } \\
\text { expensive it is becoming to cope are making } \\
\text { my life so much harder. }\end{array}$ \\
\hline Church community and friends. & Swimming and go to sport events. \\
\hline Having friends around. & My major \\
\hline My dog & Friends \\
\hline Exercise & Volunteering \\
\hline Extracurricular activities & Think and analyze \\
\hline Friends from my own country & Engaging with other students \\
\hline My friends and Mentality & $\begin{array}{l}\text { It helps a lot having people that come from } \\
\text { the same country as yours, and also keeping } \\
\text { in touch with some pets from other students. } \\
\text { It's been hard, but so far it's been ok. }\end{array}$ \\
\hline Friends & Breathing techniques \\
\hline $\begin{array}{l}\text { Talking to my family over the phone or } \\
\text { messaging. }\end{array}$ & $\begin{array}{l}\text { American people are the nicest people! I } \\
\text { wouldn't live without my friends here. }\end{array}$ \\
\hline $\begin{array}{l}\text { Knowing that I came here for a dream to seek } \\
\text { my education. }\end{array}$ & Sports, Faith, Friends \\
\hline Family and friends & Assistance of my family in the home country. \\
\hline Advising center at ESB & \\
\hline
\end{tabular}

